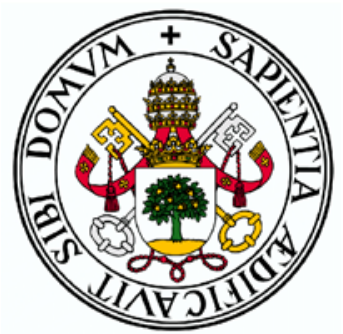

Universidad de Valladolid

Facultad de Ciencias Económicas y Empresariales

Departamento de Economía Financiera y Contabilidad

\author{
PROGRAMA DE DOCTORADO \\ NUEVAS TENDENCIAS EN DIRECCIÓN DE EMPRESAS
}

\title{
LA SELECCIÓN DE INVERSIONES Y FUENTES DE FinANCIACIÓN EN LA PRÁCTICA. El CASO DE LA EMPRESA ESPAÑOLA.
}

Presentada por Pablo César San Martín Mosqueira para optar al grado de doctor por la Universidad de Valladolid

Dirigida por:

Dr. D. Pablo de Andrés Alonso

Dr. D. Gabriel de la Fuente Herrero

Valladolid, diciembre de 2012 

Dedico este trabajo a mi amada familia. A mi esposa Dorenis, a mis hijos Samuel e Ignacio y a los esperados Gabriel y Benjamín. 

Sean estas primeras líneas de agradecimiento a Dios, por la posibilidad que me dio de vivir esta gratificante y enriquecedora experiencia.

A mis apreciados directores de tesis quienes han sabido conducir este trabajo. Al Dr. Gabriel de la Fuente Herrero quien ha sido más que un director, un amigo y sabio consejero. Al Dr. Pablo de Andrés Alonso quien a pesar de la distancia ha demostrado su proximidad en todo momento. Ambos han permitido llegar al final de esta etapa y obtener los resultados que sea han alcanzado.

A la Comisión Nacional de Investigación Científica y Tecnológica (CONICYT), organismo dependiente del Ministerio de Educación del Gobierno de Chile, quien a través de su programa Formación de Capital Humano Avanzado me concedió la beca Presidente de la República que permitió financiar mi estancia en la Universidad de Valladolid y con ello que este sueño sea hoy una realidad.

A los profesores de los departamentos de Economía Financiera y Contabilidad y de Organización de Empresas y Comercialización e Investigación de Mercados de la Universidad de Valladolid por su ayuda, apoyo y orientación.

A mis padres infinitas gracias, pues ellos siempre me han brindado consejo y consuelo. Mucho de lo que soy se lo debo a ellos. A mis hermanos, Natalia y Jacob, porque en todo momento y a pesar de la distancia han sido un constante aliento. Y a Juan Manuel y Vicente por sus buenos deseos.

A mis queridos José, María Angélica, Víctor, Claudia, Enoc, Aylin, Tomás e Isidora, pues nunca he dejado de sentir sus palabras de ánimo para que este proyecto familiar se concrete. 
A todos aquellos quienes, en la cercanía y en la distancia, han colaborado para que esta experiencia me hiciera una persona más consciente de las cosas realmente importantes en la vida.

Sean estas últimas líneas para agradecer expresamente a mi familia, que pacientemente ha asumido el "coste de oportunidad" de los esfuerzos dedicados a esta investigación: a mi esposa Dorenis por su constante e incondicional apoyo, compresión y dedicación mientras yo estaba "ausente"; a mis queridos hijos Samuel e Ignacio por transmitirme cada día la alegría para continuar y cada mañana el deseo de dar lo mejor; y a los esperados Gabriel y Benjamín pues junto a aquellos son la mayor motivación de mi vida. 
"Un viaje de mil millas comienza con el primer paso" Lao Tse

Filósofo chino (570 - 490 a.C) 



\section{ÍNDICE DE CONTENIDOS}

CAPÍTULO 1: INTRODUCCIÓN..................................................................1

\section{CAPÍTULO 2: TEORÍA Y PRÁCTICA DE LAS DECISIONES DE} INVERSIÓN Y FINANCIACIÓN ..........................................................................13

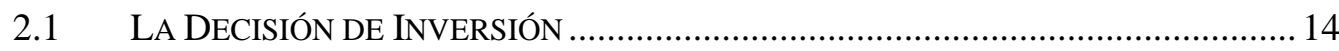

2.1.1 Los modelos teóricos de selección de inversiones..................................... 16

2.1.1.1 El Valor Actual Neto (VAN) ................................................................. 16

2.1.1.2 El Valor Actual Neto Ampliado ……………………………………….... 19

2.1.1.3 La Tasa Interna de Rendimiento (TIR) ................................................ 21

2.1.1.4 El Índice de Rentabilidad (IR) ………………........................................ 21

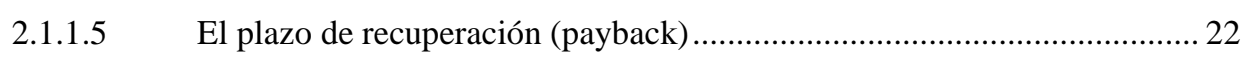

2.1.1.6 El análisis de sensibilidad y los modelos de simulación.............................. 22

2.1.2 La práctica de la selección de inversiones................................................. 24

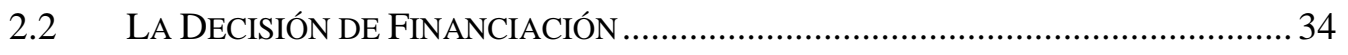

2.2.1 Las explicaciones teóricas de la decisión de financiación......................... 34

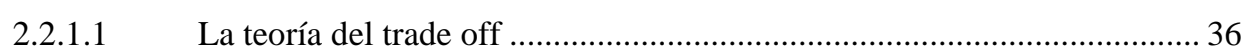

2.2.1.2 La teoría del pecking order .................................................................. 38

2.2.1.3 El modelo de agencia............................................................................ 40

2.2.1.4 El modelo de monitoreo del mercado o market timing................................ 42

2.2.1.5 El modelo de los hechos estilizados ........................................................... 43

2.2.2 La práctica de la decisión de financiación.................................................. 45

\section{CAPÍTULO 3: DISEÑO DE LA INVESTIGACIÓN EMPÍRICA....................61}

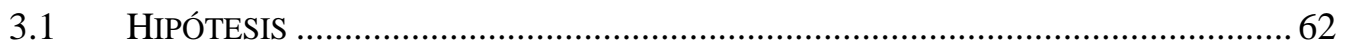

3.1.1 Factores determinantes de la elección de las técnicas de selección de

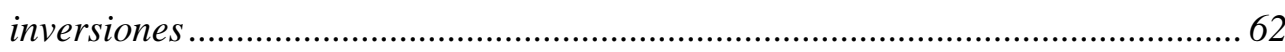

3.1.1.1 Tamaño, sector y perfil directivo ............................................................... 64

3.1.1.2 Problemas de agencia y técnicas de selección de inversiones .................... 67

3.1.1.3 Fuentes de valor y técnicas de selección de inversiones............................... 69

3.1.1.4 Decisiones de financiación y técnicas de selección de inversiones ........... 72

3.1.2 Factores determinantes de la elección del patrón de financiación.......... 75 
3.1.2.1 Tamaño, sector y perfil directivo …………............................................... 75

3.1.2.2 Naturaleza de las fuentes de valor ................................................................ 79

3.1.2.3 El modelo de los determinantes estándar del endeudamiento y el patrón de

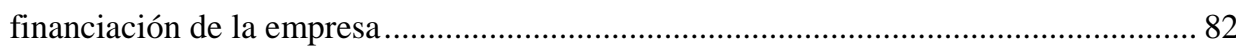

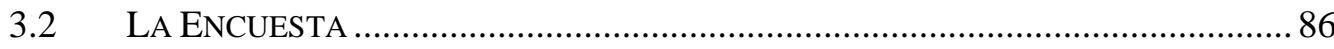

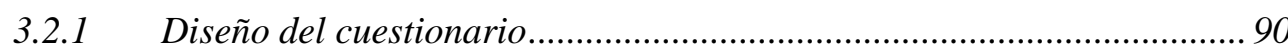

3.2.2 Envío de la encuesta y tasa de respuesta ............................................... 91

3.2.3 Potenciales limitaciones a la investigación por medio de encuestas...... 93

3.3 MODELOS ECONOMÉTRICOS Y TÉCNICAS DE ESTIMACIÓN ...............................95

CAPÍTULO 4: DESCRIPCIÓN DE LA MUESTRA.......................................103

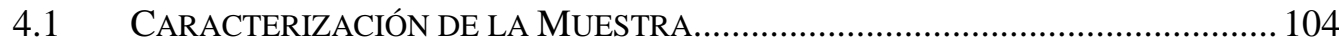

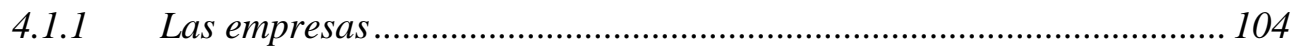

4.1.2 Los directores financieros................................................................. 107

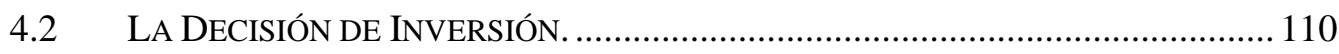

4.2.1 Las técnicas de selección de inversiones utilizadas ............................... 110

4.2.2 El Coste de Capital de la Inversión........................................................ 116

4.2.3 Otros condicionantes de la decisión de inversión .....................................118

4.3 LA DECISIÓN DE FINANCIACIÓN.................................................................... 123

4.3.1 Descripción del endeudamiento de las empresas.................................... 123

4.3.2 Patrón de comportamiento y niveles de deuda....................................... 133

CAPÍTULO 5: ANÁLISIS DE RESULTADOS ...............................................147

5.1 CARACTERIZACIÓN ESTADÍSTICA DE LAS VARIABLES DE LOS MODELOS ....... 147

5.2 LAS TÉCNICAS SELECCIÓN DE INVERSIONES................................................ 151

5.3 LA SELECCIÓN DE LAS FUENTES DE FINANCIACIÓN …….................................. 176

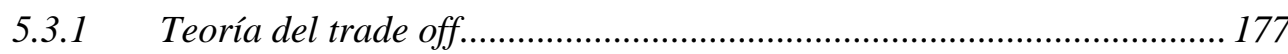

5.3.2 Teoría del pecking order ..................................................................... 179

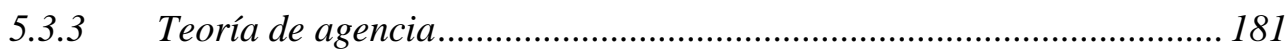

5.3.4 Teoría del market timing ......................................................................... 184

CAPÍTULO 6: CONCLUSIONES ...............................................................213

REFERENCIAS BIBLIOGRÁFICAS.......................................................221

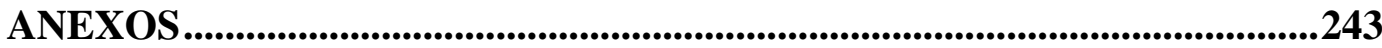


Anexo 2.1. Trabajos De Referencia Relevantes en la Presente

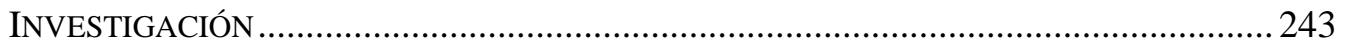

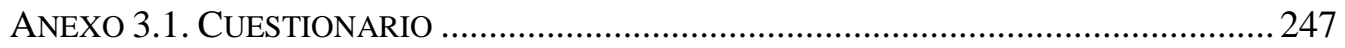

ANEXo 3.2. CARTA DE PRESENTACIÓN Y OBJETIVOS................................................ 249

ANEXO 5.1: MATRIZ DE CORRELACIONES DE VARIABLES INDEPENDIENTES Y DE

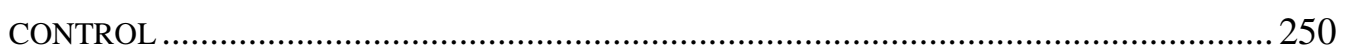




\section{ÍNDICE DE TABLAS}

TABLA 2.1 TÉCNICA DE SELECCIÓN DE INVERSIONES MÁS UTILIZADA................. 32

TABLA 2.2 FACTORES DETERMINANTES DE LA ESTRUCTURA DE CAPITAL: PREDICCIONES TEÓRICAS Y EVIDENCIA EMPÍRICA RELEVANTE.............

TABLA 2.3 PERCEPCIÓN DIRECTA ACERCA DEL COSTE DE CAPITAL Y DEL CONCEPTO DE ESTRUCTURA DE CAPITAL ÓPTIMA.................................. 47

TABLA 2.4 FACTORES DETERMINANTES DEL NIVEL DE ENDEUDAMIENTO............ 53

TABLA 2.5 EVIDENCIA EMPÍRICA ACERCA DE LAS TEORÍAS DE ESTRUCTURA DE CAPITAL

TABLA 3.1 VARIABLES EXPLICATIVAS EN LA LITERATURA.......................... 63

TABLA 3.2 EVIDENCIA DEL GAP TEORÍA Y PRÁCTICA FINANCIERA OBTENIDA CON LA TÉCNICA DEL CUESTIONARIO.

TABLA 3.3. NIVEL DE RESPUESTA................................................. 92

TABLA $3.4 \quad$ PRUEBAS DE SESGO DE NO RESPUESTA............................... 94

TABLA 4.1 TÉCNICAS DE SELECCIÓN DE INVERSIONES............................ 111

TABLA 4.2 RELACIÓN ENTRE TÉCNICAS.......................................... 115

TABLA 4.3 NÚMERO CONDICIONADO DE TÉCNICAS................................ 116

TABLA 4.4 RESPUESTA CONDICIONADA FRENTE A DISTINTOS TIPOS DE

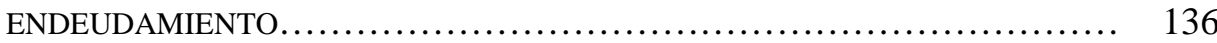

TABLA 4.5 RELACIÓN ENTRE VARIABLES DEL PATRÓN DE FINANCIACIÓN............ 145

TABLA 5.1 ESTADÍSTICA DESCRIPTIVA DE LAS VARIABLES INDEPENDIENTES Y DE

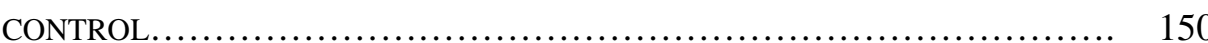

TABLA 5.2 INFLUENCIA DE LAS CARACTERÍSTICAS DE LA EMPRESA SOBRE LA TÉCNICA UTILIZADA.............................................. 152

TABLA 5.3 INFLUENCIA DE LAS CARACTERÍSTICAS DEL DIRECTOR FINANCIERO SOBRE LA TÉCNICA UTILIZADA....................................... 154

TABLA 5.4 TÉCNICAS DE SELECCIÓN DE INVERSIONES Y CARACTERÍSTICAS DE LA EMPRESA Y DEL DIRECTOR FINANCIERO 
TABLA 5.5 TÉCNICA DE $\quad$ SELECCIÓN $\quad$ DE $\quad$ INVERSIONES $\quad \mathrm{Y}$ MECANISMOS DE DISCIPLINA................................................... 159

TABLA 5.6 TÉCNICA DE SELECCIÓN DE INVERSIONES Y FUENTES DE VALOR.......... 162

TABLA 5.7 TÉCNICA, MECANISMOS DE DISCIPLINA Y FUENTES DE VALOR............ 164

TABLA 5.8 ROBUSTEZ FRENTE A LAS VARIABLES DE CONTROL Y LA COTIZACIÓN EN BOLSA........................................................... 167

TABLA 5.9 ROBUSTEZ FRENTE A LAS VARIABLES DE CONTROL Y DE DEUDA.......... 169

TABLA 5.10 ROBUSTEZ FRENTE A LAS VARIABLES DE FUENTES DE VALOR............. 170

TABLA 5.11 ROBUSTEZ FRENTE A DEFINICIÓN DE LA VARIABLE DEPENDIENTE “OPCIONES REALES”................................................. 172

TABLA 5.12 TÉCNICA Y PATRÓN DE FINANCIACIÓN.................................. 175

TABLA 5.13 CONSIDERANDOS DE LA DECISIÓN DE FINANCIACIÓN SEGÚN CARACTERÍSTICAS DE LA EMPRESA Y DEL DIRECTOR FINANCIERO........ 186

TABLA 5.14 INFLUENCIA DE LAS CARACTERÍSTICAS DE LA EMPRESA SOBRE EL PATRÓN DE FINANCIACIÓN SEGUIDO POR LA EMPRESA.................... 193

TABLA 5.15 INFLUENCIA DE LAS CARACTERÍSTICAS DEL DIRECTOR FINANCIERO SOBRE EL PATRÓN DE FINANCIACIÓN SEGUIDO POR LA EMPRESA.......... 195

TABLA 5.16 PATRÓN DE FINANCIACIÓN Y CARACTERÍSTICAS DE LA EMPRESA Y DEL DIRECTOR FINANCIERO........................................... 197

TABLA 5.17 PATRÓN DE FINANCIACIÓN Y FUENTES DE VALOR.......................... 199

TABLA 5.18 VARIABLES DE CONTROL Y DE FUENTES DE VALOR........................ 202

TABLA 5.19 ROBUSTEZ SOBRE LA VARIABLE DEPENDIENTE TARGET $\ldots . . . \ldots \ldots \ldots \ldots \ldots . . . . .203$

TABLA 5.20 DETERMINANTES ESTÁNDAR DEL ENDEUDAMIENTO Y EL PATRÓN DE FINANCIACIÓN DE LA EMPRESA....................................... 205

TABLA 5.21 INTERACCIÓN DE LOS DETERMINANTES ESTÁNDAR Y EL PATRÓN DE FINANCIACIÓN DE LA EMPRESA......................................... 210 


\section{ÍNDICE DE FIGURAS}

FIGURA 2.1 USO DE DCF Y PB COMO MÉTODO PRIMARIO …....................... 28

FigurA 2.2 TEORÍA ESTÁtICA DEL TRADE OFF DE LA ESTRUCTURA DE CAPITAL...... 37

FIGURA 2.3 RELACIÓN DE PREFERENCIA DE FUENTES DE FINANCIACIÓN SEGÚN LA TEORÍA DEL PECKING ORDER....................................... 40

FIGURA 3.1 $\quad$ EVOLUCIÓN DE TRABAJOS POR MEDIO DE ENCUESTAS.................... 88

FIGURA 4.1 DISTRIBUCIÓN DE LAS EMPRESAS SEGÚN TAMAÑO........................ 104

FIGURA 4.2 DISTRIBUCIÓN DE EMPRESAS POR NÚMERO DE TRABAJADORES........... 105

FiguRA 4.3. $\quad$ DISTRIBUCIÓN DE LAS EMPRESAS POR SECTORES DE ACTIVIDAD......... 105

FIGURA 4.4 DISTRIBUCIÓN DE EMPRESAS SEGÚN PERSONALIDAD JURÍDICA............ 106

FIGURA 4.5 EMPRESAS SEGÚN COTIZACIÓN EN BOLSA............................... 106

FIGURA 4.6 INVERSIÓN EXTRANJERA........................................ 106

FIGURA 4.7 DISTRIBUCIÓN DE DIRECTORES FINANCIEROS SEGÚN EDAD.............. 107

FIGURA 4.8 PROMEDIO DE AÑOS DE EXPERIENCIA.................................. 108

FIGURA 4.9 FORMACIÓN DEL DIRECTOR FINANCIERO................................ 108

FIGURA 4.10 PARTICIPACIÓN EN LA PROPIEDAD DE LA EMPRESA...................... 109

FiguRA 4.11 PARTICIPACIÓN EN EL CONSEJO DE ADMINISTRACIÓN.................... 109

FIGURA 4.12 IMPLICACIÓN EN LAS DECISIONES DE INVERSIÓN........................ 109

FIGURA 4.13 IMPLICACIÓN EN LAS DECISIONES DE FINANCIACIÓN..................... 110

FiguRA 4.14 PORCENTAJE DE DIRECTORES FINANCIEROS QUE UTILIZAN "SIEMPRE" O "CASI SIEMPRE" LA TÉCNICA DE SELECCIÓN DE INVERSIONES............ 112

FIGURA 4.15 RELACIÓN ENTRE FRECUENCIA DE USO Y CONFIANZA.................. 113

FigurA 4.16 PORCENTAJE DE EMPRESAS QUE DESCONOCEN LA TÉCNICA.............. 114

FIGURA 4.17 NÚMERO DE TÉCNICAS UTILIZADAS.................................... 114 
FIGURA 4.18 DISTRIBUCIÓN DE LAS EMPRESAS SEGÚN LA TASA DE DESCUENTO UTILIZADA.......

FIGURA 4.19 EMPRESAS SEGÚN PROCEDIMIENTO DE ESTIMACIÓN DE LA TASA DE DESCUENTO.

FIGURA 4.20 PORCENTAJE DE EMPRESAS QUE AJUSTAN LA TASA DE DESCUENTO (TD) Y LOS FLUJOS DE TESORERÍA (FT) SEGÚN LOS ELEMENTOS DE CORRECCIÓN....

Figura 4.21 PESO MEDIO DE CONSIDERANDOS HABITUALES EN LA DECISIÓN DE INVERSIÓN

FigURA 4.22 IMPORTANCIA MEDIA ATRIBUIDA EN EL PROCESO DE CREACIÓN DE VALOR.

FIGURA 4.23 DISTRIBUCIÓN DE EMPRESAS SEGÚN RELEVANCIA DE SUS OPORTUNIDADES FUTURAS DE INVERSIÓN EN EL VALOR DE LA EMPRESA.

FIGURA 4.24 DISTRIBUCIÓN DE LAS EMPRESAS SEGÚN FRECUENCIA CON LA QUE SUS INVERSIONES ABREN NUEVAS OPORTUNIDADES DE NEGOCIO............ 121

FIGURA 4.25 IMPORTANCIA MEDIA ATRIBUIDA A FUENTES DE FLEXIBILIDAD........... 122

FigURA 4.26 FRECUENCIA MEDIA DE EJERCICIO DE LAS FUENTES DE FLEXIBILIDAD.... 123

FIGURA 4.27 RELEVANCIA MEDIA DE LAS FUENTES DE FINANCIACIÓN................ 124

FIGURA 4.28 NIVEL Y TIPO DE ENDEUDAMIENTO................................ 125

FIGURA 4.29 DISTRIBUCIÓN DE LAS EMPRESAS SEGÚN SU ENDEUDAMIENTO MEDIO...

FIGURA 4.30 PORCENTAJE DE EMPRESAS QUE PERSIGUEN UN NIVEL DE ENDEUDAMIENTO OBJETIVO............................................

FIGURA 4.31 DISTRIBUCIÓN DE LAS EMPRESAS SEGÚN EL GRADO DE CUMPLIMIENTO DEL NIVEL OBJETIVO DE ENDEUDAMIENTO......................... 127

FIGURA 4.32 INFLUENCIA MEDIA SOBRE EL NIVEL DE ENDEUDAMIENTO.............. 128

FigURA 4.33 PORCENTAJE DE EMPRESAS QUE RESPONDEN “IMPORTANTE" O “MUY IMPORTANTE” A LA INFLUENCIA SOBRE EL NIVEL DE ENDEUDAMIENTO

FIGURA 4.34 INFLUENCIA MEDIA SOBRE LA DECISIÓN DE ENDEUDAMIENTO........... 131

FIGURA 4.35 INFLUENCIA MEDIA SOBRE EL PLAZO DE LA DEUDA.................... 132

FIGURA 4.36 PERSPECTIVAS DE FUTURO $\quad \mathrm{Y}$ RELACIÓN ENTRE INVERSIÓN $\mathrm{Y}$ FINANCIACIÓN. 
FIGURA 4.37 NIVELES DE DEUDA Y VARIABLES TOT.......................... 138

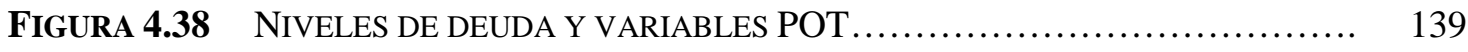

FIGURA 4.39 NIVELES DE DEUDA Y VARIABLES AGE............................. 140

FIGURA 4.40 NIVELES DE DEUDA Y VARIABLES TIMING ........................... 140

FIGURA 4.41 FLEXIBILIDAD FINANCIERA Y TIPOS DE DEUDA....................... 141

FIGURA 4.42 DEUDA OBJETIVO Y TIPOS DE DEUDA................................ 142

FigURA 4.43 PROBLEMA DE SUBINVERSIÓN Y TIPOS DE DEUDA......................... 143

FIGURA 4.44 PROBLEMA DE SUSTITUCIÓN DE ACTIVOS Y TIPOS DE DEUDA.............. 143

FIGURA 4.45 VENTANA DE OPORTUNIDAD Y TIPOS DE DEUDA....................... 144 

“En teoría, no existe diferencia entre teoría y práctica.

Pero en la práctica sí la hay”

Jan L.A. van de Snepscheut

(1953 - 1994) 



\section{CAPÍTULO 1: INTRODUCCIÓN}

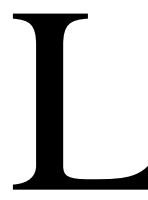

as Finanzas Corporativas son la rama de la Economía Financiera que se ocupa del estudio de cómo se financian las empresas (Zingales, 2000). Como disciplina científica intenta dar respuesta a las interrogantes que surgen en el ámbito de la empresa con relación a la obtención de recursos financieros y su asignación al logro de “combinaciones únicas de activos e individuos” (Zingales, 2000) con los que adquirir y explotar oportunidades de negocio.

Dentro de las Finanzas Corporativas, se suele utilizar el término "Dirección Financiera” para identificar el ámbito de estudio de las tres decisiones financieras de inversión, financiación y dividendo y su efecto sobre el valor de la empresa. La decisión de inversión, o de presupuesto de capital, es aquella relativa a la asignación de recursos en la configuración de una combinación concreta de negocios actuales y oportunidades de crecimiento ${ }^{1}$. La decisión de financiación, o de estructura de capital, hace referencia a la búsqueda y elección de las fuentes y medios, presentes y futuros, con los que obtener los recursos necesarios para financiar sus inversiones. Finalmente, la decisión de dividendo hace referencia a la distribución de la renta generada en cada ejercicio entre los aportantes de recursos propios.

De acuerdo con Brealey, Myers y Allen (2010) “el secreto del éxito en la dirección financiera consiste en incrementar el valor de la empresa”. Aceptado que el objetivo de la empresa es la creación de valor, los problemas financieros

\footnotetext{
${ }^{1}$ De acuerdo con la terminología acuñada por el artículo seminal de Myers (1977), el activo de la empresa está compuesto por negocios actuales o activos en funcionamiento (Assets-in-Place) y opciones de crecimiento (Growth options).
} 
deben formularse en clave de valor y las respuestas a las principales preguntas pasan siempre por el tamiz de un determinado modelo de valoración. Las respuestas a los problemas e incluso el modo en que las preguntas son formuladas quedan condicionadas por el modelo de valoración y sus supuestos de partida, aunque el éxito final dependa de su capacidad para explicar las decisiones adoptadas en la práctica por los directivos financieros. El resultado es una amalgama de modelos de valoración que ofrecen posibles respuestas de lo que debe ser (enfoque normativo) y lo que es (enfoque positivo) en el ámbito de las decisiones financieras de la empresa.

Los modelos de valoración y sus supuestos de partida actúan simultáneamente de puente y abismo que une y separa los dos lados de las finanzas corporativas: la teoría y la práctica. Aunque académicos y directivos comparten el interés por hallar nuevos modelos con los que poder tomar mejores decisiones, los “mejores” modelos teóricos no son siempre los más utilizados por los directivos (Graham y Harvey, 2001) y las teorías financieras a duras penas consiguen explicar las decisiones financieras adoptadas en las empresas (Graham y Leary, 2011).

La separación entre la teoría y la práctica es una constante en la evolución de las finanzas corporativas. El conocimiento de este distanciamiento ha de servir para guiar el esfuerzo destinado al desarrollo y la difusión de los modelos teóricos. No son extrañas las referencias a la responsabilidad de la teoría financiera en la mejora de la práctica financiera (Hwang y Chang, 1999). A modo de ejemplo, Ramirez et al. (1991) destacan como uno de los principales objetivos de la investigación financiera el de ayudar a los directivos financieros a tomar mejores decisiones financieras; mientras que Herbert y Wallace (1996), Hwang y Chang (1999) y Gómez-Bezares (2005) sugieren que los investigadores debieran preocuparse más por identificar los verdaderos problemas financieros de la empresa.

Pero no son menos frecuentes las denuncias de su separación de facto. Por ejemplo, son bien conocidas las críticas a los modelos financieros de selección de 
proyectos a los que se culpa de entorpecer la innovación, productividad y competitividad (Hayes y Garvin, 1982; Sharp, 1991). De forma gráfica, Bettis y Hit (1995) califican el empleo de este tipo de modelos como un mero "ritual corporativo” carente de toda significación o relevancia en la adopción práctica de decisiones de inversión. Baker et al. (2010) declaran que desafortunadamente algunos investigadores en finanzas están más interesados en sus elegantes y sofisticadas teorías, modelos y técnicas estadísticas que en dar las respuestas que necesitan los que toman decisiones.

Críticas de este tipo recuerdan las palabras de Michael Brennan sobre que el profesor de finanzas tiene mucho más que decir de la política de financiación que de la decisión de inversión (Brennan, 1995). Y sin embargo, no son menos los trabajos que denuncian la escasa capacidad de la teoría para explicar el modo en que los directivos deciden financiar sus inversiones y la insuficiente capacidad predictiva y siquiera explicativa de las modelos de estructura de capital (Graham y Leary, 2011; Welch, 2011; Azofra y Rodríguez, 2012). En un exhaustivo análisis de las decisiones financieras adoptadas en la práctica por los directivos de las empresas, Graham y Harvey (2001) sentencian: "Nuestro estudio acerca de las prácticas de las finanzas corporativas es tranquilizador $\mathrm{y}$, a la vez, desconcertante". Tranquilizador por el hecho de que los encuestados indican hacer uso del CAPM o que el VAN sea la principal herramienta de selección de inversiones. Sin embargo, desconcertante, precisamente porque los directivos son mucho menos propensos a seguir los preceptos de las teorías de la estructura de capital.

La publicación del trabajo "The theory and practice of corporate finance: evidence from the field" de Graham y Harvey (2001) supuso un hito en la evolución nuestro de conocimiento sobre el distanciamiento entre teoría y práctica, por cuanto tiene de innovación metodológica y también por el efecto imitación ejercido en la literatura financiera, que ha llevado a que en pocos años se multiplique la evidencia internacional recogida en las revistas especializadas. Uno de los principales elementos diferenciadores del trabajo de Graham y Harvey 
(2001) es la utilización de una encuesta o survey como instrumento de aproximación al problema objeto de estudio.

Como es bien sabido, la investigación empírica se base en el análisis de la información obtenida sobre la realidad a partir de la observación tanto directa como indirecta. La observación indirecta se basa en datos “objetivos” recogidos de fuentes secundarias, tales como los datos contables y de mercado proporcionados por las grandes bases de datos del tipo de COMPUSTAT ${ }^{\circledR}$, DATASTREAM ${ }^{\circledR}$ o CRSP ${ }^{\circledR}$. La observación directa se utiliza para la obtención de datos objetivos (hechos) y subjetivos (opiniones, creencias, actitudes,...). Los datos primarios son datos nuevos, los cuales han sido obtenidos con un propósito concreto y por medio de la participación directa del investigador en el estudio de campo, entrevistas, encuestas, experimentos,.... Los datos secundarios han sido obtenidos con anterioridad por agentes diferentes al investigador que los utiliza y con la finalidad genérica de describir la realidad.

La mayoría de las investigaciones empíricas desarrolladas en el campo de la Dirección Financiera basan sus conclusiones en el análisis de la observación indirecta, cuyos datos son escrutados a partir de sofisticadas herramientas econométricas que detectan relaciones transversales y dinámicas entre variables cuantitativas y reportan medidas numéricas sobre su significación estadística. Tradicionalmente, los estudios basados en la investigación directa han sido mucho menos frecuentes, cuyo lugar en las principales publicaciones científicas de Economía Financiera se reduce casi a lo anecdótico, como muestran los datos aportados por Tufano (2001) sobre el número de artículos publicados en las revistas Journal of Finance, Journal of Financial Economics y Review of Financial Studies en el año 1999: menos del 27\% de los trabajos empíricos fueron elaborados a partir de datos primarios (incluidos los obtenidos por simulación) frente al 73,4\% de los basados en datos secundarios.

La razón de esta preferencia de las revistas hacia los trabajos basados en contrastes econométricos e información cuantitativa de grandes bases de datos no es difícil de comprender. Los resultados procedentes de fuentes secundarias son 
más fáciles de replicar y las técnicas econométricas facilitan la "generalización estadística” que los evaluadores y editores de las revistas suelen utilizar para medir la objetividad y solidez de las conclusiones.

Sin embargo, muchos de los problemas y de las preguntas que nos planteamos en finanzas no pueden resolverse mediante la observación indirecta. Así lo denunciaban los editores del Journal of Financial Economics en el año 1989 cuando ponían en marcha la sección dedicada a la Investigación Clínica, pensada para contribuir al desarrollo de la economía financiera, ya que, según los propios editores, este tipo de trabajos no sólo permitiría complementar sino que también fortalecer otras pruebas teóricas y empíricas. El término "clínica” se tomaba prestado de la literatura médica para indicar evidencia basada en el análisis de casos individuales o de relativamente pocas observaciones, cuyo interés procedía de hecho de que a) aportaba luz desde un punto de vista distinto al hasta entonces cubierto por la revista, b) permitía desafiar las teorías aceptadas y c) hacía uso de fuentes de datos únicas (Jensen et al., 1989).

El estudio del distanciamiento entre la teoría y la práctica de la Dirección Financiera es una de esas cuestiones difíciles de resolver a través de la contrastación econométrica de datos secundarios. No existen bases de datos sobre los criterios empleados por los responsables de la empresa para la adopción de las decisiones financieras y menos aún sobre las motivaciones y preferencias de los directivos. En el modelo neoclásico de empresa, esta laguna no supone un impedimento para la exclusión de las fuentes de información primaria, puesto que se supone que el decisor es el homo economicus racional y maximizador a quien nada puede apartarle de la aplicación de los preceptos teóricos. Pero la apertura de la caja negra de la empresa, por la teoría de la agencia, y posteriormente de la caja negra del individuo, por la propia evolución del modelo de hombre en la teoría de la agencia y las teorías conductistas, dejan al descubierto las lagunas de muchos de los modelos financieros y abren el camino a nuevas líneas de investigación basadas en supuestos más realistas sobre el individuo decisor y sugieren la idoneidad de la fuentes de información directa para la estimación de variables, 
tales como los costes de agencia, problemas de asimetrías de información o motivaciones y preferencias de los directivos, que no pueden aproximarse de manera realista por otros medios.

Entre las fuentes de observación directa posibles para abordar este problema destaca la recopilación de información, tanto cuantitativa como cualitativa, mediante las respuestas obtenidas de cuestionarios por los agentes responsables (altos directivos, financieros y generales, principalmente). La ventaja del cuestionario es que permite obtener descripciones medibles de algunos aspectos de una población bajo estudio cuando la información que se requiere no está disponible. La recolección de datos se realiza por medio de preguntas estructuradas y predefinidas a los encuestados y el objetivo perseguido es la generalización de los resultados a una población más amplia (Pinsonneault y Kraemer, 1993).

Aunque la técnica del cuestionario no sea el enfoque académico estándar en finanzas ${ }^{2}$ y "siga siendo menospreciado en algunos círculos académicos por poco científico", no obstante presenta el particular atractivo de "su capacidad para proporcionar un puente entre la teoría y la práctica, entre el mundo académico y los directores de empresas” (Graham, 2004).

El trabajo de Graham y Harvey (2001) no es la primera de las investigaciones de este tipo y, sin embargo, supuso un antes y un después para el uso de esta técnica de investigación en finanzas, pues propició el reconocimiento y la aceptación de la técnica en algunas de las revistas científicas “top” de finanzas, impulsó una oleada de investigaciones similares en distintas realidades mundiales y, por supuesto, permitió conocer con mayor amplitud el gap entre teoría y práctica. $^{3}$

${ }^{2}$ La escasa popularidad de esta técnica de observación empírica en Finanzas contrasta con su aceptación generalizada en otras disciplinas de la Economía de la Empresa, como es el caso de la Organización de Empresas o, especialmente, el Márketing.

${ }^{3}$ Entre las réplicas a las que dio origen el trabajo de Graham y Harvey cabe destacar los de Brounen et al. (2004); Benetti et al. (2007); Vasiliuo y Daskalakis (2009b), Maquieira et al. (2012). 
Nuestro trabajo pretende contribuir a esta línea de investigación por una triple vía, primero, profundizando en el estudio de las posibles explicaciones del distanciamiento entre la teoría y la práctica de la Dirección Financiera, segundo, participando en la difusión del cuestionario como herramienta de investigación empírica y el análisis de su adecuación al problema objeto de estudio y, tercero, ampliando la evidencia empírica disponible para el caso de las empresas españolas ${ }^{4}$.

Concretamente, este trabajo se sirve de la literatura teórica y empírica previa para identificar las distintas técnicas y modelos que debieran utilizar y las que efectivamente aplican los directores financieros en la resolución de los problemas de inversión y financiación. La literatura precedente pone de manifiesto que los directivos utilizan simultáneamente diferentes técnicas de selección de inversiones, unas teóricamente apropiadas y otras que lo son menos. Entre las técnicas financieras utilizadas suelen figurar el Valor Actual Neto (VAN), la Tasa Interna de Rendimiento (TIR) y el plazo de recuperación o payback, junto con modelos más sofisticados como las opciones reales y la simulación. Aparte de evidenciar el empleo de modelos de diferente utilidad, los trabajos anteriores sugieren que ciertas características de la empresa, como el sector o el tamaño, y de los directivos, como la formación o edad, pueden ayudar a explicar la inclinación del directivo por la técnica de selección de inversiones utilizada. Nuestro trabajo profundiza en las explicaciones aportadas por la literatura previa para justificar el tipo de técnica adoptada y las amplía a partir de la consideración de los mecanismos de disciplina, la naturaleza de las fuentes de valor de la inversión y el patrón de comportamiento financiero de la empresa.

\footnotetext{
${ }^{4}$ La evidencia de este tipo disponible para el caso español se reduce básicamente a cuatro trabajos. Rayo et al. (2007) analizan las técnicas de selección de inversiones utilizadas por las empresas españolas, con especial énfasis en los determinantes del uso de las opciones reales. Bancel y Mittoo (2004) estudian la estructura de capital en 16 países europeos, entre los que se encuentra España con 7 observaciones. Finalmente, Ayala y Rodriguez (2000) e Iturralde y Maseda (2004) revisan la gestión financiera de empresas de las Comunidades Autónomas de La Rioja y del País Vasco, respectivamente.
} 
En lo que atañe a las decisiones de financiación las explicaciones teóricas provienen principalmente de las implicaciones del trade-off, tanto en su versión estática como dinámica, el orden de preferencia (pecking-order), el modelo de la agencia y el market timing. Aunque todas ellas ofrecen explicaciones lógicas y registran cierto respaldo empírico, la evidencia acumulada hasta el momento dista mucho de ser concluyente. A este respecto, han servido de poco el arsenal de bases de datos empíricos y el despliegue de pruebas econométricas dirigidas a relacionar el nivel de endeudamiento con las variables propuestas por estos modelos. Más bien al contrario, algunos trabajos recientes sugieren que la ausencia de resultados convincentes proviene en parte de la utilización de este tipo de estrategias de investigación empírica (Graham y Leary, 2011; Azofra y Rodríguez, 2012).

La reciente evidencia empírica construida por medio de encuestas pretende resolver algunos de los problemas asociados a la contrastación con grandes muestras y aproximaciones indirectas. En lugar de plantear implicaciones sobre variables que no pueden ser medidas sino a través de aproximaciones más o menos acertadas, las encuestas permiten obtener información directa sobre las motivaciones de los directivos y la importancia atribuida a los diferentes factores “teóricamente” determinantes de sus decisiones. Los resultados así obtenidos ofrecen una nueva perspectiva sobre las decisiones de financiación y permiten evaluar no sólo la adecuación al patrón de comportamiento de cada teoría, sino también la posible influencia de las características generales de la empresa y sus directivos en la explicación del patrón de comportamiento.

Algunas de las investigaciones con encuestas han encontrado cierta relación entre las características generales de las empresas y sus directivos con la adhesión del comportamiento financiero a una u otra teoría. Nuestro trabajo profundiza en el estudio de este tipo de relaciones y, en particular, en la influencia de la naturaleza de las fuentes de valor de la inversión. Sirviéndonos del modelo de descomposición del valor de Myers (1977) y de la evidencia precedente respecto a la relación entre endeudamiento y el valor de las oportunidades de crecimiento, 
planteamos una posible explicación de las diferencias observadas en la adhesión de los directivos a las teorías de la estructura de capital. La naturaleza intangible y específica de los activos que son fuente de las oportunidades de inversión futura y la condición intercambiable de la flexibilidad de la inversión y la flexibilidad financiera son los principales soportes de nuestro razonamiento.

El resto del trabajo se estructura de la siguiente manera. En el capítulo 2 se presenta una revisión de los antecedentes en la literatura. La primera parte del capítulo revisa los principales hallazgos en relación con las técnicas de selección de inversiones empleadas por las empresas. La segunda parte del capítulo se encarga de discutir los resultados encontrados en anteriores investigaciones realizadas por medio de encuestas respecto a las decisiones de financiación adoptadas por los directivos y el patrón de comportamiento financiero exhibido por sus empresas.

En el capítulo 3, se derivan las hipótesis a contrastar, se describe el diseño de la investigación empírica y se presentan los modelos econométricos estimados. Sirviéndonos de la evidencia empírica previa sobre el distanciamiento entre la teoría y la práctica financiera y de las propuestas de explicación recogidas en la literatura precedente, proponemos siete hipótesis contrastables empíricamente. La principal finalidad de estas hipótesis es la de guiar el análisis empírico del problema objeto de estudio y los resultados de su contrastación deben ayudarnos a avanzar en la comprensión del problema objeto de estudio formulado.

La particular naturaleza de las variables que conforman las hipótesis obliga a recurrir a la encuesta como instrumento de aproximación empírica. La segunda parte de este capítulo describe el diseño de la investigación empírica y, en particular, las características de la encuesta y el proceso de recogida de información. Este capítulo concluye con la especificación de los modelos y las técnicas de estimación elegidos en función de la naturaleza de las hipótesis y de la información recogida por medio de la encuesta. 
El capítulo 4 recoge los resultados alcanzados por el presente estudio. En primer lugar se presentan la descripción de la muestra, por medio de las principales características de la empresa y del director financiero de la misma. La segunda parte del capítulo, de manera descriptiva, presenta la evidencia de las prácticas de selección de inversiones realizadas por las empresas así como las prácticas en relación con el coste de capital. En la tercera parte del capítulo se describe el endeudamiento de las empresas, así como otros elementos considerados por los directores financieros para la adopción de sus decisiones de financiación.

Seguidamente, en el capítulo 5 se presenta el análisis de los resultados. En la primera sección se describen las variables utilizadas en el análisis y posteriormente, en las secciones dos y tres se presenta el contraste de las siete hipótesis del trabajo. La sección dos discute los resultados de estimación de los modelos econométricos con los que se contrastan las hipótesis uno a la cuarta, que justifican la mayor o menor utilización de las técnicas de selección de inversiones con relación a determinados factores. La tercera sección presenta los resultados de la contrastación de las hipótesis 5 a 7, que relacionan los elementos considerados por los directores financieros en sus decisiones de financiación con el patrón de comportamiento financiero exhibido.

El capítulo 6 concluye con la revisión de los aspectos más relevantes del presente estudio, los principales resultados y sus implicaciones básicas. El trabajo no está exento de limitaciones, a las que se hace una referencia final que se vincula con las futuras líneas de investigación que el presente trabajo nos ha ayudado a identificar.

A modo de síntesis, el trabajo de investigación realizado puede resumirse en la tesis, presentada para la colación del grado de doctor, que podría expresarse en los términos siguientes: "las características de la empresa y del director financiero $y$, en particular, la naturaleza de las fuentes de valor de la empresa y la interrelación de la inversión y la financiación, influyen de manera significativa en las técnicas y considerandos manejados por el director financiero en la adopción 
de las decisiones de inversión y financiación”; contribuyendo de esta forma a ampliar la discusión teórica y base empírica sobre la separación entre la teoría y la práctica financiera. 
CAPÍTULO 1 


\section{CAPÍTULO 2: TEORÍA Y PRÁCTICA DE LAS DECISIONES DE INVERSIÓN Y FINANCIACIÓN}

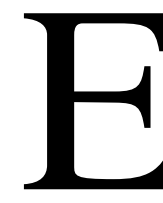

n los últimos años, la literatura financiera ofrece una buena muestra del renovado interés de los académicos y directivos por conocer el grado en que la teoría y los modelos que se enseñan en las aulas y manuales de finanzas corporativas, son aplicados en la empresa. El creciente número de investigaciones y publicaciones sobre este tema probablemente haya estimulado la preocupación de los académicos por los problemas de aplicación práctica de los modelos y puede que el interés de los directivos por las nuevas propuestas teóricas. Sin embargo, los hallazgos de estas investigaciones revelan sobre todo que algunas de las herramientas desaconsejadas desde el punto de vista académico, siguen plenamente vigentes en la práctica empresarial. Y por el contrario, las recomendaciones de la academia tardan años o incluso décadas para en alcanzar relativa aceptación desde el punto de vista práctico.

Este capítulo se dedica a la revisión de la literatura que ha estudiado el distanciamiento entre la teoría y la práctica de las decisiones de inversión y financiación de la empresa. En el epígrafe primero se presentan de forma resumida las principales técnicas de selección de inversiones propuestas en los manuales de dirección financiera: Valor Actual Neto, Valor Actual Neto Ampliado, Tasa Interna de Rendimiento, Índice de Rentabilidad, Análisis de Sensibilidad y Modelos de Simulación. La segunda parte de este primer epígrafe se dedica a revisar la evidencia disponible sobre lo que realmente aplican los 
directivos para seleccionar los proyectos de inversión. El análisis de esta literatura permite alcanzar una impresión general del gap entre la teoría y la práctica a lo largo del tiempo y diferentes realidades geográficas.

El epígrafe segundo aborda el estudio de la relación entre la teoría y la práctica de la decisión de financiación. Tras una breve revisión de cuatro de los principales modelos de estructura de capital: Trade off, Pecking Order, Agencia y Market Timing; el resto del capítulo se dedica a discutir la evidencia disponible sobre los argumentos utilizados por los directivos para adoptar las decisiones de financiación y a evaluar su relación con los preceptos de los modelos teóricos.

\subsection{La Decisión de Inversión}

Una idea extendida entre académicos y directivos es que el éxito y supervivencia futura de una empresa dependen principalmente del acierto de sus decisiones de inversión presentes. En las sucesivas ediciones de su célebre manual de finanzas corporativas, Brealey y Myers sentencian que una buena inversión sigue siéndolo aunque no se financie de manera óptima, pero una mala inversión será una decisión equivocada por muy bien que se diseñe su financiación. Paradójicamente, Michael J. Brennan señalaba en el discurso conmemorativo del vigésimo quinto aniversario de la Financial Management Association, que en el año 1995 el profesor de finanzas tenía mucho más que decir sobre la política de financiación que sobre la decisión de inversión (Brennan, 1995).

La investigación financiera reciente ha contribuido a cubrir parte de estas lagunas desde diferentes flancos. El modelo de agencia ha ayudado a explicar, a partir de los modelos de sobreinversión y subinversión, algunas de las decisiones ineficientes observadas en la práctica. Las finanzas behaviouristas han arrojado luz sobre las influencias psicológicas y emocionales que condicionan las decisiones de los directivos financieros. El enfoque de las opciones reales ha proporcionado nuevas herramientas de valoración más adecuadas a la naturaleza 
de la inversión empresarial y de sus resultados, tangibles e intangibles, generados a lo largo del tiempo. Finalmente, la propia literatura sobre el gap entre práctica y teoría financiera se ha ocupado de averiguar si los directivos financieros utilizan los modelos propuestos por la teoría y de investigar las razones de la brecha observada.

Esta última línea de investigación se inició hace más de medio siglo con la identificación de las técnicas de selección de inversiones utilizadas por las empresas norteamericanas en Miller (1960) e Istvan (1961) y ha sido sucesivamente actualizada y ampliada a la práctica totalidad de los países. En términos generales, esta literatura revela que el ritmo de adopción de las nuevas herramientas propuestas por la teoría financiera es mucho más lento de lo que cabría esperar (Triantis, 2005) y, en todo caso, muy distante de la rápida velocidad con la que se incorporan en la empresa otro tipo de innovaciones tecnológicas, productivas o de gestión.

Aunque se aprecia una progresiva sofisticación de las técnicas de selección empleadas por los directivos financieros, el panorama general apenas ha cambiado en los últimos 30 años. Unas pocas grandes empresas en sectores de alto crecimiento, son proclives a la adopción de técnicas innovadoras, en especial para el análisis de inversiones específicas, mientras que la mayor parte de las empresas siguen utilizando métodos más simples y, desde el punto de vista teórico, menos satisfactorios, como es el caso del plazo de recuperación (payback) o la tasa interna de rendimiento (TIR). Estudios recientes, tales como Block (1997), Graham y Harvey (2001), Chance y Peterson (2002) ó Brounen et al. (2004) revelan que el payback y la TIR continúan siendo generalmente preferidos al Valor Actual Neto (VAN) y el VAN ampliado. Este tipo de usos directivos se enmarca en un contexto de avenencia casi universal de los académicos en la defensa del VAN o, en su caso el VAN ampliado, como los modelos de selección de inversiones más apropiados desde una perspectiva teórica. 


\subsubsection{Los modelos teóricos de selección de inversiones}

Las técnicas que suelen explicarse en las clases de Dirección Financiera pueden clasificarse en: las que debieran utilizarse, las que se utilizan y las que no deberían utilizarse. En el primer grupo se encuentran el VAN, VAN ampliado y los modelos de simulación; en el segundo Tasa Interna de Rendimiento (TIR), el Índice de Rentabilidad (IR) y el análisis de sensibilidad; y en el tercero, entre otros, el plazo de recuperación (payback). ${ }^{5}$

\subsubsection{El Valor Actual Neto (VAN)}

Aceptada la maximización del valor de la empresa como el objetivo que guía el proceso decisional de la firma que desarrolla su actividad en un entorno incierto y dinámico, la dirección de la empresa debiera jerarquizar el conjunto de oportunidades de inversión según la contribución de cada una de ellas a la consecución de dicho fin y acometer primero aquellas con mayor incidencia positiva sobre el valor total de la entidad. Así formulado el problema de la asignación de recursos queda reducido a la estimación del valor adicional que cada una de las oportunidades proporciona a la empresa cuando es incorporado a la cartera de inversiones y la selección de proyectos se transforma en un puro ejercicio de valoración (Myers y Turnbull, 1977).

Convertir el problema de la selección de inversiones en otro de valoración supone un paso adelante en su concreción, pero no por ello queda resuelto. La nada trivial estimación de la competencia de los proyectos en la creación de valor requiere un modelo analítico que permita traducir la "utilidad” de las distintas alternativas en unidades monetarias. No en vano, de la valoración de activos se ha dicho que constituye una de las preocupaciones centrales de las finanzas (Baldwin y Clark, 1992; Zingales, 2000).

\footnotetext{
${ }^{5}$ Ya en 1985, Haka et al. (1985) dividían las técnicas entre sofisticadas (VAN, TIR e IR) e ingenuas (rentabilidad contable y payback).
} 
La hipótesis de mercados de capitales perfectos, eficientes y completos a través de los cuales los inversores poseedores de información diversa llegan a un consenso sobre la capacidad de la empresa para generar riqueza, motiva la adopción del mercado como marco de valoración en el análisis de las fuentes de valor de los proyectos de inversión (Andrés y Azofra, 1992). De hecho, la capacidad tanto predictiva como explicativa del criterio de maximización del valor de la empresa en relación con las efectivas decisiones de inversión depende en buena medida de la propia eficiencia de los mercados de capital. Siempre que la información disponible permita el “correcto” funcionamiento de los mercados, se garantizará que las decisiones ineficientes sean penalizadas y, por tanto, que las empresas persigan la maximización del valor total de la firma (Fama, 1978).

La hipótesis de mercados perfectos, eficientes y completos constituye la base de uno de los fundamentos esenciales de la teoría financiera: el principio de aditividad (Myers, 1996). Según este principio, el valor de mercado de la cartera de proyectos de la empresa es igual a la suma de los valores individuales de cada uno de estos proyectos y el criterio de selección de inversiones puede formularse en términos del valor de mercado individual de cada uno de los proyectos en relación con su coste de realización, o lo que es lo mismo, en términos del Valor Actual Neto (VAN).

El VAN se define como la diferencia entre el valor del proyecto (lo que adquiere la empresa al invertir en el proyecto) y el desembolso (lo que paga por su adquisición), es decir:

$$
\mathrm{VAN}=-\mathrm{A}+\mathrm{V}
$$

donde $A$ representa el desembolso requerido y $V$ el valor del proyecto. El criterio VAN establece que la empresa debe acometer en primer lugar aquel proyecto cuyo valor actual neto positivo sea mayor. El valor del proyecto (V) se determina como la suma de los valores actuales de los sucesivos flujos de tesorería que se espera que genere el proyecto a lo largo de su vida económica; siendo cada uno de éstos igual al valor esperado del flujo de tesorería actualizado a la tasa de descuento apropiada: 


$$
\mathrm{V}=\sum_{\mathrm{t}=1}^{\mathrm{T}}\left(\mathrm{E}_{0}\left(\mathrm{~F}_{\mathrm{t}}\right) \prod_{\tau=1}^{\mathrm{t}}\left(\frac{1}{1+\mathrm{E}_{0}\left(\mathrm{~K}_{\tau}\right)}\right)\right)
$$

siendo $t(=1,2, \ldots, T)$ el momento de cobro -ó pago- del flujo de tesorería de valor aleatorio $F_{t} ; E_{0}(x)$ el operador esperanza matemática de la variable aleatoria $x$ condicionada a la información disponible en el momento 0 ; y $E_{0}\left(K_{\tau}\right)$ la tasa de descuento apropiada para descontar unidades monetarias obtenidas en el momento $\tau$ al instante $\tau-1$.

Si tasa de descuento adecuada para actualizar los flujos de tesorería esperados fuese constante e independiente del flujo y del intervalo temporal al que se aplica, como normalmente se supone, entonces la ecuación anterior se transformaría en la más familiar de las expresiones de valoración del modelo de descuento:

$$
V=\sum_{t=1}^{T}\left[\frac{E_{0}\left(F_{t}\right)}{(1+K)^{t}}\right]
$$

según la cual, el valor de la inversión es la suma de los valores actuales de los flujos de tesorería esperados.

La determinación la tasa de descuento apropiada se obtiene a partir del concepto del coste de oportunidad, como la rentabilidad a la que renuncia la empresa como consecuencia de la realización del proyecto. Otro de los pilares de las finanzas neoclásicas nos indica como estimar dicho coste de oportunidad. De acuerdo con el Capital Asset Pricing Model (CAPM) la rentabilidad que cabe esperar de cada activo es función del riesgo y, más concretamente, del riesgo que no puede eliminarse mediante la diversificación.

Más concretamente, la rentabilidad esperada en equilibrio de cualquier activo con riesgo es igual a la rentabilidad que proporciona un activo libre de riesgo más una prima por el riesgo sistemático, que es igual al precio o prima que paga el mercado por unidad de riesgo sistemático por la cantidad de riesgo sistemático. Es decir, la rentabilidad esperada en equilibrio para un activo $i$ cualquiera es:

$$
E\left(R_{i}\right)^{E Q}=R_{F}+\left[E_{M}-R_{F}\right] \cdot \beta_{i}
$$


donde $R_{F}$ representa la rentabilidad del activo libre de riesgo, $E_{M}$ es la rentabilidad esperada de la cartera de mercado, compuesta por todos los activos con riesgo de la economía, y $\beta_{\mathrm{i}}$ es una medida del riesgo sistemático o sensibilidad de la rentabilidad del activo $i$ a las variaciones del mercado, que se define a partir de la covarianza entre su rentabilidad y la de la cartera de mercado entre la varianza de la rentabilidad de la cartera de mercado.

La combinación del principio de aditividad del valor y del CAPM en la determinación del VAN se ha convertido en el modelo "estrella" de los actuales manuales de Dirección Financiera. El VAN de un proyecto de inversión proporciona una medida directa de su contribución al objetivo de creación de valor, que permite incorporar el valor temporal del dinero y el precio del riesgo por el que teóricamente se paga en el mercado. Su propuesta inicial suele atribuirse a los trabajos de Brennan (1973), Myers y Turnbull (1977) y Fama (1977) y en la actualidad es defendido en los círculos académicos por su consistencia teórica y sencillez práctica.

\subsubsection{EI Valor Actual Neto Ampliado}

Siempre que no existan otras fuentes de valor y que el coste de oportunidad sólo dependa del riesgo sistemático, la superioridad teórica del modelo es indiscutible. Sin embargo, los resultados de la inversión empresarial no son únicamente monetarios. Algunas inversiones empresariales no proporcionan flujo de tesorería positivo alguno y sin embargo resultan cruciales para la competitividad y supervivencia de la empresa. Es por ejemplo el caso de las inversiones en investigación y desarrollo, cuyo único resultado, en caso de éxito, es conocimiento o habilidades.

De acuerdo con el enfoque de las opciones reales, los resultados de la inversión empresarial pueden dividirse en monetarios y no monetarios. Los resultados monetarios son los flujos de tesorería directamente generados por la inversión y representan la única fuente de valor considerada por el modelo de 
valoración convencional de descuento de flujos. Los resultados no monetarios son los recursos que también brotan de la inversión pero cuya naturaleza es de tipo intangible: conocimiento (tecnológico, de producto, mercado,...), imagen de marca, fidelidad de clientes, reputación,... Según el enfoque de las opciones reales, estos resultados tienen valor en la medida en que permiten a la empresa hacer algo que no podría hacer sin ellos (Fuente, 2004; Andrés et al., 2005). Lo que las empresas “pueden” hacer gracias a ellos, son las opciones reales: de lanzar un nuevo producto, de entrar en un nuevo mercado,...

Se trata de una redefinición del valor de la inversión, desde la cuantificación monetaria de la corriente de flujos de tesorería esperados, a la cuantificación monetaria de la capacidad para generar flujos de tesorería. El valor de la inversión procede de la corriente de flujos esperados y del ejercicio eficiente de las posibilidades de decisión (opciones reales) que otorga a la empresa. Estas posibilidades de actuación son, entre otras, las opciones de inversión futura, de ampliación o reducción de la dimensión del proyecto, de intercambio de productos, de intercambio de factores, de modificación del ritmo operativo, de abandono prematuro,...

El VAN y el VAN ampliado son medidas directas de la contribución de la inversión al objetivo de creación de valor. Ambos modelos aproximan el incremento neto del valor de la empresa que cabe esperar de la inversión a partir de la diferencia entre lo que se paga (desembolso) y lo que se obtiene (valor de la inversión). El VAN calcula el valor de la inversión a partir de la corriente de flujos de tesorería que se espera que genere la inversión y los principios financieros del valor temporal del dinero y la relación de mercado entre rentabilidad y riesgo. El VAN ampliado se define como el VAN más el valor actual de sus opciones reales. Las opciones reales representan derechos de inversión y de abandono análogos a los contenidos en las opciones financieras de compra y de venta y, en consecuencia, pueden valorarse a partir de los mismos argumentos de réplica y arbitraje en los que se fundamentan las fórmulas de Black y Scholes (1973) y el modelo binomial (Cox, Ross y Rubinstein, 1979). 


\subsubsection{La Tasa Interna de Rendimiento (TIR)}

Íntimamente relacionado con el VAN se encuentra el criterio TIR. La TIR se define como la tasa de descuento, $r$, que hace el VAN igual a cero. Es decir:

$$
\text { r t.q. VAN }=0 \Rightarrow-A+\sum_{t=1}^{T}\left[\frac{E_{0}\left(F_{t}\right)}{(1+r)^{t}}\right]=0
$$

La TIR es una medida de la rentabilidad sobre el capital invertido en cada momento. El criterio de aceptación consiste en invertir en un proyecto siempre que su TIR supere a su coste de oportunidad. Los manuales de dirección financiera demuestran que VAN y TIR coinciden siempre en cuanto a aceptación/rechazo de proyectos independientes, pero pueden diferir en su jerarquización. En caso de conflicto, el VAN es superior a la TIR dado que permite medir directamente el grado de consecución de cada proyecto al objetivo de creación de valor.

\subsubsection{EI Índice de Rentabilidad (IR)}

Otra de las medidas de rentabilidad normalmente ilustrada en los cursos de finanzas es el Índice de Rentabilidad (IR). El IR se define como el cociente entre el valor actual de la corriente de flujos de tesorería esperados y el desembolso, es decir, es igual a uno más el cociente entre el VAN y desembolso:

$$
I R=\frac{\sum_{t=1}^{T}\left[\frac{E_{0}\left(F_{t}\right)}{(1+r)^{t}}\right]}{A}=\frac{A+\text { VAN }}{A}=1+\frac{\text { VAN }}{A}
$$

El criterio de aceptación consiste en exigir que el $I R$ sea superior a la unidad, lo cual se consigue si y sólo si el VAN es positivo. Aunque coincidan en términos de aceptación/rechazo de proyectos independientes, VAN e IR no tienen por qué coincidir en la jerarquización de proyectos. Al igual que en caso de la $T I R$, el $I R$ supone una medida relativa de la creación de valor que no tiene por qué implicar 
la elección que contribuya en mayor medida a la consecución del objetivo de maximización del valor total de la empresa. ${ }^{6}$

\subsubsection{El plazo de recuperación (payback)}

El plazo de recuperación o payback mide el tiempo necesario para que los flujos de tesorería generados por el proyecto cubran el desembolso realizado. El payback puede calcularse teniendo en cuenta el valor temporal del dinero mediante la actualización de los flujos de tesorería, en cuyo caso se habla del payback descontado:

$$
p \min \text { t.q. } A=\sum_{t=1}^{p}\left[\frac{E_{0}\left(F_{t}\right)}{(1+r)^{t}}\right]
$$

El criterio de aceptación consiste en exigir que el payback sea inferior a un plazo máximo que los responsables de la empresa han de determinar. Este modelo no proporciona un método objetivo que permita establecer el plazo máximo para la aceptación de la inversión. Además, los proyectos así seleccionados no tienen por qué ser los que contribuyan en mayor medida a la consecución del objetivo de creación de valor. El payback es un criterio de liquidez que conduce a aceptar los proyectos que permiten recuperar el desembolso antes, sin considerar los flujos de tesorería, positivos o negativos, que generen a partir del plazo de recuperación.

\subsubsection{El análisis de sensibilidad y los modelos de simulación}

La consideración del riesgo en el análisis de los proyectos de inversión puede realizarse de manera aproximada mediante el análisis de los intervalos de variación de las variables de las que depende el VAN para los que se mantiene un resultado de aceptación o jerarquización de proyectos. El análisis de sensibilidad consiste en determinar estos intervalos para cada una de las variables,

\footnotetext{
${ }^{6}$ Además, el IR presenta la desventaja de estar referido al horizonte de vida del proyecto. A efectos de comparación con otras rentabilidades de referencia, requiere restar la unidad y calcular su TAE (tasa anual equivalente).
} 
considerando el resto de variables constantes (es decir, aplicando el ceteris paribus, tan habitual en los modelos económicos). La posición del valor inicialmente estimado dentro del intervalo y la amplitud del propio intervalo son utilizados por el responsable de la decisión de inversión para determinar el grado de confianza asociado, para obtener una “sensación” de confianza respecto a cada alternativa.

Aunque supone una aproximación al riesgo, el análisis de sensibilidad presenta el inconveniente de que no proporciona una medida directa del riesgo y se centra en el riesgo del proyecto en sí mismo, sin considerar el aportado a la cartera de negocios en la que se integra. Pero la principal limitación de este modelo es que supone que las variables analizadas son independientes y las variaciones equiprobables de cada una de ellas no afectan al comportamiento estadístico del resto.

Los modelos de simulación permiten resolver esta última limitación. De hecho, los modelos de simulación podrían considerarse como un análisis de sensibilidad avanzado que permite considerar el comportamiento estadístico de cada variable del proyecto y su interrelación. El objetivo de los modelos de simulación es la caracterización del comportamiento estadístico de una función dependiente de múltiples variables aleatorias interdependientes. Aplicado sobre el VAN, la simulación proporciona una aproximación a su función de distribución estadística, que se obtiene a partir del supuesto comportamiento probabilístico de las variables aleatorias de las que dependen los flujos de tesorería y de la generación "simulada” de múltiples trayectorias futuras.

Los modelos de simulación no proporcionan un criterio de decisión, sino que sirven para ampliar la información disponible sobre la caracterización probabilística de la inversión. 


\subsubsection{La práctica de la selección de inversiones}

El interés por conocer el tipo de técnicas empleadas por los directivos en la selección de sus inversiones se remonta a principios de los años 60, con los trabajos de Miller (1960) e Istvan (1961). Según Kim y Ulferts (1996), la secuencia de los sucesivos estudios publicados en la década de los 60 y 70 evidencia la progresiva adopción de modelos teóricamente superiores, basados en el descuento de flujos. A pesar de esta tendencia, la denuncia del distanciamiento entre la teoría y la práctica de selección de inversiones es una constante en la literatura financiera. En 1970, Mao advirtió de la creciente disparidad entre las propuestas de la teoría financiera y los usos de la práctica empresarial (Mao, 1970). A través del estudio en profundidad de ocho casos, Mao observó que los directivos preferían utilizar herramientas simples, como el plazo de recuperación (payback) o el beneficio contable, a modelos más apropiados desde una perspectiva teórica, como el VAN o la tasa interna de rentabilidad (TIR).

Desde entonces, la brecha entre la teoría y la práctica empresarial no ha hecho más que aumentar, debido, por un lado, al mantenimiento del lento ritmo de adopción de este tipo de innovaciones en la empresa y, por otro, a la aceleración del proceso de producción científica de las finanzas empresariales.

La evidencia inicial aportada por Miller (1960) e Istvan (1961) para las empresas norteamericanas, ha sido actualizada por sucesivos trabajos, como los de Stanley y Block (1984); Payne et al. (1999); Graham y Harvey (2001) ó Baker et al. (2011a). Esta evidencia ha sido ampliada con el análisis de las empresas de otros países, entre los que destaca, el Reino Unido (Pike, 1996; Arnold y Hatzopoulos, 2000), Sudáfrica (Hall y Millard, 2010), Argentina (Pereiro, 2006), Indonesia (Leon et al., 2008), Australia (Truong et al., 2008), Japón (Shinoda, 2010) y España (Rayo et al., 2007), entre otros.

En el ámbito de las comparaciones internacionales, son bien conocidos los trabajos de Brounen et al. (2004) para distintos países de la Europa continental (Reino Unido, Holanda, Alemania y Francia) y de Kester et.al. (1999) para países 
del Asia Pacífico (Australia, Hong Kong, Indonesia, Malasia, Filipinas y Singapur). Posteriormente, la comparativa internacional se despliega con los trabajos de Hermes et al. (2007) para Holanda y China; Cohen y Yagil (2007) para cinco países en tres continentes (Estados Unidos, Reino Unido, Alemania, Canadá y Japón); Brunzell et al. (2013) para países nórdicos (Dinamarca, Finlandia, Islandia, Noruega y Suecia); Maquieira et al. (2012) para países latinoamericanos (Argentina, Chile, Colombia, Ecuador, Perú, Uruguay y Venezuela, Bolivia, Brasil, Costa Rica, El Salvador y México) y Chazi et al. (2010) para países del golfo pérsico (Bahréin, Kuwait, Omán, Arabia Saudita, Qatar y Emiratos Árabes Unidos).

En términos generales, las técnicas preferidas por los directivos son el payback, la TIR y el VAN. La literatura nos muestra que las técnicas más antiguas y menos sofisticadas no se dejan de utilizar, pero además nos revelan que las más recientes, y más apropiadas desde el punto de vista teórico, no encuentran el sitial que les corresponde. A pesar de que según la teoría financiera, el criterio del VAN es más correcto que el payback y la TIR, los resultados de las investigaciones muestran que la TIR y el payback son las técnicas preferidas por los directivos (Graham y Harvey, 2001; Iturralde y Maseda, 2004; Cohen y Yagil, 2007). La tabla 2.1 recoge una síntesis de los resultados acumulados en la literatura sobre las técnicas de selección más utilizadas en las empresas de diferentes países.

El debate sobre la superioridad del VAN o la TIR, se remonta a más de un siglo (Osborne, 2010) y aunque se considera resuelto y cerrado desde el punto de vista académico, parece seguir abierto para los profesionales de las finanzas. En su conocido manual Brealey, Myers y Allen (2010), sugieren que los métodos que no contemplan el descuento de flujos son inapropiados y que "el método del valor actual neto (VAN) debiera de ser usado de manera preferente sobre otras técnicas de descuento de flujos”. El VAN (positivo/negativo) de un proyecto de inversión mide la variación (incremento/disminución) del valor de la empresa que se espera se produzca como consecuencia de su aceptación. La TIR y otras medidas de rentabilidad, también miden la creación de valor, pero en términos relativos con 
respecto a la inversión realizada. Las medidas de rentabilidad relativa pueden ser más intuitivas y fáciles de comparar (en economía estamos acostumbrados a comparar porcentajes), pero no miden directamente el grado de contribución de cada proyecto al objetivo de creación de valor de la empresa. El VAN, sí.

Desde la perspectiva de la práctica financiera, la TIR presenta la ventaja de “encajar” mejor en el proceso cognitivo de los directivos (Evans y Forbes, 1993; Pindado, 2004) aparte de que su expresión en porcentaje facilita la comparación con múltiples y cotidianas referencias financieras (tales como el coste de capital de la empresa, los tipos de interés, las primas de riesgo, la inflación,...). Burns y Walker (1997) y Cohen y Yagil (2007) indican que la TIR puede ser elegida por su facilidad de comprensión y el hecho de que es fácilmente comparable con los resultados de otras oportunidades de inversión.

Como contrapunto a esta evidencia, Burns y Walker (2009) sugieren que, a pesar de la mayor popularidad de la TIR, el VAN suele ser una técnica más confiable por los directivos: cuando las empresas tienen problemas para decidir respecto de un proyecto en concreto se decantan por los resultados arrojados por el VAN. Apap y Masson (2004 - 2005) encuentran que un 56\% de las empresas confían en el VAN en caso de duda acerca de los resultados.

Por su parte, el payback parece ser elegido por la sencillez de su cálculo y facilidad de compresión. Graham y Harvey (2001), Ryan y Ryan (2002) y Brounen et al. (2004) encuentran que el payback no descontado es la herramienta preferida para el 69,2\% de las empresas del Reino Unido, el 64,7\% de Holanda y más de la mitad de las empresas norteamericanas, alemanas y francesas. Detrás de estos resultados parecen estar tanto la simplicidad del método como la falta de conocimiento y/o familiaridad con técnicas más sofisticadas (Graham y Harvey, 2002). Aunque se trata de una medida de liquidez, los directivos parecen utilizarlo para aproximar el riesgo de la inversión (Burns y Walker, 1997), identificando la rápida recuperación con una menor exposición a la incertidumbre del futuro o, incluso, para aproximar el valor de las opciones reales (McDonald, 2000). 
Según las investigaciones recientes, esta técnica continúa vigente entre las prácticas habituales de la selección de inversiones y su uso es mucho más frecuente de lo esperado y aconsejado por parte de la teoría financiera. Sin embargo, no es menos cierto que no suele ser la principal técnica de evaluación de inversiones. Los estudios revelan que el payback es una importante técnica de uso secundario y que complementa los resultados de técnicas más sofisticadas (Klamer, 1972; Gitman y Forrester, 1977; Kim y Farragher, 1981; Stanley y Block, 1984; Kim et al., 1986) y que la tendencia a acumular técnicas responde al principio de “cuantas más, mejor” (Pike, 1996).

Aparte del payback, los directivos utilizan otros métodos heurísticos (los llamados rules of thumb) que ayudan a complementar los resultados cuantitativos de los modelos de mayor rigor (véanse Poterba y Summers (1995), Jagannathan y Meier (2002), Berkovitch e Israel (2004), McDonald (2006), Magni (2008) y Holmen y Pramborg (2009)). Este tipo de prácticas ha sido interpretado principalmente como síntoma de las deficiencias de los modelos financieros propuestos por la teoría y su incapacidad para capturar todas las fuentes de valor, aunque también existe cierta evidencia empírica que encuentra indicios relacionados con la propia cualificación de los directivos.

El análisis longitudinal muestra que el uso de las técnicas de descuentos de flujos, DCF (Discounted Cash Flow), ha incrementado sustancialmente en el tiempo ${ }^{7}$. Aún más, el uso de estas técnicas como criterio primario ha aumentado constantemente, mientras que el uso del payback como herramienta principal ha ido constantemente decreciendo en el tiempo. La figura 2.1 grafica esta tendencia al alza de las técnicas del tipo DCF y a la baja del periodo de recuperación ${ }^{8}$,

${ }^{7}$ En su trabajo acerca de las motivaciones para la realización de fusiones y adquisiciones, Mukherjee et al. (2004), revelan que las técnicas de descuento de flujos (DCF) son el método dominante para evaluar decisiones de adquisición de empresas tanto cotizadas como no cotizadas.

${ }^{8}$ La comparativa considera trabajos realizados en EE.UU durante los últimos 50 años. Este contexto ofrece una gran cantidad de información y los trabajos son comparables en términos del tipo de empresas que investigan. Se han descartado aquellos trabajos en que se consideraban sólo empresas pequeñas, puesto que su comportamiento no ha seguido el comportamiento de la empresa media. De la misma forma fueron descartados aquellos trabajos en que no se pregunta directamente por la principal herramienta de selección de inversiones. 
mediante la representación del porcentaje de empresas que utilizan los métodos $D C F$ versus las que hacen uso del PB como herramienta de selección primaria en la evaluación de los proyectos de inversión.

Figura 2.1: Uso de DCF y PB como método primario

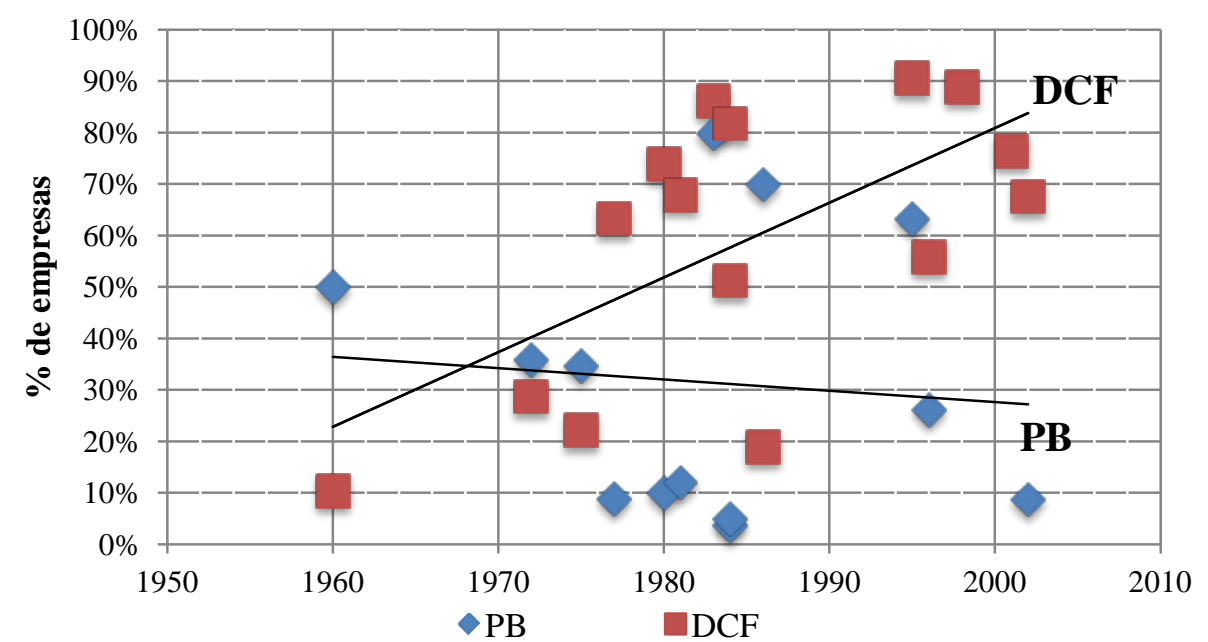

Fuente: Istvan (1961); Klammer (1972); Petry (1975); Gitman y Forrester (1977); Kim y Farrager (1981); Moore y Reichert (1983); Klammer y Walker (1984); Stanley y Block (1984); Kim et al. (1986); Gilbert y Reichert (1995); Shao y Shao (1996); Bruner et al. (1998); Graham y Harvey (2001); Klammer et al. (2002).

Tan importante como la elección del modelo correcto de selección de inversiones, lo es su correcta aplicación. Bennouna et al. (2010) denuncian que muchos de los problemas provienen del uso incorrecto de los modelos. Drury y Tayles (1997) declaran que "a pesar del incremento en el uso de las técnicas de descuento de flujos como teóricamente superiores, varios autores en el Reino Unido y EEUU han afirmado que las empresas están sub invirtiendo porque aplican mal las técnicas de DCF o malinterpretan sus resultados”. Aparentemente, algunos de los parámetros utilizados en la estimación de los flujos descontados se calculan de manera inconsistente ${ }^{9}$. Investigaciones como las de Trigeorgis (1993),

\footnotetext{
${ }^{9}$ Bennouna et al. (2010) señalan problemas asociados a la estimación de los flujos de caja, así como a la tasa de descuento utilizada, pero también en la utilización de tasas inadecuadas, que aunque calculadas correctamente, sólo son válidas para el momento y condiciones en que fueron calculadas. Otra fuente de problemas en este proceso es la inadecuada consideración de la
} 
Triantis y Borison (2001) y Copeland (2002) hacen referencia a las desventajas de utilizar herramientas como las DCF cuando se toman decisiones de presupuesto de capital y sugieren el uso de las opciones reales para complementar los métodos de evaluación existentes.

Uno de los modelos más recomendados desde el palco académico y menos utilizado en la arena de la práctica son las opciones reales (Busby y Pitts, 1997). A modo de cierre de su estudio, Klamer (1972) concluía que lo que era teoría “avanzada” en la década de los 1950 se estaba convirtiendo en la práctica de los 1970. De manera particular, Triantis (2005) señalaba que si el VAN tardó tanto tiempo en ser ampliamente aceptado por las empresas, entonces las opciones reales, siendo una herramienta más sofisticada, tardaría también décadas en ser integrada en las organizaciones ${ }^{10}$. En el survey "Real options. State of the practice”, publicado en el año 2001, Triantis y Borison (2001)revelan que sólo un tercio de los participantes de su encuesta dijo haber realizado algún esfuerzo por desarrollar cálculos precisos de valor en el uso de las opciones reales, con lo que conjeturaba que su uso estaba más asociado a una herramienta de planificación estratégica de tipo cualitativa que a una técnica de valoración en sí misma.

Truong et al. (2008) declaran que las opciones reales constituyen un punto de apoyo, pero que aún no han alcanzado el estatus de "uso corriente”. Ahora bien, en el survey realizado por Alkaraan y Northcott (2006) analizan el proceso de toma de decisión estratégica en la empresa y el rol que juegan las emergentes herramientas de análisis, entre las que se encuentran el balanced scorecard, el análisis de cadena de valor, benchmarking, Technology Roadmapping (TRM) y el enfoque de opciones reales. La opinión de uno de los entrevistados al referirse al enfoque de opciones reales, resultaba reveladora: "El enfoque de opciones reales es más bien un ejercicio académico que algo real para las empresas”.

incertidumbre o de las fuentes de flexibilidad asociada a los proyectos de inversión de la empresa. Estos autores sugieren el uso de modelos de simulación para el caso de la incertidumbre a la que se enfrenta la empresa y el uso de los modelos de opciones reales para el caso de la flexibilidad asociada a los proyectos.

${ }^{10}$ Revista CFO Magazine de julio de 2003. Ver también Ghahremani et al. (2012). 
Las razones atribuidas al lento proceso de adopción de las opciones reales son múltiples. Mathews et al. (2007) atribuyen el bajo desarrollo en este campo a la complejidad de la técnica y también a la dificultad de adaptación, debido a las particularidades de los procesos de tomas de decisión estratégicas en las empresas. El estudio de campo de Block (2007) permite extraer las siguientes explicaciones: a) los directores desconocen la técnica $(42,7 \%)$, b) los métodos de descuento de flujo son un método ampliamente probado (25,6\%), c) las opciones reales requieren demasiada sofisticación (19,5\%), y d) lleva a que los directivos asuman demasiados riesgos (12,2\%). Similares justificaciones son esgrimidas en el estudio de Baker et al. (2011b) para el caso de Canadá y por Rayo et al. (2007) para el caso de España. Estos últimos concluyen que la baja utilización del modelo de opciones responde no sólo a la propia cualificación de los directivos, sino además a la errónea percepción de las premisas básicas del modelo.

La evidencia también revela que las empresas frecuentemente utilizan más de una técnica de selección de inversiones. El lento y gradual proceso de incorporación de herramientas más sofisticadas se produce de manera acumulativa, de modo que las más antiguas no son abandonadas, sino que sirven de herramientas complementarias a los resultados arrojados por las más recientes. El trabajo de Truong et al. (2008) revela que las empresas de su muestra pueden llegar a ser usuarias de hasta nueve técnicas distintas, siendo cuatro técnicas la combinación que mayor cantidad de usuarios dice tener (26\%). Este comportamiento puede explicarse a la luz de la desconfianza y aversión al riesgo de los directivos ${ }^{11}$, quienes encuentran en la utilización de múltiples técnicas no sólo una forma de enriquecer el proceso de análisis (Arnold y Hatzopoulos, 2000), sino también una estrategia para reducir su responsabilidad.

En muchos de estos casos, estas combinaciones se realizan por medio de técnicas financieras junto a no financieras (Proctor y Canada, 1992; Arnold y

${ }^{11}$ Adler (2000) reconoce que los directivos tienden a utilizar más de una técnica, algunos de ellos conjuntos de técnicas. Estos, sin embargo, deben comprender que diferentes técnicas pueden enviar señales (evaluaciones) mixtas, que indiquen invertir y otras indiquen no invertir, por lo que deben estar preparados para hacer frente a tales dilemas. El estilo directivo y las características de las oportunidades de crecimiento debieran ayudar a dilucidar estas situaciones. 
Hatzopoulos, 2000; Ayala y Rodríguez, 2000). Basados en los resultados de su investigación Apap y Masson (2004 - 2005) encuentran que para los ejecutivos encuestados a) algunos métodos dan más información que otros (72\%); b) los diferentes gestores prefieren distintos métodos (31\%) y c) existe falta de confianza en una sola herramienta de selección de inversiones (16\%). Por su parte, Bierman (1993) asegura que los directivos no tienen excesiva fe en una medida en concreto, sino que más bien utilizan múltiples técnicas para "pintar el cuadro" de la inversión. 


\section{Tabla 2.1: Técnica de selección de inversiones más utilizada}

Clasificación de trabajos empíricos previos que revisan las técnicas de selección de inversiones según el país de procedencia de las empresas de la muestra analizada. En las columnas se indican las técnicas más utilizadas, donde DF = Métodos de descuento de flujos (VAN o TIR). VAN = Valor actual neto. TIR = Tasa interna de retorno. Payback = Plazo de recuperación. $\mathrm{OR}=$ Valoración a través de opciones reales. $\mathrm{TRC}=$ Tasa de rendimiento contable. $\mathrm{ROI}=$ Rendimiento sobre la inversión (return over investment).

\begin{tabular}{|c|c|c|c|c|c|c|c|}
\hline $\begin{array}{l}\quad \text { TTécnica } \\
\text { País }\end{array}$ & $\begin{array}{l}\text { DF (VAN o } \\
\text { TIR) }\end{array}$ & VAN & TIR & Payback & OR & TRC & ROI \\
\hline USA & $\begin{array}{l}\text { Chen (1995), } \\
\text { Klamer et al } \\
\text { (2002) } \\
\text { Chen (2008) }\end{array}$ & $\begin{array}{l}\text { Petry y Sprow (1993) } \\
\text { Ryan y Ryan (2002) }\end{array}$ & $\begin{array}{l}\text { Oblak y Helm (1980) } \\
\text { Stanley y Block (1984) } \\
\text { Bierman (1993) } \\
\text { Burns y Walker (1997) } \\
\text { Payne et al (1999) } \\
\text { Graham y Harvey (2001); } \\
\text { Cohen y Yagil (2007) } \\
\end{array}$ & $\begin{array}{l}\text { Mao (1970) } \\
\text { Schall et al (1978) } \\
\text { Moore y Reichert (1983) } \\
\text { Block (1997) }\end{array}$ & & Istvan (1961) & Miller (1960) \\
\hline Canadá & $\begin{array}{l}\text { Jog y } \\
\text { Srivastava } \\
(1995) \\
\end{array}$ & $\begin{array}{l}\text { Bennouna et al (2010) } \\
\text { Baker et al (2011a) }\end{array}$ & $\begin{array}{l}\text { Payne et al (1999) } \\
\text { Graham y Harvey (2001); } \\
\text { Cohen y Yagil (2007) }\end{array}$ & & & & \\
\hline UK & $\begin{array}{l}\text { Busby y Pitts } \\
\text { (1997) } \\
\text { Klamer et al } \\
(2002)\end{array}$ & Alkaraan y Northcott (2006) & $\begin{array}{l}\text { Arnold y Hatzopoulos } \\
\text { (2000); Cohen y Yagil } \\
\text { (2007) }\end{array}$ & $\begin{array}{l}\text { Pike (1996) } \\
\text { Drury y Tayles (1996) } \\
\text { Brounen et al (2004) } \\
\text { Baddeley (2006) }\end{array}$ & & & \\
\hline Holanda & & $\begin{array}{l}\text { Brounen et al (2004) } \\
\text { Hermes et al (2007) }\end{array}$ & & & & & \\
\hline Alemania & & Sridharan y Schuele (2008) & Cohen y Yagil (2007) & $\begin{array}{l}\text { Brounen et al (2004) } \\
\text { Sridharan y Schuele (2008) }\end{array}$ & & & \\
\hline Francia & & & & & $\begin{array}{l}\text { Brounen } \\
\text { et al } \\
(2004)\end{array}$ & & \\
\hline España & & & & $\begin{array}{l}\text { Ayala y Rodriguez (2000) } \\
\text { Iturralde y Maseda (2004) } \\
\text { Rayo et al (2007) }\end{array}$ & & & \\
\hline Portugal & & & Moutinho y Mouta (2006) & & & & \\
\hline Italia & $\begin{array}{l}\text { Cescon } \\
(2010)\end{array}$ & & & & & & \\
\hline Suecia & & & & $\begin{array}{l}\text { Sandahl y Sjögren (2003) } \\
\text { Holmen y Pramborg (2009) }\end{array}$ & & & \\
\hline
\end{tabular}


TEORÍA Y PRÁCTICA DE LAS DECISIONES DE INVERSIÓN Y FINANCIACIÓN

\begin{tabular}{|c|c|c|c|}
\hline Chipre & & & Lazaridis (2004) \\
\hline Finlandia & & & Liljeblom y Vaihekoski (2004) \\
\hline $\begin{array}{l}\text { República } \\
\text { Checa }\end{array}$ & & & Scholleova et el (2010) \\
\hline Croacia & & Dedi y Orsag (2007) & \\
\hline Australia & $\begin{array}{l}\text { Kester et al (1999) } \\
\text { Truong et al (2008) }\end{array}$ & & \\
\hline Japón & & Cohen y Yagil (2007) & Shinoda (2010) \\
\hline China & Chan et al (2008) & Hermes et al (2007) & \\
\hline Hong Kong & & & $\begin{array}{l}\text { Ann et al (1987) } \\
\text { Kester et al (1999) }\end{array}$ \\
\hline Taiwan & & & Haddad et al (2010) \\
\hline Indonesia & Kester et al (1999) & & Leon et al (2008) \\
\hline Malasia & & & $\begin{array}{l}\text { Ann et al (1987) } \\
\text { Kester et al (1999) }\end{array}$ \\
\hline Filipinas & & & Kester et al (1999) \\
\hline Singapur & & & $\begin{array}{l}\text { Ann et al (1987) } \\
\text { Kester et al (1999) }\end{array}$ \\
\hline India & & $\begin{array}{l}\text { Anand (2002) } \\
\text { Singh et al. (2012) }\end{array}$ & Verma et al. (2009) \\
\hline Sudáfrica & Maroyi y van der Poll (2012) & & Hall y Millard (2010) \\
\hline Argentina & Pereiro (2006) & & \\
\hline Brasil & Benetti et al (2007) & & \\
\hline Kuwait & El-Sady et al (2011) & Al-Mutairi et al (2012) & \\
\hline Colombia & & Vélez y Nieto (1986) & \\
\hline Perú & Mongrut y Wong (2005) & & \\
\hline $\begin{array}{l}\text { Países } \\
\text { nórdicos }\end{array}$ & Brunzell et al (2013) & & \\
\hline Latinoamérica & Maquieira et al (2012) & & \\
\hline Golfo Pérsico & Chazi et al (2010) & & \\
\hline
\end{tabular}




\subsection{La Decisión de Financiación}

Una impresión que empieza a extenderse en la investigación sobre la financiación empresarial es que a pesar de todo lo que hemos aprendido acerca del problema de la financiación, todavía sabemos muy poco. El análisis de la evolución del “conteo” que realizan Brealey y Myers sobre "lo que sabemos y no sabemos” en el último capítulo de su manual de Principios de Finanzas Corporativas parece relativamente positivo. Desde la primera edición de 1981 a la novena edición de 2010 (a la que Franklin Allen se incorpora como coautor), cabe destacar el desplazamiento del topic de la estructura de capital desde el pasivo (lo que no sabemos) al activo (lo que sabemos). Las revisiones de Harris y Raviv (1991) y Frank y Goyal (2007), entre otras, ponen de relieve los importantes avances cosechados por la investigación con relación a la decisión de financiación de las empresas.

A pesar de los logros, la literatura reciente empieza a dudar que el camino por el que discurre este tipo de investigación nos conduzca realmente a la meta que nos proponíamos alcanzar. Críticas recientes, como las vertidas en Graham y Leary (2011); Welch (2011; 2012), Azofra y Rodríguez (2012), animan a reflexionar sobre el rumbo de nuestra investigación, la validez de los resultados obtenidos e, incluso, la utilidad de las evidencia habitualmente analizada. Retomando la cita comentada de Brennan (1995), respecto a que el profesor de finanzas tiene más que decir de la decisión de financiación que de la de inversión, podríamos preguntarnos si lo que se supone que saben los profesores coincide con lo que saben los profesionales y directivos.

\subsubsection{Las explicaciones teóricas de la decisión de financiación}

Las actuales explicaciones de las decisiones de financiación de la empresa no pueden entenderse sin la referencia a dos trabajos seminales: el de Modigliani y 
Miller (1958) y el de Jensen y Meckling (1976). El trabajo de Modiglani y Miller (M\&M) supuso una ruptura con el pensamiento financiero dominante hasta la fecha de su publicación, basado en un conjunto de reglas heurísticas que prescribían las medidas conducentes a minimizar el coste de capital de la empresa (Bernstein, 2006; Azofra y Fuente, 2008). M\&M abordan el problema de la financiación con un nuevo método de análisis que introduce el mercado de capitales como marco de valoración de las decisiones de la empresa. A partir de un razonamiento hipotético deductivo y de los supuestos de mercados perfectos y racionalidad del inversor, M\&M demuestran que la explotación de las oportunidades de arbitraje garantiza la irrelevancia de la estructura de capital. El valor de la empresa, el coste del capital y la rentabilidad requerida de los proyectos de inversión son independientes de sus decisiones de financiación. El valor de la empresa depende únicamente de la capacidad de sus inversiones para generar renta y no de la combinación de fuentes de financión elegida. La estructura de capital sólo influye en cómo se reparte una renta que viene dada por la inversión de la empresa.

El trabajo de M\&M cambió la orientación de la investigación en finanzas desde su tradicional enfoque descriptivo y normativo a otro de marcado carácter positivo (Azofra y Fuente, 2008). El aporte de M\&M va mucho más allá de sus proposiciones. En esencia, las implicaciones de su trabajo representan el inicio de la moderna teoría financiera y el desarrollo del concepto de irrelevancia no ha hecho más que alentar la investigación en finanzas, relajando los supuestos de mercados perfectos y considerando múltiples fricciones de mercado. Azofra y Fernández (1992) plantean que una vez que la hipótesis de mercados perfectos es relajada, el análisis de las decisiones financieras gira en torno a tres consideraciones. Primero, que en mercados imperfectos las decisiones financieras pudieran influir en la evaluación de la empresa por parte del mercado (efecto valoración). Segundo, las empresas ajustan su estructura financiera de manera secuencial en el tiempo; estos ajustes, no exentos de costes, generan retardos en las modificaciones, con lo que no logran completamente los ajustes deseados desde el punto de vista normativo. Tercero, que las fricciones o imperfecciones de 
mercado pudieran dar lugar a interdependencias entre las decisiones financieras de la empresa (de inversión, de financiación y de dividendos).

\subsubsection{La teoría del trade off}

La investigación financiera posterior al trabajo M\&M se centró en el análisis de las implicaciones derivadas de las distintas imperfecciones presentes en los mercados de capitales reales. La observación del mundo real y la evidencia empírica verificada por la investigación en finanzas sugiere que los mercados de capital son imperfectos, lo que hace necesario teorías de estructura de capital basadas en mercados imperfectos. Las fricciones de mercado, tales como los impuestos (de sociedades y a las rentas de las personas físicas), los costes de quiebra o los costes de transacción, provocan que la renta total a repartir entre los propietarios de las distintas fuentes de financiación de la empresa difiera de la renta generada por su cartera de proyectos.

El análisis de las fricciones del mercado y sus implicaciones en las conclusiones de M\&M sustentan el desarrollo de la teoría que Myers (1984a) acuñó como teoría estática del trade off. Según esta teoría existe un ratio de endeudamiento óptimo para el cual se maximiza la diferencia entre los beneficios del endeudamiento (básicamente el ahorro de impuestos derivado de la deducibilidad de los gastos financieros) y los costes del endeudamiento (como consecuencia del incremento de la probabilidad de insolvencia y el consiguiente valor actual de los costes de quiebra). La dirección debe, por tanto, intentar equilibrar la ventaja fiscal de la deuda y los costes directos e indirectos de insolvencia y quiebra de manera que se minimice el coste de capital. Este punto, de estructura de capital óptima, que maximiza el valor de la empresa en el mercado se obtiene cuando el incremento marginal en el valor actual de los beneficios fiscales se iguala al incremento marginal en el valor actual de los costes de quiebra (Chen y Kim, 1979; Bradley et al., 1984).

De acuerdo al pensamiento anterior y la teoría subyacente a) la decisión de financiación afecta el valor de la empresa, b) la dirección debe trabajar 
activamente para gestionar la estructura de capital y c) la empresa puede alcanzar una estructura de capital óptima, existente en el equilibrio entre los beneficios y costes de la deuda. La figura 2.2 muestra la relación entre el valor de la empresa y el endeudamiento calculado según la ecuación fundamental de la teoría estática del trade off:

Valor de la empresa

$=$ Valor de la empresa sin deuda $+V A$ de la ventaja fiscal de la deuda

- VA de los costes esperados de insolvencia financiera y quiebra

Figura 2.2: Teoría estática del trade off de la estructura de capital

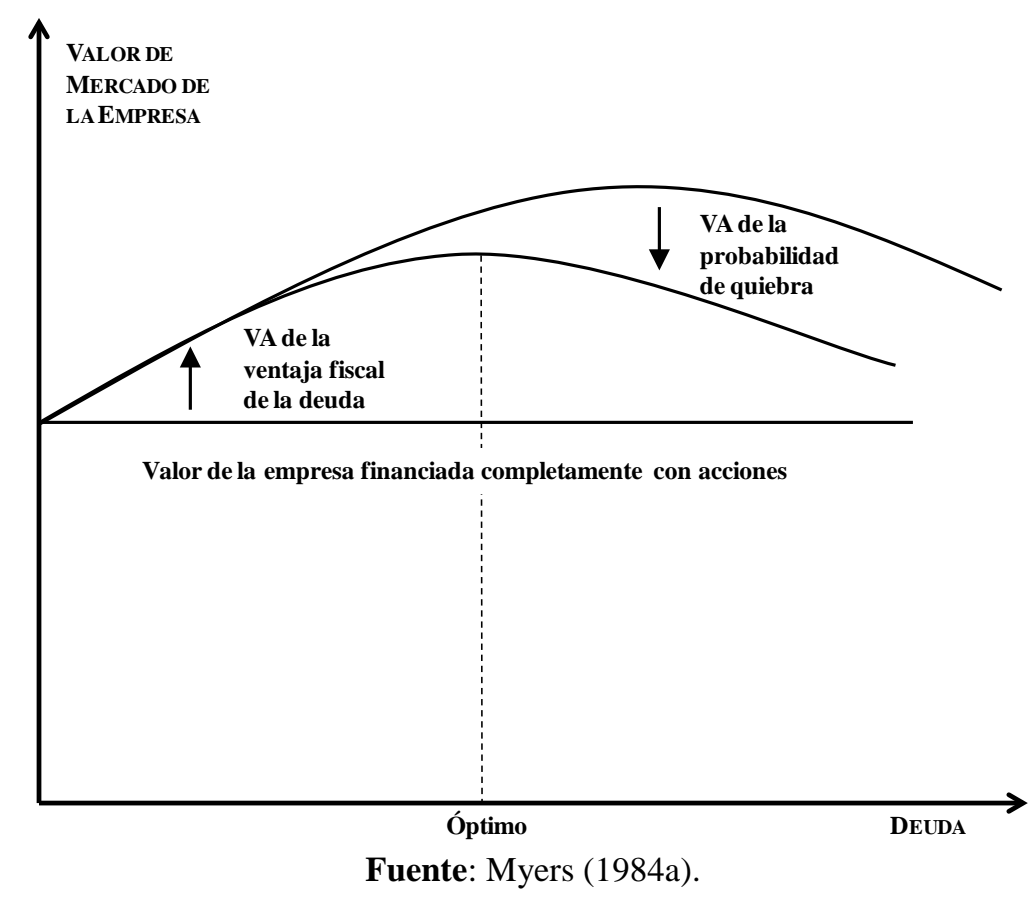

Bajo la teoría estática del trade off los niveles observados de endeudamiento se corresponden con los niveles óptimos y las desviaciones observadas en el tiempo se corresponden a cambios en la estructura de capital óptima (Myers, 1984a). Sin embargo, los continuos movimientos del mercado provocan desviaciones en los ratios de endeudamiento de las empresas que sus directivos intentan ajustar al ratio objetivo. La literatura del trade off explica este 
comportamiento a partir de diferentes modelos de ajuste parcial con los que se mide la velocidad de ajuste al ratio objetivo.

Si a esta visión dinámica del ajuste, se le añade la consideración de las fricciones del mercado, la teoría estática del trade off se convierte en otra dinámica en la que los directivos fijan intervalos de endeudamiento óptimo, en lugar de ratios óptimos (Frank y Goyal, 2007; Azofra y Rodríguez, 2012). Desde esta perspectiva, la intervención de los directivos se reduce a aquellos casos en los que el ratio de endeudamiento rebasa los límites del intervalo objetivo, lo cual parece encajar mejor con la evidencia empírica observada en el contraste de los modelos de ajuste (Graham y Leary, 2011).

\subsubsection{La teoría del pecking order}

La teoría del pecking order fundamenta su planteamiento en los problemas informativos y la asimétrica distribución de la información entre los insiders y outsiders de la empresa (Myers, 1984a; Myers y Majluf, 1984) ${ }^{12}$. De acuerdo con esta teoría, los insiders poseen información privada acerca de la situación actual y perspectivas futuras de sus negocios que no pueden transmitir a los outsiders sin errores de interpretación y elevados costes. Para reducir estos costes, los directivos siguen un orden de preferencia en la financiación de sus oportunidades de inversión, que se inicia con el recurso a los fondos generados internamente (beneficios retenidos) y continúa con las fuentes de financiación externa, empezando por los capitales ajenos, pasando por las fórmulas híbridas de endeudamiento y terminando con la emisión de nuevas acciones.

La demanda de fondos externos a través de la emisión de capitales ajenos y propios se produce como consecuencia de los desajustes entre los fondos internamente generados y la disponibilidad de oportunidades de inversión rentables y a la búsqueda del ratio óptimo de endeudamiento que postula la teoría

\footnotetext{
${ }^{12}$ Aunque el término Pecking Order es acuñado por Myers (1984a), el origen de este modelo suele atribuirse al trabajo de Donaldson (1961). Akerlof (1970) introduce los problemas de selección adversa originados por las asimetrías informativas, que constituyen la base del pecking order.
} 
del trade off (Shyam-Sunder y Myers, 1999; Azofra y Rodríguez, 2012). De acuerdo con la teoría del pecking order, las empresas eligen sus fuentes de financiación de manera que se minimicen los costes de selección adversa. Las empresas rentables aprovecharán la ventaja de los menores costes informativos de los fondos internos para incrementar su valor, con lo que la utilización de deuda será menor que la sugerida por la teoría del trade-off. Por su parte, las empresas con mayores oportunidades de crecimiento preferirán seguir una política flexible que permita minimizar los costes de su futura financiación, procurando generar holguras financieras que igualmente reflejarán ratios de endeudamiento inferiores de los asociados al trade-off óptimo (Myers, 1984a).

De acuerdo a esta teoría, a) no existen recomendaciones o políticas óptimas, b) no existe un equilibrio, por lo que tampoco existe una estructura de capital óptima y c) el nivel de endeudamiento observado en las empresas es reflejo del cúmulo de decisiones de financiación realizadas por los directivos durante el tiempo (Myers, 1984a; 2001).

Shyam-Sunder y Myers (1999) presentan evidencia que sugiere las empresas financian sus déficits de fondos con deuda y concluyen que la teoría del pecking order proporciona una buena aproximación del comportamiento financiero ${ }^{13}$.

El orden de preferencias en la financiación de las oportunidades de inversión que se le presentan a la empresa se grafican en la figura 2.3. La figura representa la relación entre la elección de la fuente de financiación y el nivel de inversión bajo la hipótesis detrás de la teoría del pecking order. C* representa la cantidad de fondos internos disponibles para la inversión. (D-C) representa la cantidad de deuda que una empresa puede emitir sin llegar a producir un apalancamiento excesivo.

${ }^{13}$ El trabajo de Shyam-Sunder y Myers (1999), por su simpleza y capacidad para probar la teoría del pecking order, ha suscitado réplicas e importantes comentarios. Ejemplo de ello son los trabajos de Chirinko y Singha (2000), Frank y Goyal (2003) y Lemmon y Zender (2010). 
Figura 2.3: Relación de preferencia de fuentes de financiación según la teoría del pecking order

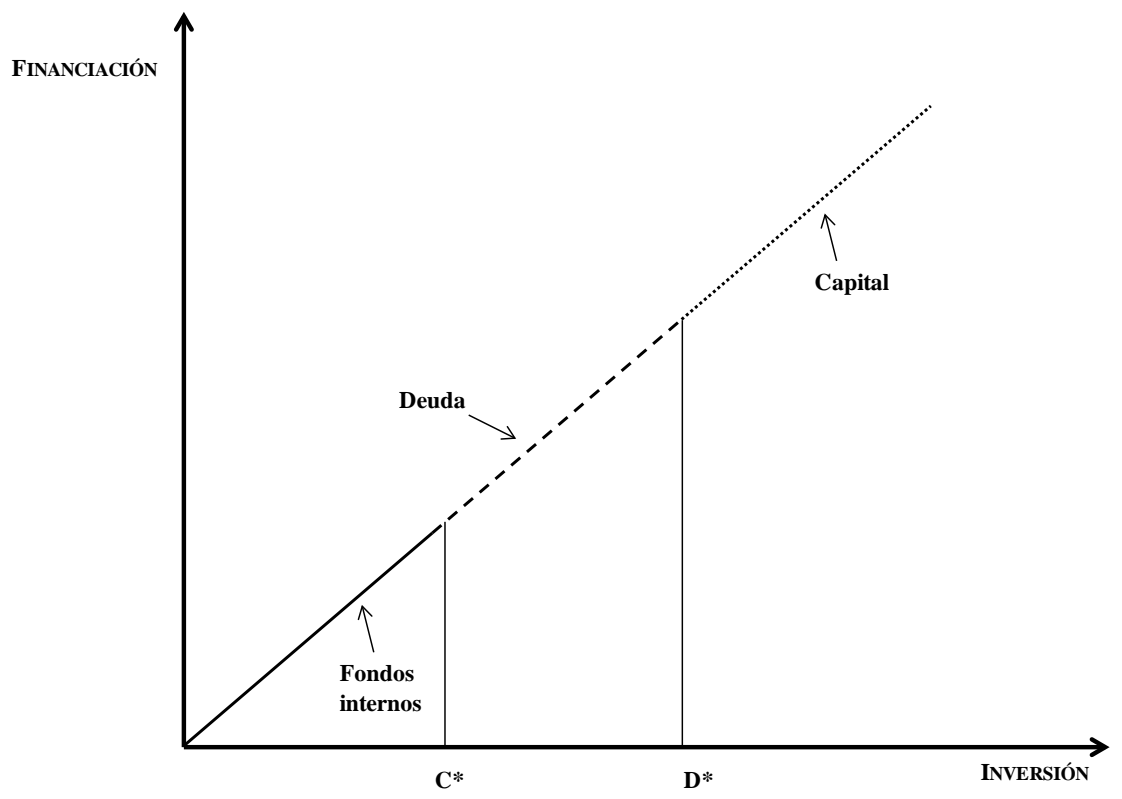

Fuente: Leary y Roberts (2010).

\subsubsection{El modelo de agencia}

El trabajo de Jensen y Meckling (1976) supone un cambio radical en la concepción del problema de financiación imperante desde Modigliani y Miller (1958). Jensen y Meckling muestran que las decisiones de financiación repercuten no sólo en la distribución de la renta de la empresa, sino que influyen sobre la propia capacidad para generar renta.

Jensen y Meckling abren la caja negra de la empresa y muestran que en la misma cooperan diversos grupos de individuos que persiguen sus propios intereses, en un contexto de información imperfecta. En este modelo de empresa, las decisiones de financiación influyen sobre los sistemas de incentivos y los mecanismos de control de la empresa y, de este modo, afectan al comportamiento esperado en la relación de cooperación.

Concretamente con relación a la decisión de endeudamiento, la teoría de la agencia considera las relaciones de agencia entre los directivos y los accionistas, por un lado, y entre los accionistas y los acreedores, por otro. En la primera de las 
relaciones, los problemas de información y observación del comportamiento, pueden favorecer el que los directivos adopten decisiones en su propio interés y en perjuicio del objetivo de maximización de valor, por ejemplo, mediante la inversión en proyectos no rentables de los que obtienen beneficios personales (lo que se conoce como problema de sobreinversión). En este caso, el uso de deuda emerge como otra potencial solución, debido a que el servicio a la deuda, por una parte, reduce el flujo de caja libre (free cash flow) (Jensen, 1986), pero también genera una mayor presión a los directivos haciéndoles velar por un mejor desempeño a fin de reducir la probabilidad de insolvencia financiera y quiebra (Grossman y Hart, 1982).

Por otra parte, los conflictos de agencia entre acreedores y accionistas pueden motivar la adopción de decisiones ineficientes, que beneficien a uno de estos partícipes en perjuicio del valor total de la empresa como consecuencia del asimétrico reparto de riesgo y rentabilidad. Ocurre cuando la empresa en dificultades financieras rechaza oportunidades de inversión rentables cuyo VAN sería absorbido por el incremento del valor de la deuda (problema de subinversión) o cuando la empresa redistribuye el valor de las acciones y de la deuda mediante el incremento del riesgo de sus inversiones (problema de sustitución de activos). En este contexto, el endeudamiento a corto plazo puede servir para reducir los incentivos a rechazar oportunidades rentables o las clausulas restrictivas para controlar el problema de sustitución de activos.

De resultas de este tipo de razonamiento, la literatura financiera propone una versión extendida del trade off (Myers, 1984a), que incorpora los beneficios y costes de agencia de cada una de las alternativas de financiación. De acuerdo con este modelo, el valor de la empresa es igual valor de la empresa financiada sin deuda más el valor actual de las ventajas fiscales de la deuda menos el valor actual de los costes directos e indirectos de quiebra y más (menos) el valor actual de los beneficios (costes) de agencia. 
Valor de la empresa

$$
\begin{aligned}
& \text { = Valor de la empresa financiada sólo con acciones } \\
& +V A \text { de la ventaja fiscal de la deuda } \\
& \text { - VA de los costes de insolvencia financiera y quiebra } \\
& + \text { +-VA de los costes / beneficios de agencia }
\end{aligned}
$$

De la misma forma que en la versión reducida de la teoría, los directores pueden trabajar activamente para maximizar el valor de su empresa, pero en esta versión extendida del trade off el nivel óptimo de estructura de capital es más difícil de determinar, puesto que depende también de factores tales como la naturaleza de las inversiones actuales y futuras de la empresa, los posibles conflictos de agencia entre partícipes, los mecanismos de control, los problemas informativos, la señalización de las decisiones financieras ${ }^{14}, \ldots$

\subsubsection{El modelo de monitoreo del mercado o market timing}

También basada en los problemas informativos y la asimétrica distribución de información, la teoría del monitoreo del mercado o momento oportuno del mercado (market-timing), interpreta las decisiones de financiación de la empresa como reacción de los directivos a las oportunidades de beneficio que otorgan los desequilibrios temporales del mercado. Baker y Wurgler (2002) formalizan las bases de este modelo según el cual las empresas emiten acciones cuando su precio es elevado y las recompran cuando se encuentran infravaloradas.

Según este modelo existe un momento oportuno para las actuaciones financieras de la empresa, que Graham y Harvey (2001) denominan “ventanas de oportunidad" (windows of opportunity). Este tipo de actuaciones afecta no sólo al coste de capital, sino que también tiene consecuencias sobre la estructura de capital de la empresa, que es reflejo del cúmulo de actuaciones realizadas por la

\footnotetext{
${ }^{14}$ Ross (1977), Bhattacharya (1979) y Myers y Majluf (1984) sientan las bases de la teoría de la señalización que estudia el papel informativo de las decisiones financieras en un contexto de información asimétrica en el que los inversores externos tienen dificultad para distinguir entre empresas de alta y baja calidad.
} 
empresa en la explotación de las oportunidades que ofrece la incorrecta valoración de sus títulos.

\subsubsection{El modelo de los hechos estilizados}

Las teorías que acabamos de presentar han sido sistemáticamente escrutadas por medio de modelos econométricos de muy variada naturaleza y la evidencia que proporcionan las bases de datos financieros y de mercado de empresas de todo el mundo ${ }^{15}$. El principal resultado de la contrastación de las predicciones empíricas de estas teorías ha sido la identificación de una serie de "hechos estilizados” sobre los factores que influencian las decisiones de estructura de capital de las empresas. Esta evidencia respalda parcialmente algunas de las explicaciones aportadas por las teorías del trade off y del pecking order, pero también pone al descubierto sus limitaciones en la justificación de la "heterogeneidad de las estructuras de capital, en las variaciones de los ratios de endeudamiento o en las decisiones de emisión de títulos” (Azofra y Rodríguez, 2012).

Harris y Raviv (1991) realizan una extensa revisión de investigaciones previas que les permite identificar los principales factores determinantes de la estructura de capital de la empresa, entre los que se encuentran, el tamaño de la empresa, las oportunidades de crecimiento, la rentabilidad, los escudos fiscales de origen distinto al endeudamiento, la probabilidad de quiebra y la tangibilidad del activo. Por su parte, Frank y Goyal (2009) identifican un total de veintinueve factores determinantes de la estructura de capital de los que seis de ellos dan respuesta al $27 \%$ de las variaciones experimentadas por el endeudamiento de las empresas analizadas $^{16}$. Estos seis factores son: el endeudamiento medio del sector, la tangibilidad del activo, el tamaño, la inflación esperada, el ratio market-to-book y

15 Aunque suelen presentarse como explicaciones que contienden entre sí por que explican la manera en que las empresas realizan sus decisiones de estructura de capital (Lindblom et al., 2011), algunos trabajos recientes destacan la complementariedad de algunos de sus argumentos (Graham y Leary, 2011).

${ }^{16} \mathrm{El}$ resto de factores sólo dan respuesta a un $2 \%$ adicional. 


\section{CAPÍTULO 2}

la rentabilidad. Frank y Goyal (2009) encuentran que el endeudamiento está positivamente relacionado con los cuatro primeros factores y negativamente con los dos últimos.

La tabla 2.2 resume las predicciones teóricas y la evidencia empírica recogida en algunos de los trabajos más conocidos. Otros factores considerados son: las restricciones financieras (Korajczyk y Levy, 2003); la protección de los derechos de los acreedores (La Porta et al., 1997); la estructura del mercado de deuda (González y González, 2008); las condiciones macroeconómicas (Azofra y Rodríguez, 2012). 
Tabla 2.2: Factores determinantes de la estructura de capital: Predicciones teóricas y evidencia empírica relevante

\begin{tabular}{|c|c|c|c|c|}
\hline $\mathbf{N}^{\mathbf{o}}$ & $\begin{array}{c}\text { Factores } \\
\text { determinantes de la } \\
\text { estructura de capital }\end{array}$ & $\begin{array}{l}\text { Teoría del } \\
\text { Trade off }\end{array}$ & $\begin{array}{l}\text { Teoría del } \\
\text { Pecking } \\
\text { Order }\end{array}$ & Evidencia empírica anterior \\
\hline 1 & $\begin{array}{l}\text { Oportunidades de } \\
\text { crecimiento }\end{array}$ & - & - & $\begin{array}{l}\text { Harris y Raviv (1991); Smith y Watts } \\
\text { (1992); Rajan y Zingales (1995); } \\
\text { Lang et al. (1996) Wald (1999); } \\
\text { Baker y Wurgler (2002); Fama y } \\
\text { French (2002); Frank y Goyal (2003); } \\
\text { Johnson (2003); Hovakimian et al. } \\
\text { (2004); Barclay et al. (2006); } \\
\text { Flannery y Rangan (2006); Frank y } \\
\text { Goyal (2009). }\end{array}$ \\
\hline 2 & Tamaño & + & + & $\begin{array}{l}\text { Harris y Raviv (1991); Rajan y } \\
\text { Zingales (1995); Berger y Ofek } \\
\text { (1995); Fama y French (2002); Frank } \\
\text { y Goyal (2003); Korajczyk y Levy } \\
\text { (2003); Flannery y Rangan (2006); } \\
\text { Frank y Goyal (2009); González y } \\
\text { González (2012). }\end{array}$ \\
\hline 3 & $\begin{array}{l}\text { Garantía de los activos } \\
\text { (collateral value) y } \\
\text { tangibilidad }\end{array}$ & + & + & $\begin{array}{l}\text { Harris y Raviv (1991); Frank y Goyal } \\
\text { (2003); Frank y Goyal (2004); } \\
\text { Flannery y Rangan (2006); Frank y } \\
\text { Goyal (2009). }\end{array}$ \\
\hline 4 & Rentabilidad & + & - & $\begin{array}{l}\text { Harris y Raviv (1991); Hovakimian et } \\
\text { al. (2001); Fama y French (2002); } \\
\text { Frank y Goyal (2003); Korajczyk y } \\
\text { Levy (2003); Flannery y Rangan } \\
\text { (2006); Kayhan y Titman (2007); } \\
\text { Frank y Goyal (2009). }\end{array}$ \\
\hline 5 & $\begin{array}{l}\text { Escudos fiscales } \\
\text { distintos a la deuda } \\
\text { (Non-debt tax shield) }\end{array}$ & - & & $\begin{array}{l}\text { DeAngelo y Masulis (1980); Titman y } \\
\text { Wessels (1988); Harris y Raviv } \\
\text { (1991); Downs (1993); Fama y } \\
\text { French (2002); Korajczyk y Levy } \\
\text { (2003); Flannery y Rangan (2006). }\end{array}$ \\
\hline
\end{tabular}

\subsubsection{La práctica de la decisión de financiación}

El grueso de la evidencia empírica sobre la financiación de la empresa se concentra principalmente en los resultados de las decisiones de los directivos. Apenas existe evidencia directa relativa al modo y los motivos por los que los directores financieros eligen entre las distintas fuentes de financiación. Los pocos 
estudios disponibles obtienen esta información a partir de las respuestas de los directivos a cuestionarios. Los primeros trabajos no pasaban de ser meras descripciones de los resultados de los cuestionarios (ver, por ejemplo, Stonehill et al. (1975)). Más recientemente esta técnica se ha empleado para complementar las conclusiones alcanzadas en los estudios empíricos convencionales sobre la heterogeneidad observada (Frank y Goyal, 2007). Frank y Goyal (2007), entre otros, han destacado los beneficios derivados de la complementariedad de los resultados obtenidos a través de este tipo de técnica de observiación directa.

Norton (1990; 1991a) propone el uso de encuestas con el propósito de observar el “interior” del proceso de decisión financiera y examinar las motivaciones, comportamientos y creencias que guían las decisiones de estructura de capital. El uso de este enfoque metodológico ha permitido conocer las prácticas, percepciones y creencias de los directivos de las empresas y ha puesto de manifiesto la distancia entre teoría y práctica empresarial también en lo que concierne a esta decisión.

Aunque la mayoría de los estudios realizados por medio de encuestas ${ }^{17}$ se centran en grandes empresas de Estados Unidos, también existe evidencia en la literatura sobre empresas que pertenecen a otros países (Bancel y Mittoo, 2004; Beattie et al., 2006; Brounen et al., 2006; Lindblom et al., 2011) y que tienen distintos tamaños (Chazi et al., 2010; Nor et al., 2012).

Entre las aportaciones notorias de la investigación con encuestas se encuentra el trabajo pionero de Donaldson (1961), basado en entrevistas a una muestra de 25 grandes empresas de Estados Unidos. Donaldson evidenció que los directores de las empresas favorecían el uso de los recursos internos y sólo recurrían a la financiación externa cuando la necesidad era inevitable, aportando las bases de la teoría del pecking order de la estructura de capital. Años más tarde Stonehill et al. (1975) encuentran que empresas de diferentes países ${ }^{18}$ no se rigen por un ratio de deuda objetivo, sino que aprovechan las oportunidades de mercado que se les

\footnotetext{
${ }^{17}$ Ver Anexo 2.1

${ }^{18}$ Francia, Japón, Holanda, Noruega y Estados Unidos.
} 
presenten para buscar financiación. La conclusión final de los autores es que el comportamiento de los encuestados no se encuentra en línea con los postulados de la teoría del trade off.

Los dos estudios precedentes no dan cuenta de comportamientos asociados a la teoría del trade off, pero tampoco dan señales claras de comportamientos acordes con la teoría del pecking order. Scott y Johnson (1982) estudiaron las prácticas financieras de grandes empresas de Estados Unidos. Los autores establecen que los participantes creen que "el uso prudente del endeudamiento puede reducir el coste de capital de la empresa y que su uso puede afectar el valor de mercado de la acción”. La tabla 2.3 recoge los resultados a cuatro preguntas planteadas en el cuestionario de Scott y Johnson. Las cuatro preguntas abordan cuestiones referidas a la estructura de capital. Los resultados indican que los directores financieros participantes “creen” en la existencia de una estructura de capital óptima, sustentando la teoría del trade off.

Tabla 2.3: Percepción directa acerca del coste de capital y del concepto de estructura de capital óptima

\begin{tabular}{l|c}
\hline Preguntas & $\begin{array}{c}\text { Respuestas } \\
\text { positivas }\end{array}$ \\
\hline $\begin{array}{l}\text { ¿Existe relación funcional entre su coste de capital y el nivel de } \\
\text { deuda que utiliza en su estructura financiera? }\end{array}$ & $92 \%$ \\
\hline $\begin{array}{l}\text { ¿Existe un monto de deuda “apropiado” en su capitalización que } \\
\text { resulta en un menor coste de capital? }\end{array}$ & $92 \%$ \\
\hline $\begin{array}{l}\text { ¿El uso excesivo de deuda podría resultar en un aumento del coste de } \\
\text { la deuda que utiliza su empresa? }\end{array}$ & $97 \%$ \\
\hline $\begin{array}{l}\text { ¿El uso excesivo de deuda podría resultar en que el precio de } \\
\text { mercado de la acción se vea negativamente afectado? }\end{array}$ & $90 \%$ \\
\hline
\end{tabular}

Fuente: Scott y Johnson (1982). 
Apoyo extra a los postulados del trade off se extrae del hecho de que los encuestados respondan que establecen de manera activa niveles de endeudamiento de referencia (un 87\% de las empresas establece un ratio de deuda objetivo y un 91\% asegura que este se mueve entre el 0\% y más de 51\%). En síntesis, los resultados del cuestionario indican que i) las empresas utilizan sus ratios de deuda objetivo como un input en el proceso de toma de decisiones financieras; ii) los ejecutivos participantes están de acuerdo con la existencia del concepto de estructura óptima de capital ${ }^{19}$ y iii) que éstos reconocen la idea de la capacidad de endeudamiento empresarial (y tienen precisas definiciones al respecto).

Posteriores encuestas han permitido la comparación explícita del poder explicativo del trade off y el pecking order. A partir de las respuestas obtenidas de empresas del Fortune 500, Pinegar y Wilbricht (1989) encuentran mayor respaldo a la jerarquía de las fuentes de financiación (aproximadamente un 70\% de los encuestados parecen seguirla) que al mantenimiento de un ratio de deuda objetivo. El seguimiento al orden de preferencias propuesto por el pecking order es señal de un comportamiento acorde a la teoría, sin embargo, para los autores las razones para hacerlo son menos claras. La teoría del pecking order se fundamenta en la existencia de asimetrías de información, no obstante, los resultados del estudio no encuentran relación estadísticamente significativa entre la percepción directiva acerca de la eficiencia de mercado y la estrategia financiera. Finalmente, Pinegar y Wilbricht perciben que para los encuestados los principios de planificación financiera son mucho más importantes que las teorías de estructura de capital.

Los resultados agregados del trabajo de Norton, (1989; 1990; 1991a) son aparentemente contradictorios. Las evidencias encontradas son parciales y no muestran patrones claros hacia una u otra teoría. Por una parte, las empresas siguen un comportamiento del tipo pecking order, pero al igual que en Pinegar y Wilbricht (1989), no parece que emerja del reconocimiento de la existencia de asimetrías informativas. Por otra, las empresas más grandes buscan mantener un

\footnotetext{
${ }^{19}$ Los encuestados creen que el uso prudente del endeudamiento puede bajar el coste de capital de la empresa y que el uso de deuda puede afectar el precio de las acciones en circulación.
} 
determinado ranking de deuda y un nivel de endeudamiento objetivo, sin embargo otros elementos de la teoría del trade off no parecen importantes, como los costes de insolvencia financiera o los costes de agencia. En los dos últimos trabajos (1990 y 1991a) se evidencia una fuerte aversión de las empresas pequeñas al uso excesivo de deuda.

En un cuarto trabajo, Norton (1991b) encuentra que i) el proceso de decisión de estructura de capital difiere entre las empresas; ii) los costes de agencia y de información asimétrica son más importantes para las empresas más pequeñas, no cotizadas y experimentado, o próximas a experimentar, problemas financieros ${ }^{20}$; y iii) que la influencia de las motivaciones directivas en las decisiones de estructura de capital podrían ser incluso mayores que las supuestas en la teoría de agencia.

Allen (1991) extiende la evidencia con las respuestas de 48 empresas australianas cotizadas. Aunque los encuestados aseguraron atribuir cierta importancia al establecimiento de ratios de deuda objetivo y las implicaciones fiscales de la deuda, los resultados se encuentran más de acuerdo con la idea del mantenimiento de una reserva en la capacidad de endeudamiento, tal y como argumenta la teoría del orden de preferencia y los resultados de Donaldson (1961). Las respuestas indican: i) la predilección por la utilización de los fondos internos; ii) a la hora de realizar grandes expansiones, los encuestados prefieren el uso de deuda frente a las acciones ${ }^{21}$ y iii) los límites al endeudamiento de la empresa son más interna que externamente generados. Sin embargo, Allen también encuentra cierta evidencia a favor de la consideración de las condiciones de mercado y contraria a la teoría del pecking order: cuando las condiciones de mercado son favorables se emiten acciones con la intención de reducir el endeudamiento.

Posteriormente Allen compara los determinantes de las decisiones de financiación de las empresas australianas con las empresas del Reino Unido y

\footnotetext{
${ }^{20}$ Estas mismas cuestiones son de poca importancia para las empresas grandes, financieramente estables, cuya dirección tiene expectativas positivas del futuro. Cabe destacar que la comparación del tamaño se realiza entre empresas pertenecientes todas ellas al Fortune 500.

${ }^{21}$ Esta preferencia no se evidencia en la financiación de adquisiciones.
} 
Japón (Allen, 2000). A diferencia de las empresas japonesas, las empresas del Reino Unido y las australianas procuran el mantenimiento de capacidad de endeudamiento adicional, tal y como establece la teoría del pecking order. La evidencia sugiere que esta política responde no tanto al control del riesgo de quiebra, como a la generación de la holgura necesaria para el aprovechamiento de las futuras oportunidades de inversión.

Haciendo uso del cuestionario de Pinegar y Wilbricht (1989), Kamath (1997) obtiene evidencia de los CFOs de las empresas cotizas en el New York Stock Exchange (NYSE) que ratifica el mayor poder explicativo de la teoría del peking order frente al trade off. De acuerdo con el análisis de Kamath (1997) existe el doble de probabilidades de que las empresas sigan un comportamiento acorde con la teoría del pecking order (65\%) que a la búsqueda de una estructura de capital objetivo (35\%). Adicionalmente, los encuestados indican que tanto el riesgo como la rentabilidad de los proyectos a ser financiados son los determinantes más importantes de las decisiones de financiación a largo plazo y que no realizan prácticas tendientes a señalizar al mercado con el objeto de que se revaloricen sus títulos.

Mediante un exhaustivo cuestionario Graham y Harvey (2001), obtienen información sobre las motivaciones de las decisiones de financiación de 392 directivos de empresas estadounidenses. La evidencia recogida sugiere que las empresas establecen un ratio de deuda objetivo, aunque no demasiado estricto. La flexibilidad financiera es de suma importancia para los encuestados: la emisión de acciones se realiza con la finalidad de mantener el ratio de deuda objetivo, sobre todo en las empresas más endeudadas. De manera contraria, la emisión de deuda no parece tener relación con la existencia de beneficios acumulados.

Graham y Harvey evalúan los costes y beneficios de emitir deuda. La ventaja fiscal tiene una importancia moderada en la elección del monto apropiado de deuda y los potenciales costes de insolvencia financiera apenas revisten relevancia para los encuestados. El uso de deuda para mitigar los conflictos de agencia entre accionistas y la dirección tampoco parece ser importante, sin embargo la 
evidencia sugiere que se emplean medios alternativos, como fomentar la participación en la propiedad al directivo. Los encuestados no parecen atribuir importancia al uso de deuda a fin de fomentar la eficiencia en la gestión como tampoco a que se comprometa una parte importante del flujo de caja a pago de intereses.

En relación con consideraciones de control corporativo, Graham y Harvey sugieren que hay pruebas sólo moderadas de que las empresas emitan acciones para diluir la participación de algunos inversores. Tampoco parece haber demasiado sustento a la idea de que las empresas utilizan el endeudamiento para evitar tomas de control; de que emitan deuda cuando las tasas de interés son bajas, ni deuda de corto plazo cuando los tipos de corto plazo son bajos o cuando se espera una bajada en las tasas de largo plazo. Sin embargo, encuentran cierta evidencia favorable al aprovechamiento de las oportunidades brindadas por los menores tipos de interés de la deuda en el exterior.

Aunque no se aborda explícitamente la cuestión si los encuestados siguen un orden de preferencia en las fuentes de financiación, Graham y Harvey preguntan por algunas de las cuestiones teóricas en las que se basa la teoría del pecking order. Las respuestas sugieren que la deuda es emitida cuando los beneficios no son suficientes para financiar las actividades de la empresa. Además, encuentran evidencia que sugiere que la emisión de capital se ve afectada por la sobre o infravaloración de las acciones. Sin embargo, existe poca evidencia con relación a la emisión de deuda cuando el valor de mercado del capital se encuentra subvalorado o a favor de la utilización de deuda como mecanismo de señalización.

Graham y Harvey concluyen que su estudio proporciona evidencia moderada acerca de que las empresas siguen la teoría del trade off y establecen un ratio de endeudamiento objetivo. Otros resultados, como la importancia de la flexibilidad financiera, consistentes con la teoría del pecking order, tampoco encuentra sólida evidencia. Los resultados, además, indican poca o contradictoria evidencia en relación con cuestiones como la señalización, los costes de transacción, los costes de subinversión, la sustitución de activos o del flujo de caja libre. La tabla 2.4 
resume los resultados parciales del trabajo de Graham y Harvey con relación a los principales determinantes del nivel de endeudamiento, en comparación con los obtenidos en los posteriores trabajos que, haciendo uso del mismo cuestionario, extienden el análisis a otros países. En términos generales, los resultados indican que, a pesar de las diferencias institucionales, las percepciones de los directores financieros acerca de estas cuestiones, con ciertos matices, no difieren. 
TEORÍA Y PRÁCTICA DE LAS DECISIONES DE INVERSIÓN Y FINANCIACIÓN

Tabla 2.4: Factores determinantes del nivel de endeudamiento

\begin{tabular}{|c|c|c|c|c|c|c|c|c|c|c|c|}
\hline \multirow{2}{*}{$\begin{array}{l}\text { Ranking } \\
\text { G\&H } \\
(2001)\end{array}$} & & $\begin{array}{l}\text { Graham } \\
\text { y Harvey }\end{array}$ & $\begin{array}{l}\text { Bancel y } \\
\text { Mittoo) }\end{array}$ & \multicolumn{4}{|c|}{ Brounen et al. (2006) } & \multirow{2}{*}{$\begin{array}{c}\text { Beattie et } \\
\text { al. (2006) } \\
\text { UK }\end{array}$} & \multirow{2}{*}{$\begin{array}{c}\begin{array}{c}\text { Benetti et } \\
\text { al. (2007) }\end{array} \\
\text { Brasil }\end{array}$} & \multirow{2}{*}{$\begin{array}{c}\begin{array}{c}\text { Chazi et } \\
\text { al. (2010) }\end{array} \\
\begin{array}{l}\text { Medio } \\
\text { oriente }\end{array}\end{array}$} & \multirow{2}{*}{$\begin{array}{c}\text { Maquieira } \\
\text { et al. } \\
(2012)\end{array}$} \\
\hline & & EE.UU & Europa & UK & Holanda & Alemania & Francia & & & & \\
\hline 1 & Flexibilidad financiera & 2,59 & 3,39 & 2,13 & 2,32 & 2,17 & 1,84 & & 2,22 & 2,91 & 2,24 \\
\hline 2 & Calificación crediticia & 2,46 & 2,78 & 1,48 & 1,53 & 1,85 & 1,58 & & 1,61 & 2,00 & 1,59 \\
\hline 3 & Volatilidad de flujos de tesorería & 2,32 & 2,33 & 1,73 & 2,06 & 1,67 & 1,54 & 2,72 & 2,20 & 2,45 & 1,84 \\
\hline 4 & $\begin{array}{l}\text { El ahorro de impuestos (deducibilidad } \\
\text { de intereses) }\end{array}$ & 2,07 & 2,59 & 1,68 & 1,90 & 1,28 & 1,57 & 2,34 & 1,94 & & 1,94 \\
\hline 5 & Los costes de transacción & 1,95 & 1,94 & 1,68 & 1,26 & 1,5 & 1,42 & & 2,07 & 2,32 & 1,54 \\
\hline 6 & Nivel de deuda de empresas del sector & 1,49 & 1,84 & 1,11 & 1,37 & 1,14 & 1,24 & & 1,35 & 1,52 & 0,59 \\
\hline 7 & Potenciales costes quiebra & 1,24 & 1,76 & 1,37 & 1,42 & 0,65 & 1,22 & 1,95 & 1,45 & 1,54 & 0,78 \\
\hline 8 & $\begin{array}{l}\text { Limitamos el endeudamiento para que } \\
\text { nuestros clientes/proveedores no se } \\
\text { preocupen por una potencial quiebra }\end{array}$ & 1,24 & 1,97 & 1,62 & 0,96 & 1,1 & 1,62 & 2,62 & 1,80 & 1,84 & \\
\hline 9 & $\begin{array}{l}\text { Restringimos el endeudamiento para } \\
\text { que los beneficios de los futuros } \\
\text { proyectos sean capturados de manera } \\
\text { íntegra por los accionistas }\end{array}$ & 1,01 & & 1,30 & 0,73 & 1,06 & 1,27 & & 1,42 & 1,88 & \\
\hline 10 & Evitar potenciales tomas de control & 0,73 & 0,85 & 0,58 & 0,38 & 0,48 & 0,61 & 1,54 & 0,95 & 0,61 & \\
\hline 11 & $\begin{array}{l}\text { El coste de los impuestos personales } \\
\text { de los acreedores }\end{array}$ & 0,68 & 0,96 & 0,65 & 0,61 & 0,75 & 0,84 & 1,02 & 1,14 & & \\
\hline 12 & $\begin{array}{l}\text { Se emite deuda para señalizar a la } \\
\text { competencia que es poco probable que } \\
\text { reduzcamos nuestra producción }\end{array}$ & 0,40 & 0,44 & 0,60 & 0,24 & 0,43 & 0,40 & & 0,85 & 1,03 & \\
\hline 13 & Deuda como mecanismo de disciplina & 0,33 & 0,73 & 0,52 & 0,27 & 0,31 & 0,63 & 1,46 & 0,64 & 0,67 & \\
\hline 14 & $\begin{array}{l}\text { Deuda como arma de negociación } \\
\text { frente a empleados }\end{array}$ & 0,16 & 0,27 & & & & & & 0,52 & 0,50 & \\
\hline
\end{tabular}


La visión del director financiero europeo y el rol que juega el entorno institucional en las decisiones de estructura de capital pueden apreciarse en Bancel y Mittoo (2004), a partir del análisis de una muestra de empresas de dieciséis países europeos ${ }^{22}$. Entre las conclusiones del trabajo cabe destacar que los determinantes de la estructura de capital son similares entre países europeos y de Norteamérica, aunque se aprecian diferencias según la calidad del sistema legal del país. En términos generales, la flexibilidad financiera y el rating de crédito son los factores más importantes en las decisiones de estructura de capital. También encuentran evidencia clara a favor de un comportamiento acorde con la teoría del trade off (por ejemplo, un 75\% declara seguir un ratio de deuda objetivo), junto con otros indicios que no responden a ninguna teoría en particular. A modo de conclusión, los autores postulan que la estructura de capital es el resultado de una compleja interacción de varias características institucionales así como de características propias de la empresa.

Una visión complementaria de las empresas europeas es la proporcionada por Brounen et al. (2006) ${ }^{23}$. En línea con los resultados precedentes, encuentran que dos tercios de las empresas de Reino Unido, Holanda y Alemania poseen ratios de deuda objetivo, aunque menos de un tercio de las empresas francesas lo establece. Los determinantes principales del nivel de deuda vuelven a ser, como en Graham y Harvey (2001) y Bancel y Mittoo (2004), la flexibilidad financiera, la clasificación crediticia y la volatilidad de los ingresos y flujos (véase tabla 2.4). Aparte del establecimiento de ratios de deuda objetivo, otros indicios favorables a la teoría estática del trade off son la alta importancia atribuida a la existencia de beneficios fiscales y a los costes de quiebra. Menor respaldo recibe la teoría del pecking order, que sólo encuentra cierto sustento en la relevancia de la flexibilidad financiera ${ }^{24}$.

${ }^{22}$ Austria, Bélgica, Grecia, Dinamarca, Finlandia, Islandia, Italia, Francia, Alemania, Holanda, Noruega, Portugal, España, Suiza, Suecia y Reino Unido.

${ }^{23}$ En este caso, para empresas de Alemania, Holanda, Francia y Reino Unido.

${ }^{24} \mathrm{Y}$ que, por otra parte, puede responder a motivaciones distintas, como, por ejemplo, las relacionadas con los problemas de agencia. 
Beattie et al. (2006) ratifican los principales resultados de trabajos anteriores para el caso de las empresas del Reino Unido y sugieren que las diferencias internacionales podrían no ser demasiado importantes en el debate de la estructura de capital y si serlo, sin embargo, el oportunismo de los directivos en la selección de la teoría. Los resultados de Beattie et al. (2006) confirman la relevancia de cuestiones tales como el beneficio fiscal de la deuda, la tangibilidad del activo, la emisión de deuda en casos de infravaloración de las acciones. Sin embargo, también obtienen evidencia de que otros elementos carecen de la relevancia pronosticada por la teoría, por ejemplo, el equilibrio entre beneficio fiscal de la deuda y costes de quiebra ó el uso de la deuda como mecanismo de control corporativo. Beattie et al. (2006) entienden que sus resultados refutan aspectos fundamentales de las teorías de la estructura de capital y sugieren que las teorías del trade off y del pecking order no son mutuamente excluyentes. Concluyen que nuestra comprensión de la estructura de capital de las empresas sigue siendo incompleta y la evidencia indica que las teorías existentes no son capaces de capturar la compleja y multidimensional heterogeneidad contenida en las opiniones de los encuestados ${ }^{25}$.

La idea de la complementariedad de las teorías incompletas es corroborada en Lindblom et al. (2011) para el caso de las empresas suecas. Lindblom et al. (2011) identifican un comportamiento financiero mixto, que se encuentra a medio camino entre distintas teorías, y que responde a una noción de equilibrio entre la estructura de capital actual y la óptima. Sus resultados muestran una mezcla entre apoyo y contradicción a los postulados de las principales teorías de estructura de capital, de la que concluyen que la elección entre deuda y capital propio no es, desde el punto de vista práctico, una elección del tipo blanco o negro entre pecking order o trade off, como se ha sugerido desde el punto de vista teórico. Para Lindblom et al. (2011) se hace necesario revisar la teoría del pecking order y proponer una versión extendida, que incorpore tanto elementos de agencia como

\footnotetext{
${ }^{25}$ Una reciente publicación, de Jong et al. (2011) evalúan empíricamente las teorías del trade off y pecking order. Sus resultados se encuentran fuertemente en contra de la teoría del trade off, aunque en línea con las predicciones de la teoría del pecking order.
} 
de señalización. Los autores sugieren además, que la adopción de una estructura de capital objetivo, bajo esta nueva propuesta, podría ser interpretado como una "señal".

Entre los principales resultados destaca la adopción de un ratio de deuda objetivo, acorde con la teoría del trade off, y la preferencia de la gran mayoría de los directivos por la utilización de fondos generados internamente y seguidamente de los préstamos bancarios, coherente con los postulados del pecking order. Este orden de preferencia contrasta con el hecho de que muy pocas empresas hacen uso de las acciones como última alternativa financiera, así como con la escasa importancia otorgada a la flexibilidad financiera. Adicionalmente, los resultados indican que los directivos opinan que es posible monitorizar el mercado con el objetivo de reducir costes, aunque se muestran indiferentes a los tipos de interés de mercado.

La tabla 2.5 resume los resultados hasta aquí presentados en relación con la evidencia encontrada de las principales teorías de estructura de capital. Se presentan los mismos trabajos en orden cronológico. 
TEORÍA Y PRÁCTICA DE LAS DECISIONES DE INVERSIÓN Y FINANCIACIÓN

Tabla 2.5: Evidencia empírica acerca de las teorías de estructura de capital

\begin{tabular}{|c|c|c|c|c|}
\hline \multirow{2}{*}{ Trabajo } & \multicolumn{4}{|c|}{ Teorías de estructura de capital } \\
\hline & Trade off & Pecking Order & Agencia & Market timing \\
\hline Stonehill et al (1975) & No & $\mathrm{N} / \mathrm{V}$ & $\mathrm{N} / \mathrm{V}$ & $\mathrm{N} / \mathrm{V}$ \\
\hline Scott y Johnson (1982) & $\begin{array}{l}\text { Fuerte: } \\
\text { 1) Existe relación entre coste } \\
\text { de capital y nivel de deuda; } \\
\text { 2) Existe un monto de deuda } \\
\text { apropiado; 3) Uso excesivo } \\
\text { uso de deuda podría } \\
\text { aumentar coste de deuda }\end{array}$ & $\mathrm{N} / \mathrm{V}$ & $\mathrm{N} / \mathrm{V}$ & $\mathrm{N} / \mathrm{V}$ \\
\hline Pinegar y Wilbricht (1989) & No & $\begin{array}{l}\text { Parcial: } 70 \% \text { parece seguir } \\
\text { orden de preferencias en la } \\
\text { financiación. }\end{array}$ & $\mathrm{N} / \mathrm{V}$ & $\mathrm{N} / \mathrm{V}$ \\
\hline $\begin{array}{l}\text { Norton (1990) y Norton } \\
\text { (1991a) }\end{array}$ & $\begin{array}{l}\text { Parcial: Buscan mantener } \\
\text { ranking de deuda y } \\
\text { establecen ratios de deuda } \\
\text { objetivo }\end{array}$ & $\begin{array}{l}\text { Parcial: Siguen orden de } \\
\text { preferencias en la financiación }\end{array}$ & $\mathrm{N} / \mathrm{V}$ & $\mathrm{N} / \mathrm{V}$ \\
\hline Allen (1991) & NO & $\begin{array}{l}\text { Parcial: Prefieren mantener } \\
\text { capacidad de endeudamiento } \\
\text { en reserva y usar sus fondos } \\
\text { internos primero. }\end{array}$ & $\mathrm{N} / \mathrm{V}$ & $\begin{array}{l}\text { Parcial: Cuando condiciones } \\
\text { de mercado son favorables } \\
\text { emiten acciones para reducir } \\
\text { deuda }\end{array}$ \\
\hline Graham y Harvey (2001) & $\begin{array}{l}\text { Parcial: } \\
\text { Moderada importancia: 1) } \\
\text { Deducciones fiscales; 2) } \\
\text { Relación deuda/acciones en } \\
\text { nuevas emisiones }\end{array}$ & $\begin{array}{l}\text { Parcial: } \\
\text { 1) Flexibilidad financiera; 2) } \\
\text { Emisión de deuda y emisión } \\
\text { de capital cuando se agotan } \\
\text { los recursos internos. }\end{array}$ & $\begin{array}{l}\text { Parcial: } \\
\text { 1) Limitar la emisión de deuda } \\
\text { más importante para empresas } \\
\text { en crecimiento; 2) Calce de } \\
\text { los activos con la madurez de } \\
\text { la deuda. }\end{array}$ & $\begin{array}{l}\text { Parcial: } \\
\text { 1) Evolución reciente del } \\
\text { valor de mercado de acciones } \\
\text { es importante en las nuevas } \\
\text { emisiones; } 2 \text { ) Se emite deuda } \\
\text { cuando se aprecia tipos de } \\
\text { interés bajos. }\end{array}$ \\
\hline
\end{tabular}




\begin{tabular}{|c|c|c|c|c|}
\hline Bancel y Mittoo (2004) & $\begin{array}{l}\text { Parcial: } \\
\text { Moderada importancia: 1) } \\
\text { Ventaja fiscal de la deuda; } \\
\text { 2) volatilidad de ingresos; 3) } \\
\text { potenciales costes de quiebra }\end{array}$ & $\begin{array}{l}\text { Parcial: } \\
\text { Moderada importancia: La } \\
\text { flexibilidad financiera es el } \\
\text { factor más importante en la } \\
\text { definición del nivel de deuda. }\end{array}$ & $\begin{array}{l}\text { Débil: para las hipótesis de } \\
\text { sustitución de activos y free } \\
\text { cash flow. }\end{array}$ & $\begin{array}{l}\text { Parcial: } \\
\text { Moderada importancia: 1) } \\
\text { Emiten deuda cuando 1) el } \\
\text { tipos de interés es bajo y/o 2) } \\
\text { acciones infravaloradas }\end{array}$ \\
\hline Brounen et al. (2006) & $\begin{array}{l}\text { Parcial: } \\
\text { Moderada importancia: } \\
\text { Las empresas poseen ratios } \\
\text { de deuda objetivo, } \\
\text { equilibrando costes y } \\
\text { beneficios de la deuda. }\end{array}$ & $\begin{array}{l}\text { Parcial: } \\
\text { Moderada importancia: } \\
\text { Flexibilidad financiera más } \\
\text { importante en nivel de deuda, } \\
\text { aunque no se debe a razones } \\
\text { de pecking order. }\end{array}$ & No & No \\
\hline Beattie et al. (2006) & $\begin{array}{l}\text { Parcial: } \\
\text { Moderada importancia. } \\
\text { 40\% de las empresas poseen } \\
\text { ratios de deuda objetivo. }\end{array}$ & $\begin{array}{l}\text { Parcial: } \\
\text { Moderada importancia. 60\% } \\
\text { de las empresas sigue orden de } \\
\text { preferencias. Valoran la } \\
\text { flexibilidad financiera, no por } \\
\text { teoría del pecking order. }\end{array}$ & $\mathrm{N} / \mathrm{V}$ & $\mathrm{N} / \mathrm{V}$ \\
\hline $\begin{array}{l}\text { Vasiliou y Daskalakis } \\
\text { (2009a) }\end{array}$ & No & (20) & No & $\begin{array}{l}\text { Fuerte: La mayoría de } \\
\text { empresas se financió con } \\
\text { acciones aprovechando la } \\
\text { bonanza del mercado. }\end{array}$ \\
\hline $\begin{array}{l}\text { Vasiliou y Daskalakis } \\
\text { (2009b) }\end{array}$ & $\mathrm{N} / \mathrm{V}$ & $\mathrm{N} / \mathrm{V}$ & $\mathrm{N} / \mathrm{V}$ & No \\
\hline Lindblom et al (2011) & $\begin{array}{l}\text { Parcial / Fuerte: } 1 \text { ) } \\
\text { Empresas establecen target; } \\
\text { 2) Estructura de Capital se } \\
\text { asocia a nivel de deuda y 3) } \\
\text { nivel de deuda se compara } \\
\text { frecuentemente con target }\end{array}$ & $\begin{array}{l}\text { Fuerte: Siguen orden de } \\
\text { preferencias sugerida por la } \\
\text { teoría }\end{array}$ & $\begin{array}{l}\text { Parcial. Débil evidencia del } \\
\text { problema free cash flow, sin } \\
\text { embargo, la dirección crea } \\
\text { flexibilidad financiera con ese } \\
\text { objetivo. }\end{array}$ & $\begin{array}{l}\text { Débil: } 73 \% \text { de las empresas } \\
\text { buscan oportunidades para } \\
\text { disminuir el coste de capital. }\end{array}$ \\
\hline
\end{tabular}

NO: no existe evidencia a favor de estos argumentos teóricos; N/V: no verificado 
En resumen, la evidencia aportada por los surveys corrobora la existencia de un gap entre la teoría y la práctica de las decisiones de estructura de capital. Los resultados de los primeros trabajos no difieren apenas de la evidencia encontrada en los más recientes, lo que sirve de prueba de la consistencia y vigencia de esta separación. Las teorías de la estructura de capital explican tan sólo parcialmente las decisiones adoptadas en la práctica por los directivos. Las razones de esta separación entre teoría y práctica y de la complementariedad de los distintos enfoques emergen como problemas relevantes que debe abordar la investigación de las finanzas corporativas. 
CAPÍTULO 2 


\section{CAPÍTULO 3: DISEÑO DE LA INVESTIGACIÓN EMPÍRICA}

$\mathrm{E}$ $\mathrm{n}$ un intento de encontrar una justificación al distanciamiento entre la teoría y la práctica financiera documentado por la literatura empírica, la literatura reciente ha evaluado distintas relaciones. En el ámbito de los modelos de inversión, los trabajos recientes han analizado la influencia de algunas características de la empresa y sus directivos en las desviaciones observadas. Las variables más utilizadas han sido el sector de actividad, el tamaño empresarial y la formación del directivo. En el ámbito de la financiación, se estrecha la evidencia disponible sobre cuestiones consideradas por los directivos para la adopción de sus decisiones de estructura de capital. Los pocos trabajos disponibles de este tipo se limitan a estimar la adhesión a uno u otro patrón de comportamiento y comprobar la existencia de diferencias significativas de los resultados, principalmente, por tamaños, sectores de actividad y países. Las conclusiones alcanzadas por la literatura precedente sugieren la existencia de algunas regularidades que animan a profundizar en el estudio teórico y empírico del gap entre la teoría y la práctica de la dirección financiera.

El objetivo de este capítulo es ofrecer una ruta con la que guiar el análisis empírico del problema objeto de estudio a través de la formulación de hipótesis contrastables empíricamente. Sin embargo, nuestra intención no es proponer un nuevo modelo que explique el distanciamiento documentado en la literatura. $\mathrm{Ni}$ siquiera nos servimos de un modelo preexistente para ampliarlo y completarlo. Al contrario, el razonamiento que empleamos para plantear nuestras hipótesis es ecléctico y se sirve de argumentaciones y especulaciones de diferentes 
procedencias. Concretamente, aprovechamos los resultados e interpretaciones de los trabajos empíricos revisados para plantear la influencia del tamaño y el perfil directivo y dar así continuidad a la línea de investigación esbozada por la literatura precedente. El modelo de valoración de las opciones reales nos ayuda a fundamentar la influencia de las distintas fuentes de valor de la inversión, mientras que el concepto de empresa de la teoría de la agencia permite plantear la relación entre las desviaciones y los mecanismos de disciplina y las relaciones entre las decisiones de inversión y de financiación. El resultado son siete hipótesis explicativas del gap que son contrastadas en la parte empírica de este trabajo a partir del análisis exhaustivo de la información obtenida de una encuesta a directivos de empresas españolas.

El resto del capítulo se articula del siguiente modo. Los epígrafes 1 y 2 presentan la discusión teórica que fundamenta, respectivamente, las hipótesis sobre los determinantes de las técnicas de selección de inversiones y los patrones de financiación utilizados por el director financiero. El epígrafe 3 recoge el diseño de la investigación empírica con mención especial al instrumento de aproximación empírica elegido: la encuesta. En el epígrafe 4 se describen los modelos y las técnicas econométricas aplicadas en el análisis de la evidencia obtenida con la encuesta para el contraste de las hipótesis formuladas.

\subsection{Hipótesis}

\subsubsection{Factores determinantes de la elección de las técnicas de selección de inversiones}

Aparte de documentar la persistente separación entre teoría y práctica, la investigación financiera ha intentado aportar explicaciones a este distanciamiento y el lento proceso de adopción de innovaciones en este campo. Las razones manejadas con mayor frecuencia por los investigadores giran en torno a las 
características de la empresa (Schall et al., 1978; Schall y Sundem, 1980; Block, 1997; Graham y Harvey, 2001; Brounen et al., 2004; Block, 2005; Rayo et al., 2007; Truong et al., 2008) y el perfil del director financiero (Graham y Harvey, 2001; Brounen et al., 2004; Hermes et al., 2007; Rayo et al., 2007; Leon et al., 2008; Baker et al., 2011a; Brunzell et al., 2013).

Sin embargo, la evidencia empírica previa y los desarrollos teóricos aportan explicaciones complementarias a las prácticas de selección de inversiones y su distanciamiento con las recomendaciones teóricas. La tabla 3.1 muestra un resumen de las variables con mayor poder explicativo.

\section{Tabla 3.1: Variables explicativas en la literatura}

Variables estadísticamente significativas en la explicación del tipo de técnica de selección de inversiones utilizada por los directivos de la empresa. La evidencia analizada en estos trabajos corresponde a diferentes muestras de distintos países.

\begin{tabular}{|c|c|c|}
\hline Empresa & CEO / CFO & Entorno \\
\hline $\begin{array}{l}\text { Tamaño: Moore y Reichert (1983); } \\
\text { Payne et al. (1999); Graham y Harvey } \\
\text { (2001); Brounen et al. (2004); } \\
\text { Verbeeten (2006); Hermes et al. (2007); } \\
\text { Leon et al. (2008); Sridharan y Schuele } \\
\text { (2008); Baker et al. (2011a); }\end{array}$ & $\begin{array}{l}\text { Formación: Graham y Harvey } \\
\text { (2001); Brounen et al. (2004); } \\
\text { Hermes et al. (2007); Meier y } \\
\text { Tarhan (2007); Rayo et al. (2007); } \\
\text { Leon et al. (2008); Chazi et al. } \\
\text { (2010); Baker et al. (2011a); } \\
\text { Brunzell et al. (2013). }\end{array}$ & $\begin{array}{l}\text { País: Payne et al. } \\
\text { (1999); Brounen et al. } \\
\text { (2004); Hermes et al. } \\
\text { (2007); Brunzell et al. } \\
\text { (2013) }\end{array}$ \\
\hline $\begin{array}{l}\text { Sector industrial: Moore y Reichert } \\
\text { (1983); Graham y Harvey (2001); } \\
\text { Verbeeten (2006); Hermes et al. (2007); } \\
\text { Leon et al. (2008); Truong et al. (2008); }\end{array}$ & $\begin{array}{l}\text { Edad: Graham y Harvey (2001); } \\
\text { Hermes et al. (2007); Chazi et al. } \\
\text { (2010) }\end{array}$ & $\begin{array}{l}\text { Riesgo país: Shao y } \\
\text { Shao (1996); Holmen } \\
\text { y Pramborg (2009) }\end{array}$ \\
\hline $\begin{array}{l}\text { Cotiza en bolsa: Brounen et al. (2004); } \\
\text { Hermes et al. (2007); Leon et al. (2008) }\end{array}$ & $\begin{array}{l}\text { Accionista: Graham y Harvey } \\
\text { (2001) }\end{array}$ & $\begin{array}{l}\text { Riesgo financiero: } \\
\text { Verbeeten (2006) }\end{array}$ \\
\hline $\begin{array}{l}\text { Regulada: Chazi et al. (2010); Graham } \\
\text { y Harvey (2001) }\end{array}$ & $\begin{array}{l}\text { Años de experiencia: Graham y } \\
\text { Harvey (2001) }\end{array}$ & \\
\hline Capital extranjero: Leon et al. (2008) & Implicación: Rayo et al. (2007) & \\
\hline $\begin{array}{l}\text { Exportaciones: Graham y Harvey } \\
\text { (2001); Hermes et al. (2007) }\end{array}$ & & \\
\hline \multicolumn{3}{|l|}{$\begin{array}{l}\text { Orientación al accionista: Brounen et } \\
\text { al. (2004) }\end{array}$} \\
\hline \multicolumn{3}{|l|}{$\begin{array}{l}\text { Endeudamiento: Graham y Harvey } \\
\text { (2001) }\end{array}$} \\
\hline \multicolumn{3}{|l|}{ Dividendo: Graham y Harvey (2001) } \\
\hline \multicolumn{3}{|l|}{$\begin{array}{l}\text { Rentabilidad: Haka et al. (1985); } \\
\text { Graham y Harvey (2001) }\end{array}$} \\
\hline $\begin{array}{l}\text { Riesgo: Verbeeten (2006); Sridharan y } \\
\text { Schuele (2008) }\end{array}$ & & \\
\hline
\end{tabular}




\subsubsection{Tamaño, sector y perfil directivo}

Entre las características de la empresa consideradas por la literatura destaca el tamaño de la empresa (Schall et al., 1978; Block, 1997; Brounen et al., 2004; Danielson y Scott, 2006; Sridharan y Schuele, 2008) y el sector de actividad (Schall et al., 1978; Schall y Sundem, 1980; Block, 2005; Rayo et al., 2007). Estas variables figuran en la mayoría de los trabajos explicativos. El argumento es que las empresas de mayor tamaño son las que disponen de mayores recursos para adquirir herramientas analíticas e informáticas y para contratar a personal más cualificado, necesarios para la adopción de las técnicas más sofisticadas. Una de las más importantes conclusiones del trabajo de Graham y Harvey (2001) es que existen diferencias fundamentales entre empresas pequeñas y grandes. Las empresas pequeñas son menos sofisticadas $y$, entre otras cosas, son menos propensas a la utilización del VAN, como criterio de decisión en la selección de sus inversiones.

Otra de las variables tradicionalmente utilizadas para explicar las diferencias encontradas entre teoría y práctica es el sector de actividad de la empresa. No todas las grandes empresas utilizan técnicas más sofisticadas. El trabajo de Block (2005) indica que existen diferencias significativas en el comportamiento de empresas por sectores de actividad. El sector de actividad de la empresa está íntimamente relacionado con el riesgo de sus inversiones y este último condiciona directamente la mayor o menor adecuación de la técnica de selección de inversiones utilizada. En sectores maduros, el menor riesgo de sus inversiones reduce las consecuencias del incorrecto tratamiento y valoración del riesgo de sus inversiones; mientras que en sectores de elevado riesgo, los errores de su incorrecto tratamiento pueden tener consecuencias graves en el proceso de creación de valor.

Verbeeten (2006) verifica que el sector de actividad tiene un impacto significativo en las prácticas de presupuesto de capital. Concretamente, las empresas del sector de servicios financieros y, en menor medida, de construcción y de servicios públicos parecen aplicar técnicas más sofisticadas que las empresas 
de los sectores industriales y de servicios no financieros. De manera particular para el caso de las opciones reales, la literatura indica que sectores de actividad tecnológicamente más complejos (tecnología, energía, servicios públicos) tienden a utilizar técnicas más sofisticadas (Triantis y Borison, 2001; Block, 2007).

Más recientemente, el análisis del sector de actividad se ha ampliado para considerar la influencia del entorno institucional (Brunzell et al., 2013), con relación al nivel de desarrollo económico de su país de origen (Hermes et al., 2007) y el riesgo del propio contexto institucional (Shao y Shao, 1996; Verbeeten, 2006; Holmen y Pramborg, 2009).

De hecho, la evidencia empírica acumulada muestra diferencias en el tipo de técnica utilizada en distintos países: Las empresas anglo-americanas parecen preferir la aplicación del VAN y la TIR (Graham y Harvey, 2001; Baker et al., 2011a) mientras que las empresas europeas recurren en mayor medida a la utilización del payback (Brounen et al., 2004; Rayo et al., 2007; Holmen y Pramborg, 2009). Esta evidencia comparada revela que el país de origen es un aspecto importante en la elección de las técnicas de selección de inversiones. A esta misma conclusión llegan Hermes et al. (2007) comparando las prácticas de las empresas holandesas y chinas.

Adicionalmente, la evidencia empírica ha verificado otros factores del contexto de los negocios tales como el "riesgo país”. Shao y Shao (1996) verifican una asociación positiva entre el uso de técnicas más sofisticadas en función del mayor riesgo político y financiero al que se enfrentan las filiales de empresas norteamericanas en el extranjero. El trabajo de Holmen y Pramborg (2009) verifica que ante aumentos (disminuciones) de riesgos de expropiación en el país de destino de inversiones directas en el extranjero (FDI, por sus siglas en inglés) aumenta el uso del payback (VAN). Cuando el riego es alto se hace más valiosa la opción de esperar antes que la empresa decida emprender el proyecto. Este comportamiento es consistente con los planteamientos de McDonald (2000) y Boyle y Guthrie (2006) que afirman que técnicas menos sofisticadas, como el payback, pueden aproximar el valor de opciones asociadas a los proyectos. Por su 
parte, Verbeeten (2006) encuentra que las empresas les atribuyen mayor importancia y utilidad a técnicas más sofisticadas en escenarios de incertidumbre financiera (de tipo de cambios, de interés, etc.).

Junto al tamaño y al sector de actividad, el perfil del director financiero se ha revelado como otra de las influencias determinantes del tipo de técnica predominante. Entre las características de los directivos de mayor poder explicativo se encuentran su formación, (Graham y Harvey, 2001; Brounen et al., 2004; Brunzell et al., 2013), edad (Graham y Harvey, 2001; Hermes et al., 2007) e implicación en las decisiones de la empresa (Rayo et al., 2007).

El hecho de que los directores financieros cuenten con formación universitaria superior especializada parece redundar en el uso de técnicas teóricamente más apropiadas. Trabajos como los de Graham y Harvey (2001), Meier y Tarhan (2007) y Baker et al. (2011a) relacionan el uso de métodos de presupuesto de capital más sofisticados al mayor nivel de formación del director financiero. Rayo et al. (2007), concluyen que la baja utilización de técnicas más sofisticadas, entre las que se encuentra el modelo de opciones, se debe no sólo a la baja cualificación de los directivos, sino además a la percepción errónea acerca de las premisas básicas de los modelos. Por ello, variables como la formación del directivo y el grado de implicación en las decisiones, llevan a un mayor conocimiento y, por ende, una mayor utilización de técnicas más sofisticadas. Verbeeten (2006) destaca que un alto nivel de habilidad directiva en el área de presupuesto de capital otorga la capacidad y voluntad de adoptar nuevas técnicas (aunque más que reemplazar las antiguas, añadan nuevas al análisis).

La relación entre el sector de actividad y las técnicas utilizadas puede interpretarse indirectamente a partir de su relación con el tamaño de la empresa y el perfil de sus directivos. La actividad realizada suele determinar una dimensión óptima o mínima eficiente (Becker et al., 1999; Kumar et al., 2002) ${ }^{26}$. Igualmente,

${ }^{26}$ Kumar et al. (2002) concluyen que aquellas industrias más intensivas en capital físico, que pagan mayores salarios y que realizan mayores inversiones en investigación y desarrollo, albergan a empresas de mayor tamaño. 
el tipo de operaciones implicadas en la producción y distribución determina el tipo de conocimiento y habilidades de los directivos que son más útiles para la empresa (Rajagopalan y Datta, 1996; Bloom y Van Reenen, 2010).

En términos generales, la revisión de estos resultados puede utilizarse para interpretar que las empresas responden, condicionadas por su tamaño, al mayor riesgo de su inversión mediante la contratación de directivos con capacidad y voluntad para adoptar técnicas más sofisticadas (Verbeeten, 2006). Esta síntesis permite formular la primera de las hipótesis a contrastar:

HIPÓTESIS 1: Cuanto mayor es el tamaño de la empresa, el riesgo del negocio y la capacitación de sus directivos, mayor es su propensión a utilizar el VAN, los modelos de simulación y los modelos de opciones reales y menor la propensión a utilizar la TIR, el payback y el análisis de sensibilidad.

\subsubsection{Problemas de agencia y técnicas de selección de inversiones}

Una explicación complementaria es la basada en la discrecionalidad directiva y los mecanismos de disciplina. Los trabajos de Jensen y Meckling (1976) y Myers (1977) revolucionaron la investigación de las finanzas corporativas, desplazando su eje de rotación sobre las implicaciones de la separación entre la propiedad y el control y la influencia de las características de los contratos de financiación en el comportamiento de los agentes y, por ende, sobre la discrecionalidad de la dirección para actuar sobre la renta generada por la empresa. Las mismas razones argumentadas por la teoría financiera de la agencia para explicar las decisiones de inversión ineficientes pueden emplearse para comprender la utilización de técnicas de selección inapropiadas.

De hecho, la utilización del payback como herramienta de selección de inversiones y la justificación en términos de su utilidad para aproximar el riesgo, supone una manifestación clara de este tipo de problemas. En la medida en que los objetivos del directivo dependan de la consecución de resultados a corto plazo, el plazo de recuperación influirá sobre el riesgo soportado, no ya por la empresa, 
sino por el propio directivo: un mayor plazo de recuperación aumentará el riesgo asociado al próximo ascenso, incremento de sueldo o simple renovación en el cargo. Esta presión de corto plazo, estudiada por ejemplo por Graham et al (2006), puede traer aparejadas decisiones miopes en el desarrollo de su actividad directiva y desembocar, finalmente, en acciones de destrucción de valor. Estas presiones cortoplacistas pueden deberse a las condiciones financieras de la empresa, pero también a motivaciones de agencia (Statman, 1982; Pike, 1985).

Según Pike y Ooi (1988), los directores financieros pueden estar sesgados hacia el corto plazo por dos razones: a) puede que esperen salir de la empresa antes de que termine la vida del proyecto $\mathrm{y}$ b) sus bonus y perspectivas de ascenso se encuentren relacionados con el rendimiento anual de los proyectos, lo que lleva a que les sea más conveniente menores periodos de recuperación. Por ello, las compensaciones por resultados pueden inducir (y, desde ese punto de vista, justificar) la mayor utilización del payback. El ser humano racional se encaminará hacia aquello que le beneficie más y el director financiero no es la excepción. Además de lo anterior, Liljeblom y Vaihekoski (2009) encuentran relación entre el tipo de propietario de la empresa y el uso del payback, donde una mayor cantidad de propietarios orientados hacia el corto plazo lleva a rebajar los periodos de recuperación de los proyectos.

Danielson y Scott (2006), estudiando empresas pequeñas, sostienen que éstas prefieren basar sus decisiones utilizando el payback, como técnica de evaluación, y la intuición (gut feel), basada en experiencia de inversiones previas, debido a que, entre otras posibles, tienen limitados recursos destinados a la gestión y a la falta de experiencia en finanzas y contabilidad. Además este tipo de empresas suelen adolecer de restricciones financieras con lo que les interesará utilizar medidas de liquidez de los proyectos (tales como el payback). La mayor certeza de los flujos de caja más inmediatos frente a la mayor incertidumbre de los flujos más alejados en el tiempo actúa como impulsor, en la mente del gestor (y en muchas de los casos, que coincide con el propio dueño) hacia la mayor frecuencia de uso del payback. 
La evidencia empírica aporta algunos indicios sobre el poder explicativo de este tipo argumentos: Brounen et al. (2004) encuentran que la orientación al accionista influye significativamente sobre el tipo de técnica utilizada; Brounen et al. (2004), Hermes et al. (2007) y Leon et al. (2008) encuentran relación con el hecho de que la empresa cotice en bolsa; y Leon et al. (2008) y Graham y Harvey (2001) documentan síntomas de influencia del endeudamiento y el dividendo. El efecto de los mecanismos de control sobre la discrecionalidad directiva sustenta la segunda de las hipótesis que nos proponemos contrastar:

HIPÓTESIS 2: La presión de los mecanismos de disciplina reduce la propensión a utilizar técnicas teóricamente inferiores (como el payback, TIR o análisis de sensibilidad) y aumenta la propensión a utilizar técnicas superiores (como el VAN, las opciones reales y los modelos de simulación).

\subsubsection{Fuentes de valor y técnicas de selección de inversiones}

Los argumentos tradicionales del tamaño, sector y perfil directivo planteados en la hipótesis 1, pueden servir para justificar el uso de complejas técnicas cuantitativas, pero sorprende que pueda determinar la elección entre el cálculo del VAN al estilo de los manuales de dirección financiera y la estimación del payback: Una vez realizada la compleja tarea de predecir los flujos de tesorería futuros que requieren ambos modelos, la complejidad adicional de la primera respecto a la segunda se reduce a unos conocimientos básicos de finanzas y de manejo de hojas de cálculo.

La influencia de las características de la empresa y del perfil del directivo puede esconder, sin embargo, el efecto de la diferente naturaleza de las fuentes de valor de las inversiones. Cuando la única fuente de valor son los flujos directamente generados por la inversión y el nivel de flexibilidad es reducido, el valor de las opciones reales es próximo a cero y la técnica apropiada desde una perspectiva teórica es el VAN (Adner y Levinthal, 2004; Krychowski y Quélin, 2010). Por el contrario, cuando las principales fuentes de valor son los resultados no monetarios, en tanto generadores de oportunidades de crecimiento y de 
flexibilidad, los modelos de descuento fallan en la identificación de las mejores oportunidades y se hace necesaria la utilización de los modelos de opciones reales (Myers, 1984b). El valor de la flexibilidad y de las oportunidades de crecimiento es apalancado además por el riesgo de los negocios, de manera que cuanto mayor sea el riesgo de la inversión mayores son los errores cometidos por la utilización de las técnicas más simples.

Cuando el proyecto genera, además de flujos de tesorería, otros resultados "no monetarios", tales como el conocimiento, la imagen de marca o la flexibilidad, la teoría financiera propone "ampliar" el VAN con el valor de los derechos de decisión (opciones reales) en los que se materializan los anteriores resultados intangibles. Comoquiera que las inversiones que no proporcionan algunos de estos resultados estratégicos son difíciles de imaginar (Kulatilaka y Marcus, 1992) una de las técnicas de frecuente utilización debiera ser el VAN ampliado con las opciones reales. Esta tesis viene además reforzada por el potencial explicativo de los corolarios de este modelo, ya que incluso aquellos gerentes que nunca han oído hablar de las opciones reales actúan y deciden como si respondiesen a sus preceptos (Myers, 1996), por ejemplo, cuando emprenden una inversión en un proyecto de I+D con VAN negativo en busca de nuevas oportunidades o cuando involucran a la firma en nuevos mercados, desconocidos y aparentemente poco rentables, por su valor estratégico.

Cumplido el plazo de los 10 años augurado por Tom Copeland (2000) para que las opciones reales sustituyeran al descuento de flujos, parece evidente la existencia de problemas relacionados con la aplicación práctica que dificultan la adopción del modelo teóricamente superior. Los estudios más recientes ponen de manifiesto la progresiva adopción del enfoque de las opciones reales como técnica de selección de inversiones, aunque todavía a una distancia considerable del método del descuento (Busby y Pitts, 1997). La elevada complejidad operativa de los modelos (Newton y Pearson, 1994), la falta de comprensión de la filosofía del enfoque por parte de los directivos (Myers, 1996; Baker et al., 2011b) o el incumplimiento de algunos de los supuestos requeridos por los modelos 
matemáticos (Lander y Pinches, 1998), son algunos de los argumentos esgrimidos para justificar la remisa difusión práctica del enfoque.

En esta misma línea, Block (2007) y Baker et al. (2011b) descubren que las razones esgrimidas por los directores financieros para justificar la no utilización de las opciones reales son principalmente: el desconocimiento de los directivos, la dificultad de la técnica, la falta de aplicabilidad al negocio, la mayor familiaridad con el descuento de flujos o el hecho de que las opciones reales induzca a asumir mayores riesgos. En el caso de las empresas españolas, los resultados de Rayo et al. (2007) confirman la baja utilización del modelo de opciones y señalan a la cualificación de los directivos, la percepción de las premisas básicas del modelo y el grado de implicación en las decisiones financieras, como posibles factores explicativos.

Este tipo de explicaciones ofrecen una visión ciertamente negativa de los directores financieros, que parecen no contar con incentivos suficientes para adoptar nuevas herramientas de selección de inversiones, que siendo superiores a las habitualmente empleadas, demandan un mayor esfuerzo y comportan mayor complejidad. Esta valoración encuentra soporte adicional en los resultados empíricos que relacionan el tamaño de la empresa o la formación del directivo con la técnica utilizada: Aquellas empresas de mayor tamaño -y presumiblemente con mayores recursos- son las más proclives a contratar directivos más preparados y dispuestos a utilizar los modelos de valoración de opciones reales.

Frente a esta hipótesis, cabe pensar una visión mucho más benévola con los directores financieros, que explica el tipo de técnica utilizada en función de la naturaleza de las inversiones habitualmente evaluadas. Concretamente, planteamos que la propensión a utilizar técnicas de valoración basadas en las opciones reales incrementa cuando disminuye el peso de los flujos de tesorería como fuente de valor de las inversiones y aumenta la relevancia de los resultados intangibles o estratégicos, en cuanto generadores de oportunidades de crecimiento y flexibilidad. La “no aplicabilidad” de las opciones reales argumentada por los directivos entrevistados en Baker et al. (2011b) respalda esta propuesta 
explicativa. En esta misma línea, Chen (2008) concluye que empresas con alta estandarización en sus productos tienden a poner mayor énfasis en métodos asociados al descuento de flujos, mientras que empresas con baja estandarización tienden a poner mayor énfasis en técnicas no financieras. Contrariamente, la evidencia documentada en Alkaraan y Northcott (2006) parece indicar que la naturaleza estratégica de las inversiones y sus resultados no influyen en la adopción de los modelos basados en opciones reales. Con objeto de profundizar en la comprensión de la decisión de adoptar este tipo de técnicas se plantea la tercera de las hipótesis a contrastar:

HIPÓTESIS 3: La propensión a utilizar los modelos de valoración de opciones reales (descuento de flujos) es mayor cuanto más (menos) relevante son las oportunidades de crecimiento y flexibilidad como fuentes de valor de la inversión de la empresa.

\subsubsection{Decisiones de financiación y técnicas de selección de inversiones}

La utilización de los modelos menos apropiados desde una perspectiva teórica también encuentra una explicación razonable a la luz de los problemas de información asimétrica asociados a la financiación de inversiones (Thakor, 1990). En un contexto de información asimétrica, la financiación interna implica menor coste que la financiación externa (Myers, 1984a). En este caso, los directivos pueden preferir proyectos que reporten fondos suficientes para financiar “internamente” las futuras oportunidades de crecimiento, siendo este incentivo más acusado cuanto mayor sea la velocidad de generación de nuevas oportunidades de inversión ${ }^{27}$. Como consecuencia, los directivos de las empresas financieramente restringidas o con déficit de fondos financieros se preocuparán por conocer el plazo de recuperación (payback) de las distintas alternativas disponibles y elegirán en primer lugar las de mayor liquidez (Lefley, 1996).

27 Pruitt y Gitman (1991) verifican que par el 65\% de sus encuestados que el nivel actual de beneficios determina el nivel actual de inversiones de la empresa. 
El anterior argumento pone al descubierto la necesidad de considerar las posibles interrelaciones entre las técnicas de selección de inversiones y el patrón de financiación de la empresa. Desde que Modigliani y Miller demostraran la independencia de las decisiones de inversión y de financiación en un contexto de mercados perfectos (Modigliani y Miller, 1958), la literatura financiera no ha cesado de ofrecer argumentos que explican el modo en que distintas imperfecciones de los mercados sostienen los vínculos existentes entre las decisiones de inversión y de financiación de la empresa ${ }^{28}$. A este respecto Azofra y Miguel (1990) señalan que las investigaciones empíricas realizadas en los últimos años han permitido verificar que las decisiones de la empresa se determinan conjuntamente.

Los trabajos de Jensen y Meckling (1976) y Myers (1977) ponen de manifiesto que la estructura de capital tiene implicaciones más allá del reparto de la renta generada por las inversiones de la empresa, que alcanzan su propia capacidad generadora de renta. La renta esperada no puede considerarse dada, sino que depende de las futuras decisiones directivas y éstas, a su vez, del sistema de incentivos y mecanismos de control que se derivan de las estructura de capitalpropiedad de la empresa.

Trabajos posteriores como los de Mauer y Triantis (1994); Mauer y Ott (2000); Childs et al. (2005); Mauer y Sarkar (2005); Billet et al. (2007); Gamba y Triantis (2008); Gamba et al., (2008); Morellec y Zhdanov (2008); Tserlukevich (2008) ó Hackbarth (2009), entre otros, ayudan a desarrollar la comprensión de los problemas de subinversión y de sustitución de activos incialmente planteados por Jensen y Meckling (1976) y Myers (1977) y la relación entre las decisiones de inversión y de financiación.

En este contexto, no resulta difícil comprender que las decisiones de financiación puedan ofrecer información no sólo del riesgo y la naturaleza de los negocios para los que se obtienen los fondos, sino también del tipo de decisiones que cabe esperar de los responsables de la empresa y, por ende, del tipo de

${ }^{28}$ Ejemplo de ello es el trabajo de Myers (1974). 
técnicas de selección de inversiones utilizados. Probablemente, la relación más obvia sea la ya comentada entre restricciones financieras y payback. De acuerdo con la teoría del pecking order, las empresas que se enfrentan a mayores restricciones financieras derivadas de las imperfecciones informativas tenderán a financiar sus proyectos de inversión siguiendo un orden de preferencia que minimice los costes informativos asociados a cada una de las fuentes de financiación disponibles. Dado que la retención de recursos generados implica los menores costes posibles, los directivos de estas empresas tenderán a utilizar técnicas que permitan elegir los proyectos de inversión según el plazo de recuperación del capital invertido y las futuras necesidades de fondos.

En el caso de las empresas que eligen su política de financiación de manera que se minimicen los costes de agencia asociados a los problemas de subinversión y sustitución de activos, cabe esperar una mayor propensión de los directivos a identificar la estrategia óptima de adquisición y ejercicio de las opciones de inversión y desinversión y, consecuentemente, la mayor relevancia de los modelos de valoración de opciones reales. Finalmente, aquellas empresas cuyos directivos adopten las decisiones de financiación basados en la maximización de la diferencia entre los beneficios y costes revelan un estilo directivo basado en la utilización de los modelos tradicionales de creación de valor y, por tanto, una mayor propensión a la utilización del VAN y la TIR.

A modo de síntesis, la relación entre el patrón de financiación y las técnicas de selección de inversiones utilizadas puede formularse a partir de la siguiente hipótesis:

HIPÓTESIS 4: El patrón de financiación de la empresa está relacionado con los modelos de selección de inversiones:

H4.1: Una política financiera basada en la maximización del trade off entre beneficios y costes de financiación incrementa la propensión de uso del VAN y la TIR. 
H4.2: Una política de financiación acorde con el pecking order incrementa la probabilidad de utilización del plazo de recuperación.

H4.3: Una política de financiación basada en la minimización de los costes de agencia incrementa la probabilidad de utilización de los modelos de opciones reales.

\subsubsection{Factores determinantes de la elección del patrón de financiación}

La literatura empírica sobre la forma en que los directores financieros deciden sus estructuras de capital pone de relieve que las teorías actuales son incompletas y en cierto grado complementarias. El gap entre la teoría y la práctica demanda la atención de los investigadores en la búsqueda de explicaciones lógicas de las desviaciones que permitan completar los modelos actuales y avanzar en la compresión de la realidad de las decisiones de financiación.

Esta misma literatura resalta la compleja heterogeneidad de las empresas como atenuante de los fallos de las teorías en la explicación de las decisiones de financiación. Las empresas siguen diferentes teorías, a veces varias de manera simultánea, exhibiendo patrones complejos que no pueden ser explicados de manera satisfactoria por una única teoría. Ante esta diversidad, se hace necesaria la identificación de patrones de comportamiento de las empresas elaborados a partir de nuestras actuales teorías, que nos ayuden a identificar las posibles desviaciones y a indagar en sus causas. La evidencia acumulada aporta algunos indicios sobre la existencia de características de las empresas que explican la mayor adhesión a una u otra de las teorías de estructura de capital.

\subsubsection{Tamaño, sector y perfil directivo}

Una de las variables más utilizadas en el análisis de la adhesión a una u otra teoría de estructura de capital es el tamaño de la empresa. En términos generales, la evidencia indica que las empresas de mayor tamaño se muestran más proclives 
al establecimiento y seguimiento de ratios de endeudamiento objetivo, tal y como pronostica la teoría del trade off. La explicación de esta asociación gira en torno a las mayores posibilidades de financiación de las grandes empresas que favorece el establecimiento de niveles objetivo de endeudamiento que maximicen la diferencia entre los beneficios y los costes de las distintas fuentes disponibles.

Norton (1990), Brounen et al. (2004), Beattie et al. (2006), Vasiliou y Daskalakis (2009b), De Jong y Verwijmeren (2010), Karadeniz et al. (2011), Lindblom et al. (2011), encuentran que las grandes empresas son más propensas a seguir una estructura de capital objetivo. Los directivos de las grandes empresas se muestran especialmente interesados en explotar las ventajas fiscales de la deuda (Brounen et al., 2004; Beattie et al., 2006). Sin embargo, los costes de quiebra son menos relevantes en las grandes empresas (Bancel y Mittoo, 2004; Nor et al., 2012), tal y como cabe esperar por su mayor capacidad de refinanciación en comparación con las compañías de menor dimensión.

Con relación al orden de preferencia que establece la teoría del pecking order no parece que los resultados empíricos respalden la influencia esperada de la dimensión de la empresa. De acuerdo con el razonamiento teórico, las empresas más pequeñas son más proclives a padecer problemas y asimetrías informativas, que dificulten y encarezcan su acceso a las fuentes de financiación (Pettit y Singer, 1985), por lo que en principio cabría esperar que cuanto menor es la dimensión de la empresa mayor es el ajuste de su política de financiación a la teoría del orden de preferencia.

Limdblom et al. (2011) y Nor et al. (2012) encuentran evidencia que confirma la mayor relevancia de la teoría pecking order en la explicación de las empresas de menor tamaño. Sin embargo, otros resultados empíricos previos no respaldan relación alguna entre el tamaño y el orden de preferencia (Beattie et al., 2006). Por el contario, existe evidencia que revela la mayor propensión de las grandes empresas a generar holguras financieras y medidas conducentes a asegurar cierto grado de flexibilidad financiera (Allen, 2000; Beattie et al., 2006; Bancel y Mittoo, 2011; Nor et al., 2012). Este resultado es contrario a lo que 
cabría esperar debido a los menores problemas de información asimétrica y su mayor capacidad de autofinanciación, sin embargo, puede ser coherente con la complementariedad entre las teorías del trade off y el pecking order (Beattie et al., 2006; Lindblom et al., 2011). En todo caso, la relevancia de la flexibilidad en las decisiones financieras de las empresas y su relación con el tamaño sugiere que aquella puede obedecer a razones distintas de las esgrimidas por la teoría del pecking order (Graham y Harvey, 2001; Brounen et al., 2006).

Buena parte de los problemas de agencia se encuentran asociados a la separación entre propiedad y control y, por tanto, su relevancia incrementa con el tamaño de la empresa. Otros problemas, como los originados por el conflicto entre accionistas y acreedores no guardan una relación tan obvia con el tamaño, aunque en conjunto puedan retroalimentarse con una mayor dimensión. Así lo confirma, por ejemplo, el trabajo de Chazi et al. (2010) que encuentra que la relevancia de los problemas de sustitución de activos asociado al conflicto entre accionistas y acreedores incrementa con el tamaño de la empresa. Lindblom et al. (2011) observan que las empresas más pequeñas son las que más relevancia dan a los problemas de subinversión.

Finalmente, el ajuste del comportamiento financiero de la empresa a la teoría del monitoreo del mercado (market timing) se prevé mayor para las empresas de mayor tamaño, pues son las que cuentan con mayores posibilidades de acceso a la información y las propias oportunidades brindadas por el mercado. Norton (1990) observa que las empresas de mayor tamaño dan más importancia a las estrategias basadas en la curva de rendimiento y Lindblom et al. (2011) encuentran que las empresas de mayor tamaño son las que recurren en mayor medida a la recompra de acciones para ajustar la estructura de capital.

Junto con el tamaño de la empresa, otra de las variables que puede incidir en el gap entre teoría y práctica de la financiación es la formación de los directivos. Colemann y Robb (2012) evalúan la influencia de la titulación académica en el orden de preferencia de fuentes de financiación, descubriendo que la menor cualificación académica propicia el mayor recurso a los fondos internamente 
generados mientras que la formación de tipo posgrado favorece la obtención de financiación mediante emisiones de nuevas acciones. En términos generales, de una mayor preparación en las teorías financieras cabe esperar una mayor capacidad para analizar los problemas de financiación y plantear soluciones apropiadas. Cuanto mayor sea la complejidad de estos problemas, mayor será la probabilidad de que el directivo con formación superior actúe de manera teóricamente óptima. Por ello, no parece que en el establecimiento de ratios de endeudamiento objetivo o de órdenes de preferencia pueda diferir según la formación del directivo. De manera análoga, la consideración de los determinantes de los problemas de agencia y la identificación de las ventanas de oportunidad requieren de un nivel de conocimientos y habilidades propias de niveles de formación superior. Wu et al. (2008) sugieren que la mayor preparación del dueño/director favorece un mayor aprovechamiento de la financiación bancaria.

Finalmente, el sector de actividad merece mención expresa también en este ámbito. La variable sector suele ser una constante en los contrastes econométricos tradicionales, normalmente incorporada en forma de variable de control o instrumento de robustez. Algunos de los trabajos basados en encuestas también han evaluado la influencia del sector de actividad de la empresa en el poder explicativo de las teorías de la estructura de capital. En principio, el tipo de negocios desarrollados influye tanto en el riesgo de la renta generada como en la naturaleza de los activos en los que se invierte. Ambos factores inciden en la probabilidad de insolvencia, las asimetrías informativas y los problemas de agencia haciendo que las teorías asociadas a estas cuestiones sean más o menos relevantes en la explicación de las decisiones de financiación.

La evidencia disponible no contribuye a respaldar este tipo de argumentos. Fan y So (2004) no encuentran respaldo a la influencia de la industria. Beattie et al. (2006) observan que la propensión de las empresas a adoptar una estructura de capital objetivo o a seguir una jerarquía de fuentes de financiación no está relacionada con la clasificación industrial. Sin embargo, sus resultados evidencian 
diferencias significativas entre sectores con respecto a la relevancia de la flexibilidad financiera.

A modo de síntesis, la relación entre el patrón de financiación y las variables de tamaño y perfil directivo puede formularse a partir de la siguiente hipótesis:

HIPÓTESIS 5: El patrón de financiación de la empresa depende del tamaño de la empresa y perfil de su director financiero:

H5.1: Cuanto mayor es el tamaño de la empresa mayor la relevancia de las teorías trade off, agencia y monitoreo del mercado en la explicación de las decisiones de financiación de la empresa; y menor la relevancia de la teoría pecking order.

H5.2: Cuanto mayor es el nivel de formación del directivo, mayor es la relevancia de la teoría de la agencia y la teoría del monitoreo del mercado en las decisiones de financiación de la empresa.

\subsubsection{Naturaleza de las fuentes de valor}

El enfoque de las opciones reales reconoce que los resultados de la inversión empresarial no se reducen a los de tipo monetario. La inversión proporciona resultados monetarios (flujos de tesorería) junto con otros activos no monetarios (intangibles o estratégicos). De acuerdo con este planteamiento, el modelo de opciones reales establece que el valor de un activo depende del tetranomio “rentabilidad-riesgo-potencia-flexibilidad” (Fuente, 2004).

La potencia se define como la capacidad de un negocio para abrir nuevas oportunidades de inversión. Dicha capacidad procede de los denominados resultados estratégicos o intangibles de la inversión empresarial: el conocimiento tecnológico, de producto o mercado, la imagen de marca, la fidelidad de clientes, la reputación,... El mayor o menor valor de este tipo de activos depende de las nuevas posibilidades de actuación que proporciona a la empresa y, en particular, 
del valor de las opciones de crecimiento u oportunidades de negocio que brinda a la empresa ${ }^{29}$.

La flexibilidad de la inversión se define como la cualidad de adaptación de sus resultados mediante la adopción de futuras decisiones. Un activo se dice que es más flexible que otro si permite actuar en mayor medida sobre sus resultados, potenciando las ganancias y reduciendo las posibles pérdidas. Un activo más flexible tiene más valor que otro de idénticas características pero menos flexible.

Esta descomposición de las fuentes de valor ofrece una explicación adicional a la posible adhesión a un patrón u otro de financiación. Por un lado, la naturaleza observable del valor procedente de los resultados monetarios facilita su conocimiento por parte de los outsiders de la empresa. Los estados financieros y las obligaciones informativas legales sirven de cauce para su difusión en el mercado y su escrutinio por los analistas e inversores. Los resultados no monetarios de los que procede la potencia (oportunidades de crecimiento) carecen de la materialidad y concreción necesarios para poder ser objeto de un tipo de difusión similar. La consecuencia más directa es el posible desajuste entre el “verdadero" valor de la empresa, que incluye el valor de las opciones reales, y el valor percibido por los inversores y registrado en el mercado.

En aquellas empresas en las que los resultados intangibles y estratégicos predominen sobre los resultados monetarios, los problemas de información asimétrica y de agencia se hacen más relevantes en las decisiones de financiación y, por tanto, cabe esperar un comportamiento directivo más interesado por los problemas explicados por la teoría del pecking order y de agencia. Por el contrario, cuanto mayores son los resultados monetarios, se hace más relevante la minimización del coste de capital. En este caso, el interés de los directivos reflejará los pronósticos de la teoría del trade off.

${ }^{29}$ De acuerdo a Krychowski y Quelin (2010) no todos los proyectos encajan en la lógica de las opciones reales. Estos deben reunir cuatro principales características: irreversibilidad, incertidumbre, flexibilidad y revelar información durante mientras esté “viva” la opción. 
Por su parte, la flexibilidad de la inversión permite a la empresa reducir la volatilidad de la renta generada por las inversiones y, de este modo, reduce los problemas de liquidez e insolvencia de la empresa. Además, la capacidad para actuar sobre los resultados proporciona "escudos fiscales" alternativos a la deducibilidad de la deuda, en forma de periodificación de los resultados e impuestos a pagar. Ambos motivos sugieren que la mayor flexibilidad de la inversión puede reducir la relevancia de los argumentos de la teoría del trade-off en las decisiones financieras de la empresa.

Trigeorgis (1993) y Mauer y Triantis (1994), entre otros, analizan la relación entre la flexibilidad de la inversión y la flexibilidad financiera. Por lo general, ambas flexibilidades desempeñan funciones sustitutivas. La mayor flexibilidad de la inversión reduce la volatilidad de los flujos de tesorería y con ello la relevancia de las holguras financieras. Indirectamente, la estabilidad o persistencia del flujo se materializa en credibilidad entre los inversores (Berger, 2003; Ertimur et al., 2003) lo cual contribuye a reducir las asimetrías informativas asociadas a las fuentes de financiación externa y hace que la teoría del pecking order pierda poder explicativo. Adicionalmente, las menores asimetrías informativas y mayores posibilidades para potenciar las ganancias y acotar las pérdidas permiten posicionar a la empresa en el mejor aprovechamiento de las ventanas de oportunidad. De ahí que quepa esperar una relación positiva entre flexibilidad y el interés de los directivos por los indicadores de la teoría del market timing.

Finalmente, la mayor discrecionalidad directiva asociada a la flexibilidad de la inversión incrementa la relevancia de los problemas de selección adversa y riesgo moral de la empresa. La posibilidad de aplazar la inversión, de modificar la dimensión de los compromisos, la opción de abandono prematuro de los negocios actuales, las opciones de sustitución de inputs y output o las opciones de modificación del ritmo productivo son buenos ejemplos de la flexibilidad de la empresa. En la medida que estas opciones puedan ejercerse para beneficiar a uno de los partícipes de la empresa en perjuicio de otros grupos, los problemas de 
agencia se convierten en cuestiones de primer orden para los directivos, en especial, para el diseño de la estructura de capital.

A modo de síntesis, los fundamentos del enfoque de opciones reales permiten plantear la hipótesis que se enuncia a continuación.

HIPÓTESIS 6: El patrón de financiación de la empresa depende de la naturaleza de las fuentes de valor de la empresa:

H 6.1: Cuanto mayor es la relevancia de las oportunidades de crecimiento mayor es la adecuación de la teoría de pecking order y la teoría de la agencia, y menor la del trade off en la explicación de las decisiones de financiación de la empresa.

H 6.2: Cuanto mayor es la relevancia de la flexibilidad como fuentes de valor, mayor es la adecuación de las teorías del trade off y del market timing y menor la del pecking order y agencia en la explicación de las decisiones de financiación de la empresa.

\subsubsection{El modelo de los determinantes estándar del endeudamiento y el patrón de financiación de la empresa}

Más de medio siglo de investigación sobre la influencia de la estructura de capital en el valor de la empresa y de los factores determinantes de las decisiones de financiación han dado entre otros resultados lo que se conoce como el modelo de los hechos estilizados. Este modelo relaciona distintas medidas de endeudamiento corporativo con una serie de variables que sobresalen de un amplio conjunto por su significatividad estadística y consistencia teórica (Bradley et al., 1984; Harris y Raviv, 1991; Fama y French, 2002; Frank y Goyal, 2009).

Dejando a un lado la influencia de los factores institucionales (Rajan y Zingales, 1995) y condiciones macroeconómicas y agregados monetarios (Azofra y Rodríguez, 2012) que han demostrado contribuir notablemente a la explicación de las decisiones de financiación de la empresa, la literatura precedente destaca cuatro características de la empresa por su especial relevancia en la explicación de 
la estructura de capital: tamaño, oportunidades de crecimiento, tangibilidad de los activos y rentabilidad.

La mayoría de los estudios revelan que el nivel de endeudamiento de la empresa aumenta con el tamaño (Rajan y Zingales, 1995; Frank y Goyal, 2009). Esta relación es coherente con la teoría del trade off, en la medida en que el mayor tamaño implique menor probabilidad de quiebra (Rajan y Zingales, 1995; Shumway, 2001) ${ }^{30}$. Dado que las empresas más grandes suelen estar más diversificadas (Berger y Ofek, 1995; Comment y Jarrell, 1995), cabe esperar que sus flujos de tesorería sean menos volátiles (Ghosh, 2007) y, por tanto, presenten menor riesgo de dificultades financieras.

La relación positiva entre tamaño y nivel de endeudamiento puede explicarse en cierto modo desde la teoría del pecking order. Las empresas más grandes presentan, en general, menores problemas de información asimétrica, dado que suelen estar sujetas a mayores obligaciones legales informativas. Además las empresas de mayor tamaño suelen gozar de mayor reputación (Diamond, 1989) y su mayor visibilidad en el mercado propicia una mayor supervisión y, por todo ello, están sujetas a menores costes de transacción (Titman y Wessels, 1988; Parsons y Titman, 2008). Este tipo de relaciones sugiere que las empresas más pequeñas pueden preferir la financiación interna a la externa y hacer un menor uso del endeudamiento (Norton, 1990).

La evidencia empírica da cuenta de la relación positiva entre endeudamiento y tangibilidad de los activos de la empresa (Titman y Wessels, 1988; Frank y Goyal, 2009). Esta evidencia encaja tanto en la teoría del trade-off como en la del pecking order. Según la teoría del trade off los activos tangibles y menos específicos presentan un mayor valor de liquidación que los activos intangibles y más específicos (Williamson, 1988) y, por ello, sirven de mejor garantía crediticia (Harris y Raviv, 1990; Rajan y Zingales, 1995; Graham, 2000). En consecuencia,

\footnotetext{
${ }^{30}$ Shumway (2001) encuentra que para los distintos niveles de deuda las empresas más grandes presentan menor probabilidad de quiebra.
} 
la tangibilidad ${ }^{31}$ del activo incrementa la capacidad de endeudamiento y reduce los costes de insolvencia financiera. Desde la perspectiva del pecking order, los activos intangibles presentan mayores problemas de asimetría informativa (Myers, 1984a; Myers y Majluf, 1984; Benmelech y Bergman, 2009), lo que se ha esgrimido para defender igualmente la relación positiva entre endeudamiento y tangibilidad.

La descomposición del valor de la empresa en el valor de los negocios actuales (Assets-in-Place) y el de las oportunidades de crecimiento (Growth Options) fundamenta la relación de influencia del endeudamiento sobre la eficiencia esperada en el ejercicio de las decisiones futuras de inversión (Myers, 1977). La evidencia empírica disponible muestra que el nivel de endeudamiento está inversamente correlacionado con distintas medidas de las oportunidades de crecimiento (Titman y Wessels, 1988; Smith y Watts, 1992; Rajan y Zingales, 1995; Shyam-Sunder y Myers, 1999; Baker y Wurgler, 2002; Frank y Goyal, 2004; Hovakimian, 2004; Andrés et al., 2005; Barclay et al., 2006; Frank y Goyal, 2009).

La explicación natural de esta relación procede de la mano de la teoría de la agencia y los problemas de subinversión asociados a la financiación con deuda y el derecho de responsabilidad limitada de las acciones (Myers, 1977; Myers y Majluf, 1984). Sin embargo, también desde las teorías del trade off y el pecking order se ha intentado justificar esta evidencia, en función, respectivamente, de la mayor intangibilidad y asimetría informativa de las oportunidades de crecimiento (Cantillo y Wright, 2000). Pero incluso, la teoría del market timing proporciona una explicación lógica a la relación empírica entre el endeudamiento y las proxies habitualmente utilizadas para medir las oportunidades de crecimiento. Tomada como medida de la sobrevaloración de las acciones, la ratio de valor de mercado a valor contable estará inversamente asociada al endeudamiento desde el momento

\footnotetext{
${ }^{31}$ Frank y Goyal (2009) encuentran que tangibilidad y garantías crediticias (collateral value) son empíricamente intercambiables. La principal diferencia entre ambas variables es que las garantías colaterales incluyen a las existencias.
} 
en que las empresas prefieran emitir acciones cuando se encuentren sobrevaloradas y contratar deuda cuando las acciones estén infravaloradas.

Finalmente, la evidencia empírica revela la existencia de una relación negativa entre endeudamiento y rentabilidad de la empresa (Titman y Wessels, 1988; Harris y Raviv, 1991; Rajan y Zingales, 1995; Shyam-Sunder y Myers, 1999; Booth et al., 2001; Hovakimian, 2006). Esta evidencia se encuentra en línea con la teoría del pecking order, la cual postula que las empresas más rentables disponen de mayor disponibilidad de fondos internos, que son preferidos a otras fuentes de financiación externas. Por el contario, la teoría del trade off defiende que la relación entre endeudamiento y rentabilidad es positiva, dado que las empresas más rentables tienen mayor capacidad de endeudamiento (menor probabilidad de quiebra) y también mayor necesidad de aprovechamiento de las ventajas fiscales de la deuda (Fama y French, 2002).

La consideración conjunta del modelo de hechos estilizados y las teorías de la estructura de capital motiva la consideración de posibles diferencias en el signo y relevancia de las variables estándar según el tipo de patrón seguido por la empresa y fundamenta la séptima y última de las hipótesis de este trabajo.

HIPÓTESIS 7: La influencia de los determinantes estándar sobre el endeudamiento de la empresa está condicionada por el patrón de financiación de la empresa:

H 7.1: La relación positiva entre el endeudamiento y las variables de tamaño, tangibilidad y rentabilidad será especialmente significativa en el caso de las empresas que sigan un patrón de comportamiento acorde a la teoría del trade off.

H 7.2: La relación negativa entre el endeudamiento y la rentabilidad será especialmente significativa en el caso de las empresas que sigan un patrón de comportamiento acorde a la teoría del pecking order.

H 7.3: La relación negativa entre el endeudamiento y el peso relativo de las oportunidades de crecimiento será especialmente significativa en el caso de las empresas que sigan un patrón de comportamiento acorde a la teoría de agencia. 


\subsection{La Encuesta}

La naturaleza de las hipótesis planteadas sobre las posibles explicaciones del distanciamiento entre la teoría y la práctica de la Dirección Financiera aconsejan la adopción de la encuesta como herramienta de aproximación empírica.

Jensen et al. (1989) sugieren que muchos de los problemas y preguntas que nos planteamos en finanzas no pueden resolverse mediante el análisis de datos secundarios. En estos casos, el conocimiento obtenido por medio del análisis en profundidad de datos primarios se presenta como una posible solución. Con esta reflexión, se inauguró la sección de Investigación Clínica del Journal of Financial Economics, pensada para acoger y estimular este modelo minoritario de investigación empírica. Años más tarde, Peter Tufano (2001) presentaba una edición especial del Journal of Financial Economics dedicada al estudio clínico, en la que este tipo de investigación se definía como "aquel trabajo empírico realizado con relativamente pocos eventos los que son estudiados de manera exhaustiva” y que incluye, entre otros, el análisis de la información obtenida por medio de encuestas.

Las investigaciones empíricas basadas en encuestas presentan la ventaja de ofrecer información muy rica acerca de relativamente pocas observaciones. Aggarwal (1993) y Ryan et al.(2004) defienden que las investigaciones realizadas por medio de encuestas pueden ser muy útiles para validar empíricamente hipótesis conceptuales y de especial importancia en la evaluación y análisis de las prácticas de los profesionales financieros. Un buen ejemplo de sus beneficios es el reconocimiento recibido por trabajos como los de Graham y Harvey (2001), Brounen et al. (2004) y Bancel y Mittoo (2004), entre otros. Se trata, no obstante, de una técnica con sus propias limitaciones, cuya ventaja comparativa depende de la naturaleza del problema objeto de estudio. Aggarwal (1993) advierte que "es probable que la encuesta sea insuficiente para muchos propósitos, y, en muchos casos deficientes y poco fiables”. 
En el campo de la investigación en Economía Financiera, la encuesta ocupa un lugar especialmente marginal (Graham, 2004). Baker y Mukherjee (2007) utilizan un cuestionario para verificar la opinión de los editores de journals de finanzas acerca del uso de las encuestas como herramienta de investigación. El resultado más importante que emerge de la investigación es que los editores de revistas se muestran receptivos a la evaluación de este tipo de investigaciones, siempre y cuando, se desarrollen con la misma rigurosidad que la realizada en otro tipo de investigaciones.

Norton (1990) defiende que las preferencias, metas y actitudes de los directores financieros representan una cuestión de mayor importancia en el estudio de los problemas de dirección financiera y han sido habitualmente excluidas por el simple hecho de que no existen fuentes de datos secundarios que informen de ellas. Por el contrario, el uso de encuestas como herramienta de investigación ha demostrado ser muy útil en la obtención de este tipo de información y, por ende, el análisis de las decisiones financieras de la empresa. La información facilitada por los responsables de la empresa es la más apropiada para el contraste directo entre la teoría y la práctica empresarial y la identificación de aquellas áreas en donde las recomendaciones de la academia no son plena o correctamente implementadas.

La figura 3.1 muestra la evolución de los trabajos más relevantes realizados por medio de encuestas sobre el problema del distanciamiento entre la teoría y la práctica financiera. Se puede apreciar que el número trabajos con encuestas crece de manera exponencial en el tiempo, indicando su progresiva aceptación como una herramienta de investigación más. La tabla 3.2 complementa esta información con las credenciales básicas de algunos de estos trabajos, tales como, la muestra a partir de la cual se realiza el análisis, el porcentaje que representa de la población objetivo, los contextos en los que estas investigaciones se desarrollaron y los tópicos analizados ${ }^{32}$.

\footnotetext{
${ }^{32}$ Para un mayor detalle véase el Anexo 2.1.
} 
Figura 3.1: Evolución de trabajos por medio de encuestas

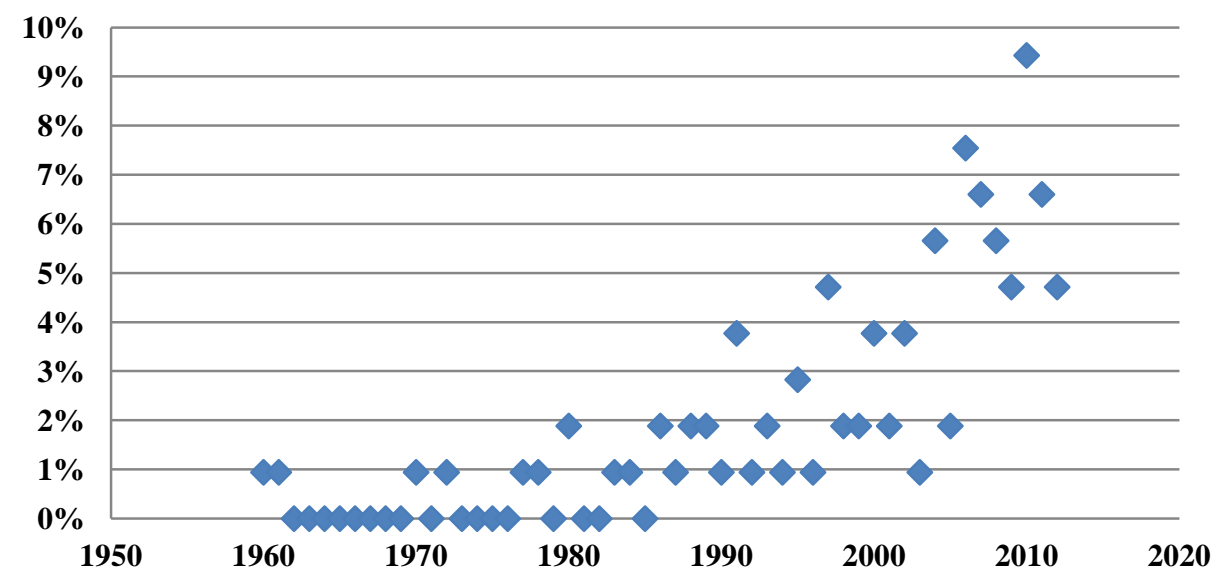


Tabla 3.2: Evidencia del gap teoría y práctica financiera obtenida con la técnica del cuestionario

La columna autor / año indica el nombre del (los) autor (es) principales y año de publicación. La columna muestra (\% de respuesta) indica el número de observaciones de la muestra $\mathrm{y}$, entre paréntesis, el porcentaje que representa la muestra de la población original. Las columnas Contexto hacen referencia al área geográfica del (los) país (es) analizados en la investigación. Las columnas tópicos indican las temáticas analizadas, las que se corresponden con $\mathrm{A}=$ Presupuesto de capital; B=Coste de capital; C=Estructura de capital.

\begin{tabular}{|c|c|c|c|c|c|c|c|}
\hline \multirow[b]{2}{*}{ Autor / Año } & \multirow[b]{2}{*}{$\begin{array}{l}\text { Muestra (\% } \\
\text { respuesta) }\end{array}$} & \multicolumn{3}{|c|}{ Contexto } & \multicolumn{3}{|c|}{ Tópicos } \\
\hline & & $\begin{array}{c}\text { Anglo } \\
\text { América }\end{array}$ & Europa & $\begin{array}{c}\text { Asia - } \\
\text { Oceanía }\end{array}$ & A & B & C \\
\hline Miller (1960) & $127(63,5 \%)$ & $\mathrm{x}$ & & & $\mathrm{x}$ & & \\
\hline Istvan (1961) & 48 entrevistas & $\mathrm{x}$ & & & $\mathrm{x}$ & & \\
\hline Donaldson (1961) & 25 entrevistas & $\mathrm{x}$ & & & & & $\mathrm{x}$ \\
\hline Мао (1970) & 8 entrevistas & $\mathrm{x}$ & & & $\mathrm{x}$ & & \\
\hline Klamer (1972) & $184(49,9 \%)$ & $\mathrm{x}$ & & & $\mathrm{x}$ & & \\
\hline Gitman y Forrester (1977) & $110(38,4 \%)$ & $\mathrm{x}$ & & & $\mathrm{x}$ & & \\
\hline Stanley y Block (1984) & $121(35,7 \%)$ & $\mathrm{x}$ & & & $\mathrm{x}$ & & \\
\hline Kim et al. (1986) & 367 (36,7\%) & $\mathrm{x}$ & & & $\mathrm{x}$ & & \\
\hline Pinegar y Wilbricht (1989) & $176(35,2 \%)$ & $\mathrm{x}$ & & & & & $\mathrm{x}$ \\
\hline Trahan y Gitman (1995) & $84(12 \%)$ & $\mathrm{x}$ & & & $\mathrm{x}$ & & \\
\hline Pike (1996) & $99(78,9 \%)$ & & $\mathrm{x}$ & & $\mathrm{x}$ & & \\
\hline Burns y Walker (1997) & $180(36 \%)$ & $\mathrm{x}$ & & & $\mathrm{x}$ & & \\
\hline $\begin{array}{l}\text { Arnold y Hatzopoulos } \\
(2000)\end{array}$ & $96(32,4 \%)$ & & $\mathrm{x}$ & & $\mathrm{x}$ & & \\
\hline Graham y Harvey (2001) & 392 (9\%) & $\mathrm{x}$ & & & $\mathrm{x}$ & $\mathrm{x}$ & $\mathrm{x}$ \\
\hline Ryan y Ryan (2002) & $205(20,5 \%)$ & $\mathrm{x}$ & & & $\mathrm{x}$ & & \\
\hline Brounen et al. (2004) & $313(5 \%)$ & & $\mathrm{x}$ & & $\mathrm{x}$ & $\mathrm{x}$ & $\mathrm{x}$ \\
\hline Bancel y Mittoo (2004) & $87(12 \%)$ & & $\mathrm{X}$ & & & & $\mathrm{x}$ \\
\hline Block (2005) & $302(30,2 \%)$ & $\mathrm{x}$ & & & $\mathrm{x}$ & & \\
\hline Verbeeten (2006) & $189(26,9 \%)$ & & $\mathrm{x}$ & & $\mathrm{x}$ & & \\
\hline Beattie et al. (2006) & $198(23 \%)$ & & $\mathrm{x}$ & & & & $\mathrm{x}$ \\
\hline Brounen et al. (2006) & $313(5 \%)$ & & $\mathrm{x}$ & & & & $\mathrm{x}$ \\
\hline Rayo et al. (2007) & $152(15,2 \%)$ & & $\mathrm{X}$ & & $\mathrm{x}$ & & \\
\hline Leon et al. (2008) & $108(47,2 \%)$ & & & $\mathrm{x}$ & $\mathrm{x}$ & & \\
\hline Chen (2008) & $115(19,1 \%)$ & $\mathrm{x}$ & & & $\mathrm{x}$ & & \\
\hline Meier y Tarhan (2009) & $114(2,8 \%)$ & $\mathrm{x}$ & & & & & $\mathrm{x}$ \\
\hline Khames et al. (2010) & $53(65,4 \%)$ & & & $\mathrm{x}$ & $\mathrm{x}$ & $\mathrm{x}$ & \\
\hline Baker et al.(2011a) & $214(28,1 \%)$ & $\mathrm{x}$ & & & $\mathrm{x}$ & & \\
\hline Lindblom et al. (2011) & $139(35,4 \%)$ & & $\mathrm{x}$ & & & & $\mathrm{x}$ \\
\hline Brunzell et al. (2013) & $157(22,1 \%)$ & & $\mathrm{x}$ & & $\mathrm{x}$ & $\mathrm{x}$ & \\
\hline
\end{tabular}




\subsubsection{Diseño del cuestionario}

La aproximación empírica a las prácticas financieras en la empresa española se realiza a partir de la información recopilada por medio de un cuestionario enviado durante el mes de febrero de 2011 a los directores financieros de las mayores empresas españolas no financieras. El diseño del cuestionario provee del alcance necesario para obtener una gran cantidad de información de los temas bajo estudio. De manera particular, esta información nos permitió no sólo conocer la experiencia de los directores financieros respecto de los temas planteados, sino además, sus intenciones y percepciones.

Basado en la literatura existente y en anteriores investigaciones de similares características, se diseñó un cuestionario preliminar que recogiera todas aquellas cuestiones que interesaba medir. La versión preliminar fue sujeta a revisión por parte de profesores de finanzas de la Universidad de Valladolid con el fin de detectar posibles errores de interpretación y recibir propuestas de mejora. Las observaciones fueron incorporadas en la nueva versión del documento. Posteriormente, el nuevo instrumento fue revisado por profesores del área de Comercialización e Investigación de Mercados, expertos en investigaciones por medio de cuestionarios, a fin de verificar la consistencia y diseño del mismo. Esto nos permitió intentar minimizar las potenciales fuentes de error y maximizar la tasa de respuesta ${ }^{33}$.

Haciendo uso de la penúltima versión del documento, la encuesta fue sometida al pretest de tres directores financieros de empresas de distintos sectores de actividad y de un directivo de una consultora de estrategia. Este proceso llevó a una corrección final en cuanto a forma (corrección de algunos conceptos) y fondo (eliminación de preguntas que podían resultar incómodas para el encuestado) que permitió definir la versión final del cuestionario.

${ }^{33}$ Groves et al. (2009) sentencia que una investigación desarrollada por medio de cuestionarios no es mejor que el peor aspecto de su diseño y su ejecución. 
El documento final incluye 40 preguntas, distribuidas en las 8 secciones siguientes:

$\checkmark$ Sección 1: Técnicas de selección de inversiones

$\checkmark$ Sección 2: Flexibilidad de las inversiones emprendidas

$\checkmark$ Sección 3: Oportunidades de crecimiento

$\checkmark$ Sección 4: Coste de capital

$\checkmark$ Sección 5: Política de Financiación

$\checkmark$ Sección 6: Consideraciones finales

$\checkmark$ Sección 7: Características de la empresa

$\checkmark$ Sección 8: Características del director financiero

Muchas de las preguntas tienen un formato de respuesta cerrada, ordenadas en cinco niveles de respuesta de menor a mayor grado: desde "muy reducida” a “muy elevada”, cuando se pregunta sobre la importancia de los factores determinantes de la decisión de inversión o de financiación presentados en la encuesta; entre "nunca” y "siempre” cuando se pregunta sobre la frecuencia de utilización de las técnicas; y entre “muy poca” y “mucha” cuando se pregunta por la confianza en las técnicas o modelos.

El cuestionario final se presenta en el Anexo 3.2.

\subsubsection{Envío de la encuesta y tasa de respuesta}

La información necesaria para el envío postal fue extraída del ranking que publica anualmente la revista Actualidad Económica con las 5.000 mayores empresas españolas. Fue utilizada la versión publicada en 2010 con información a diciembre de 2009. Por sus características especiales, las empresas financieras no fueron incluidas en la muestra inicial de destinatarias del cuestionario.

Del total de empresas del ranking se escogieron las 2.000 mayores, por volumen de ingresos, a las que se les envió el cuestionario final acompañado por una carta de presentación en la que, por una parte, se explicaban los objetivos de 
la investigación y, por otra, se garantizaba el anonimato y confidencialidad de las respuestas $^{34}$. Adicionalmente, se incluía un sobre pre-pagado para el envío postal del cuestionario cumplimentado.

Se descartó la administración de la encuesta por medio de entrevistas personales o por vía telefónica, debido al menor coste del envío postal y al hecho de que el encuestado pueden visualizar el cuestionario en toda su extensión y el contexto en que el cada pregunta se encuentra ubicada. Además, permite a los encuestados organizar, de acuerdo a su propia conveniencia, cuando responder el cuestionario. El uso creciente de internet y del correo electrónico ofrecía una alternativa adicional al envío postal de los cuestionarios y aunque más costoso (en términos económicos y de tiempo), se utilizó el envío postal en razón a la mayor tasa de respuesta esperada frente a la alternativa del email (Tse, 1998; Kaplowitz et al., 2004; Van Selm y Jankowski, 2006; Dillman et al., 2009).

El proceso de recolección de datos se inició en febrero de 2011 con el envío de los 2.000 sobres y la recepción de los primeros cuestionarios cumplimentados. En algunos casos hubo problemas con el envío postal, debido a que la empresa había cambiado de domicilio, lo que llevó a un proceso de verificación del nuevo domicilio. Posteriormente, se realizó un seguimiento telefónico con el fin de verificar la recepción de los documentos y recordar la solicitud de respuesta del cuestionario. El proceso concluyó en junio de 2011 con un total de 140 cuestionarios válidos recibidos (tabla 3.3).

Tabla 3.3: Nivel de respuesta

\begin{tabular}{|l|c|}
\hline Envío & Correo postal \\
\hline Población & 2.000 \\
\hline Respuestas & 140 cuestionarios \\
\hline Tasa de respuesta & $7 \%$ \\
\hline
\end{tabular}

${ }^{34}$ Una copia del contenido de la carta se incluye en el Anexo 3.3. 
Los 140 cuestionarios válidos equivalen a una tasa de respuesta del 7,0\%. Aunque el nivel de respuesta no es demasiado alto, se aproxima a los porcentajes obtenidos en investigaciones similares (Trahan y Gitman, 1995; Graham y Harvey, 2001; Bancel y Mittoo, 2004; Brounen et al., 2004; Pereiro, 2006).

\subsubsection{Potenciales limitaciones a la investigación por medio de encuestas}

Al igual que cualquier investigación realizada a través de encuestas, nuestro estudio se encuentra sometido a varios problemas potenciales. El primero de ellos es el problema de sesgo de respuesta o de representatividad, que puede sesgar la información recogida, incluso en el caso de tomar las cautelas habituales en este tipo de investigaciones, como el aseguramiento del anonimato y confidencialidad de respuesta mencionada en la carta de presentación, cuestionario fácil de completar, seguimiento teléfono, reenvío postal y electrónico en los casos de no recepción y posibilidad de solicitar un informe de los resultados de manera gratuita.

Siguiendo trabajos anteriores, como Herbert y Wallace (1996), Graham y Harvey (2001) y Brounen et al. (2004), se realizó una comparación del tamaño de las empresas que respondieron versus las que no respondieron. Para aproximar el tamaño de las empresas utilizamos la variable nivel de ingresos tanto de la muestra como de la población original ${ }^{35}$. A partir de estos datos, se estimó el estadístico para el test de diferencia de medias con grupos de distinta varianza. Los resultados del test indican ausencia de diferencias estadísticamente significativas entre los respectivos grupos.

Una segunda prueba sugerida por la literatura (Armstrong y Overton, 1977; Wallace y Mellor, 1988; Wallace y Cooke, 1990) consiste en evaluar características entre aquellos que responden de manera temprana y aquellos de

${ }^{35}$ Como el cuestionario y el proceso de recepción de los mismos estaba diseñado para responder de manera anónima, es imposible verificar en la población original a los que respondieron de los que no. 
respuesta tardía ${ }^{36}$. También en este caso, los resultados para ambos test en el nivel de ingresos indican ausencia de diferencias estadísticamente significativas entre los respectivos grupos. Estos resultados se recogen en la tabla 3.4.

Tabla 3.4: Pruebas de sesgo de no respuesta

\begin{tabular}{l|c|c}
\hline & \multicolumn{2}{|c}{ Volumen de ingresos } \\
\hline Media general & (1) & (2) \\
\hline Población / Temprana & \multicolumn{2}{|c}{484,48} \\
\hline Muestral / Tardía & 428,60 & 567,03 \\
\hline Dif medias $(t)$ & $1,353,38$ & $1,963,83$ \\
\hline$p$-value & $-1,5774$ & $-1,3439$ \\
\hline
\end{tabular}

La tabla provee parte de la estadística descriptiva para la variable volumen de ingresos. Se comparan las medias poblacional y la muestral por medio de test de diferencia de medias para grupos de distinta varianza (1). Estas pruebas también son aplicadas a las medias de las empresas que responden de manera temprana versus las que respondieron de manera tardía (2).

Adicionalmente, pueden presentarse problemas de respuesta asociados a la veracidad de respuesta, ya sea de manera intencionada (intentar responder lo teóricamente aceptable) o no intencionada (falta de comprensión de las preguntas o las alternativas de respuesta). Sobre estas cuestiones no existe manera de detectar los sesgos, más allá de lo que nos pudiera indicar el hecho de que los resultados de la presente investigación se encuentran bastante en línea con anteriores estudios tanto para España como para otros contextos europeos y mundiales. Las encuestas “miden creencias y no acciones” (Graham y Harvey, 2001), con lo que las respuestas pueden no reflejar la verdad. Para nuestro caso y dado que la encuesta es anónima y las respuestas confidenciales, creemos que este problema puede ser mínimo. Además, partimos de la premisa de que quien se

${ }^{36}$ La fecha de corte elegida para el análisis es el 31 de marzo de 2011, 40 días después del lanzamiento de la encuesta. 
toma el tiempo de responder el cuestionario es porque está interesado en contribuir a la investigación y sus respuestas se corresponden con la realidad.

Otra de las cuestiones planteadas en la literatura respecto de este tipo de investigación es la concerniente al individuo que finalmente responde la encuesta, en lo que atañe al puesto que ocupa y su responsabilidad en la empresa y si la respuesta realmente representa la práctica habitual de la empresa (Segelod, 1998). De manera adicional, Rappaport (1979) indica que en este tipo de estudios puede llegar a existir por parte del investigador mayor preocupación por obtener mayor cantidad de información que por la realización de inferencias estadísticas válidas, lo que reduce la fiabilidad de la extrapolación de los resultados (Tufano, 2001). Nuestra encuesta fue dirigida personal y nominativamente al director financiero de la empresa, pero carecemos de medios para garantizar que es quien finalmente responde las preguntas.

El conjunto de críticas potencialmente atribuidas al desarrollo de investigaciones por medio de cuestionarios son imposibles de refutar por completo. Aunque hemos procurado ser muy minuciosos en el diseño de las preguntas y estructura de la encuesta y tomar las cautelas recomendadas en la literatura para el envío y recepción de la información, los resultados analizados no pueden estar exentos de los problemas mencionados. De igual manera, creemos que al contrastar las respuestas condicionadas a características de las empresas y de los directores financieros, nuestro estudio permite detectar patrones de respuesta que arrojen luz sobre la relevancia de las diferentes teorías, “del mismo modo que se ve una imagen en un mosaico” (Bruner, 2002) y a pesar de las piezas defectuosas.

\subsection{Modelos Econométricos y Técnicas de Estimación}

En esta sección se presentan los modelos econométricos utilizados para contrastar cada una de las siete hipótesis enunciadas. Las primeras cuatro 
hipótesis explican la frecuencia de uso de las distintas técnicas de selección de inversiones presentadas a los encuestados. Las últimas tres hipótesis explican la importancia atribuida por los directivos a distintos elementos en la elección del patrón de financiación de la empresa.

La naturaleza de las variables dependientes analizadas en las seis primeras hipótesis es del tipo de respuesta múltiple ordenada. Con este tipo de variables, la estimación a través de los modelos de regresión clásicos presenta errores relacionados con la interpretación de las distancias de los valores, mientras que los modelos logit multinomial o probit multinomial fallan en la consideración del orden de las respuestas. Para evitar este tipo de problemas, el contraste de las hipótesis 1 a 6 se realiza a partir de la estimación de modelos probit ordenado (véase Greene, 2012).

En concreto, el modelo utilizado para el contraste de la hipótesis 1 es el siguiente:

$$
\text { técnica }_{j}=\beta \cdot \text { Empresa }_{j}+\tau \cdot C F O_{j}+e_{j}
$$

donde el subíndice $j$ representa cada una de las observaciones que componen la muestra, técnica mide la frecuencia de uso de cada técnica de selección de inversiones, Empresa y CFO definen las variables aproximativas de las características de las empresa y del director financiero de la empresa, $\beta$ y $\tau$ son los coeficientes a estimar y $e_{j}$ es la perturbación aleatoria.

Se define una variable técnica diferente para cada una de las seis técnicas de selección de inversiones siguientes: VAN, TIR, payback, opciones reales, simulación y análisis de sensibilidad. Esta variable puede tomar cinco valores desde el uno, que indica que nunca se utiliza, al cinco, que indica que siempre se utiliza. La estimación del modelo se realiza para cada una de las seis técnicas de selección de inversiones.

Las características de la empresa, EMPRESA, se aproximan por medio de las variables tamaño que aproxima la dimensión empresarial por medio del logaritmo 
neperiano de las ventas (en millones de euros), industria que es una dummy indicativa si la empresa pertenece al sector económico industria, servicios que indica si la empresa pertenece al sector servicios y persjur que es una dummy indicativa si la empresa es una sociedad de responsabilidad limitada o sociedad anónima. Las variables que caracterizan al director financiero, CFO, son edad que es variable categórica, ordenada en cinco niveles de edad, añosexper que es una variable que indica la cantidad de años de experiencia laboral del director financiero. La variable mba es una dummy que toma valor uno en los casos en el que el director financiero disponga formación de posgrado especializada en forma de MBA o máster en finanzas. ImpliDI que es una variable categórica indicativa de la percepción del director financiero acerca de su implicación en las decisiones de inversión de la empresa.

La hipótesis 2 se contrasta por medio del siguiente modelo:

$$
\text { técnica }_{j}=\delta \cdot \text { disciplina }_{j}+\pi \cdot \text { tamaño }_{j}+\mu \cdot m b a_{j}+e_{j}
$$

donde disciplina define las variables aproximativas de los mecanismos de disciplina de la empresa, mba y tamaño representan variables de control que aproximan, respectivamente, el nivel formativo del director financiero y el tamaño de la empresa. Para este caso, $\delta, \tau$, y $\mu$ son los coeficientes a estimar.

La caracterización de los mecanismos de disciplina de la empresa se realiza a partir de variables habituales en la literatura financiera. Entre las distintas alternativas, el endeudamiento se considera un instrumento eficaz para reducir el flujo de caja discrecional y aumentar la presión de la amenaza de quiebra. Obtenemos dos medidas del endeudamiento de la empresa a partir de la respuesta dada sobre el porcentaje del total de activos de la empresa que es financiado, respectivamente, con deuda (deuda) y con deuda a largo plazo (deudalp). Adicionalmente, construimos una variable que mide la frecuencia con la que se determina el valor de mercado de la empresa (medivalor), de acuerdo con la respuesta señalada en la encuesta para los cinco niveles planteados de menor a 
mayor periodicidad, y otra que indica si el director financiero participa de la propiedad de la empresa (propiedad).

Las variables tamaño y mba son variables de control, ya definidas en el modelo (1).

El modelo a estimar para el contraste de la hipótesis 3 es el siguiente:

$$
\text { técnica }_{j}=\varphi \cdot \text { fvalor }_{j}+\mu \cdot \text { mba }_{j}+\pi \cdot \text { tamaño }_{j}+e_{j}
$$

donde fvalor representa las distintas medidas de las fuentes de valor de la empresa, $\varphi$ recoge los correspondientes coeficientes a estimar, y el resto de variables coinciden en su definición con las descritas en el modelo (1).

La aproximación de la naturaleza de las fuentes de valor de la inversión se realiza a partir de la información suministrada por los directores financieros a diferentes preguntas de la encuesta. La relevancia de las oportunidades de crecimiento se aproxima a partir de las respuestas sobre la frecuencia con la que las inversiones pasadas abren nuevas oportunidades (potencia). Además, el valor de las distintas dimensiones de la flexibilidad se mide a través de las respuestas sobre la importancia atribuida por el directivo a que la inversión permita intercambiar los inputs (inputs), aplazar su iniciación (aplazar) y modificar su tamaño (modtam).

El contraste conjunto de las hipótesis 2 y 3 se realiza a partir del modelo que incluye ambos grupos de variables explicativas de manera aditiva, es decir:

$$
\text { técnica }_{j}=\delta \cdot \text { disciplina }_{j}+\varphi \cdot \text { fvalor }_{j}+\mu \cdot \text { mba }_{j}+\tau \cdot \text { tamaño }_{j}+e_{j}
$$

La estimación de estos tres modelos (modelos 2, 3 y 4) se realiza doblemente con la inclusión y exclusión de las variables dummy con las que se identifica los distintos sectores de actividad.

Respecto a la utilización del enfoque de las opciones reales, cabría alegar que su uso no es necesario en la valoración de proyectos que no generen opciones. En consecuencia, los directivos podrían responder una baja frecuencia de uso por la 
escasez de proyectos generadores de opciones y no por motivos de estilo directivo. Para controlar por este posible sesgo y comprobar la robustez de los resultados de las hipótesis 2 y 3, se vuelve a estimar el anterior modelo con la sustitución de la variable dependiente categórica "técnica” por una dummy que toma el valor cero cuando la respuesta a la frecuencia de uso de las opciones reales es nunca y uno en caso contrario.

Para contrastar la hipótesis 4 se define el siguiente modelo:

$$
\text { técnica } a_{j}=\theta \cdot \text { patrón }_{j}+e_{j}
$$

donde patrón representa las distintas variables aproximativas del patrón de financiación seguido por la empresa y $\theta$ recoge los correspondientes coeficientes a estimar.

La aproximación del patrón de financiación seguido por la empresa se realiza a partir de la información suministrada por los directores financieros a seis preguntas relativas a la decisión de financiación de la empresa. Los patrones de financiación se aproximan por medio de una variable dicotómica y por variables categóricas ordenadas en cinco niveles según nivel de importancia atribuida por los directores financieros: Target que es una variable dicotómica que indica si la empresa establece (o no) un ratio de deuda objetivo; deudaobj que es una variable categórica que indica la importancia atribuida a la búsqueda de una estructura de financiación objetivo; redwacc que refleja la importancia (en cinco niveles) a la utilización de deuda para reducir el coste medio ponderado del capital. flexifin que refleja la importancia atribuida a la flexibilidad financiera; CPinteresbajo que indica la importancia atribuida a la utilización de deuda de corto plazo cuando los tipos de interés son bajos; sustitución que aproxima la importancia atribuida a utilizar deuda de corto plazo para evitar invertir en proyectos de riesgo elevado; y finalmente, CPcosterentab que refleja la importancia atribuida a la contratación de deuda de corto plazo para reducir el coste de financiación y subir rentabilidad de los accionistas. 
Estas variables son de naturaleza categórica ordenada y reflejan la importancia atribuida por los encuestados con relación a sus decisiones de financiación. La asignación de un patrón de financiación se realiza en virtud de la representatividad de cada uno de ellos con cuestiones relativas a las cuatro teorías de estructura de capital revisadas, trade off, pecking order, market timing y teoría de agencia. Así, la mayor importancia atribuida a la búsqueda de una estructura de financiación objetivo (target y deudaobj) y a la utilización de deuda para reducir el coste medio ponderado del capital (redwacc) se asocian a un patrón de comportamiento acorde con la teoría del trade off. La mayor importancia atribuida a la flexibilidad financiera (flexifin) se asocia con un patrón acorde con la teoría del pecking order. Cuanto mayor relevancia se atribuye a la contratación de deuda de corto plazo a la espera de bajos tipos de interés (CPinterésbajo) mayor adhesión se espera al patrón de financiación del tipo market timing. Por último, las dos últimas variables se asocian a cuestiones referidas a la teoría de agencia. Por una parte, la utilización de deuda de corto plazo para reducir el incentivo a invertir en proyectos de riesgo elevado se asocia a la importancia atribuida a la resolución del problema de agencia de sustitución de activos. Por otra parte, la utilización de deuda de corto plazo para reducir el coste de financiación y aumentar la rentabilidad de los accionistas (CPcosterentab) se asocia a la importancia atribuida a la resolución del problema de agencia de subinversión.

La hipótesis 5, que explica el patrón de financiación seguido por la empresa en función de características de la empresa y del director financiero, se contrasta por medio del siguiente modelo:

$$
\text { patrón }_{j}=\beta \cdot \text { Empresa }_{j}+\tau \cdot C F O_{j}+e_{j}
$$

Se define una variable patrón diferente para cada una de los cuatro patrones de financiación, similares a los contemplados en la hipótesis 4 o modelo (5), según la relevancia otorgada a las variables: deudaobj, redwacc, flexifin, CPinterésbajo, sustitución y CPcosterentab. Las variables independientes son coincidentes con las utilizadas en el modelo (1), para contrastar la hipótesis 1 
(tamaño, industria, servicios, persjur, edad, añosexp y mba), excepto para el caso de impliDI que es reemplazada por impliDF, que igualmente es una variable categórica de cuatro niveles y que indica, para este caso, la percepción del director financiero respecto del grado de implicación en las decisiones de financiación de la empresa.

El contraste de la hipótesis 6 se realiza por medio del modelo siguiente:

$$
\text { patrón }_{j}=\varphi \cdot \text { fvalor }_{j}+\mu \cdot m b a_{j}+\tau \cdot \text { tamaño }_{j}+e_{j}
$$

Las variables aproximativas de las fuentes de valor de la empresa y las variables de control se corresponden con las utilizadas en el modelo (3), y son potencia, inputs, modtam, aplazar, referidas a las fuentes de valor, y tamaño y $m b a$, variables de control.

La hipótesis 7, que relaciona el nivel de endeudamiento de la empresa y los determinantes estándar utilizados en la literatura en función de la menor o mayor adhesión a los patrones de financiación, se realiza por medio del método de los mínimos cuadrados ordinarios (OLS) debido al carácter de la variable dependiente deuda. El modelo para el contraste de la hipótesis es revisado separadamente para cada uno de los grupos obtenidos, de acuerdo a la mayor (menor) adhesión a cada uno de los patrones de financiación.

$$
\text { deuda }_{j}=\gamma \cdot \text { determinante }_{j}+e_{j}
$$

La variable dependiente es deuda, que se corresponde con la respuesta de los encuestados a la pregunta sobre el nivel de endeudamiento de la empresa, medido como deuda total entre total activos (en porcentaje).

Los determinantes estándar utilizados en las regresiones del tipo OLS son: tamaño: variable aproximativa de la dimensión empresarial y calculada por medio del logaritmo neperiano de los ingresos; tangibilidad que se define como la diferencia entre uno y la proporción que representa el valor contable neto del inmovilizado intangible sobre el activo total; rentab1 que mide el grado de acuerdo/desacuerdo en cuanto a que la empresa aumentará mucho sus beneficios 
dentro de cinco años; rentab2 que se corresponde con la importancia atribuida a la rentabilidad de la inversión pasada; $M B$ que indica la percepción de la superioridad del valor de la empresa respecto de su valor contable y potencia que es una variable categórica indicativa de la frecuencia con que las inversiones pasadas abren nuevas oportunidades de inversión. $\gamma$ representa los coeficientes a estimar y $e_{j}$ es la perturbación aleatoria.

Esta regresión base (nivel de deuda en función de los determinantes estándar) ha sido revisada a su vez en función del nivel de adhesión a los patrones de financiación utilizados en las hipótesis anteriores (hipótesis 5 y 6). La segmentación de la muestra por la mayor (menor) adhesión a cada uno de los patrones de financiación se realiza a partir de la mediana de cada una de las variables representativas de los patrones. 


\section{CAPÍTULO 4: DESCRIPCIÓN DE LA MUESTRA}

$\mathrm{E}$ l objetivo de este capítulo es describir la evidencia obtenida de las respuestas a la encuesta. El capítulo se articula en tres grandes secciones. La primera de ellas, caracteriza a las empresas y directores financieros de la muestra. En segundo lugar, se presenta información relativa a la decisión de inversión y se describen cuáles son las técnicas utilizadas por los directores financieros en la selección de inversiones y aspectos tales como la frecuencia de uso, confianza o relación entre técnicas. La descripción de las técnicas utilizadas se complementa con la información recabada sobre los usos en la estimación del coste de capital y las opiniones de los directivos respecto de otros condicionantes de la decisión de inversión. La tercera sección aborda cuestiones referidas a la decisión de financiación. Primero se describe el endeudamiento de las empresas de la muestra, para luego describir la importancia atribuida por los directores financieros a los considerandos propuestos por la teoría en la decisión de financiación. El análisis de la información permite medir el grado de adecuación a los cuatro patrones teóricos de financiación considerados y su vinculación con el nivel de deuda de la empresa. 


\subsection{Caracterización de la Muestra}

\subsubsection{Las empresas}

La figura 4.1 ilustra la distribución de la muestra de acuerdo con el volumen de ventas (en millones de euros). El porcentaje de empresas con ventas superiores a 500 millones es cercano al 30\%. En el extremo opuesto, las firmas con ventas inferiores a 50 millones de euros apenas suponen el 10\% de la muestra. Estos datos deben interpretarse teniendo en cuenta que la selección de empresas se obtiene a partir de un directorio de las mayores compañías españolas. Por este motivo no debe extrañar que el 44,4\% de las empresas generen cifras de negocio comprendidas entre los 100 y los 500 millones de euros. De término medio, las empresas de la muestra son más grandes que las de Ayala y Rodriguez (2000) e Iturralde y Maseda (2004).

Figura 4.1: Distribución de las empresas según tamaño

(según volumen de ventas en millones de euros)

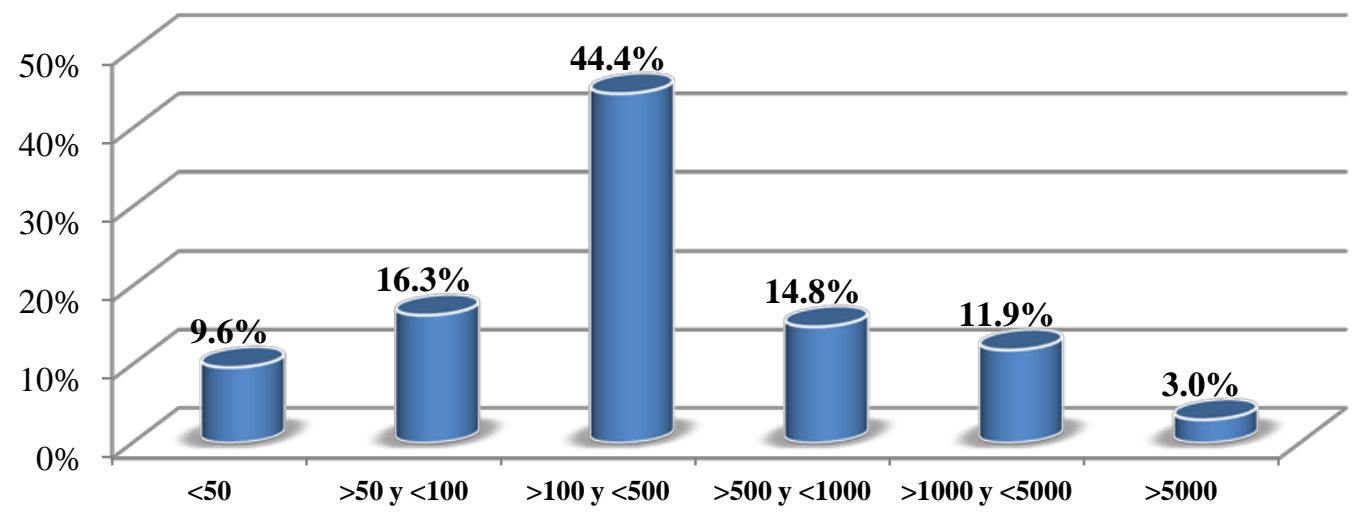

En lo que atañe al número de trabajadores, la figura 4.2 muestra que cerca del $52 \%$ de las empresas contratan a 500 o más trabajadores y el 31,9\% tiene entre 100 y 500 empleados en plantilla. 
Figura 4.2: Distribución de empresas por número de trabajadores

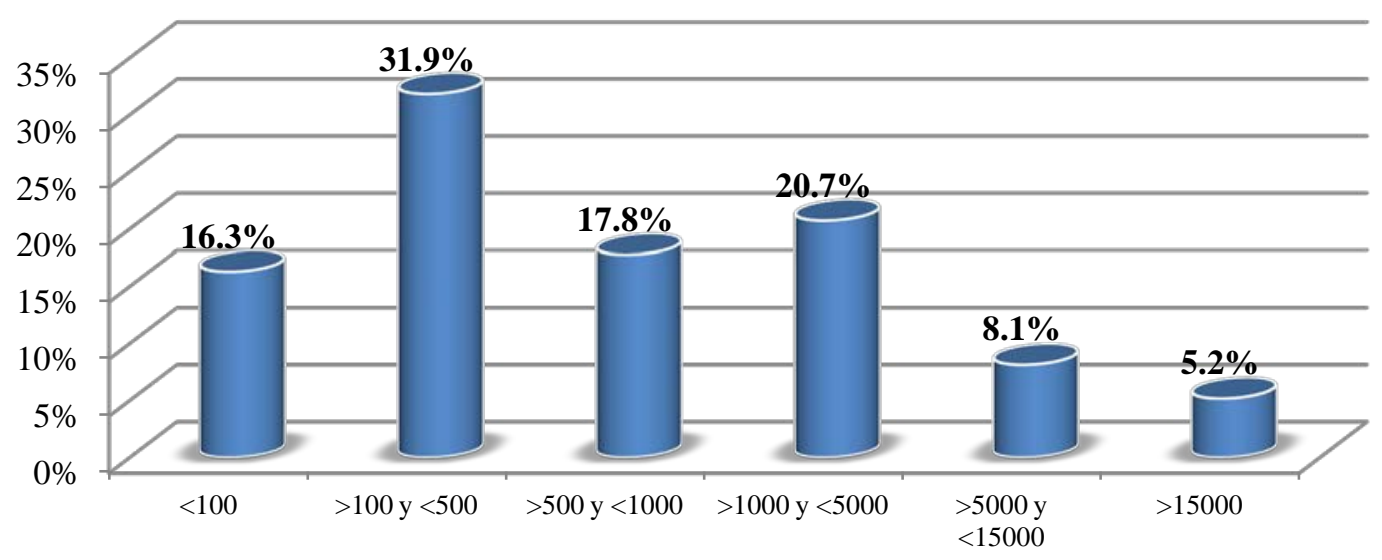

La figura 4.3 refleja la distribución de las empresas por sectores de actividad. Dos tercios de la muestra se concentran en los sectores Industria $(36,8 \%)$ y Servicios (32,4\%). El resto de empresas desarrollan su actividad en los negocios de Energía (8,8\%), Servicios inmobiliarios (5,9\%) y Tecnología y Telecomunicaciones (1,5\%).

Figura 4.3: Distribución de las empresas por sectores de actividad

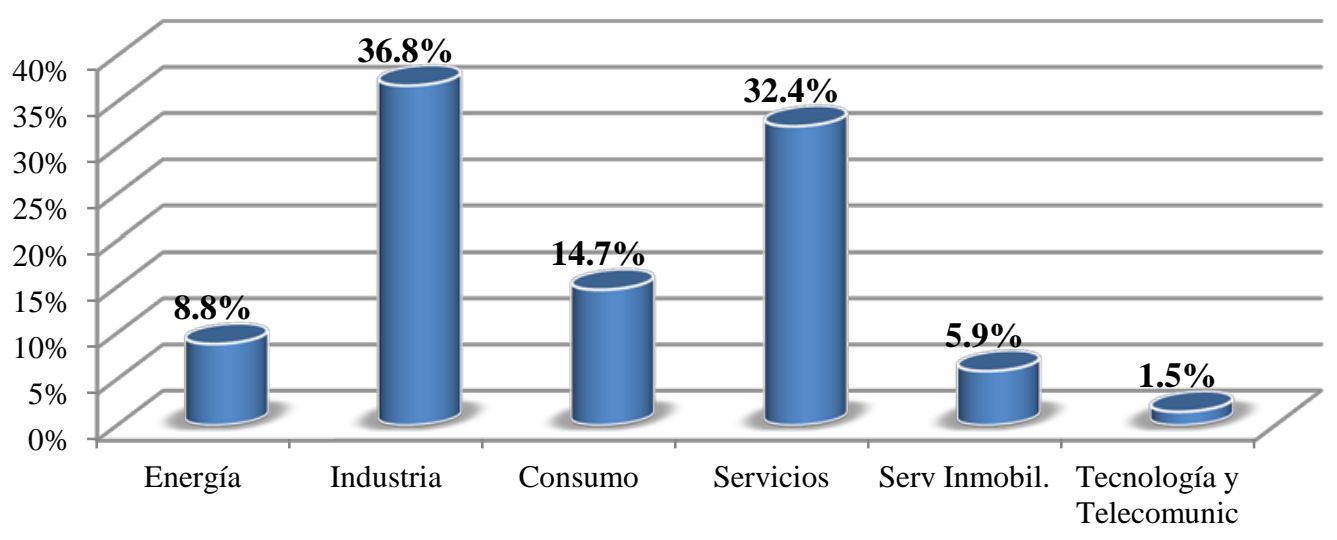

La figura 4.4 muestra la distribución de las empresas según su personalidad jurídica. La mayoría de empresas (el 68,4\%) son sociedades anónimas. El resto de empresas revisten la forma de sociedad limitada (21,3\%), sociedad anónima 
unipersonal (8,8\%) y sociedad limitada unipersonal (1,5\%). A pesar de tratarse de una muestra construida a partir de las empresas de mayor tamaño, sólo el 14\% de las compañías cotizan en Bolsa (figura 4.5). Por último, la figura 4.6 muestra que el 53\% de las empresas de la muestra cuentan con actividad internacional.

Figura 4.4: Distribución de empresas según personalidad jurídica

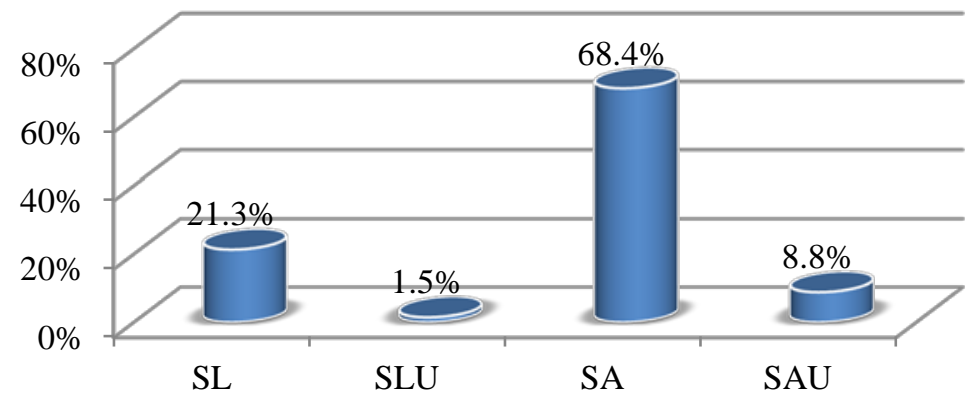

Figura 4.5: Empresas según cotización en bolsa

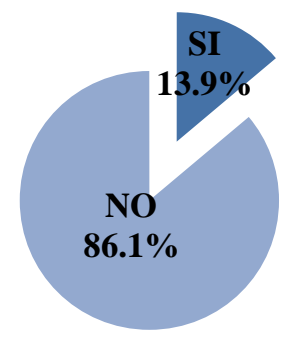

Figura 4.6: Inversión extranjera

(Porcentaje de empresas que invierten en el extranjero)

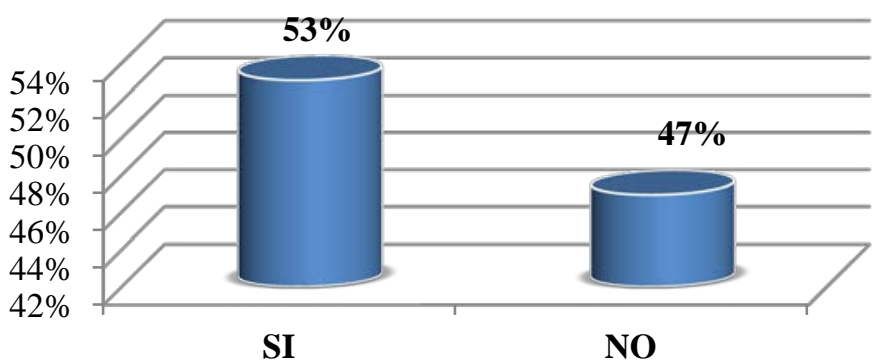




\subsubsection{Los directores financieros}

En una primera aproximación a la muestra de empresas analizadas, la figura 4.7 refleja la distribución por edades de los directores financieros que responden a la encuesta. La mayoría (45,2\%) tiene entre 40 y 49 años, mientras que los menores de 30 y mayores de 60 contabilizan, respectivamente, el 0,7\% y 5,2\% de la muestra. Esta información nos revela que los directores de la muestra son, de término medio, más jóvenes que los encuestados por Graham y Harvey (2001) y Brounen et al. (2004), donde una mayoría de los directivos financieros tenían entre 50 y 59 años.

Figura 4.7: Distribución de directores financieros según edad

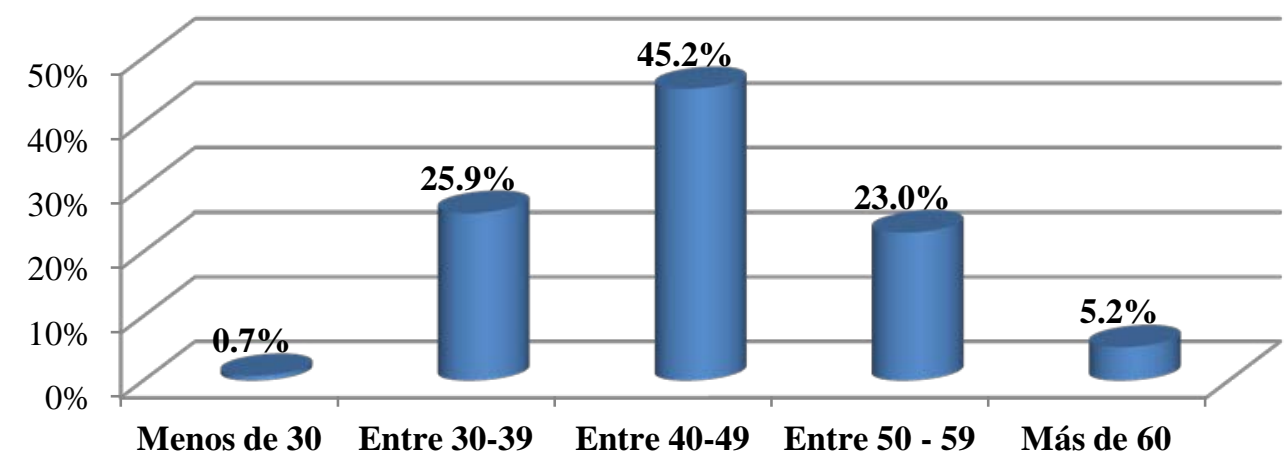

Los directores financieros que responden a la encuesta acumulan de media más de 20 años de experiencia laboral, cerca de 13 años trabajando en la empresa y 9,5 años en el cargo (figura 4.8). 
Figura 4.8: Promedio de años de experiencia

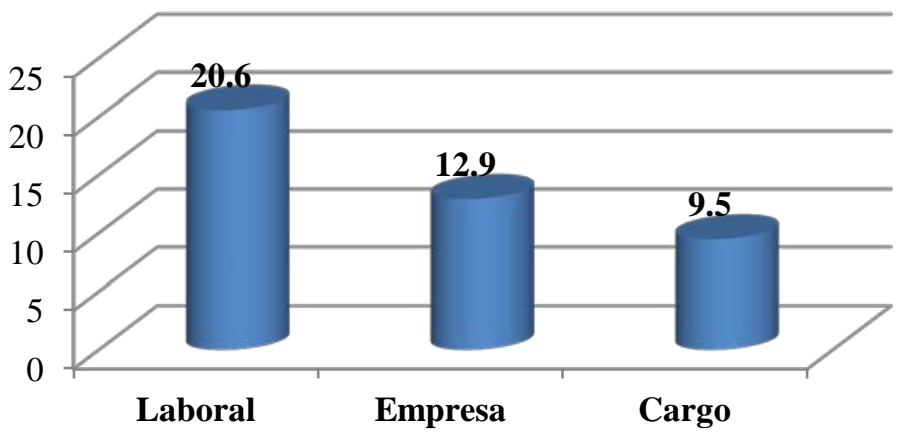

En lo que atañe a la formación de los directores financieros, la figura 4.9 muestra que la práctica totalidad posee titulación universitaria, principalmente una licenciatura (95,5\%). Los directores financieros en posesión de un MBA representan el 39,1\% de la muestra. Algo más del 20\% de los directivos posee un máster de especialización en finanzas o similar y sólo el 2,3\% ha optado por el título de doctor.

Figura 4.9: Formación del director financiero

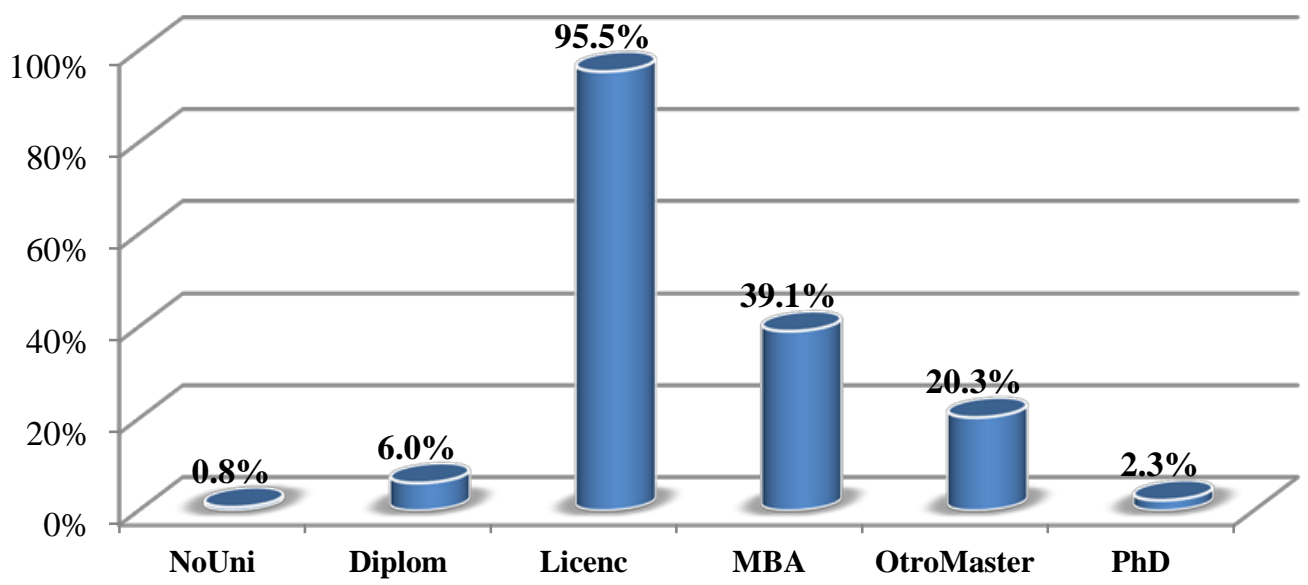

Por lo que se refiere a su participación en el accionariado y en los órganos de gobierno, las respuestas recibidas indican que, del conjunto de directores financieros, tan sólo el 10,5\% participan en la propiedad de la empresa (figura 4.10) y cerca del 30\% forman parte del Consejo de Administración (figura 4.11). 
Figura 4.10: Participación en la propiedad de la empresa

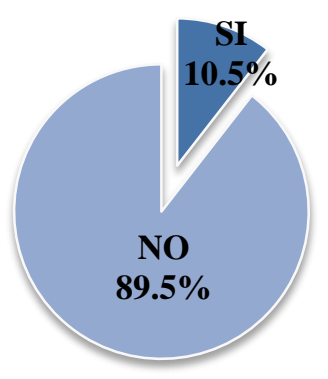

Figura 4.11: Participación en el Consejo de Administración

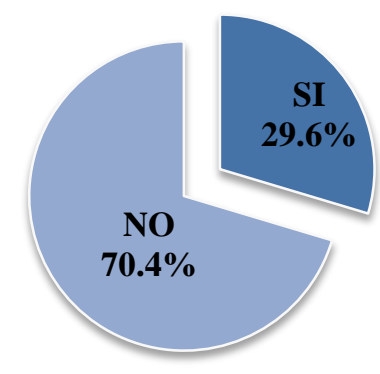

Las siguientes figuras indican el grado de implicación percibida por el director financiero tanto en las decisiones de inversión (figura 4.12) como de financiación (figura 4.13) de la empresa que participa. Cabe hacer notar la percepción que tiene el director financiero respecto de ambas cuestiones. Si bien su implicación es ambas es clara, parece más proclive a implicarse en la decisión de financiación que en la decisión de inversión empresarial.

\section{Figura 4.12: Implicación en las decisiones de inversión}

(Distribución de los directores financieros según implicación percibida en las decisiones de inversión)

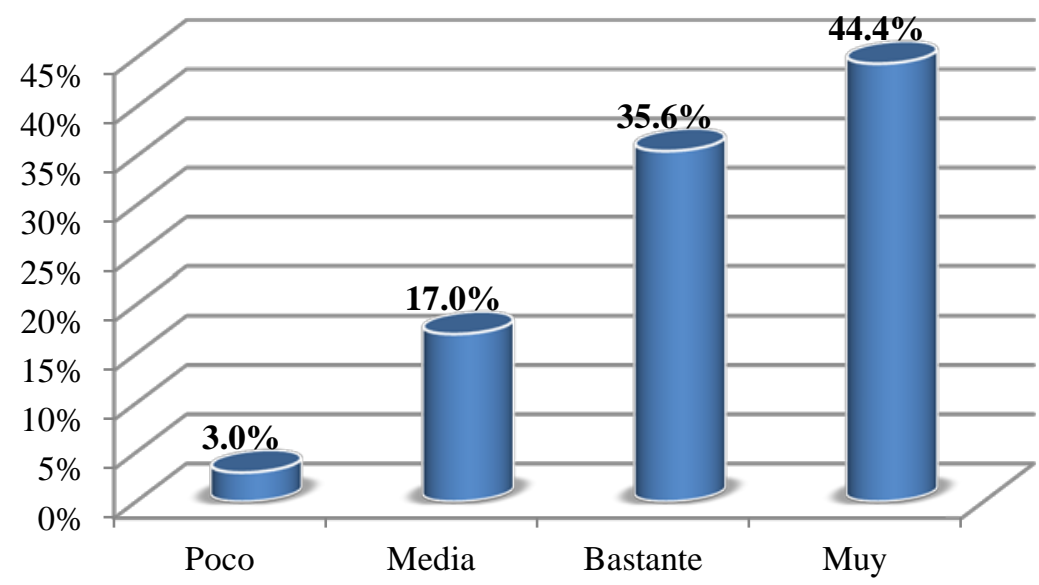


Figura 4.13: Implicación en las decisiones de financiación

(Distribución de los directores financieros según implicación percibida en las decisiones de financiación)

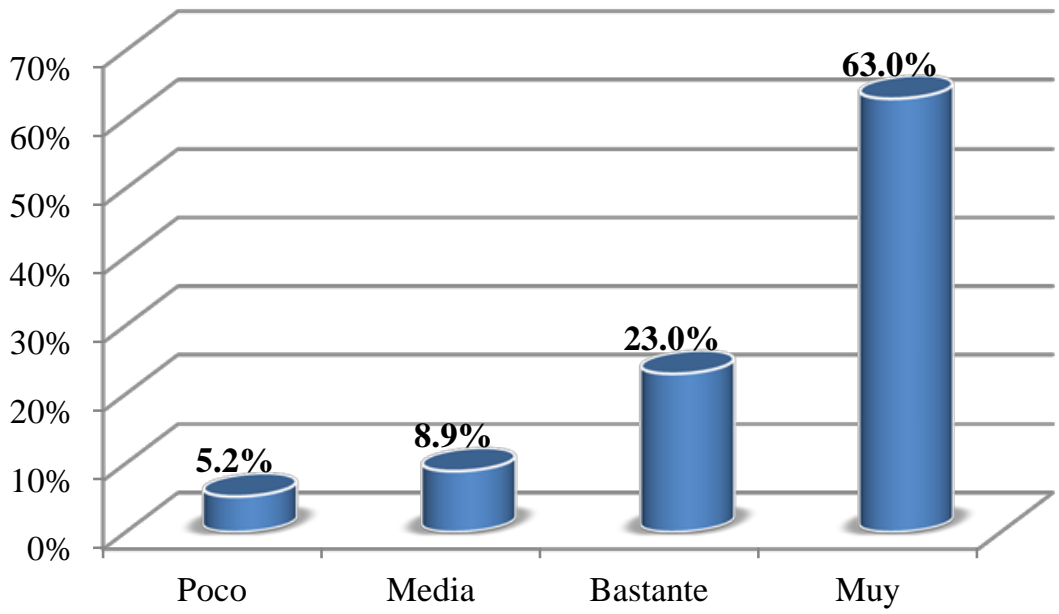

\subsection{La Decisión de Inversión.}

\subsubsection{Las técnicas de selección de inversiones utilizadas}

La caracterización de las prácticas de selección de inversiones de las empresas de la muestra se realiza a partir de la respuesta de los directores financieros a la frecuencia de uso de siete de las técnicas más habituales en los manuales de Dirección Financiera. Las técnicas presentadas son Valor Actual Neto (VAN), Tasa Interna de Rentabilidad (TIR), Periodo de Recuperación o Payback (PB), Índice de Rentabilidad (IR), Valoración a través de Opciones Reales (OR), Análisis de Sensibilidad (ASENSI) y Modelos de Simulación (SIMUL).

La tabla 4.1 muestra el resumen de los resultados obtenidos a la pregunta sobre frecuencia de uso de las siete técnicas de selección de inversiones. Las técnicas más utilizadas son la TIR, el payback y el VAN (con medias de uso 4,15; 4,12 y 3,93, respectivamente). El análisis de sensibilidad, los modelos de simulación y el índice de rentabilidad son menos empleadas (3,48; 3,35 y 3,05, 
respectivamente). La técnica con menor uso es la valoración a través de opciones reales (con una media de 2.20) y es, precisamente, la que mayor porcentaje de directores financieros declara que no utiliza nunca $(39,1 \%)$.

\section{Tabla 4.1: Técnicas de selección de inversiones}

La tabla presenta los resultados obtenidos a la pregunta sobre la frecuencia de uso de las técnicas de presupuesto de capital en las empresas de la muestra. La pregunta aparece formulada con respuesta cerrada múltiple según una escala tipo Likert de cinco niveles. La estimación de la media se obtiene a partir de la asignación de valores de 1 a 5 a los niveles ordenados de menor a mayor frecuencia de uso.

\begin{tabular}{|c|c|c|c|c|c|c|c|}
\hline \multirow[b]{2}{*}{ Técnica } & \multirow[b]{2}{*}{ Obs. } & \multicolumn{5}{|c|}{ Porcentaje de empresas que utilizan la técnica } & \multirow[b]{2}{*}{ Media } \\
\hline & & Nunca & $\begin{array}{c}\text { Rara } \\
\text { vez }\end{array}$ & $\begin{array}{c}\text { Algunas } \\
\text { veces }\end{array}$ & $\begin{array}{c}\text { Casi } \\
\text { siempre }\end{array}$ & Siempre & \\
\hline VAN & 140 & $5,0 \%$ & $11,4 \%$ & $17,9 \%$ & $17,1 \%$ & $48,6 \%$ & 3,93 \\
\hline TIR & 139 & $2,9 \%$ & $7,9 \%$ & $15,1 \%$ & $19,4 \%$ & $54.7 \%$ & 4.15 \\
\hline Payback & 140 & $3,6 \%$ & $6,4 \%$ & $15,0 \%$ & $24,3 \%$ & $50,7 \%$ & 4,12 \\
\hline Índice de rentabilidad & 136 & $22,8 \%$ & $14,0 \%$ & $21,3 \%$ & $19,1 \%$ & $22,8 \%$ & 3,05 \\
\hline Opciones Reales & 133 & $39,1 \%$ & $21,1 \%$ & $25,6 \%$ & $9,0 \%$ & $5,3 \%$ & 2,20 \\
\hline Análisis de sensibilidad & 136 & $9,6 \%$ & $16,2 \%$ & $19,9 \%$ & $25,7 \%$ & $28,7 \%$ & 3,48 \\
\hline Modelos de simulación & 137 & $13,1 \%$ & $13,9 \%$ & $25,5 \%$ & $19,0 \%$ & $28,5 \%$ & 3,35 \\
\hline
\end{tabular}

La figura 4.14 refleja el porcentaje de usuarios que declaran utilizar "casi siempre” o "siempre” cada una de las técnicas de selección de inversiones (esta categorización suele ser habitual en este tipo de estudios, a objeto de caracterizar al usuario de la técnica). Las tres técnicas más relevantes siguen siendo las mismas que las de la tabla 4.1, aunque en distinto orden. El modelo más utilizado es el payback (el 75,0\% de directores financieros responde utilizarlo siempre o casi siempre), seguida de la TIR (74,1\%) y el VAN (65,7\%). De nuevo, la técnica menos utilizada es la valoración de opciones reales (tan sólo el 14,3\% de los directores financieros dicen utilizarla siempre o casi siempre). El análisis de sensibilidad, los modelos de simulación y el índice de rentabilidad son aplicados siempre o casi siempre por aproximadamente la mitad de las empresas (54,4\%; 47,5\% y 41,9\%, respectivamente). 
Figura 4.14: Porcentaje de directores financieros que utilizan "siempre" o "casi siempre" la técnica de selección de inversiones

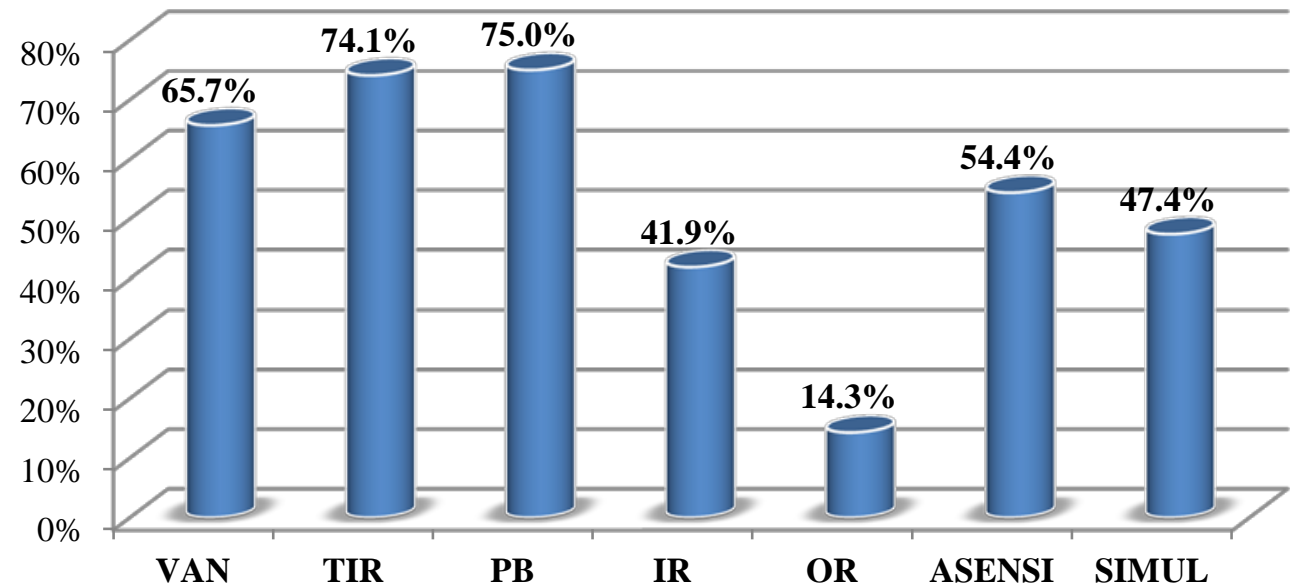

Los resultados sobre el predominio del payback y la TIR son similares a los obtenidos en la literatura precedente para empresas británicas y españolas. Brounen et al. (2004) encuentran que el 69,23\% de las empresas británicas utilizan siempre o casi siempre el payback, un 53,13\% utilizan la TIR y un 46,97\% el VAN. En Rayo et al. (2007) los porcentajes de uso son 80,8\%, 79,6\% y 78,6\%, respectivamente, para el payback, la TIR y el VAN. En el caso de las empresas norteamericanas, hay que retrotraerse hasta el trabajo de Schall et al. (1978) para encontrar una jerarquización con similar predominio del payback: payback (74\%), TIR (65\%) y VAN (56\%). Con relación a los modelos de opciones reales, la frecuencia de uso que hemos contabilizado es menor que en otros trabajos previos: 26,59\% en Norteamérica (Graham y Harvey, 2001), 29,03\% en Reino Unido, 34,69\% en Holanda, 44,04\% en Alemania, 53,06\% en Francia (Brounen et al., 2004) y 17,09\% en España (Rayo et al., 2007).

La figura 4.15 compara el grado de confianza media reconocida por los directores financieros y la frecuencia media de uso de cada una de las técnicas. Los resultados reflejan cierta correspondencia entre confianza y frecuencia de uso. La TIR es el modelo que inspira mayor confianza, seguido del VAN y del payback. Cuando el nivel de confianza se relativiza por la frecuencia de uso, el VAN pasa a ocupar el primer lugar del ranking, seguido de la TIR y el payback. 
Aunque menos empleados en la selección de inversiones, los modelos de análisis de sensibilidad y simulación reflejan un nivel de confianza relativa similar al del payback.

Figura 4.15: Relación entre frecuencia de uso y confianza

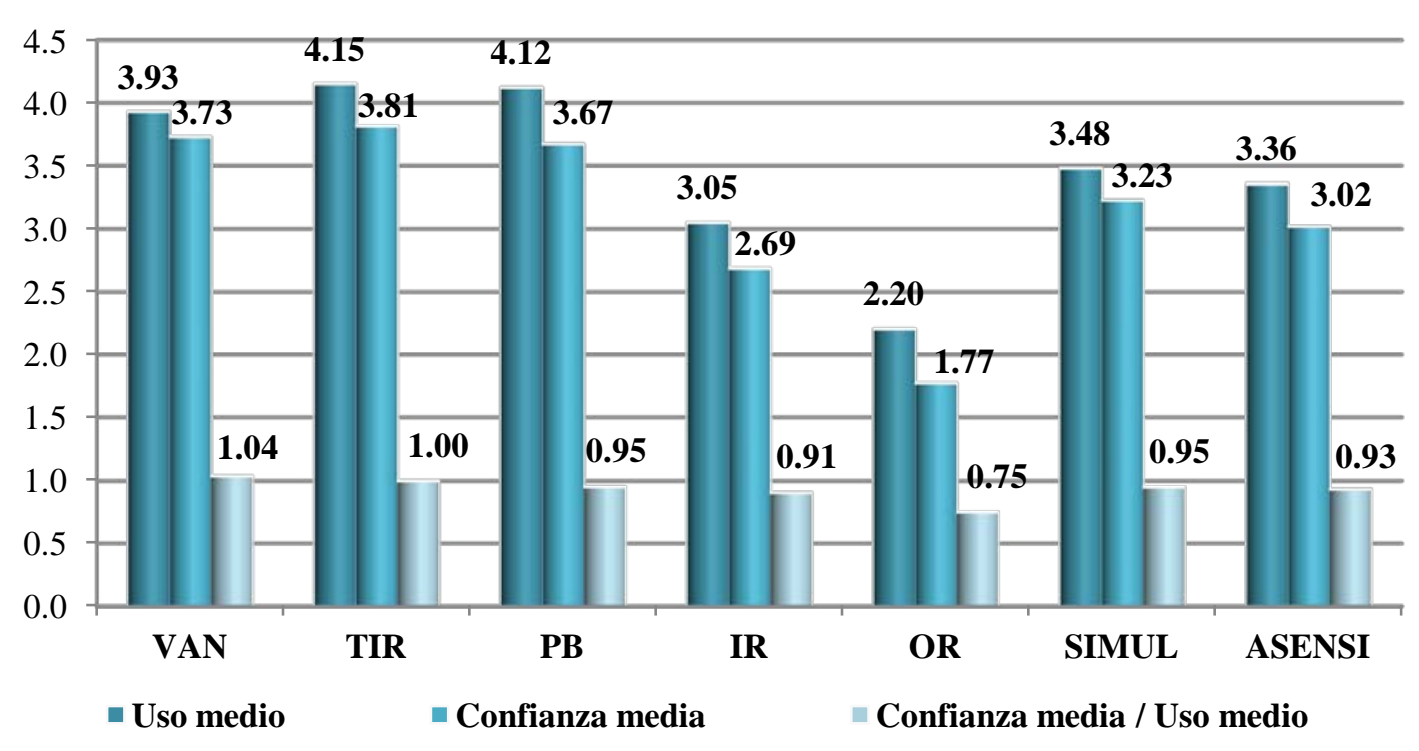

La figura 4.16 refleja el nivel de conocimiento de las distintas técnicas de acuerdo con el número de respuestas que indican no conocer el método en cuestión. Se confirma que la técnica menos conocida entre los directores financieros es el modelo de las opciones reales: el 31,4\% de los encuestados responden no conocer la técnica. Este resultado da cuenta del bajo nivel de utilización y confianza en esta técnica. El índice de rentabilidad, los modelos de simulación y el análisis de sensibilidad son desconocidos, respectivamente, para el $16,4 \%, 10,7 \%$ y $12,1 \%$ de los encuestados. 
Figura 4.16: Porcentaje de empresas que desconocen la técnica

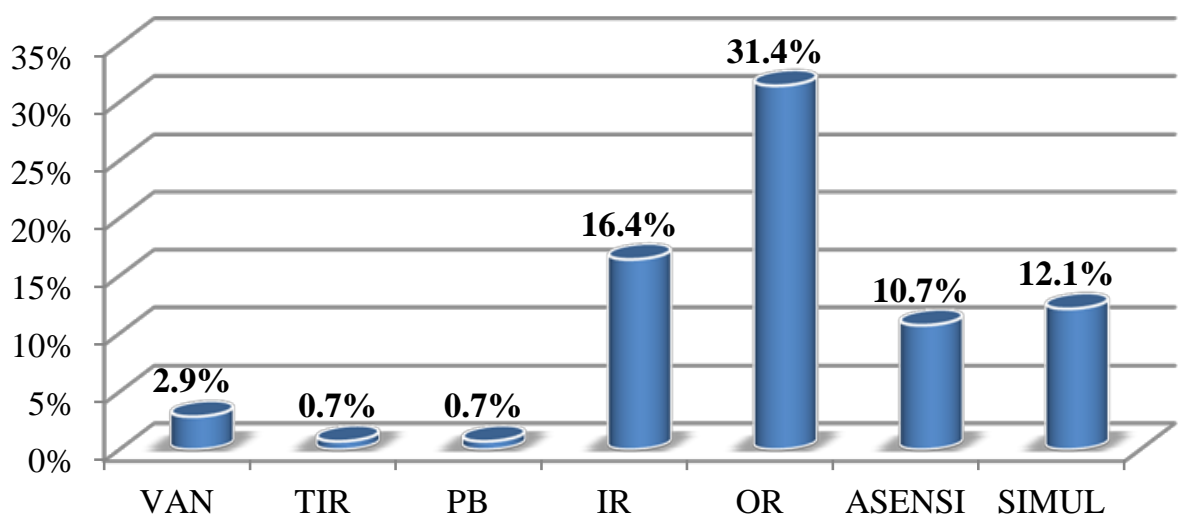

Al igual que en Pike (1996), Arnold y Hatzopoulos (2000) y Verbeeten (2006), los resultados de la encuesta indican además que las empresas españolas aplican simultáneamente varias técnicas de selección de inversiones. La figura 4.17 muestra la distribución de las empresas según el número de técnicas utilizadas. El número medio de técnicas es de 3,67 (con una desviación estándar de 1,93) y más del $40 \%$ de las empresas utilizan al menos 5 diferentes. Los valores extremos nos indican que el 9,3\% de los directores financieros no son usuarios de técnica alguna de las indicadas y el $4.3 \%$ emplean todas ellas simultáneamente.

Figura 4.17: Número de técnicas utilizadas

Distribución de las empresas según el número de técnicas que utilizan

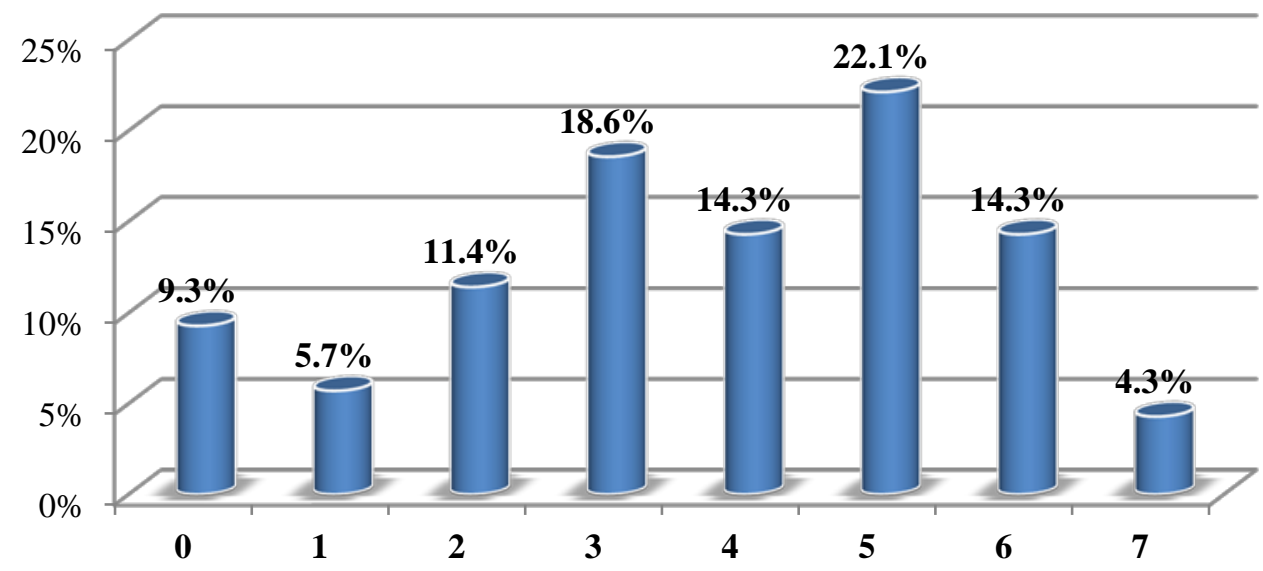


Adicionalmente, la tabla 4.2 presenta la relación entre las distintas técnicas utilizadas en la empresa. La alta correlación entre VAN y TIR indica que los directores financieros tienden a aplicarlas de forma simultánea. La correlación existente entre TIR y payback, y en menor grado VAN y payback, son también significativas. La estrecha relación entre estas tres técnicas parece respaldar la hipótesis de que los directores financieros optan por la sucesiva acumulación de técnicas con el fin de: (i) evitar la sustitución de las antiguas más conocidas, por las nuevas teóricamente superiores (Verbeeten, 2006); y (ii) reforzar los resultados, en muchos casos redundantes, que respaldan la propuesta de inversión en contextos de incertidumbre (Arnold y Hatzopoulos, 2000).

\section{Tabla 4.2: Relación entre técnicas}

La tabla muestra los coeficientes de correlación de las técnicas de selección de inversiones, siendo: VAN= Valor actual neto; TIR= Tasa interna de retorno; $\mathrm{PB}=$ payback; IR= Índice de rentabilidad; OR= Modelos de opciones reales; SIMUL= Modelos de simulación; ASENSI= Análisis de sensibilidad.

\begin{tabular}{|c|c|c|c|c|c|c|c|c|c|c|c|c|c|}
\hline & VAN & & TIR & & PB & & IR & & OR & & SIMUL & & ASENSI \\
\hline VAN & 1,0000 & & & & & & & & & & & & \\
\hline TIR & 0,7812 & $* * *$ & 1,0000 & & & & & & & & & & \\
\hline PB & 0,4608 & $* * *$ & 0,5606 & $* * *$ & 1,0000 & & & & & & & & \\
\hline IR & 0,2292 & $* * *$ & 0,2441 & $* * *$ & 0,1953 & $* *$ & 1,0000 & & & & & & \\
\hline OR & 0,1237 & & 0,1782 & $* *$ & 0,1725 & $* *$ & 0,4967 & $* * *$ & 1,0000 & & & & \\
\hline SIMUL & 0,1966 & $* *$ & 0,3564 & $* * *$ & 0,2788 & $* * *$ & 0,2735 & $* * *$ & 0,2316 & $* * *$ & 1,0000 & & \\
\hline ASENSI & 0,5025 & $* * *$ & 0,5128 & $* * *$ & 0,2468 & $* * *$ & 0,1696 & $*$ & 0,1386 & & 0,5903 & $* * *$ & 1,0000 \\
\hline
\end{tabular}

En línea con lo anterior, la tabla 4.3 muestra las otras herramientas utilizadas cuando se es usuario de cada una de las técnicas de selección de inversiones. Cuando un director financiero emplea el VAN, en 92 casos, emplea también la TIR y el payback. Similar acompañamiento puede apreciarse entre los usuarios de estas dos últimas técnicas. Sin embargo, el refuerzo que parecen necesitar los modelos de valoración de opciones reales, simulación y análisis de sensibilidad es mucho mayor, como indica el hecho de que normalmente se empleen junto con otras cuatro herramientas diferentes. 
Tabla 4.3: Número condicionado de técnicas

La tabla presenta para cada técnica que es utilizada siempre o casi siempre, cuáles son las otras técnicas que también se utilizan siempre o casi siempre.

\begin{tabular}{l|cc|cccccc}
\hline & Empresas & Otras técnicas & VAN & TIR & PB & IR & OR SIMUL ASENSI \\
\hline VAN & 92 & 2 & & $\mathrm{X}$ & $\mathrm{X}$ & & & \\
TIR & 103 & 2 & $\mathrm{X}$ & & $\mathrm{X}$ & & & \\
PB & 105 & 2 & $\mathrm{X}$ & $\mathrm{X}$ & & & & \\
IR & 57 & 3 & $\mathrm{X}$ & $\mathrm{X}$ & $\mathrm{X}$ & & & \\
OR & 19 & 4 & $\mathrm{X}$ & $\mathrm{X}$ & $\mathrm{X}$ & $\mathrm{X}$ & & \\
SIMUL & 65 & 4 & $\mathrm{X}$ & $\mathrm{X}$ & $\mathrm{X}$ & & & $\mathrm{X}$ \\
ASENSI & 74 & 4 & $\mathrm{X}$ & $\mathrm{X}$ & $\mathrm{X}$ & & $\mathrm{X}$ & \\
\hline
\end{tabular}

\subsubsection{El Coste de Capital de la Inversión}

De las respuestas hasta aquí resumidas cabe colegir que la mayoría de los directores financieros utiliza algún tipo de modelo de descuento de flujos. De manera específica, la encuesta preguntaba por la utilización de modelos de descuento de flujos y el modo empleado para estimar la tasa de descuento. Más del $90 \%$ de los directores financieros reconocen utilizar el descuento de flujos (figura 4.18).

Figura 4.18: Distribución de las empresas según la tasa de descuento utilizada

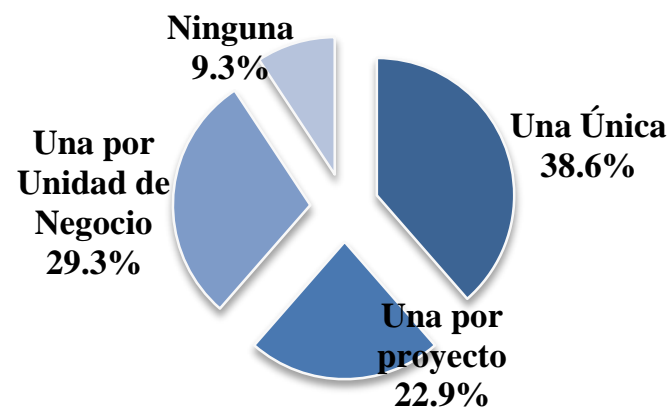

Respecto a la tasa de descuento empleada, el 39\% de los directores financieros afirman manejar un único valor para todos los proyectos de inversión 
de la empresa y cerca del 30\% de los encuestados reconocen diferenciar por unidades de negocio y aplicar una tasa distinta en cada uno de ellas. Finalmente, el $23 \%$ de los directores financieros declaran estimar una tasa de descuento distinta para cada uno de los proyectos de inversión evaluados.

En cuanto al método empleado para la estimación de las tasas de descuento, la figura 4.19 refleja que la mayoría de los directores financieros recurren al Coste de Capital Medio Ponderado (WACC), confirmando la conocida popularidad de este parámetro en la selección de inversiones (Graham y Harvey, 2001; Bancel y Mittoo, 2004; Brounen et al., 2004; Meier y Tarhan, 2009; Jagannathan et al., 2011; Da et al., 2012). En el 20,1\% de las empresas, la tasa de descuento es obtenida mediante la suma de la rentabilidad del activo libre de riesgo y una prima por el riesgo del proyecto. Otras aproximaciones menos utilizadas son la rentabilidad de la deuda (12,9\% de las empresas), la rentabilidad de las acciones $(7,2 \%)$, la rentabilidad del sector $(5,8 \%)$ y alguna diferente a las mencionadas $(5,8 \%)$.

Figura 4.19: Empresas según procedimiento de estimación de la tasa de descuento

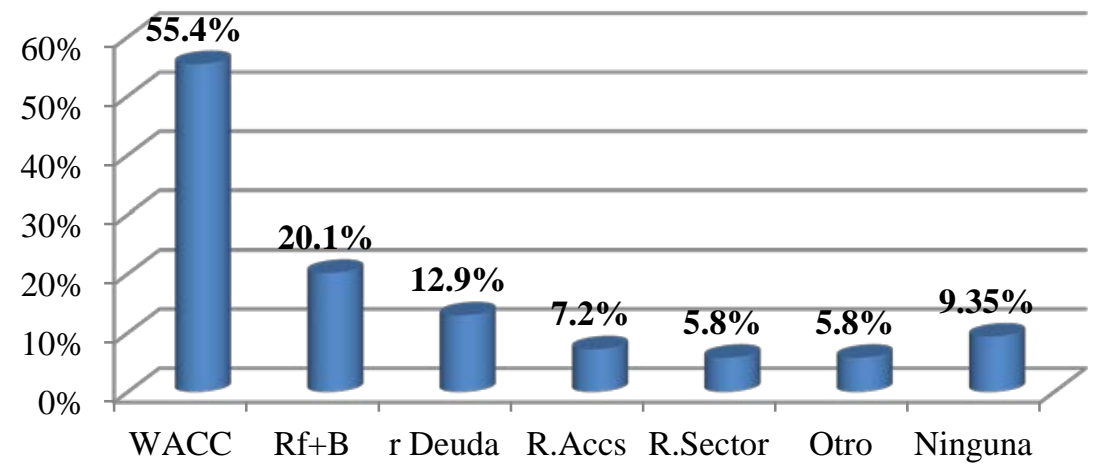

La figura 4.20 refleja el tipo de ajuste realizado por los directores financieros en la valoración de sus oportunidades de inversión. La inflación destaca como fuente principal de ajuste de la valoración, seguida de las variaciones en los tipos de interés, la financiación del proyecto y el riesgo del tipo de cambio. La corrección de la tasa de descuento se realiza especialmente para incorporar el 
efecto del riesgo sistemático, el riesgo país y cambios en los niveles y estructura temporal de los tipos de interés. La exposición al riesgo por inflación, precios de las materias primas, tipo de cambio y variaciones económicas se introduce en la valoración sobre todo a través de la corrección de los flujos de tesorería. El efecto de la financiación implica cambios en la tasa de descuento y en los flujos de tesorería por partes iguales.

Figura 4.20: Porcentaje de empresas que ajustan la tasa de descuento (TD) y los flujos de tesorería (FT) según los elementos de corrección

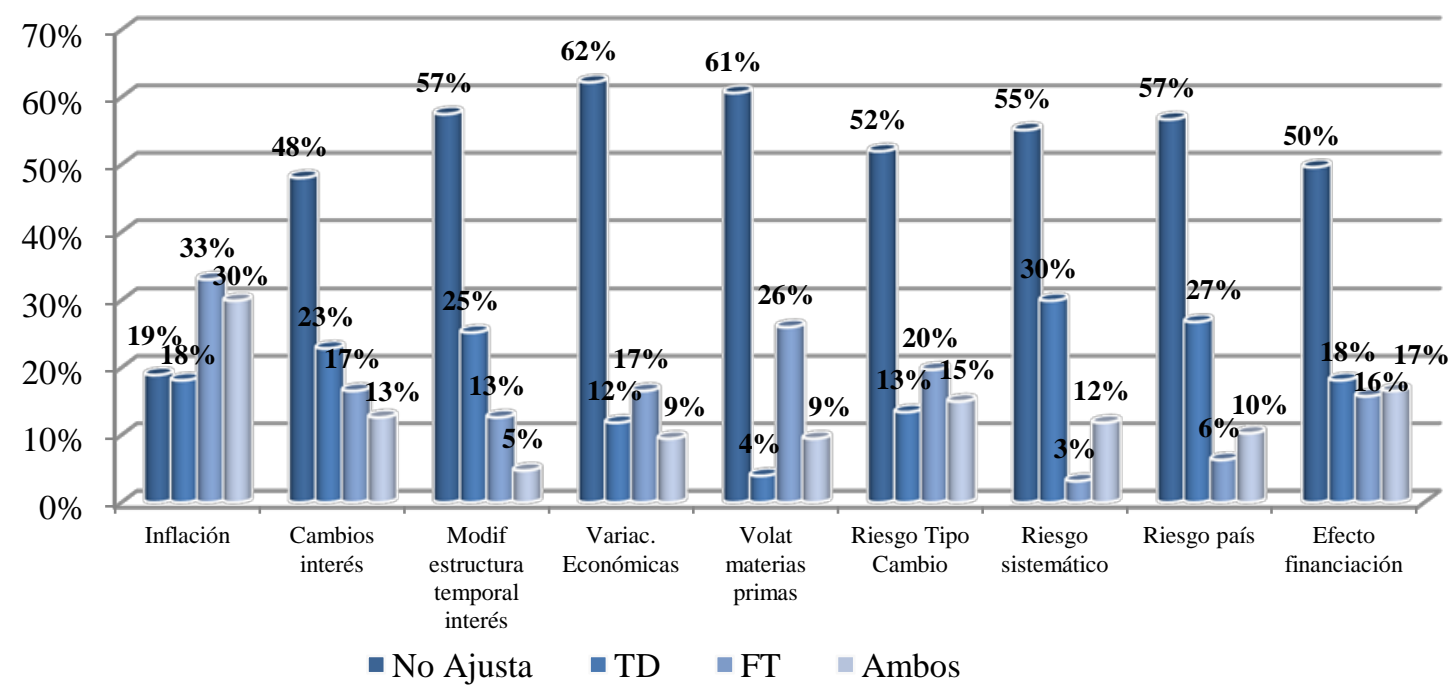

\subsubsection{Otros condicionantes de la decisión de inversión}

Los resultados de los modelos cuantitativos de selección de inversiones no son el único argumento manejado por los directos financieros en sus decisiones de inversión. La literatura especializada recoge testimonios y las estadísticas indican la influencia de otros factores de naturaleza no financiera. Los resultados de la encuesta corroboran la relevancia de considerandos del tipo de la experiencia del director financiero, las implicaciones estratégicas de la inversión, las obligaciones legales o la flexibilidad del proyecto. 
La figura 4.21 ilustra la importancia media otorgada por los directores financieros a estos otros factores, en comparación con la atribuida a los resultados de las técnicas financieras. A parte de la corta distancia en la ponderación media de los distintos argumentos, destaca que el uso de técnicas financieras sea el que mayor peso tiene en el proceso de decisión de inversiones, por una parte (con una respuesta media de 3,97 en escala de uno a cinco). Por otra, el hecho de que la intuición directiva (con media de 2,27) ocupe la última posición en el ranking de influencias, seguido de los resultados intangibles (media de 2,48). Danielson y Scott (2006) sostienen que son las empresas pequeñas las que en mayor medida prefieren basar sus decisiones en las intuición (gut feel).

Figura 4.21: Peso medio de considerandos habituales en la decisión de inversión

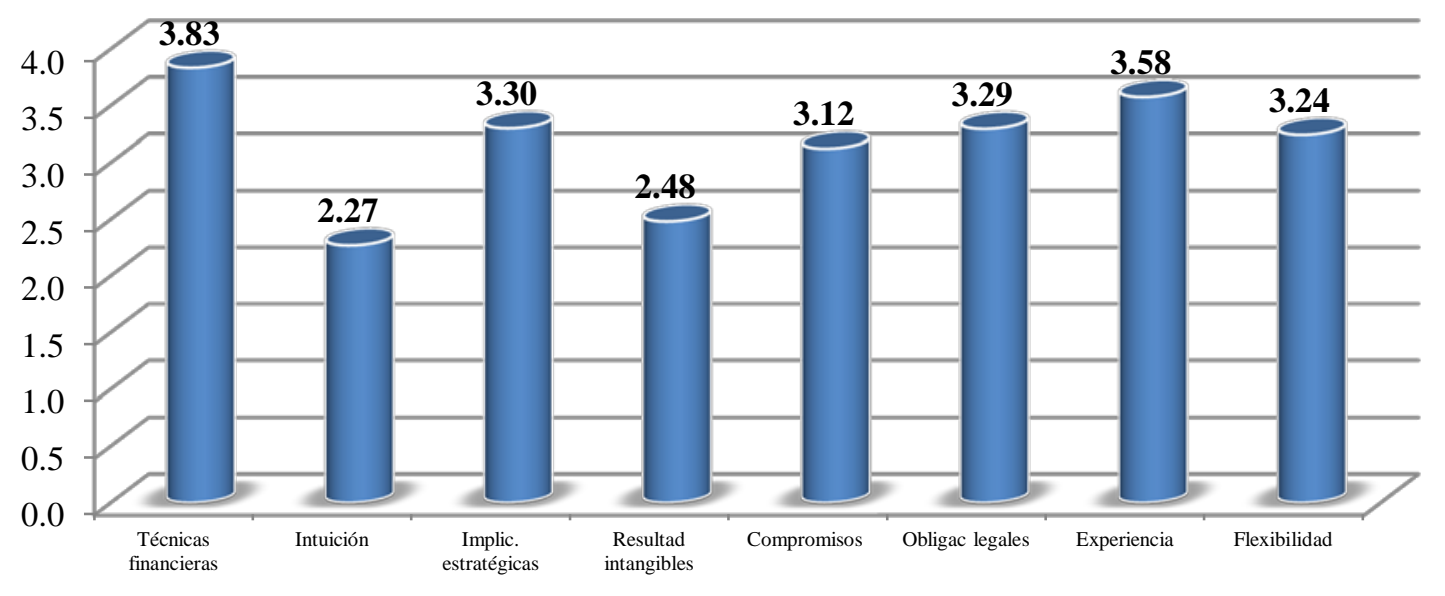

Una de las razones esgrimidas para justificar la consideración de cuestiones diferentes de los resultados de las técnicas financieras es la ineficiencia de los modelos convencionales para capturar el verdadero valor de resultados diferentes de los flujos de tesorería, pero que son cruciales para la competitividad y supervivencia de la empresa. Interpelados acerca de la importancia de factores de diversa naturaleza en el proceso de creación de valor de la empresa (véase figura 4.22), los directores financieros destacaron la función desempeñada por las oportunidades de inversión futura (media de 3,97), la ventaja en costes (media de 3,96) y la diferenciación de productos (media de 3,83) frente a la rentabilidad de 
inversiones pasadas (media de 3,21), la tecnología (media de 3,38) o las habilidades directivas (media de 3,53).

Figura 4.22: Importancia media atribuida en el proceso de creación de valor

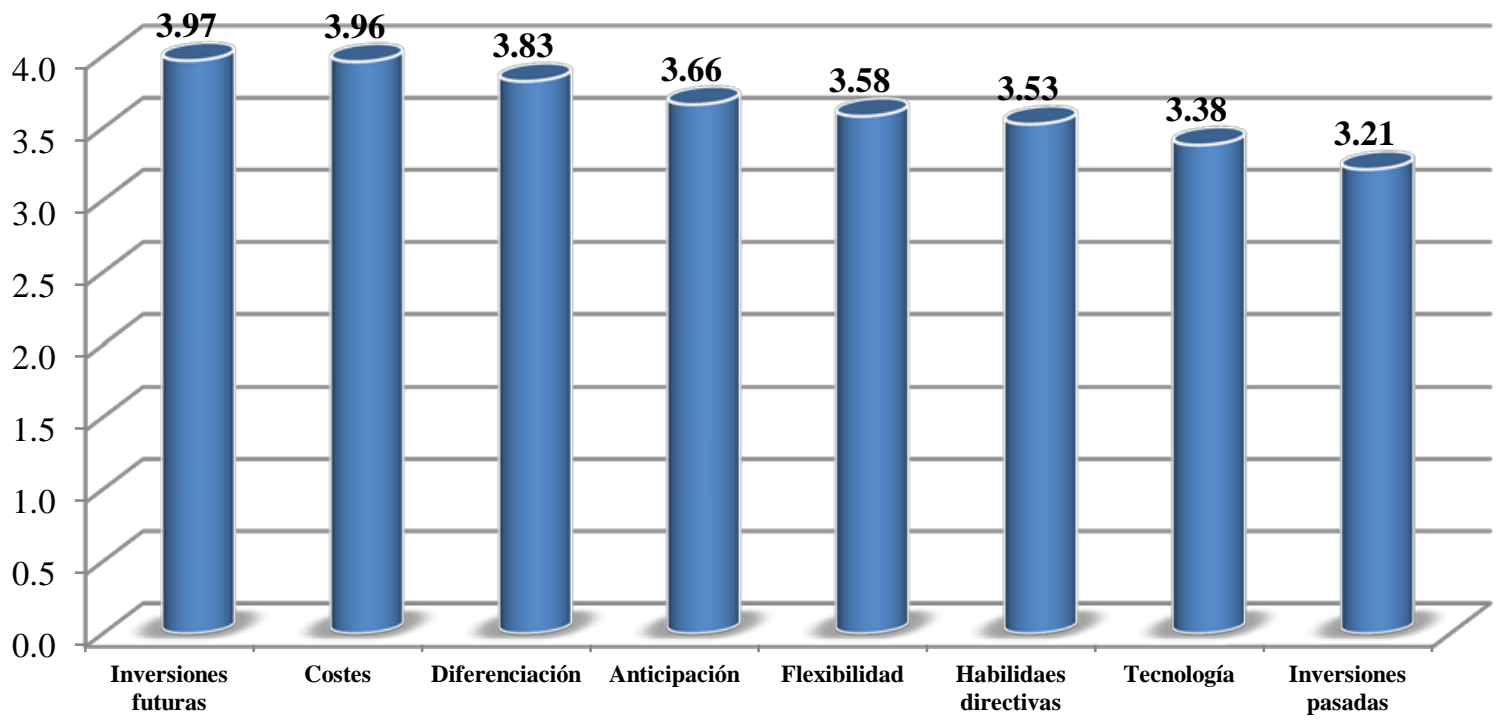

La figura 4.23 refleja la percepción de los directores financieros respecto al peso de las oportunidades futuras de inversión en el valor actual de la empresa. Tres de cada cuatro directores financieros opinan que más del $20 \%$ del valor de la empresa procede de sus oportunidades de crecimiento. Aún más ilustrativo resulta el hecho de que cerca de la mitad de los directores financieros (45\%) entienden que las oportunidades de inversión futura contabilizan más del $40 \%$ del valor actual de sus empresas. 
Figura 4.23: Distribución de empresas según relevancia de sus oportunidades futuras de inversión en el valor de la empresa

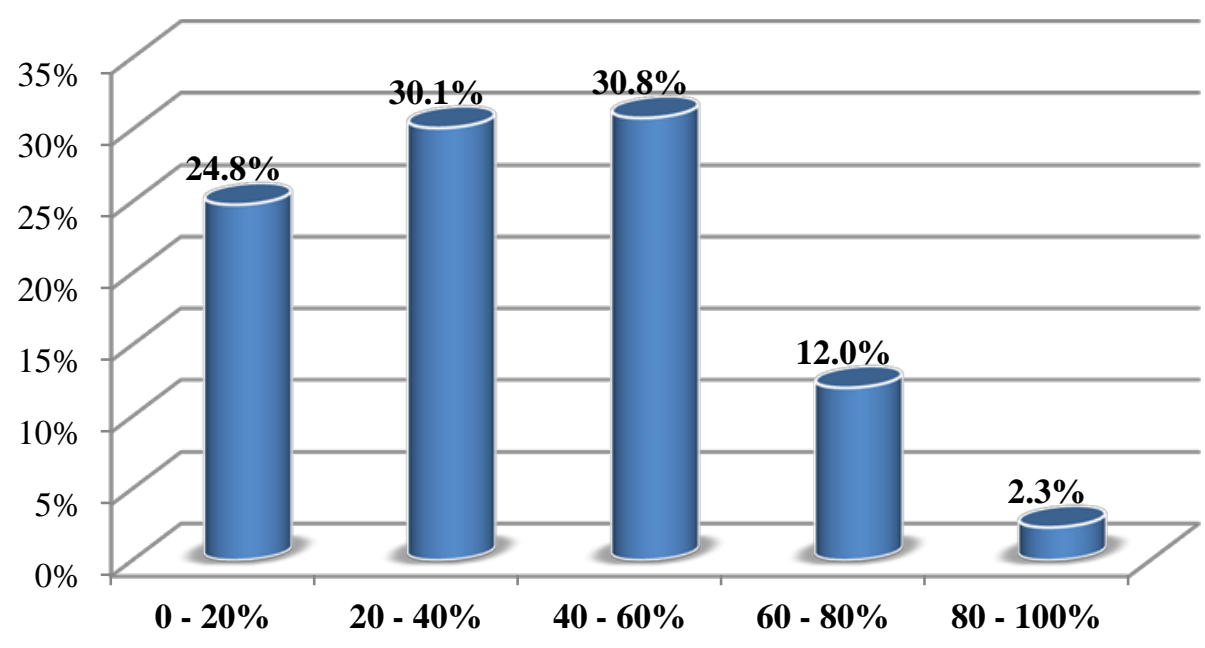

Ahondando en la relevancia de las oportunidades de crecimiento, la figura 4.24 resume la frecuencia con la que las inversiones pasadas abren nuevas oportunidades de crecimiento. Estos datos revelan la importancia de la inversión en la apertura de nuevas oportunidades de negocio: cerca del $43 \%$ de los directores financieros estiman que más del $60 \%$ de las inversiones que emprenden abren nuevas puertas a la empresa.

Figura 4.24: Distribución de las empresas según frecuencia con la que sus inversiones abren nuevas oportunidades de negocio

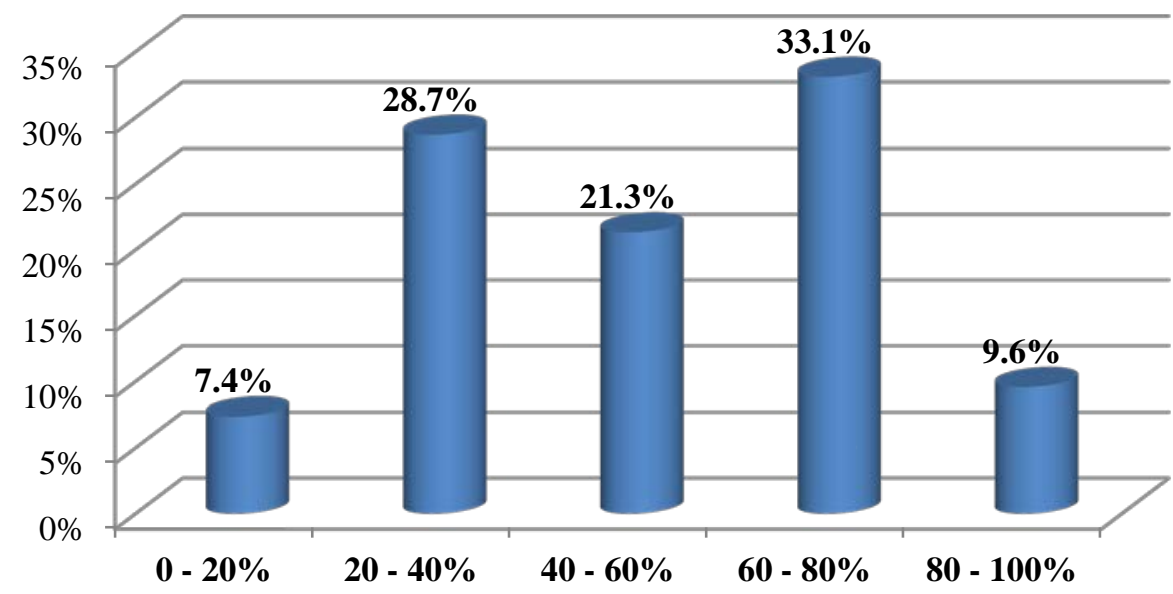


Las dos figuras siguientes profundizan en la influencia de la flexibilidad del proyecto sobre las decisiones de inversión. La figura 4.25 ilustra el peso atribuido por el director financiero a distintas fuentes de flexibilidad, a partir de una escala de cinco niveles donde 1 indica "poca” y 5 "mucha”. Los valores medios de relevancia son coherentes con los resultados de anteriores preguntas y denotan una importancia relativa moderada. Destaca la importancia concedida a que el proyecto permita modificar el ritmo operativo y el tamaño del proyecto (con medias de 3,7 y 3,6, respectivamente).

Figura 4.25: Importancia media atribuida a fuentes de flexibilidad

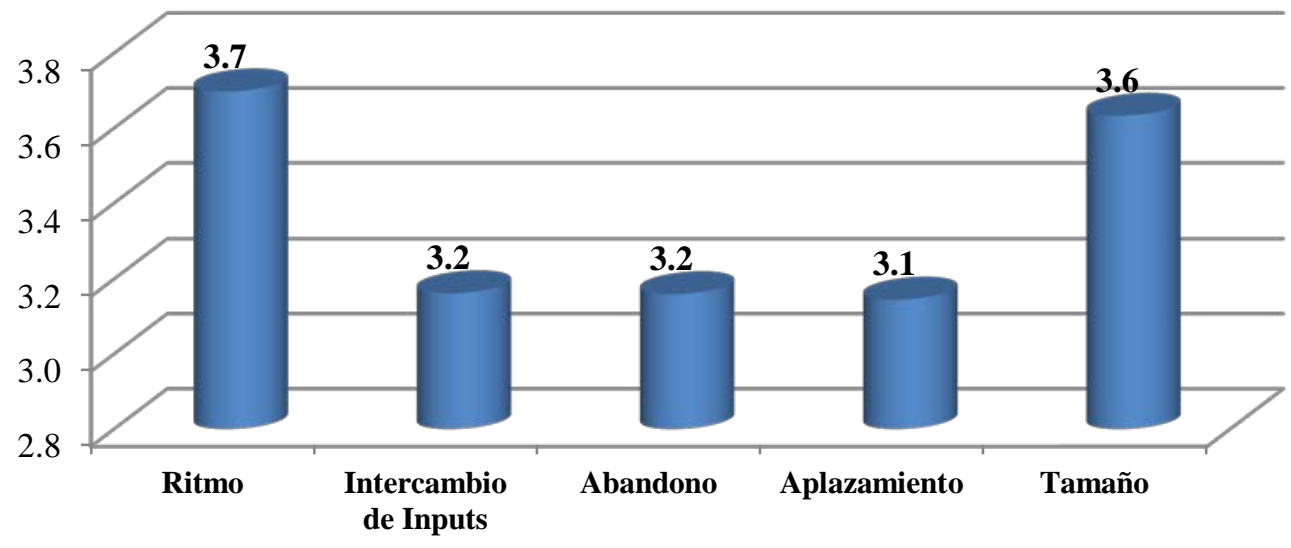

La figura 4.26 ilustra la frecuencia con la que se explotan las ventajas de los distintos tipos de flexibilidad según una escala de cinco niveles. De nuevo, la modificación del ritmo operativo y el ajuste de la dimensión del tamaño destacan sobre el resto de aplicaciones de la flexibilidad (con respuesta media de 2,8 y 2,7, respectivamente), aunque no con valores muy distantes de las posibilidades de intercambiar los inputs de producción (con media de 2,4) o aplazar la iniciación del proyecto (media de 2,4). 
Figura 4.26: Frecuencia media de ejercicio de las fuentes de flexibilidad

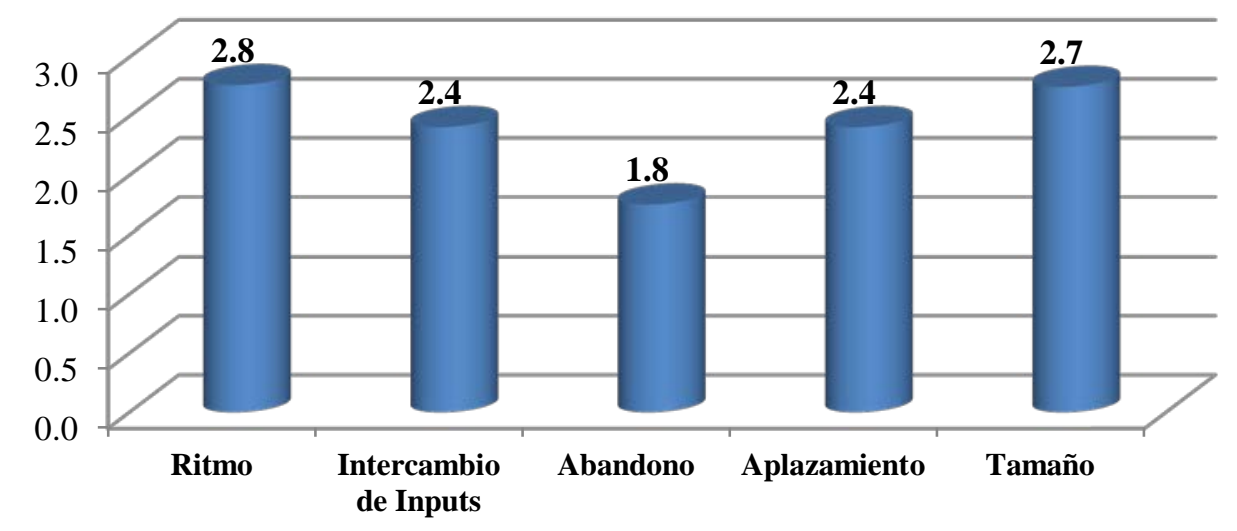

\subsection{La Decisión de Financiación.}

\subsubsection{Descripción del endeudamiento de las empresas}

Con respecto a la decisión de financiación, los resultados de este trabajo reflejan un patrón de decisión muy similar al observado en estudios similares, como Graham y Harvey (2001), Brounen et al. (2006) y Lindblom et al. (2011), entre otros. En la mayoría de las empresas de la muestra la decisión de financiación se articula en torno a un ratio de endeudamiento objetivo, siendo la retención de beneficios la fuente de financiación preferida. También hay elementos en común en esta encuesta con los encontrados para directores financieros norteamericanos y europeos. Así, la flexibilidad financiera, la accesibilidad del endeudamiento y la naturaleza de la inversión a financiar son los parámetros básicos manejados a la hora de adoptar la decisión de endeudamiento.

La figura 4.27 refleja el peso promedio de las distintas fuentes de financiación a partir de los valores elegidos en una escala de 1 a 5, donde 1 indica “Nada importante” y 5 "Muy importante”. Las respuestas reflejan que las empresas de la muestra prefieren la financiación interna (beneficios retenidos con un peso medio de 3,50 ) a la externa y que la fuente externa con mayor peso es la 
deuda bancaria $(3,47)$. Este orden de preferencia, en línea con lo indicado por la teoría del pecking order, refleja un patrón de comportamiento similar al de sus pares de Estados Unidos y de Europa (Kjellman y Hansén, 1995; Graham y Harvey, 2001; Bancel y Mittoo, 2004; Brounen et al., 2006; Lindblom et al., 2011). Sin embargo, estos resultados no se encuentran en línea por lo encontrado por Ang y Jung (1993), cuyos encuestados prefieren la utilización de endeudamiento bancario a los fondos internos. ${ }^{37}$

Figura 4.27: Relevancia media de las fuentes de financiación

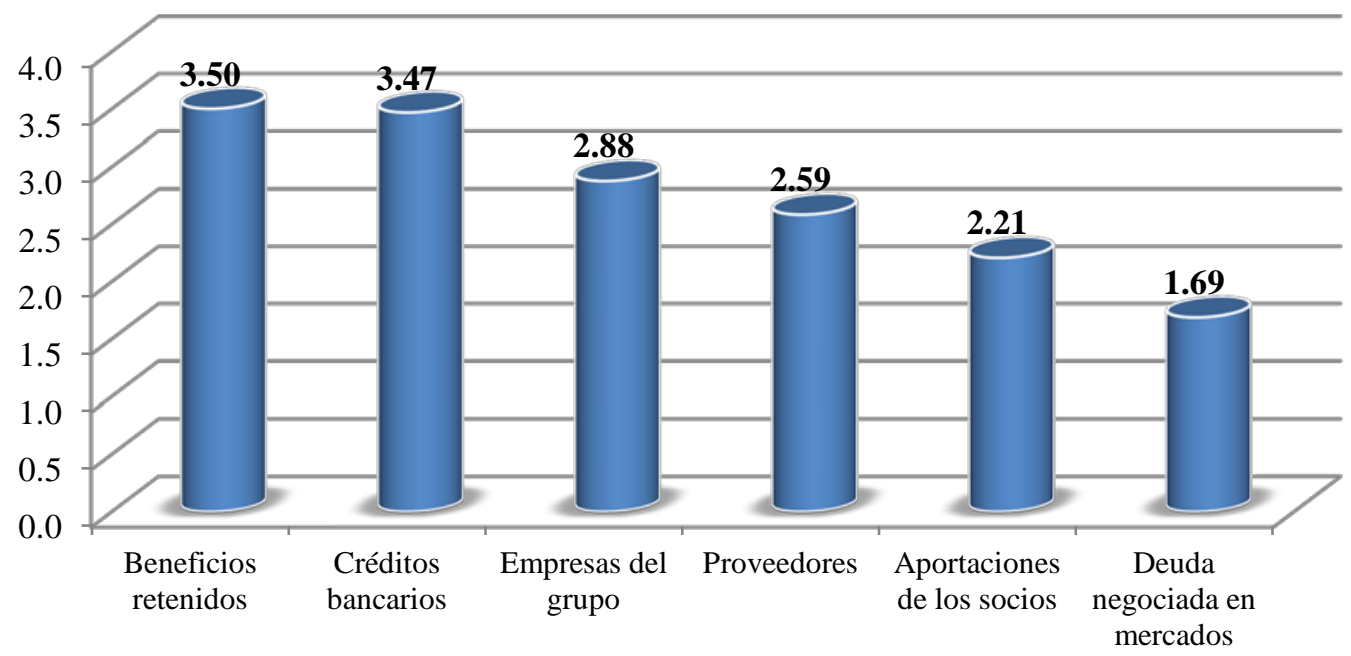

La figura 4.28 permite profundizar en la naturaleza del endeudamiento de las empresas de la muestra. En términos medios, la deuda total representa el $46 \%$ del activo. De esta deuda, el 41,6\% está formalizado mediante contratos a largo plazo (más de un año). Porcentaje similar, el 48,3\%, es deuda bancaria, La deuda con empresas del grupo contabiliza poco más del 23\% de la deuda total.

${ }^{37}$ Colombage (2007), para un mercado emergente, verifica que las empresas encuestadas tienen una clara preferencia por la jerarquía de las fuentes de financiación propuesta por la teoría del pecking order. 
Figura 4.28: Nivel y tipo de endeudamiento

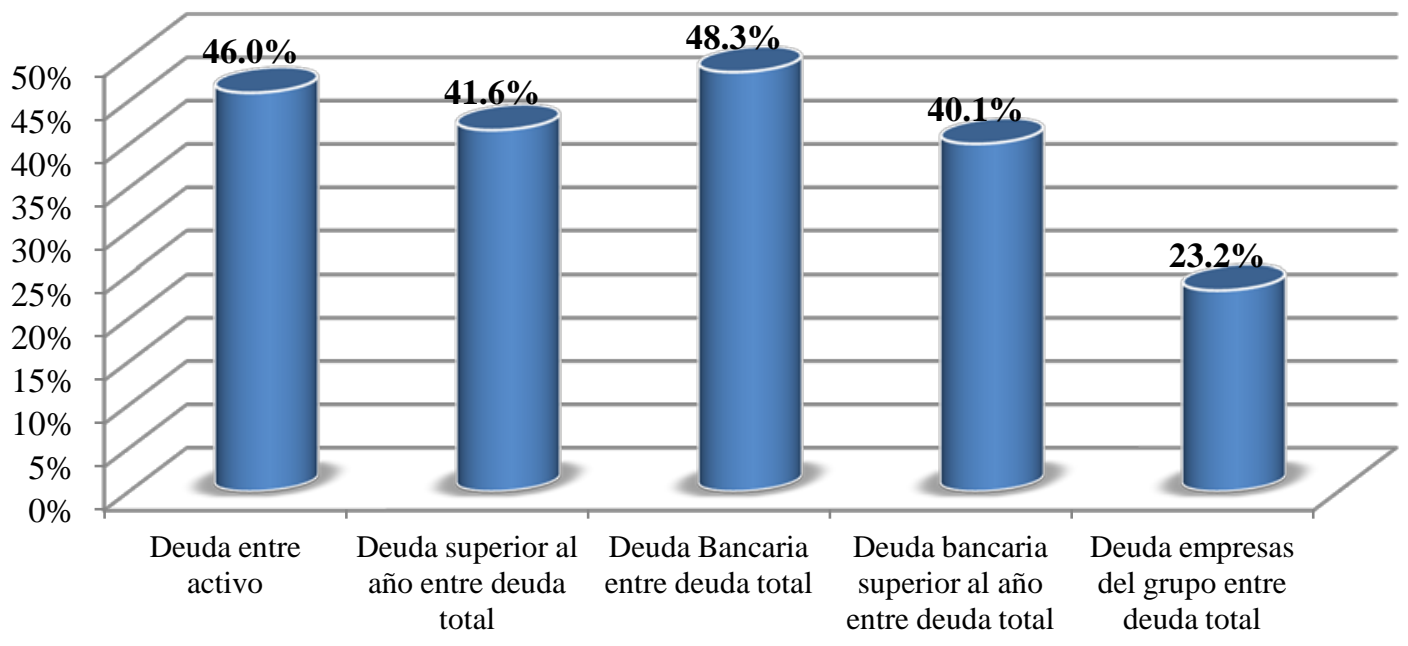

La figura 4.29 refleja la distribución de las empresas de la muestra según el nivel de endeudamiento (calculado a partir del cociente de deuda total entre total activo). Se aprecia que más de la mitad de las empresas soportan un nivel de endeudamiento superior al 50\% y en el $25 \%$ de las compañías la deuda rebasa el $70 \%$ del valor de los activos.

Figura 4.29: Distribución de las empresas según su endeudamiento medio

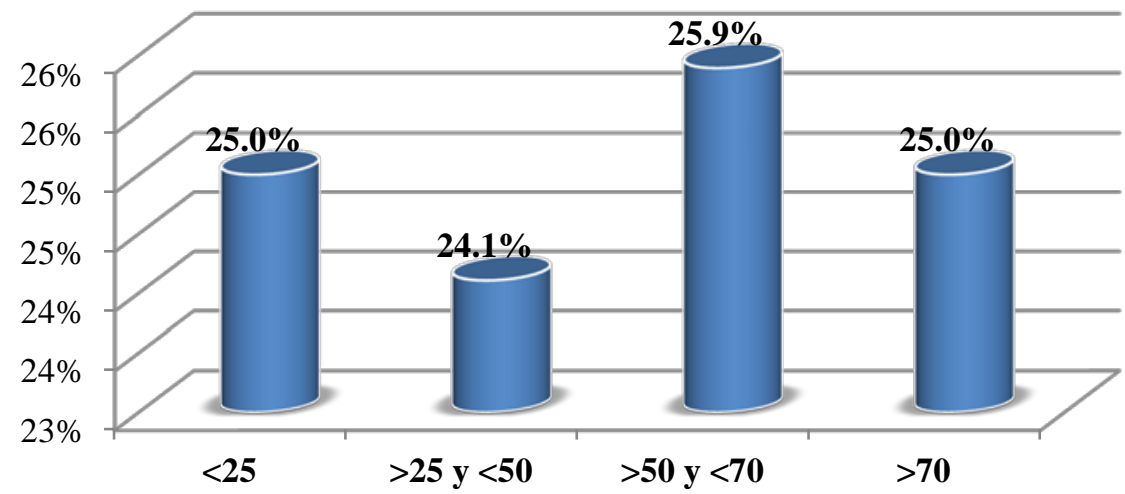

A la pregunta de si la empresa acomoda su política de financiación a un nivel de endeudamiento objetivo, dos tercios de los directores financieros respondieron afirmativamente (figura 4.30). Esta preferencia directiva da cuenta de un comportamiento que podría estar acorde con la teoría del trade off, pues los 
encuestados al responder implícitamente reconocen la existencia de un ratio de deuda óptimo, tal como lo describe la teoría.

De manera complementaria, la figura 4.31 ilustra la frecuencia con la que se consigue alcanzar el nivel de endeudamiento deseado. El 37\% de las empresas alcanza el objetivo con una frecuencia superior al $80 \%$ y el $75 \%$ de los directores financieros declara conseguir mantenerse en dicho objetivo el 60\% del tiempo. La diversidad observada en la gráfica podría, sin embargo, dar cuenta de la rigurosidad que se otorga al ajuste con el nivel deseado de deuda. Menores porcentajes de permanencia en el nivel deseado podrían asociarse a tasas más flexibles, atribuidas a una menor importancia relativa a este objetivo.

Figura 4.30: Porcentaje de empresas que persiguen un nivel de endeudamiento objetivo

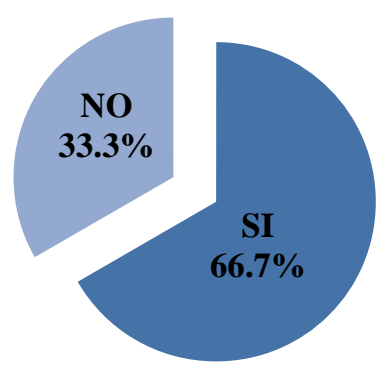


Figura 4.31: Distribución de las empresas según el grado de cumplimiento del nivel objetivo de endeudamiento

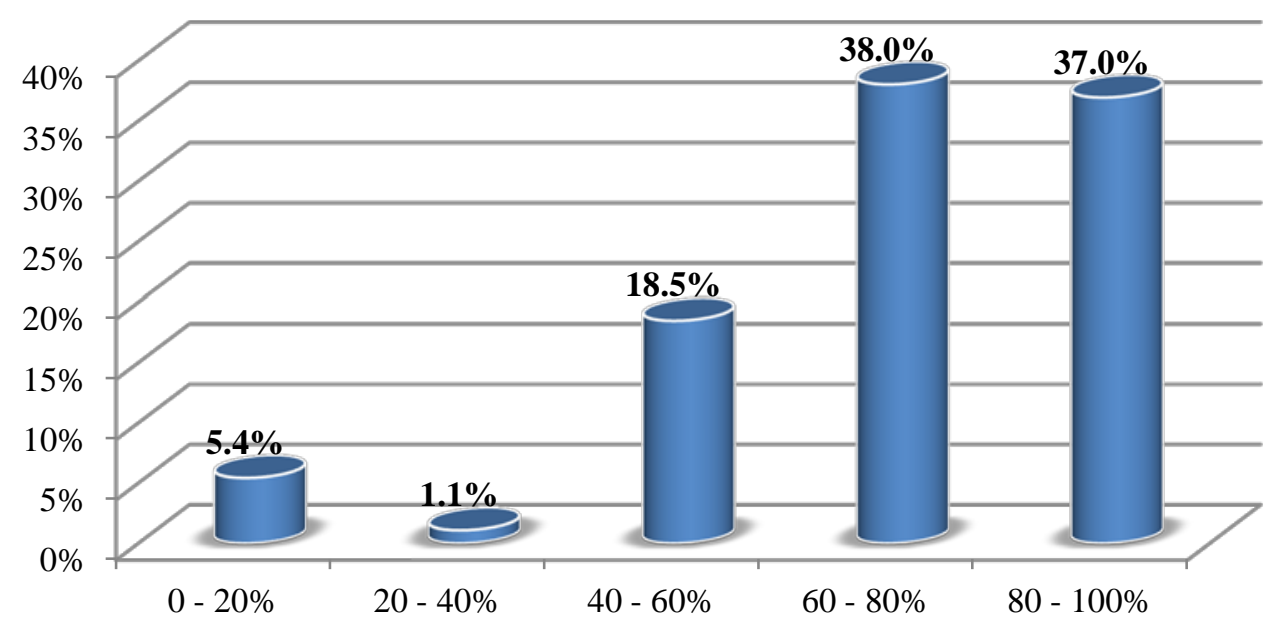

Las figuras 4.32 y 4.33 informan sobre la influencia de distintos factores en el nivel de endeudamiento de la empresa. La figura 4.32 refleja la influencia media atribuida por los directores financieros a determinados factores a partir de una escala de cinco niveles, desde "nada importante” asociado al valor 1 a "muy importante” del valor 5. De manera complementaria, la figura 4.33 muestra el porcentaje de empresas en las que cada uno de los factores resulta "importante” o “muy importante” en su influencia sobre el nivel de endeudamiento.

Los dos factores más relevantes son la flexibilidad financiera y la facilidad de acceso al endeudamiento (en ambas gráficas). Le sigue por orden de importancia, la naturaleza y la vida económica de la inversión a financiar (con medias de 3,53 y 3,37, respectivamente). La existencia de una estructura financiera objetivo ocupa un lugar intermedio entre los factores de influencia (3,37 de media e importante o muy importante para un 52,7\% de los encuestados), quizás debido en parte a lo mencionado en párrafos anteriores respecto del nivel de permanencia en el nivel deseado de deuda.

El hecho de que la flexibilidad financiera se encuentre entre los factores más importantes en la determinación del nivel de endeudamiento de la empresa no es demasiado sorprendente, pues gran parte de la evidencia encontrada por medio de 
cuestionarios así lo revela (Pinegar y Wilbricht, 1989; Kester et al., 1994; Kjellman y Hansén, 1995; Graham y Harvey, 2001; Bancel y Mittoo, 2004; Brounen et al., 2006; Lindblom et al., 2011; Maquieira et al., 2012; Nor et al., 2012). La propia definición de flexibilidad financiera lleva a asociar este concepto a la teoría del pecking order. Sin embargo, las motivaciones detrás de este factor, tal cual ha sido verificado por Graham y Harvey (2001) y Brounen et al. (2006), también podrían indicar que se debe a razones distintas a las esgrimidas por esta teoría.

Menor relevancia parece ejercer el riesgo de insolvencia y el ahorro de costes de transacción, con valores medios de influencia inferiores a 3 y señalados como “importantes” o "muy importantes" aproximadamente por un tercio de las empresas. El ahorro de impuestos y, sobre todo, el endeudamiento de la competencia ocupan un lugar marginal entre los determinantes de la decisión de endeudamiento para la mayoría de las empresas (con una media de 1,69 y un 5,5\% de los encuestados que creen que este factor es importante o muy importante).

Figura 4.32: Influencia media sobre el nivel de endeudamiento

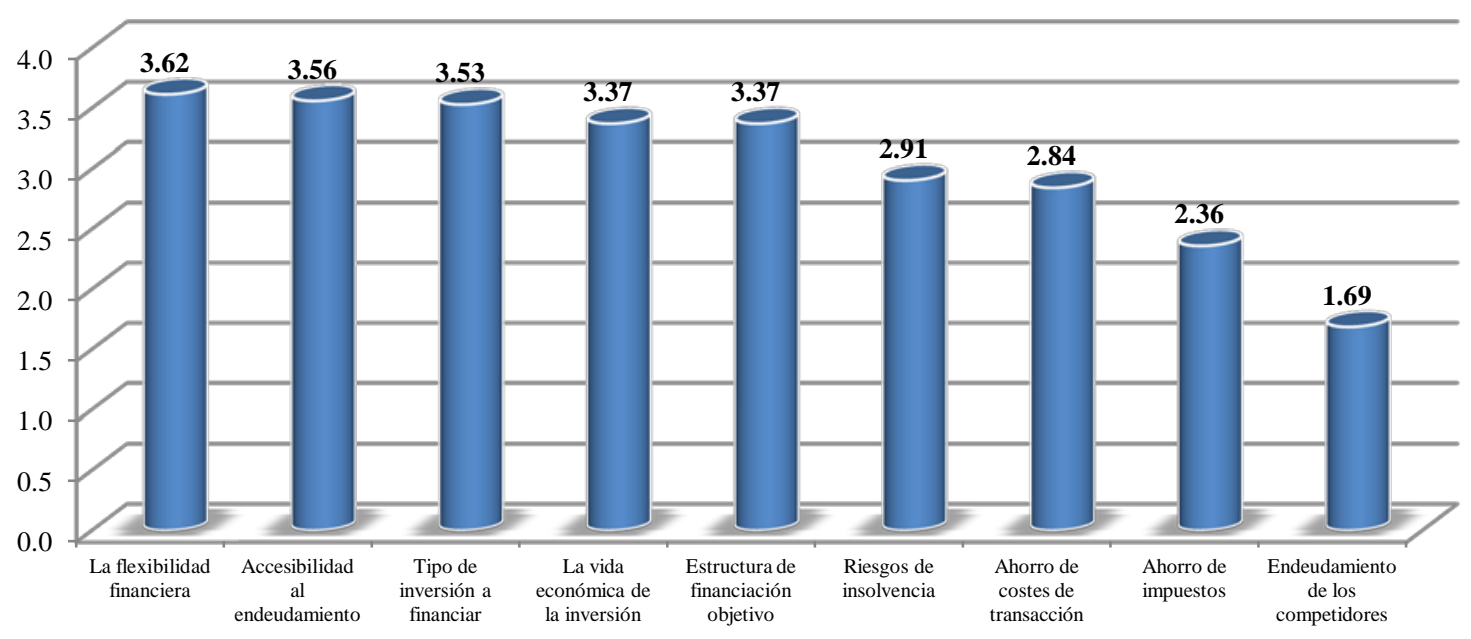


Figura 4.33: Porcentaje de empresas que responden "importante” o "muy importante” a la influencia sobre el nivel de endeudamiento

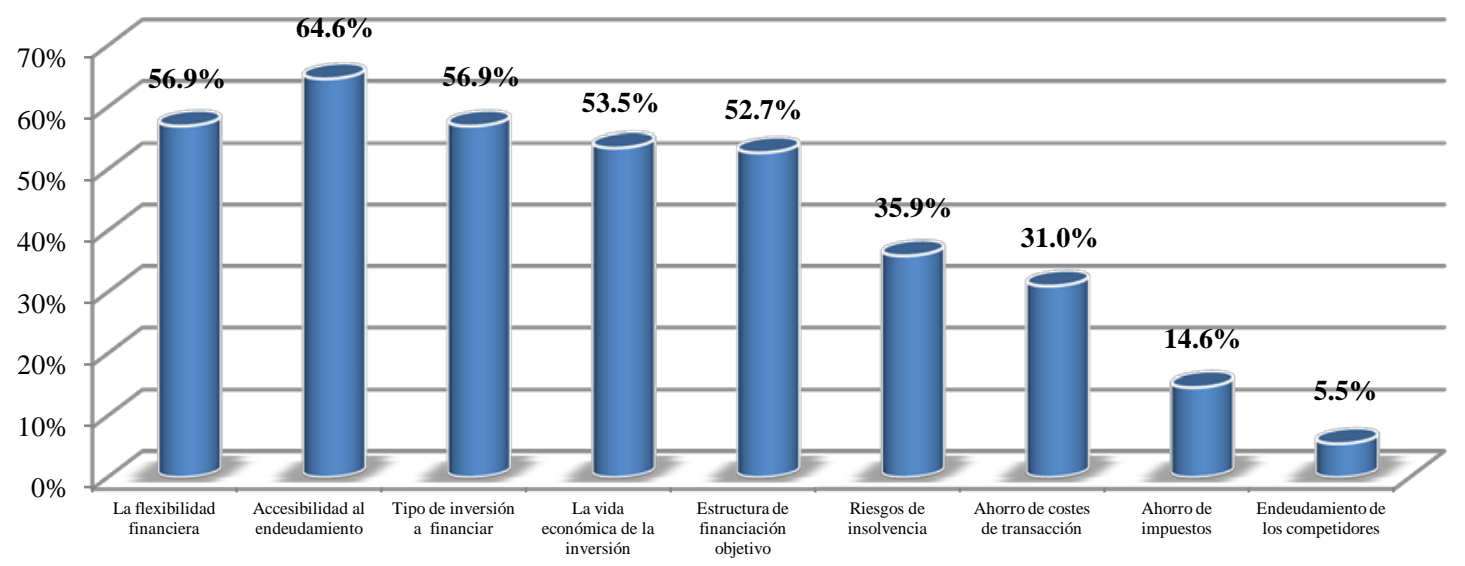

Profundizando en los factores de influencia de la decisión de endeudamiento, la figura 4.34 resume las respuestas de los directores financieros al peso de una serie de elementos que son también considerados por la teoría financiera. Los datos representados en esta figura reflejan la influencia media a partir de una escala de cinco niveles, desde "nada importante” a "muy importante” respecto de factores relevantes de manera específica para la política financiera de la empresa.

En términos generales, las respuestas de los directores financieros indican una menor influencia de estos nuevos elementos frente a los analizados en gráficas precedentes. La mayor puntuación media es la otorgada a la contratación de deuda frente a otras fuentes de financiación (con un valor medio de 3,4), una vez consumidas las reservas de fondos internos ${ }^{38}$. Esta percepción directiva, también verificada en Graham y Harvey (2001), se corresponde con los postulados del teoría del pecking order (Myers y Majluf, 1984).

\footnotetext{
${ }^{38}$ Jog y Srivastava (1994) resaltan que entre sus principales hallazgos se encuentran que la falta de fondos internamente generados es el principal impedimento para acometer proyectos de inversión (y no la falta de oportunidades de inversión en sí mismo) y que los directores financieros perciben una gran diferencia en el coste de la financiación interna versus la externa.
} 
La teoría financiera indica que los directivos aprovechan las "ventanas de oportunidad” 39 para realizar sus operaciones financieras y así sacar ventaja de estas variaciones de mercado. Sin embargo, no parece que los directores financieros recurran al endeudamiento cuando el precio de las acciones disminuye, como indica el valor de 1,3 alcanzado por su importancia media. Esto, de alguna manera, no da soporte a la teoría del market timing, que defiende la búsqueda de oportunidades para aprovechar las asimetrías de información entre empresa y mercado.

Las demás respuestas de los encuestados indican que los demás elementos considerados apenas influyen en sus decisiones de financiación. Aunque también poco importantes, la mejora de las garantías de la empresa, la bajada de los tipos de interés y las buenas relaciones con las entidades bancarias reflejan algo más de relevancia, con valores medios superiores a 2 . Le siguen por orden de importancia, la preferencia de la deuda bancaria a la deuda de mercado $(2,0)$, la utilización de la deuda para mejorar la reputación de la empresa (1,9), la tangibilidad de los activos de la empresa $(1,8)$ y la utilización del endeudamiento para reducir el coste de capital medio ponderado $(1,7)$.

${ }^{39}$ Ver Graham y Harvey (2001), Lindblom et al. (2011), también Bayless y Chaplinsky (1996) y Dutordoir y Van de Gucht (2007). 
Figura 4.34: Influencia media sobre la decisión de endeudamiento

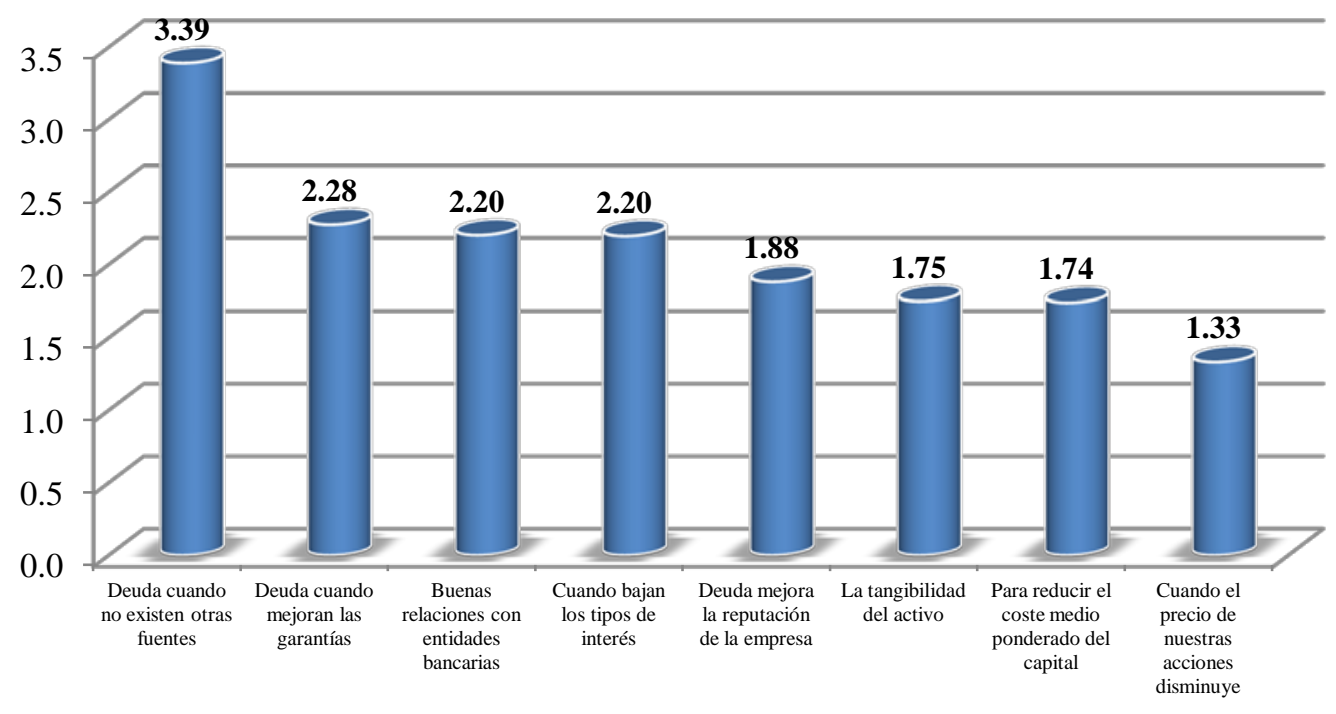

En lo que respecta al plazo del endeudamiento, la figura 4.35 muestra el grado de acuerdo de los directores financieros con respecto a los posibles motivos de la elección entre deuda a corto y largo plazo. De acuerdo con la escala de cinco valores entre 1 y 5 , los resultados indican que, sin ser totalmente determinantes, el elemento de mayor influencia es el ajuste de la vida del activo y del pasivo de la empresa (con un peso medio de 3,3), seguido por los problemas de refinanciación $(3,2)$ y el ajuste de la financiación a cada proyecto financiado $(2,9)$. Menor influencia en el plazo de la deuda parecen ejercer los problemas de insolvencia financiera, como muestra su nivel de importancia media de 2,6. Otros factores, como la bajada de los tipos de interés $(1,8)$, la reducción de los costes de financiación $(1,9)$ o el empleo de la deuda a corto como mecanismo disciplinario para reducir el incentivo riesgo $(1,5)$ apenas parecen influir en la decisión del plazo de la deuda.

Graham y Harvey (2001) señalan que la estructura de capital de la empresa puede servir para manejar el riesgo de la misma, con lo que las empresas, entre otras cosas, intentan hacer coincidir el plazo de la deuda con la vida útil de los activos. Como ya fue mencionado, nuestros resultados indican que el factor más importante en la determinación de la elección entre deuda de corto y largo plazo 
es el ajuste de la vida del activo y del pasivo, tal y como también reflejan los trabajos de Bancel y Mittoo (2004) y Brounen et al. (2006).

Figura 4.35: Influencia media sobre el plazo de la deuda

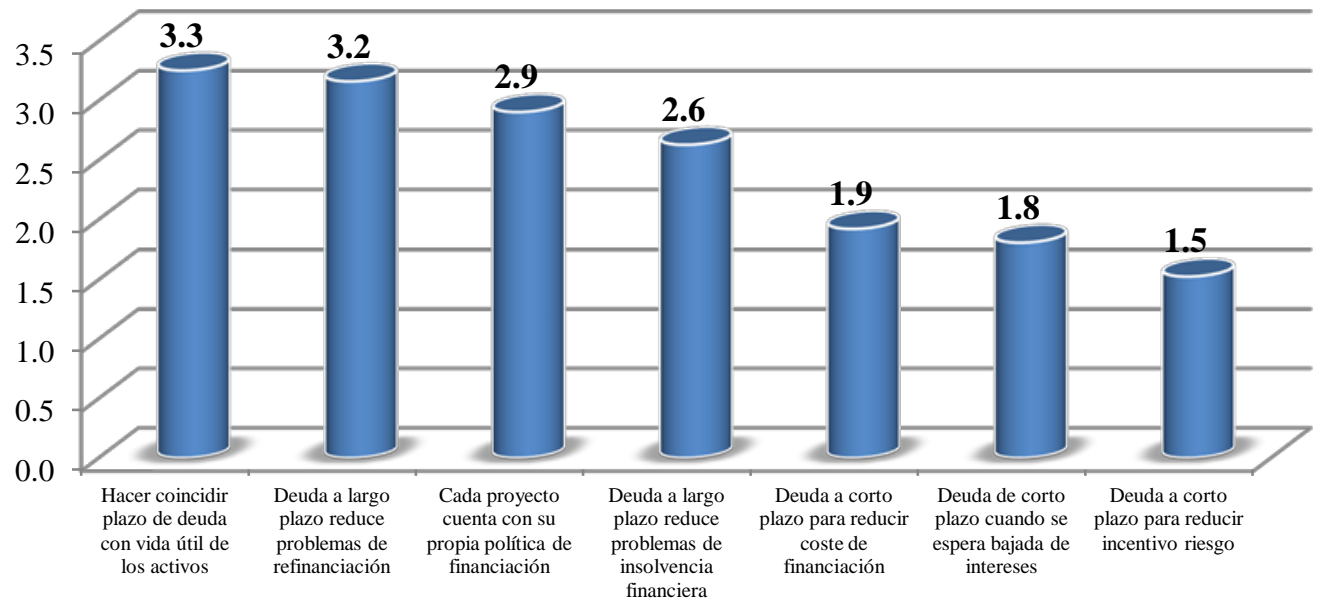

Finalmente, la figura 4.36 muestra el grado de acuerdo de los directores financieros con respecto a cinco afirmaciones sobre la situación actual y perspectivas futuras de la empresa y la relación entre sus decisiones de inversión y de financiación. Con un valor medio de 4 en una escala creciente de 1 a 5 , los directivos financieros se mostraron bastante de acuerdo con el hecho de que el valor de la empresa es muy superior a su valor en libros. El nivel de acuerdo es moderadamente positivo en relación con las perspectivas de futuro, como indica el valor medio de 3,6 con relación a la afirmación de que dentro de cinco años la empresa habrá aumentado mucho sus beneficios.

Mayor indefinición se refleja con respecto al aprovechamiento de las oportunidades de inversión de los últimos cinco años, como indica el nivel medio de acuerdo de valor 3,1. En el ámbito de la interdependencia entre inversión y financiación, los encuestados se muestran, por término medio, bastante disconformes con el hecho de que la política de financiación haya perjudicado al 
aprovechamiento de sus oportunidades de inversión (2,3) o haya influido negativamente sobre el valor de la empresa $(1,8)$.

Figura 4.36: Perspectivas de futuro y relación entre inversión y financiación

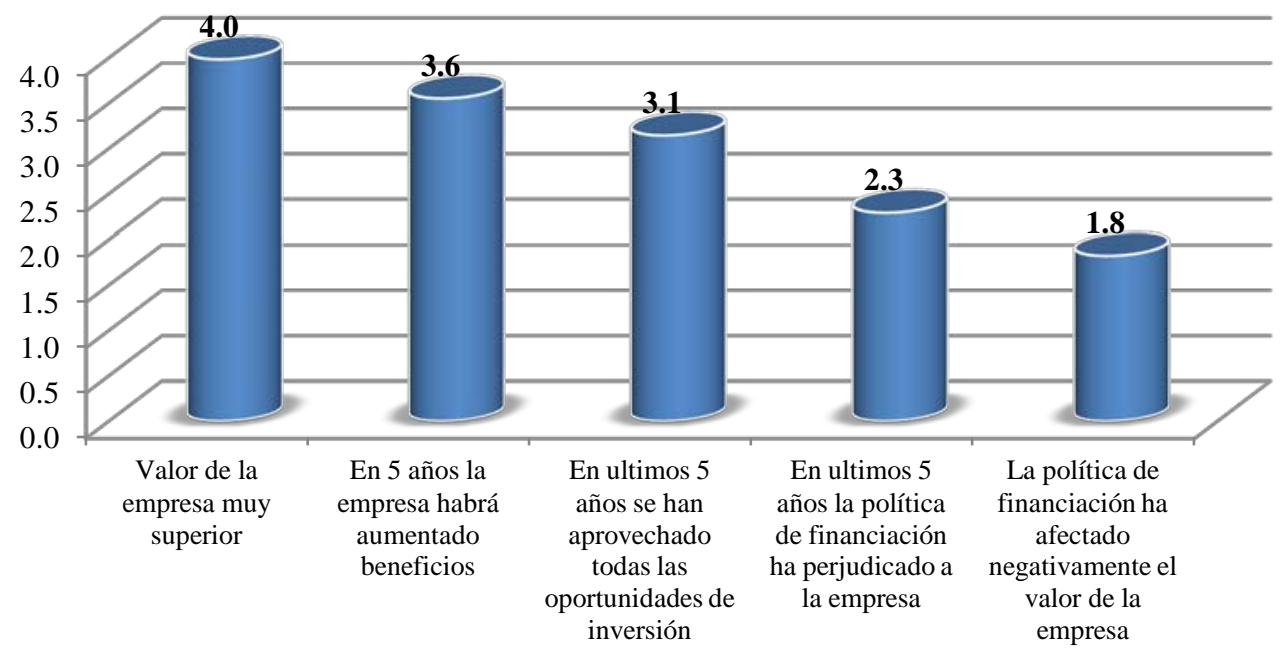

\subsubsection{Patrón de comportamiento y niveles de deuda}

La tabla 4.4 presenta las respuestas a las preguntas sobre financiación planteadas a los directores financieros. Las respuestas han sido condicionadas de acuerdo a cinco distintos tipos de endeudamiento (deuda total, deuda de largo plazo, deuda bancaria, deuda bancaria de largo plazo y deuda con el grupo) y tres niveles dentro de cada grupo.

El principal razonamiento de la teoría del trade off se articula en torno a las bondades y desventajas del endeudamiento. Curiosamente, y en contra de lo que cabría esperar, el ahorro de impuestos (beneficio que aumenta con la deuda) se relaciona de manera negativa con el mayor uso de deuda bancaria. Las empresas de mayor (menor) endeudamiento bancario atribuyen menor (mayor) importancia a la ventaja fiscal de la deuda (con medias de 2,61; 2,33 y 2,19 para empresas de bajo, medio y alto nivel de endeudamiento bancario, respectivamente). Graham (2000) concluye su trabajo señalando que las empresas están desaprovechando la 
posibilidad de crear valor aumentando su endeudamiento y, con ello, disminuyendo el pago de impuestos.

También para el factor nivel de deuda de la competencia, la variable deuda bancaria evidencia comportamientos estadísticamente significativos. Para este caso, las empresas de mayor endeudamiento bancario son las que en mayor medida valoran como referencia importante el nivel de endeudamiento de la competencia. Luego, en orden descendente, las empresas con menor nivel de deuda bancaria y finalmente las de nivel medio.

Las empresas con mayor deuda bancaria de largo plazo son las que mayor relevancia le atribuyen a la composición del activo de la empresa. Este resultado indica que las empresas valoran la tangibilidad de sus activos, porque aumenta sus garantías crediticias frente a acreedores (en este caso instituciones bancarias), pues tiene la posibilidad de amplificar la capacidad crediticia (Almeida y Campello, 2007; Hahn y Lee, 2009; Campello y Hackbarth, 2012). Además, para empresas con niveles medios de deuda bancaria de largo plazo (y en menor medida las de alto nivel) son las que en mayor medida valoran el “emparejamiento de plazos” entre activos y pasivos.

Las empresas que pertenecen a grupos empresariales, en términos generales, son las que menor preocupación expresan en relación con cuestiones del emparejamiento de plazos y problemas de refinanciación (problema de agencia), así como la disponibilidad y acceso al endeudamiento. Las razones para estos resultados radican en que este tipo de empresas podrían tener sus propios mercados internos de financiación, lo que lleva a que este tipo de problemas sean menos relevantes. Así, por ejemplo, Kahnna y Palepu (2000a; 2000b) y Khanna y Rivkin (2001) verifican que la pertenencia a grupos empresariales mejora la rentabilidad y añade valor a sus empresas afiliadas, en la medida que se repliquen 
internamente aquellas instituciones que no encuentran en mercados menos desarrollados ${ }^{40}$.

De igual manera las empresas de nivel medio de deuda a largo plazo son las que más importancia atribuyen al aprovechamiento de las "ventanas de oportunidad” que ofrece el mercado en relación con los tipos de interés.

${ }^{40}$ Gonenc (2009), para el caso de Turquía, analiza la forma en que las empresas afiliadas a un grupo empresarial transfieren recursos financieros. El argumento es que los mercados de capitales intra grupo surgen como respuestas a las imperfecciones de mercado de capitales extra grupo, con lo que la financiación interna actúa como sustituto de los mercados externos de capitales (en mercados en desarrollo). Sus resultados evidencian que en las empresas afiliadas a grupos empresariales se transfieren fondos internamente utilizando deuda negociable, derechos de caja y acciones. No obstante, cuando al interior del grupo también existe un banco, sus empresas se aprovechan en mejor medida de esta situación y exhiben mayores tasas de crecimiento de sus activos. 
Tabla 4.4: Respuesta condicionada frente a distintos tipos de endeudamiento

La tabla condiciona las variables referidas a los patrones de financiación (subdivididos por teorías de estructura de capital) a cinco tipos de endeudamiento. Se realizan pruebas de análisis de la varianza (ANOVA), las que permiten verificar diferencias estadísticamente significativas entre los grupos dentro de cada tipo de deuda. ***, **, * indica significativa al $1 \%$, $5 \%$ y $10 \%$, respectivamente.

\begin{tabular}{|c|c|c|c|c|c|c|c|c|c|c|c|c|c|c|c|c|c|c|}
\hline \multirow{2}{*}{ Teoría del Trade Off } & \multirow{2}{*}{ Media } & \multicolumn{2}{|c|}{ Importancia } & \multicolumn{3}{|c|}{ Deuda } & \multicolumn{3}{|c|}{ Deuda de largo plazo } & \multicolumn{3}{|c|}{ Deuda bancaria } & \multicolumn{3}{|c|}{$\begin{array}{c}\text { Deuda bancaria de largo } \\
\text { plazo }\end{array}$} & \multicolumn{3}{|c|}{ Deuda con el grupo } \\
\hline & & Baja & Alta & Baja & Media & Alta & Baja & Media & Alta & Baja & Media & Alta & Baja & Media & Alta & Baja & Media & Alta \\
\hline a) Ratio de endeudamiento objetivo & 0,67 & & & 0,68 & 0,63 & 0,67 & 0,59 & 0,75 & 0,61 & 0,68 & 0,71 & 0,63 & 0,56 & 0,79 & 0,66 & 0,69 & 0,77 & 0,61 \\
\hline b) Ahorro de impuestos & 2,360 & $59,2 \%$ & $14,6 \%$ & 2,29 & 2,21 & 2,61 & 2,45 & 2,06 & 2,56 & 2,61 & 2,33 & $2,19 * * *$ & 2,56 & 2,12 & 2,32 & 2,19 & 2,44 & 2,61 \\
\hline $\begin{array}{l}\text { c) Ahorro de costes de transacción } \\
\text { y negociación }\end{array}$ & 2,840 & $39,5 \%$ & $31,0 \%$ & 2,68 & 2,88 & 3,04 & 2,77 & 2,88 & 2,90 & 2,97 & 3,15 & 2,48 & 3,00 & 2,68 & 2,90 & 2,82 & 3,11 & 2,88 \\
\hline $\begin{array}{l}\text { c) Búsqueda de una estructura de } \\
\text { deuda objetivo }\end{array}$ & 3,370 & $21,7 \%$ & $52,7 \%$ & 3,41 & 3,26 & 3,57 & 3,26 & 3,69 & 3,22 & 3,61 & 3,44 & 3,17 & 3,28 & 3,50 & 3,40 & 3,38 & 3,56 & 3,42 \\
\hline $\begin{array}{l}\text { d) Nivel de endeudamiento de la } \\
\text { competencia }\end{array}$ & 1,690 & $82,0 \%$ & $5,5 \%$ & 1,78 & 1,60 & 1,81 & 1,65 & 1,65 & 1,81 & 1,68 & 1,66 & $1,74^{* *}$ & 1,50 & 1,67 & 1,83 & 1,70 & 1,75 & 1,76 \\
\hline $\begin{array}{l}\text { e) Potenciales riesgos de } \\
\text { insolvencia y quiebra }\end{array}$ & 2,910 & $36,7 \%$ & $35,9 \%$ & 3,00 & 2,86 & 2,93 & 2,84 & 2,84 & 3,03 & 2,77 & 3,09 & 2,97 & 2,66 & 2,96 & 3,13 & 3,11 & 3,25 & 2,42 \\
\hline $\begin{array}{l}\text { f) Se usa deuda para reducir el } \\
\text { WACC }\end{array}$ & 1,750 & $77,0 \%$ & $5,6 \%$ & 1,61 & 1,88 & 1,85 & 1,67 & 1,65 & 1,94 & 1,59 & 1,82 & 1,81 & 1,68 & 1,85 & 1,67 & 1,82 & 1,63 & 1,69 \\
\hline $\begin{array}{l}\text { g) Deuda LP para evitar problemas } \\
\text { de insolvencia y quiebra }\end{array}$ & 2,630 & $47,3 \%$ & $31,5 \%$ & 2,26 & 2,73 & 2,96 & 2,16 & 2,78 & 3,14 & 2,45 & 2,82 & 2,90 & 2,23 & 2,93 & 2,90 & 2,86 & 2,89 & 2,40 \\
\hline
\end{tabular}

\begin{tabular}{|c|c|c|c|c|c|c|c|c|c|c|c|c|c|c|c|c|c|c|}
\hline \multirow{2}{*}{ Teoría del Pecking Order } & \multirow{2}{*}{ Media } & \multicolumn{2}{|c|}{ Importancia } & \multicolumn{3}{|c|}{ Deuda } & \multicolumn{3}{|c|}{ Deuda LP } & \multicolumn{3}{|c|}{ Deuda Bancaria } & \multicolumn{3}{|c|}{ Deuda Bancaria de LP } & \multicolumn{3}{|c|}{ Deuda con el grupo } \\
\hline & & Baja & Alta & Baja & Media & Alta & Baja & Media & Alta & Baja & Media & Alta & Baja & Media & Alta & Baja & Media & Alta \\
\hline a) La flexibilidad financiera & 3,620 & $16,2 \%$ & $56,9 \%$ & 3,56 & 3,79 & 3,57 & 3,74 & 3,63 & 3,66 & 3,87 & 3,56 & 3,61 & 3,81 & 3,50 & 3,77 & 3,74 & 3,56 & 3,52 \\
\hline $\begin{array}{l}\text { b) Utilización de deuda cuando } \\
\text { no hay fondos internos }\end{array}$ & 3,390 & $25,8 \%$ & $55,5 \%$ & 3,42 & 3,47 & 3,74 & 3,45 & 3,31 & 3,81 & 3,38 & 3,50 & 3,71 & 3,45 & 3,50 & 3,74 & 3,72 & 3,56 & 3,13 \\
\hline $\begin{array}{l}\text { c) Uso de deuda se debe a } \\
\text { buenas relaciones con bancos }\end{array}$ & 2,200 & $60,2 \%$ & $12,5 \%$ & 1,91 & 2,28 & 2,39 & 2,07 & 2,06 & 2,34 & 1,83 & 2,62 & 2,19 & 2,10 & 2,00 & 2,45 & 2,33 & 2,33 & 2,03 \\
\hline $\begin{array}{l}\text { d) Deuda bancaria a bonos pues } \\
\text { se revela menos información }\end{array}$ & 2,050 & $68,0 \%$ & $20,5 \%$ & 1,88 & 2,27 & 2,04 & 1,93 & 2,26 & 2,00 & 1,89 & 2,19 & 2,23 & 1,87 & 2,30 & 2,14 & 2,16 & 2,63 & 2,00 \\
\hline
\end{tabular}


DESCRIPCIÓN DE LA MUESTRA

\begin{tabular}{|c|c|c|c|c|c|c|c|c|c|c|c|c|c|c|c|c|c|c|}
\hline \multirow{2}{*}{ Teoría de Agencia } & \multirow{2}{*}{ Media } & \multicolumn{2}{|c|}{ Importancia } & \multicolumn{3}{|c|}{ Deuda } & \multicolumn{3}{|c|}{ Deuda LP } & \multicolumn{3}{|c|}{ Deuda Bancaria } & \multicolumn{3}{|c|}{ Deuda Bancaria de LP } & \multicolumn{3}{|c|}{ Deuda con el grupo } \\
\hline & & Baja & Alta & Baja & Media & Alta & Baja & Media & Alta & Baja & Media & Alta & Baja & Media & Alta & Baja & Media & Alta \\
\hline $\begin{array}{l}\text { a) El endeudamiento mejora la } \\
\text { reputación de la empresa }\end{array}$ & 1,88 & $74,02 \%$ & $7,09 \%$ & 1,84 & 1,70 & 2,21 & 1,80 & 1,87 & 1,91 & 1,90 & 2,00 & 1,71 & 1,77 & 1,85 & 1,81 & 1,82 & 2,13 & 1,91 \\
\hline $\begin{array}{l}\text { b) Tipo de inversión a realizar } \\
\text { o los activos a financiar }\end{array}$ & 3,530 & $19,2 \%$ & $56,9 \%$ & 3,47 & 3,74 & 3,82 & 3,65 & 3,75 & 3,66 & 3,87 & 3,85 & 3,54 & 3,63 & 4,00 & 3,42 & 3,75 & 3,78 & 3,42 \\
\hline $\begin{array}{l}\text { c) Vida económica de la } \\
\text { inversión a financiar }\end{array}$ & 3,370 & $23,3 \%$ & $53,5 \%$ & 3,35 & 3,52 & 3,50 & 3,06 & 3,66 & 3,61 & 3,52 & 3,62 & 3,20 & 3,38 & 3,54 & 3,43 & 3,49 & 3,22 & 3,28 \\
\hline $\begin{array}{l}\text { d) A mayor garantía ofrecida } \\
\text { por los activos mayor deuda }\end{array}$ & 2,280 & $66,2 \%$ & $17,3 \%$ & 2,18 & 2,37 & 2,71 & 2,13 & 2,13 & 2,94 & 2,00 & 2,47 & 2,71 & 2,03 & 2,46 & 2,65 & 2,49 & 2,78 & 2,13 \\
\hline $\begin{array}{l}\text { e) Composición del activo es } \\
\text { importante }\end{array}$ & 1,750 & $79,8 \%$ & $8,1 \%$ & 1,64 & 1,81 & 2,00 & 1,53 & 1,90 & 2,07 & 1,79 & 2,06 & 1,81 & 1,39 & 2,11 & $2,17 * * *$ & 1,87 & 2,00 & 1,81 \\
\hline $\begin{array}{l}\text { f) Se hace coincidir plazo de } \\
\text { deuda con vida de los activos }\end{array}$ & 3,260 & $28,7 \%$ & $53,5 \%$ & 3,26 & 3,55 & 3,56 & 3,03 & 3,75 & 3,65 & 3,10 & 3,42 & 3,94 & 2,97 & 3,86 & $3,63^{*}$ & 3,71 & 3,89 & $2,91 * *$ \\
\hline $\begin{array}{l}\text { g) Deuda CP para desincentivar } \\
\text { proyectos arriesgados }\end{array}$ & 1,530 & $85,8 \%$ & $2,4 \%$ & 1,56 & 1,50 & 1,60 & 1,55 & 1,56 & 1,55 & 1,53 & 1,65 & 1,58 & 1,49 & 1,63 & 1,52 & 1,57 & 1,56 & 1,63 \\
\hline $\begin{array}{l}\text { h) Deuda LP para evitar } \\
\text { problemas de refinanciación }\end{array}$ & 3,160 & $29,7 \%$ & $50,0 \%$ & 2,76 & 3,41 & 3,67 & 2,58 & 3,50 & 3,90 & 2,80 & 3,45 & 3,83 & 2,41 & 3,71 & 3,93 & 3,55 & 4,00 & $2,81 * *$ \\
\hline $\begin{array}{l}\text { i) Deuda CP para bajar coste } \\
\text { financiación y subir } \\
\text { rentabilidad }\end{array}$ & 1,920 & $74,2 \%$ & $9,4 \%$ & 1,97 & 1,86 & 2,00 & 2,00 & 2,03 & 1,87 & 1,73 & 2,13 & 2,03 & 1,94 & 1,93 & 1,93 & 1,96 & 1,89 & 2,03 \\
\hline $\begin{array}{l}\text { j) Cada proyecto tiene su } \\
\text { propia política de financiación }\end{array}$ & 2,910 & $41,4 \%$ & $37,5 \%$ & 3,03 & 3,07 & 3,00 & 2,87 & 3,38 & 3,03 & 3,07 & 3,12 & 3,17 & 2,97 & 2,93 & 3,48 & 3,13 & 3,11 & 2,87 \\
\hline
\end{tabular}
propia política de financiación

\begin{tabular}{|c|c|c|c|c|c|c|c|c|c|c|c|c|c|c|c|c|c|c|}
\hline \multirow{2}{*}{ Market Timing Theory } & \multirow{2}{*}{ Media } & \multicolumn{2}{|c|}{ Importancia } & \multicolumn{3}{|c|}{ Deuda } & \multicolumn{3}{|c|}{ Deuda LP } & \multicolumn{3}{|c|}{ Deuda Bancaria } & \multicolumn{3}{|c|}{ Deuda Bancaria de LP } & \multicolumn{3}{|c|}{ Deuda con el grupo } \\
\hline & & Baja & Alta & Baja & Media & Alta & Baja & Media & Alta & Baja & Media & Alta & Baja & Media & Alta & Baja & Media & Alta \\
\hline $\begin{array}{l}\text { a) Disponibilidad y acceso al } \\
\text { endeudamiento }\end{array}$ & 3,560 & $16,9 \%$ & $64,6 \%$ & 3,47 & 3,63 & 3,71 & 3,35 & 3,56 & 3,94 & 3,19 & 3,85 & $3,87^{* * *}$ & 3,28 & 3,61 & 4,06 & 3,75 & 3,78 & $3,33 * * *$ \\
\hline $\begin{array}{l}\text { b) Se recurre a la deuda cuando los } \\
\text { intereses son bajos }\end{array}$ & 2,200 & $62,2 \%$ & $11,0 \%$ & 2,12 & 2,19 & 2,14 & 2,10 & 2,06 & 2,23 & 2,17 & 2,09 & 2,17 & 1,90 & 2,18 & 2,27 & 2,02 & 2,56 & 2,26 \\
\hline $\begin{array}{l}\text { c) Se usa deuda cuando precio } \\
\text { acciones disminuye }\end{array}$ & 1,340 & $92,0 \%$ & $0,8 \%$ & 1,27 & 1,33 & 1,50 & 1,23 & 1,26 & 1,47 & 1,29 & 1,32 & 1,40 & 1,27 & 1,26 & 1,40 & 1,30 & 1,13 & 1,50 \\
\hline $\begin{array}{l}\text { d) Deuda de corto plazo pues } \\
\text { espera bajada tipos de interés }\end{array}$ & 1,810 & $75,2 \%$ & $7,8 \%$ & 1,71 & 1,90 & 1,63 & 1,65 & 2,00 & 1,65 & 1,73 & 1,97 & 1,71 & 1,69 & 2,11 & 1,67 & 1,84 & 1,89 & 1,78 \\
\hline
\end{tabular}


En las figuras 4.37 a 4.40 , de manera agregada, se revisan las cuestiones referidas a nivel de endeudamiento, política de financiación y elección entre deuda de corto y largo plazo entre las principales teorías de estructura de capital analizadas (trade off, pecking order, agencia y market timing). Se realizó una subdivisión de la variable deuda (en diez deciles) a objeto verificar el comportamiento de los factores determinantes del endeudamiento de las empresas según nivel de deuda.

La figura 4.37 relaciona los niveles de deuda con los factores asociadas a la teoría del trade off (TOT). Destaca tan sólo el nivel de importancia atribuida por los directores financieros al factor "se utiliza deuda de largo plazo para evitar los potenciales riesgos de insolvencia financiera y quiebra” (Ipevitaries) muestra cierta tendencia al alza (excepto en el decil 10).

Figura 4.37: Niveles de deuda y variables TOT

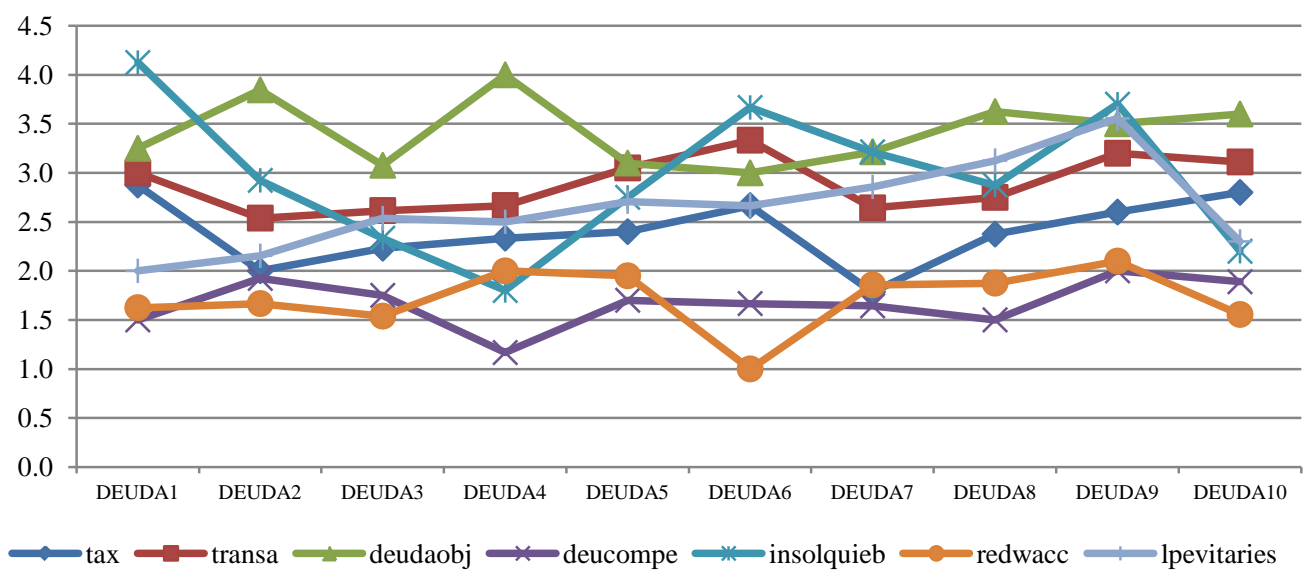

El grupo de factores de la figura 4.38 están relacionados con los factores asociados a la teoría del pecking order (POT). Al igual que en la gráfica anterior, los factores presentan un patrón bastante estable entre los distintos niveles de deuda. Sin embargo, resulta destacable la mayor importancia atribuida a la flexibilidad financiera (flexifin) y a la utilización de deuda cuando se agotan las reservas internas (nofondos), sobre todo en los niveles de deuda intermedia. 
Figura 4.38: Niveles de deuda y variables POT

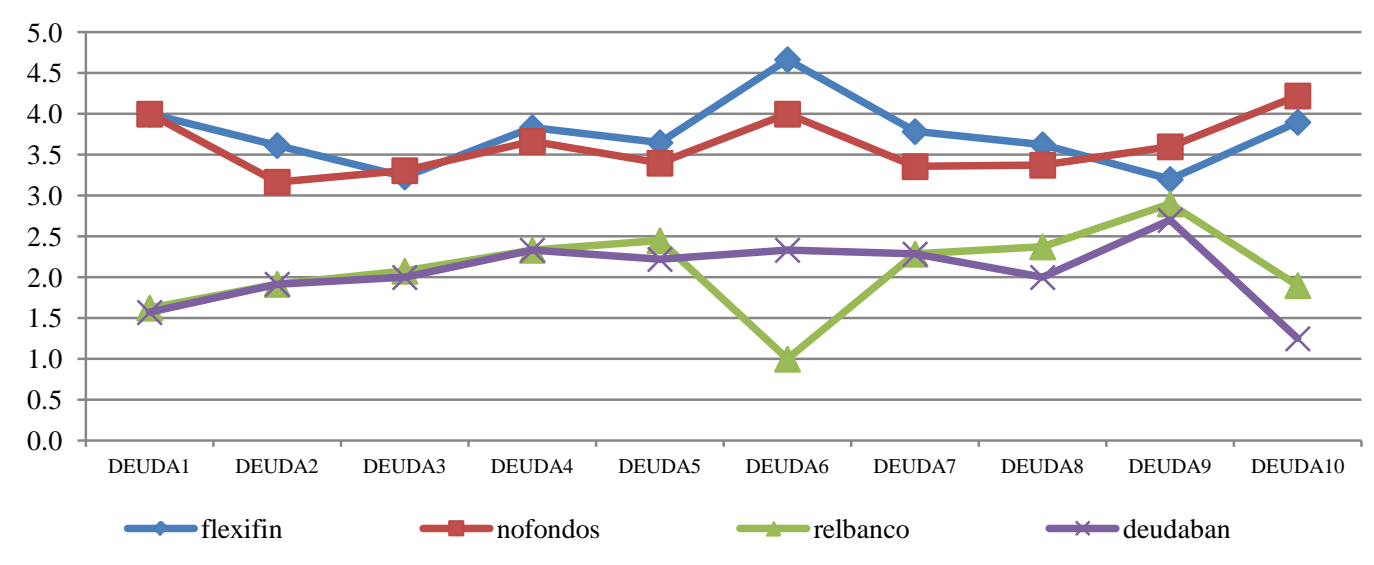

En relación con los factores relativos a la teoría de agencia (AGE) (figura 4.39), se evidencia claramente un grupo de factores de mayor importancia relativa. Prácticamente todos estos factores se relacionan con el emparejamiento de plazos de la vida útil de los activos con el plazo de la deuda de la empresa (tipoinver: tipo de inversión o activos a financiar; vidaeco: vida económica de la inversión a financiar; coincidir: hacer coincidir el plazo de la deuda con la vida útil de los activos; proyprop: cada proyecto cuenta con su propia política de financiación). De manera, adicional, estos mismos factores tienden a tener menor importancia relativa en la medida que los niveles de deuda se corresponden con los deciles intermedios. 
Figura 4.39: Niveles de deuda y variables AGE

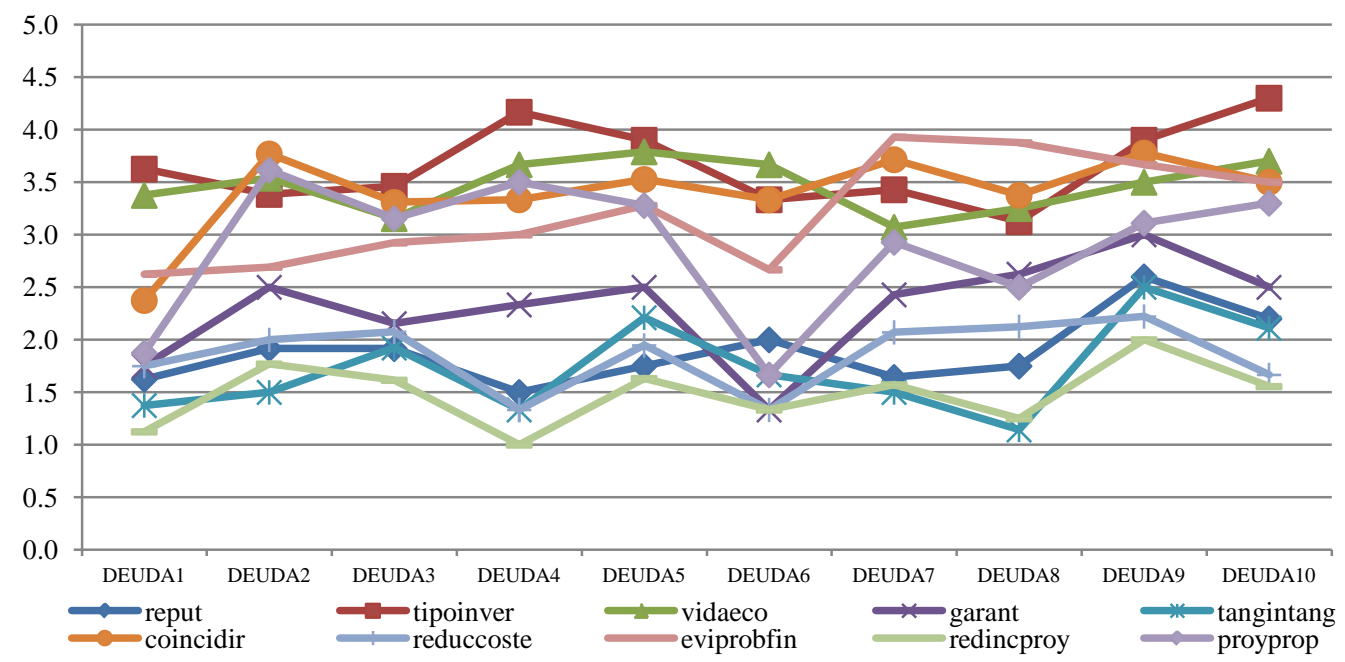

La figura 4.40 relaciona factores vinculados a la teoría del market timing (TIMING) con las categorías de endeudamiento ya señaladas. Esta gráfica no sólo permite ver la mayor importancia relativa del factor "acceso al endeudamiento" (accedeu), sino también que la tendencia seguida por los cuatro factores es bastante homogénea y estable a través de los distintos niveles de endeudamiento.

Figura 4.40: Niveles de deuda y variables TIMING

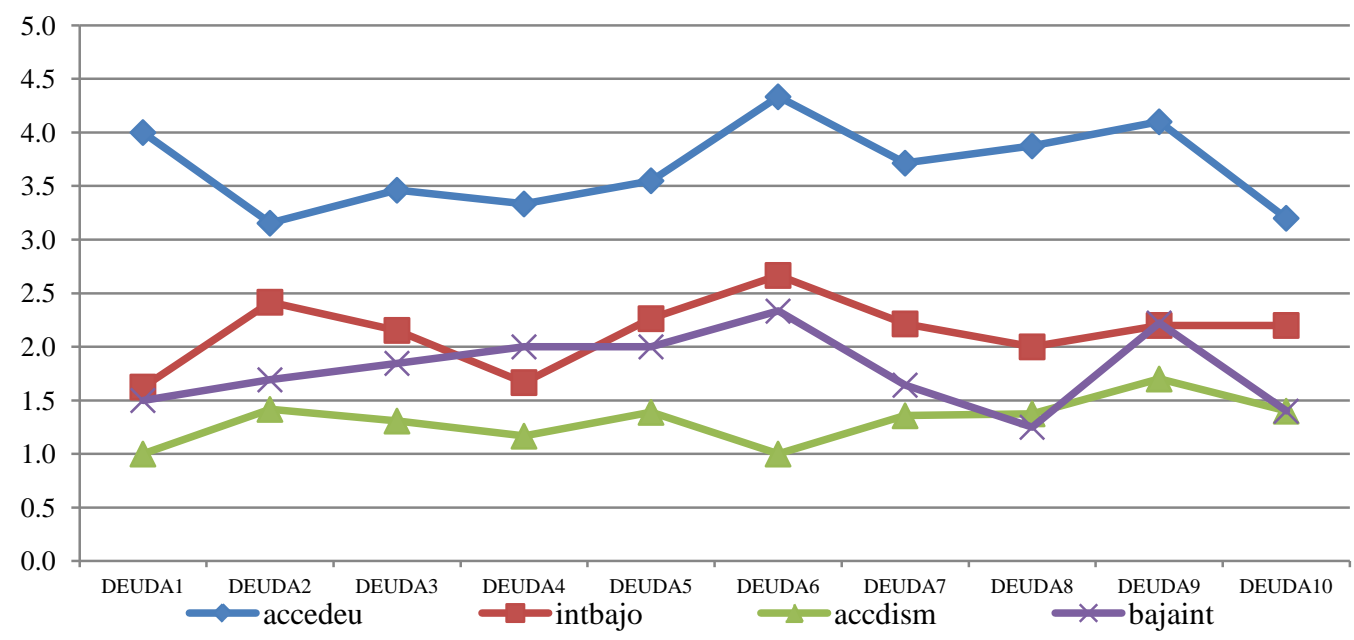


Las figuras 4.41 a 4.45 plantean relaciones parecidas a las de las figuras anteriores, pero en el sentido inverso. Se han caracterizado las teorías de estructura de capital por medio de cinco variables categóricas (flexibilidad financiera, búsqueda de estructura de financiación objetivo, subinversión, sustitución de activos y ventana de oportunidad) y respresentado los distintos tipos de endeudamiento de la empresa (deuda total, deuda de largo, deuda bancaria, deuda bancaria de largo plazo y deuda con el grupo) en quintiles.

La revisión de estas gráficas provee mayor información que las precedentes, pues se observan pautas de comportamiento más marcadas. En primer término la figura 4.41, que relaciona flexibilidad financiera y tipos de deuda, revela que son las empresas que dan nula o poca importancia a la flexibilidad financiera (primer quintil), las que en mayor medida tiene deuda contraída con el grupo, deuda que tendería a tener menor nivel de exigibilidad y menores problemas de asimetrías informativas. De manera contraria, los niveles observados de los otros tipos de endeudamiento son bajos dentro de las empresas que valoran poco este factor.

Este resultado, aunque no concluyente en si mismo, está en línea con la teoría del pecking order, pues permite señalar que son precisamente las empresas menos endeudadas las que menos aprecian la flexibilidad financiera.

Figura 4.41: Flexibilidad financiera y tipos de deuda

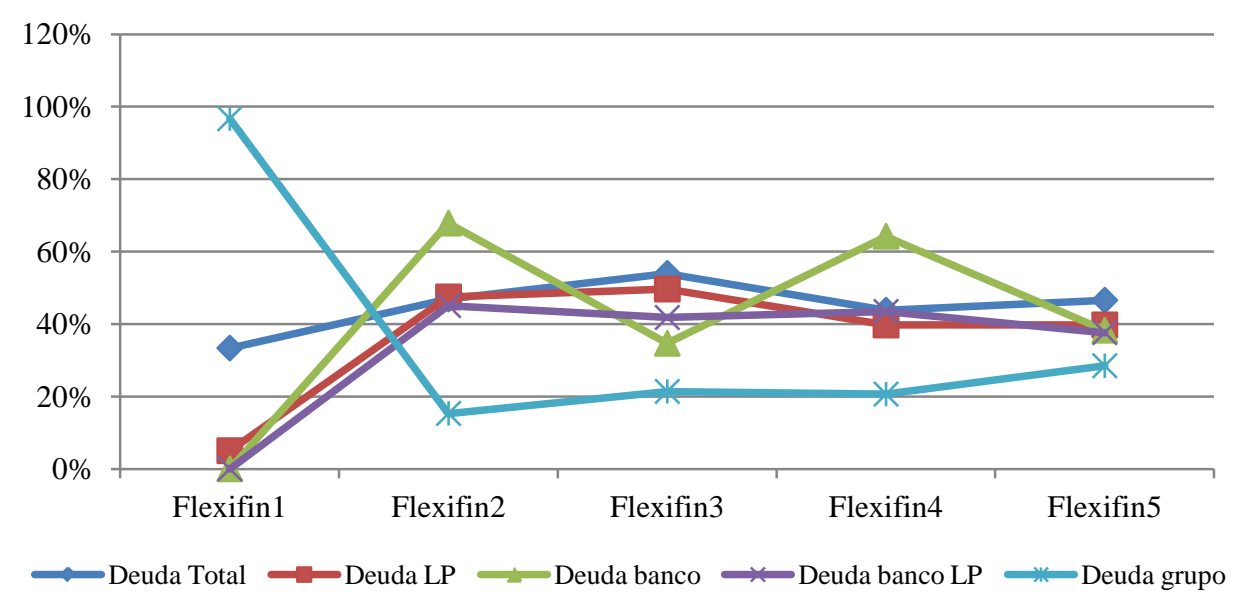


De manera puntual para el segundo quintil de la importancia atribuida a la búsqueda del nivel de deuda objetivo, de la figura 4.42, se observa que la deuda bancaria alcanza su máximo, por una parte, y el endeudamiento con el grupo su mínimo, por otra. Esta figura nos indicaría que las empresas con alta deuda bancaria no se encuentran muy interesados en la búsqueda de un objetivo de deuda y lo mismo ocurre con las empresas de muy bajo nivel de deuda con el grupo.

Figura 4.42: Deuda objetivo y tipos de deuda

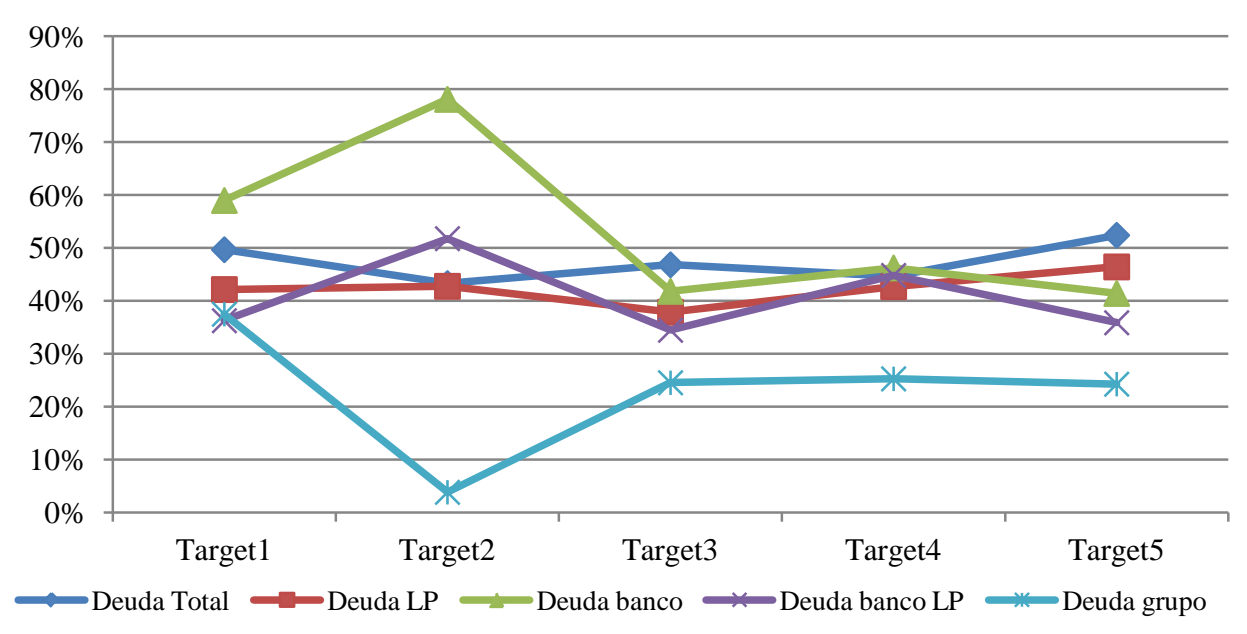

La figura 4.43 relaciona las respuestas a la importancia atribuida por los encuestados a la contratación de deuda de corto plazo para reducir el coste de financiación y así aumentar la rentabilidad de los accionistas. En general, las empresas de los directores que atribuyen alta importancia a la resolución del problema de subinversión por medio de la contratación de deuda de corto plazo se encuentran poco endeudadas. Este problema, que tiene su génesis en la relación de agencia entre accionistas y acreedores, tiene en general mayor relevancia para empresas que tienen mayor proporción de endeudamiento con el grupo. 
Figura 4.43: Problema de subinversión y tipos de deuda

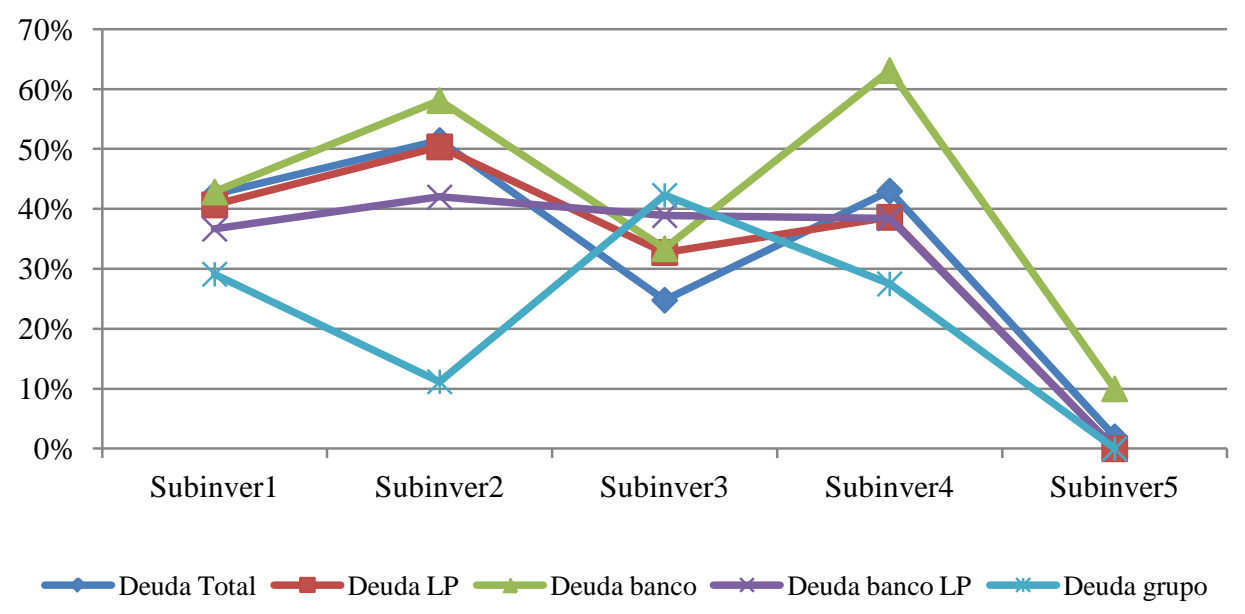

La figura 4.44 verifica la importancia atribuida por los encuestados a la resolución del problema de agencia de sustitución de activos en su relación con los distintos tipos de deuda. Queda patente en la gráfica que a mayor importancia atribuida a la resolución de este problema mayor es el nivel de deuda de la empresa, en sus distintos tipos (salvo en el caso de deuda bancaria). Curiosamente la deuda de largo plazo y la deuda bancaria de largo plazo, que son los tipos deuda que más bajos debieran estar en su relación con este factor, tienen su máximo en el cuarto quintil.

Figura 4.44: Problema de sustitución de activos y tipos de deuda

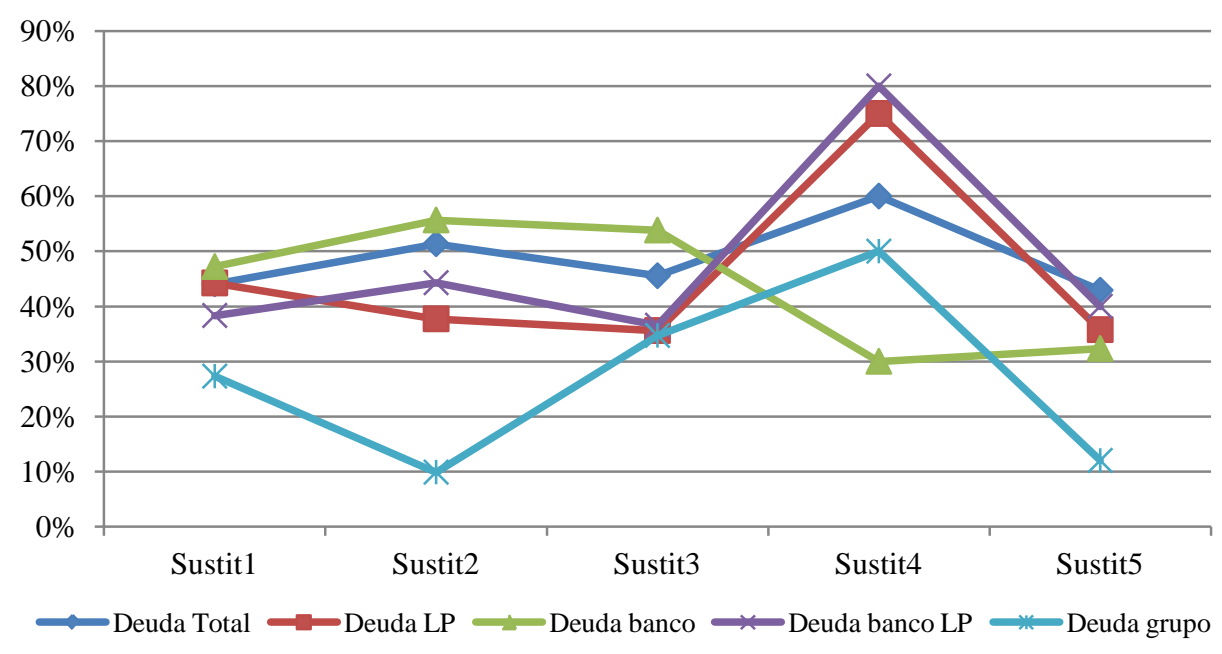


La figura 4.45 muestra los distintos tipos de deuda condicionados a la importancia atribuida a contratación de deuda de corto plazo cuando se espera la bajada de los tipos de interés. La gráfica evidencia una tendencia bastante estable entre los quintiles, salvo alguna excepción en el caso del endeudamiento bancario en el quintil tres.

Figura 4.45: Ventana de oportunidad y tipos de deuda

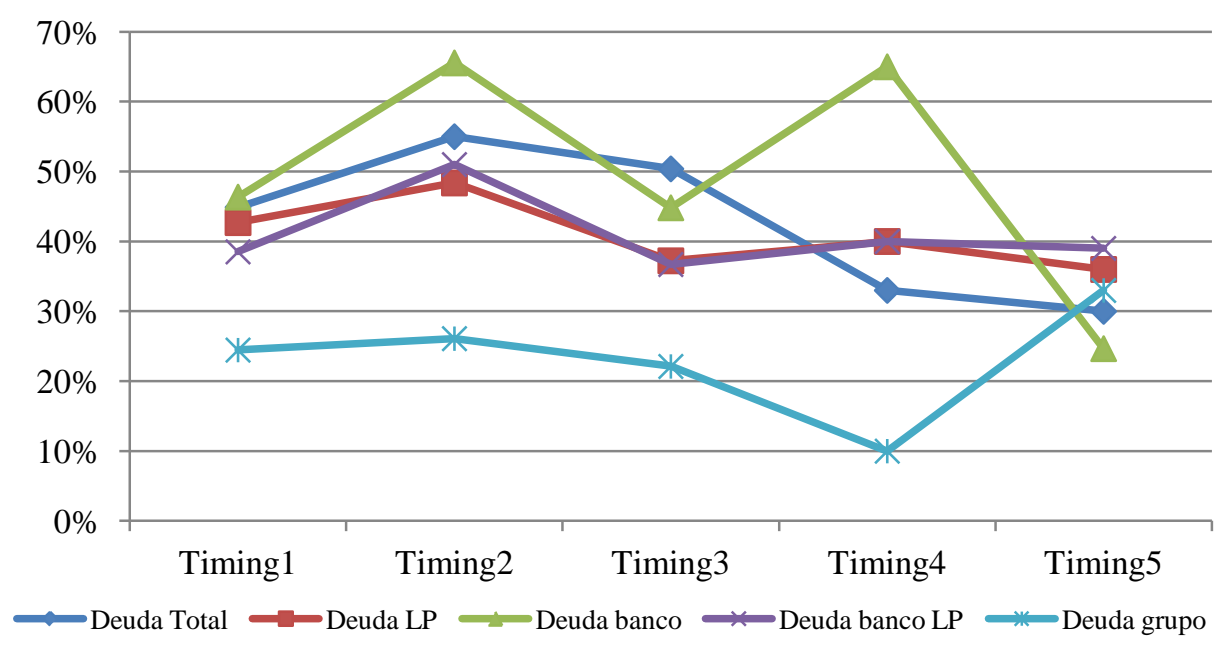

Finalmente, la tabla 4.5 presenta la relación entre las variables representativas de las teorías de estructura de capital. Todas estas variables son de tipo categórica de cinco niveles que reflejan la importancia atribuida por los encuestados a cada una de estas cuestiones. Deudaobj representa la búsqueda de estructura de financiación objetivo; RedWacc se refiere a la contratación de deuda para reducir el coste medio ponderado del capital; Flexifin representa la flexibilidad financiera; Subinver hace referencia a la contratación de deuda de corto plazo para reducir el coste de financiación y así aumentar la rentabilidad de los accionistas; Sustitución indica la contratación de deuda de corto plazo para reducir el incentivo a invertir en proyectos de riesgo elevado; Timing indica la contratación de deuda de corto plazo a la espera de bajos tipos de interés. 
La alta correlación entre deuda objetivo y flexibilidad financiera da cuenta de la disyuntiva antes ya indicada. Primero, puede que las teorías de estructura de capital no compitan entre sí, sino que sean respuestas complementarias a una misma pregunta. Segundo, la alta importancia atribuida a la flexibilidad financiera puede deberse a razones distintas a las que establece el pecking order. Como era de esperar, la correlación más alta se da entre las variables que ponen de manifiesto los problemas de agencia de subinversión y sustitución de activos.

\section{Tabla 4.5: Relación entre variables del patrón de financiación}

La tabla muestra los coeficientes de correlación de las variables categóricas según importancia atribuida, representativas del patrón de financiación, siendo: Deudaobj= Búsqueda de estructura de financiación objetivo; RedWacc=Contratar deuda para reducir coste medio ponderado del capital; Flexifin= Flexibilidad financiera; Subinver $=$ Contratar deuda de corto plazo para reducir coste de financiación y así aumentar rentabilidad accionistas; Sustitución=Contratar deuda de corto plazo para reducir incentivo a invertir en proyectos de riesgo elevado; Timing=Contratar deuda de corto plazo a la espera de bajos tipos de interés.

\begin{tabular}{|c|c|c|c|c|c|c|c|}
\hline & Deudaobj & RedWacc & Flexifin & Subinver & & Sustitución & Timing \\
\hline Deudaobj & 1,0000 & & & & & & \\
\hline RedWacc & $0,2026 * *$ & 1,0000 & & & & & \\
\hline Flexifin & $0,3426 * * *$ & $-0,0234$ & 1,0000 & & & & \\
\hline Subinver & 0,1231 & $0,2047 * *$ & 0,1217 & 1,0000 & & & \\
\hline Sustitución & 0,0404 & $0,3279 * * *$ & $0,1691 *$ & 0,5941 & $* * *$ & 1,0000 & \\
\hline Timing & 0,1011 & $0,1886 * *$ & 0,0912 & 0,3633 & $* * *$ & $0,3805 * * *$ & 1,0000 \\
\hline
\end{tabular}

***, **, * indica significativa al 1\%, 5\% y 10\%, respectivamente. 
CAPÍTULO 4 


\section{CAPÍTULO 5: ANÁLISIS DE RESULTADOS}

$\mathrm{U}$ na vez descrita la evidencia sobre las técnicas y los considerandos utilizados por los directores financieros de las empresas españolas en la adopción de sus decisiones de inversión y financiación, se aborda la contrastación de los modelos especificados en el capítulo 3 para de cada una de las siete hipótesis propuestas en el presente estudio. Este capítulo presenta los principales resultados obtenidos de la estimación de estos modelos y discute las implicaciones derivadas de su análisis.

El capítulo se articula en tres secciones. En la sección 5.1 se ofrece una caracterización estadística de las variables implicadas en el contraste de hipótesis a partir de la información recogida por medio del cuestionario. En las secciones 5.2 y 5.3 son expuestos los resultados del contraste de hipótesis. En la sección 5.2 se presentan los resultados relativos a las hipótesis de la decisión de inversión (hipótesis 1 a 4) y la sección 5.3 ofrece los resultados concernientes a la decisión de financiación (hipótesis 5 a 7).

\subsection{Caracterización estadística de las variables de los modelos}

En el capítulo anterior se ha mostrado el resumen de las respuestas recibidas a las distintas preguntas del cuestionario. A partir de esta información se aproximan las variables implicadas en los modelos e hipótesis a contrastar. La tabla 5.1 
presenta los principales estadísticos descriptivos de las variables independientes y de control ${ }^{41}$.

Las variables se definen de la siguiente forma. La variable tamaño es el logaritmo neperiano de las ventas de las empresas (expresadas en millones de euros). deuda es el cociente de deuda total entre activo total. deudalp es el cociente de deuda a largo plazo entre activo total. invext es una dummy que toma el valor uno si la empresa realiza inversiones en el extranjero y cero en caso contrario. persjur asume el valor uno si la empresa es sociedad anónima y cero cuando es de responsabilidad limitada. industria es una dummy que indica si la empresa pertenece al sector industria o no. servicios es una dummy que indica si la empresa pertenece al sector servicios. bolsa es una dummy que toma el valor uno si la empresa cotiza en bolsa y cero en caso contrario. target es una variable dummy que asume el valor uno cuando la empresa declara establecer un ratio de deuda objetivo y cero en caso contrario. medivalor es una medida categórica ordenada en cinco niveles que indica la frecuencia con la que se estima el valor de la empresa.

La variable propiedad es una dummy que indica si el director financiero participa en la propiedad de la empresa o no. La variable mba es una dummy que toma valor igual a uno si el director financiero tiene un MBA o máster especializado en finanzas y cero en caso contrario. añosexp indica la cantidad de años de experiencia profesional del director financiero. expempr indica la cantidad de años de experiencia en la empresa del director financiero. edad es una variable categórica ordenada en cinco niveles de menor a mayor y que indica la edad del director financiero. impliDI e impliDF son variables categóricas que reflejan la percepción del director financiero respecto de su grado de implicación en las decisiones de inversión y de financiación, respectivamente.

La variable potencia aproxima la frecuencia con que las inversiones pasadas abren nuevas oportunidades futuras. La variable ocenvalor es una variable

${ }^{41}$ La matriz de correlaciones de Pearson de las mismas variables analizadas se encuentra en el Anexo 5.1 
categórica ordenada en cinco niveles según el peso de las oportunidades futuras de inversión en el valor actual de la empresa. Las variables ritmo, inputs, aplazar y modtam aproximan la importancia de la flexibilidad procedente, respectivamente, de la opción de cambiar el ritmo operativo, intercambiar los factores, aplazar la inversión y adaptar su tamaño. flexibilidad es una variable categórica que indica la importancia de la flexibilidad en el proceso de creación de valor de la empresa

Las variables deudaobj, redwacc, flexifin, CPintbajo, sustitución y CPcosterentab son variables categóricas que aproximan la importancia atribuida, respectivamente a: la búsqueda de una estructura de financiación objetivo; la contratación de deuda para reducir el coste medio ponderado del capital; la flexibilidad financiera; la utilización de deuda de corto plazo cuando se espera la bajada de los tipos de interés; la utilización de deuda de corto plazo para reducir el incentivo a invertir en proyectos de riesgo elevado; la contratación de deuda de corto plazo para reducir el coste de financiación y así aumentar el la rentabilidad de los accionistas. 
Tabla 5.1: Estadística descriptiva de las variables independientes y de control

La tabla presenta el número de observaciones (N), la media (media), desviación estándar (dev), mínimo (min), máximo (max) y, en el caso de las variables categóricas, las frecuencias relativas de la muestra.

\begin{tabular}{|c|c|c|c|c|c|c|c|c|c|c|c|c|}
\hline $\mathrm{N}^{\mathrm{o}}$ & Variable & $\mathrm{N}$ & media & desv & $\min$ & $\max$ & 0 & 1 & 2 & 3 & 4 & 5 \\
\hline 1 & tamaño & 135 & 5,5 & 1,5 & 1,1 & 11,2 & - & - & - & - & - & - \\
\hline 2 & deuda & 112 & 0,5 & 0,3 & 0 & 1,1 & - & - & - & - & - & - \\
\hline 3 & deudalp & 100 & 0,2 & 0,2 & 0 & 1,1 & - & - & - & - & - & - \\
\hline 4 & añosexp & 133 & 20,6 & 7,9 & 3,5 & 40 & & & & & & \\
\hline 5 & expempr & 133 & 12,9 & 8,9 & 1 & 39 & & & & & & \\
\hline 6 & expercfo & 133 & 9,5 & 6,3 & 1 & 30 & & & & & & \\
\hline 7 & inverext & 130 & 0,5 & 0,5 & 0 & 1 & $46,9 \%$ & $53,1 \%$ & & & & \\
\hline 8 & persjur & 137 & 0,8 & 0,4 & 0 & 1 & $22,6 \%$ & $77,4 \%$ & & & & \\
\hline 9 & industria & 136 & 0,4 & 0,5 & 0 & 1 & $63,2 \%$ & $36,8 \%$ & & & & \\
\hline 10 & servicios & 136 & 0,3 & 0,5 & 0 & 1 & $67,7 \%$ & $32,3 \%$ & & & & \\
\hline 11 & bolsa & 137 & 0,1 & 0,3 & 0 & 1 & $86,1 \%$ & $13,9 \%$ & - & - & - & - \\
\hline 12 & target & 129 & 0,7 & 0,5 & 0 & 1 & $33,3 \%$ & $66,7 \%$ & & & & \\
\hline 13 & propiedad & 133 & 0,1 & 0,3 & 0 & 1 & $89,5 \%$ & $10,5 \%$ & & & & \\
\hline 14 & consejo & 135 & 0,3 & 0,5 & 0 & 1 & $70,4 \%$ & $29,6 \%$ & & & & \\
\hline 15 & mba & 132 & 0,5 & 0,5 & 0 & 1 & $51,5 \%$ & $48,5 \%$ & - & - & - & - \\
\hline 16 & medivalor & 132 & 1,4 & 1,1 & 0 & 4 & $15,9 \%$ & $55,3 \%$ & $9,9 \%$ & $14,4 \%$ & $4,6 \%$ & - \\
\hline 17 & impliDI & 130 & 3,2 & 0,8 & 1 & 4 & & $3,1 \%$ & $16,9 \%$ & $35,4 \%$ & $44,6 \%$ & \\
\hline 18 & impliDF & 130 & 3,4 & 0,9 & 1 & 4 & & $5,4 \%$ & $8,5 \%$ & $22,3 \%$ & $63,8 \%$ & \\
\hline 19 & edad & 135 & 3,1 & 0,9 & 1 & 5 & & $0,7 \%$ & $25,9 \%$ & $45,2 \%$ & $23,0 \%$ & $5,2 \%$ \\
\hline 20 & potencia & 136 & 3,1 & 1,1 & 1 & 5 & - & $7,4 \%$ & $28,7 \%$ & $21,3 \%$ & $33,1 \%$ & $9,6 \%$ \\
\hline 21 & ocenvalor & 133 & 2,4 & 1,1 & 1 & 5 & & $24,8 \%$ & $30,1 \%$ & $30,8 \%$ & $12,0 \%$ & $2,3 \%$ \\
\hline 22 & ritmo & 139 & 3,7 & 1,0 & 1 & 5 & - & $0,7 \%$ & $12,2 \%$ & $23,7 \%$ & $43,2 \%$ & $20,1 \%$ \\
\hline 23 & inputs & 136 & 3,2 & 1,0 & 1 & 5 & - & $6,6 \%$ & $14,0 \%$ & $45,6 \%$ & $24,3 \%$ & $9,6 \%$ \\
\hline 24 & abandono & 138 & 3,2 & 1,2 & 1 & 5 & - & $8,7 \%$ & $24,6 \%$ & $23,9 \%$ & $27,5 \%$ & $15,2 \%$ \\
\hline 25 & aplazar & 138 & 3,1 & 1,1 & 1 & 5 & - & $6,5 \%$ & $22,5 \%$ & $30,4 \%$ & $31,2 \%$ & $9,4 \%$ \\
\hline 26 & modtam & 139 & 3,6 & 0,9 & 1 & 5 & - & $1,4 \%$ & $8,6 \%$ & $29,5 \%$ & $46,0 \%$ & $14,4 \%$ \\
\hline 27 & flexibilidad & 127 & 3,6 & 0,9 & 1 & 5 & & $0,8 \%$ & $10,3 \%$ & $36,2 \%$ & $35,4 \%$ & $17,3 \%$ \\
\hline 28 & deudaobj & 129 & 3,4 & 1,2 & 1 & 5 & & $10,8 \%$ & $10,8 \%$ & $25,6 \%$ & $35,7 \%$ & $17,1 \%$ \\
\hline 29 & redwacc & 126 & 1,8 & 1,0 & 1 & 5 & & $55,6 \%$ & $21,4 \%$ & $17,4 \%$ & $3,2 \%$ & $2,4 \%$ \\
\hline 30 & flexifin & 130 & 3,6 & 1,1 & 1 & 5 & & $4,6 \%$ & $11,6 \%$ & $26,9 \%$ & $31,5 \%$ & $25,4 \%$ \\
\hline 31 & CPintbajo & 129 & 1,8 & 1,0 & 1 & 5 & & $54,3 \%$ & $20,9 \%$ & $17,1 \%$ & $5,4 \%$ & $2,3 \%$ \\
\hline 32 & sustitución & 127 & 1,5 & 0,8 & 1 & 4 & & $63,8 \%$ & $22,0 \%$ & $11,8 \%$ & $2,4 \%$ & $0 \%$ \\
\hline 33 & CPcosterent & 128 & 1,9 & 1,0 & 1 & 5 & & $43,7 \%$ & $30,5 \%$ & $16,4 \%$ & $8,6 \%$ & $0,8 \%$ \\
\hline
\end{tabular}




\subsection{Las técnicas selección de inversiones}

En el capítulo anterior se describió la frecuencia de uso de las distintas técnicas de selección de inversiones consideradas. La tabla 5.2 muestra la relación entre la frecuencia de uso declarada y las características generales de las empresas. Destaca la influencia del tamaño de la empresa, que incrementa la frecuencia de uso de todas las técnicas excepto las opciones reales. Cuanto mayor es el tamaño de la empresa mayor es la propensión a aplicar VAN, TIR, análisis de sensibilidad, modelos de simulación e, incluso, payback. Graham y Harvey (2001) y Brounen et al. (2004) observan también que las empresas de mayor tamaño utilizan más el VAN, TIR y análisis de sensibilidad. Payne et al. (1999) y Hermes et al. (2007) encuentran evidencia de que las empresas de mayor tamaño aplican el VAN con mayor frecuencia mientras que Moore y Reichert (1983) y Baker et al. (2011a) aportan testimonio similar para el caso de la TIR. Sin embargo, nuestros resultados se distancian de la literatura empírica previa en la relación entre tamaño y payback. En Graham y Harvey (2001) y Hermes et al. (2007) las empresas de mayor tamaño son las que menos utilizan el criterio del payback, mientras que nuestros resultados indican la relación inversa.

La pertenencia al sector de actividad parece influir en el mayor uso de algunas técnicas. Es el caso del mayor uso del payback en los sectores industriales, de la TIR y el análisis de sensibilidad en el sector inmobiliario y la simulación en el sector consumo. La comparación de la personalidad jurídica revela que las empresas que revisten la forma de Sociedad Anónima son más proclives a utilizar el VAN y la TIR. Los resultados de nuestro análisis muestran que las técnicas del VAN, TIR, payback y análisis de sensibilidad son utilizados con mayor frecuencia por las compañías que invierten en el exterior. Graham y Harvey (2001) también encuentran que las empresas con ventas en el extranjero recurren en mayor medida al uso del VAN y la TIR y Hermes et al. (2007) observa que éstas compañías son precisamente las que tienden a utilizar en menor medida el payback. 
Tabla 5.2: Influencia de las características de la empresa sobre la técnica utilizada

La tabla presenta los coeficientes estimados mediante regresiones univariantes tipo probit ordenado en las que se relaciona la frecuencia de uso de cada una de las técnicas con distintas variables representativas de las características de la empresa. Debajo de cada coeficiente, en cursiva, se muestra el pseudo R2. Las variables independientes se definen de la siguiente forma. La variable tamaño es el logaritmo neperiano de las ventas (en millones). Las variables de sector son dummies que indican la pertenencia a uno de los seis sectores considerados: energía, industria, consumo, servicios, inmobiliario y telecomunicación. La variable persjur es una dummy que adopta el valor uno si la empresa es Sociedad Anónima y cero en otro caso. La variable invext es una dummy que toma valor uno si la empresa invierte en el exterior y cero en caso contrario.

\begin{tabular}{|c|c|c|c|c|c|c|}
\hline & VAN & TIR & PB & OR & SIMUL & ASENSI \\
\hline \multirow[t]{2}{*}{ tamaño } & $0,243 * * *$ & $0,213^{* * *}$ & $0,235^{* * *}$ & 0,028 & $0,153 * *$ & $0,225 * * *$ \\
\hline & 0,0326 & 0,0263 & 0,0341 & 0,0005 & 0,0144 & 0,0279 \\
\hline \multirow[t]{2}{*}{ energía } & $-0,180$ & $-0,214$ & 0,245 & $-0,083$ & 0,340 & 0,170 \\
\hline & 0,0007 & 0,0012 & 0,0014 & 0,0002 & 0,0027 & 0,0007 \\
\hline \multirow[t]{2}{*}{ industria } & 0,016 & 0,085 & $0,435 * *$ & 0,136 & $-0,052$ & $-0,212$ \\
\hline & 0,0000 & 0,0005 & 0,0132 & 0,0013 & 0,0002 & 0,0030 \\
\hline \multirow[t]{2}{*}{ consumo } & 0,038 & $-0,088$ & 0,293 & $-0,273$ & $0,445^{*}$ & 0,162 \\
\hline & 0,0001 & 0,0003 & 0,0032 & 0,0026 & 0,0067 & 0,0009 \\
\hline \multirow[t]{2}{*}{ servicios } & $-0,209$ & $-0,195$ & $-0,539 * * *$ & $-0,189$ & $-0,380 *$ & $-0,138$ \\
\hline & 0,0029 & 0,0027 & 0,0203 & 0,0024 & 0,0089 & 0,0012 \\
\hline \multirow[t]{2}{*}{ inmobiliario } & 0,813* & $1,082 *$ & $-0,781^{* *}$ & 0,711 & 0,114 & $0,735^{*}$ \\
\hline & 0,0087 & 0,0120 & 0,0110 & 0,0066 & 0,0002 & 0,0080 \\
\hline \multirow[t]{2}{*}{ telecomunicación } & 4,975 & 4,7510 & 4,917 & 1,042 & 0,578 & 0,501 \\
\hline & 0,0079 & 0,0074 & 0,0079 & 0,0056 & 0,0013 & 0,0010 \\
\hline \multirow[t]{2}{*}{ persjur } & $0,442 * *$ & $0,523 * *$ & 0,283 & 0,329 & 0,185 & 0,263 \\
\hline & 0,0105 & 0,0154 & 0,0045 & 0,0054 & 0,0017 & 0,0035 \\
\hline \multirow[t]{2}{*}{ invext } & $0,330 *$ & $0,434 * *$ & $0,349 *$ & 0,193 & 0,310 & $0,373 * *$ \\
\hline & 0,0080 & 0,0144 & 0,0094 & 0,0027 & 0,0067 & 0,0098 \\
\hline
\end{tabular}

*** indica significativo al 1\%, ** al 5\% y * al 10\%. 
Los resultados del análisis de la influencia de las características del director financiero se presentan en la tabla 5.3. En términos generales, estos datos indican que la frecuencia de uso de las técnicas no depende del perfil del director financiero. Entre las variables analizadas, destaca la implicación en las decisiones de inversión, que influye positivamente en la frecuencia de uso de cinco de las seis técnicas analizadas (de nuevo la excepción es el modelo de las opciones reales). Este resultado se contrapone con la relación positiva encontrada por Rayo et al. (2007) entre implicación y uso de las opciones reales. La tabla 5.3 indica que el análisis de sensibilidad es menos utilizado por quienes tienen más años de experiencia en la empresa y más utilizado por quienes poseen un MBA o máster de especialidad en finanzas. Graham y Harvey (2001) encuentran que los directivos con mayor experiencia utilizan en menor medida el VAN y la TIR y en mayor medida el payback. Por lo que se refiere a la formación del director financiero, algunos trabajos previos muestran que la posesión de un MBA propicia el uso de los modelos de descuento de flujos (Graham y Harvey, 2001; Brounen et al., 2004; Hermes et al., 2007) y del análisis de sensibilidad (Brounen et al., 2004; Chazi et al., 2010). Finalmente, nuestros datos no permiten confirmar la evidencia previa relativa al mayor uso del payback y las opciones reales (Graham y Harvey, 2001) y el VAN (Hermes et al., 2007) por parte de los directores financieros de mayor edad. 


\section{Tabla 5.3: Influencia de las características del director financiero sobre la técnica utilizada}

La tabla presenta los coeficientes estimados mediante regresiones univariantes tipo probit ordenado en las que se relaciona la frecuencia de uso de cada una de las técnicas con distintas variables representativas del director financiero. Debajo de cada coeficiente, en cursiva, se muestra el pseudo R2. Las variables independientes se definen de la siguiente forma. La variable edad es una variable categórica ordenada en cinco niveles. Las variables añosexp, experemp y expercfo indican, respectivamente, el número de años de experiencia laboral, en la empresa y en el cargo de director financiero. La variable $m b a$ es una dummy que toma valor igual a uno si el director financiero tiene un MBA o máster especializado en finanzas y cero en caso contrario. La variable consejo es una dummy que toma valor uno si el director financiero es miembro del Consejo de Administración y cero en caso contrario. Finalmente, la variable impliDI es una variable categórica ordenada en cuatro niveles que mide el grado de implicación del director financiero en las decisiones de inversión de la empresa.

\begin{tabular}{lcccccc}
\hline \multirow{2}{*}{ edad } & VAN & TIR & PB & OR & SIMUL & ASENSI \\
& $-0,599$ & 0,018 & 0,166 & $-0,084$ & 0,034 & $-0,039$ \\
\cline { 2 - 2 } & 0,0008 & 0,0000 & 0,0062 & 0,0015 & 0,0002 & 0,0003 \\
\hline \multirow{2}{*}{ experemp } & $-0,003$ & 0,001 & 0,014 & $-0,002$ & $-0,001$ & $-0,007$ \\
& 0,0002 & 0,0000 & 0,0040 & 0,0001 & 0,0000 & 0,0008 \\
\hline \multirow{2}{*}{ expercfo } & $-0,006$ & $-0,002$ & 0,004 & $-0,011$ & $-0,004$ & $-0,022^{* *}$ \\
& 0,0009 & 0,0001 & 0,0004 & 0,0027 & 0,0003 & 0,0109 \\
\hline \multirow{2}{*}{ mba } & $-0,013$ & $-0,017$ & 0,000 & $-0,004$ & $-0,009$ & $-0,011$ \\
& 0,0022 & 0,0039 & 0,0000 & 0,0001 & 0,0010 & 0,0013 \\
\hline \multirow{2}{*}{ consejo } & 0,261 & 0,218 & 0,250 & $-0,063$ & 0,230 & $0,520 * * *$ \\
& 0,0050 & 0,0037 & 0,0048 & 0,0003 & 0,0037 & 0,0190 \\
\hline impliDI & $-0,110$ & $-0,031$ & 0,245 & 0,264 & 0,077 & 0,037 \\
& 0,0008 & 0,0001 & 0,0038 & 0,0043 & 0,0004 & 0,0001 \\
\hline
\end{tabular}

*** indica significativo al 1\%, ** al $5 \% \mathrm{y} *$ al $10 \%$. 
La tabla 5.4 presenta los resultados de la estimación del modelo (1), que permite contrastar de forma conjunta la influencia de las características de la empresa y del director financiero sobre la frecuencia de uso de las técnicas de selección de inversiones (hipótesis 1). Para cada técnica se muestran los resultados de dos especificaciones diferentes del modelo, atendiendo al carácter complementario de las variables y su correlación estadística ${ }^{42}$. En el modelo M1.1, las características de la empresa se aproximan por medio de las variables tamaño (que aproxima el tamaño de la empresa por medio del logaritmo neperiano de las ventas, en millones), industria (dummy indicativa si la empresa pertenece al sector económico industria) y persjur (dummy indicativa si la empresa es una sociedad anónima o sociedad de responsabilidad limitada). Las variables que caracterizan al director financiero son edad (variable categórica, ordenada de menor a mayor en cinco niveles de edad), mba (dummy que indica si el director financiero tiene un MBA o máster de especialidad en finanzas) e ImpliDI (variable categórica indicativa de la percepción del director financiero acerca de su implicación en las decisiones de inversión de la empresa). En el modelo M1.2, se intercambia la pertenencia al sector industria (industria) por la pertenencia al sector servicios (servicios), así como edad por añosexper (variable que indica la cantidad de años de experiencia laboral del director financiero).

42 Esta lógica, complementariedad y correlación estadística, se replica también en todas las siguientes estimaciones. 
Tabla 5.4: Técnicas de selección de inversiones y características de la empresa y del director financiero

La tabla presenta los coeficientes estimados mediante regresiones multivariantes tipo probit ordenado del modelo 1, con el que se relaciona la frecuencia de uso de cada una de las siete técnicas y distintas medidas de las características de la empresa y del director financiero. Las variables aproximativas son: tamaño que es el logaritmo neperiano de las ventas. industria y servicios son dummies indicativas que la empresa pertenece al sector de referencia. persjur es una dummy que indica si la empresa es sociedad anónima $(d u m=1)$ o de responsabilidad limitada $(d u m=0)$. edad es una variable categórica que indica los años de edad del director financiero. añosexp es una variable que indica los años de experiencia del director financiero. mba es una dummy que indica si el director financiero tiene un MBA o máster en finanzas. impliDI es una variable categórica representativa de la implicación del director financiero en las decisiones de inversión. Debajo de cada coeficiente, entre paréntesis, se muestra el error estándar.

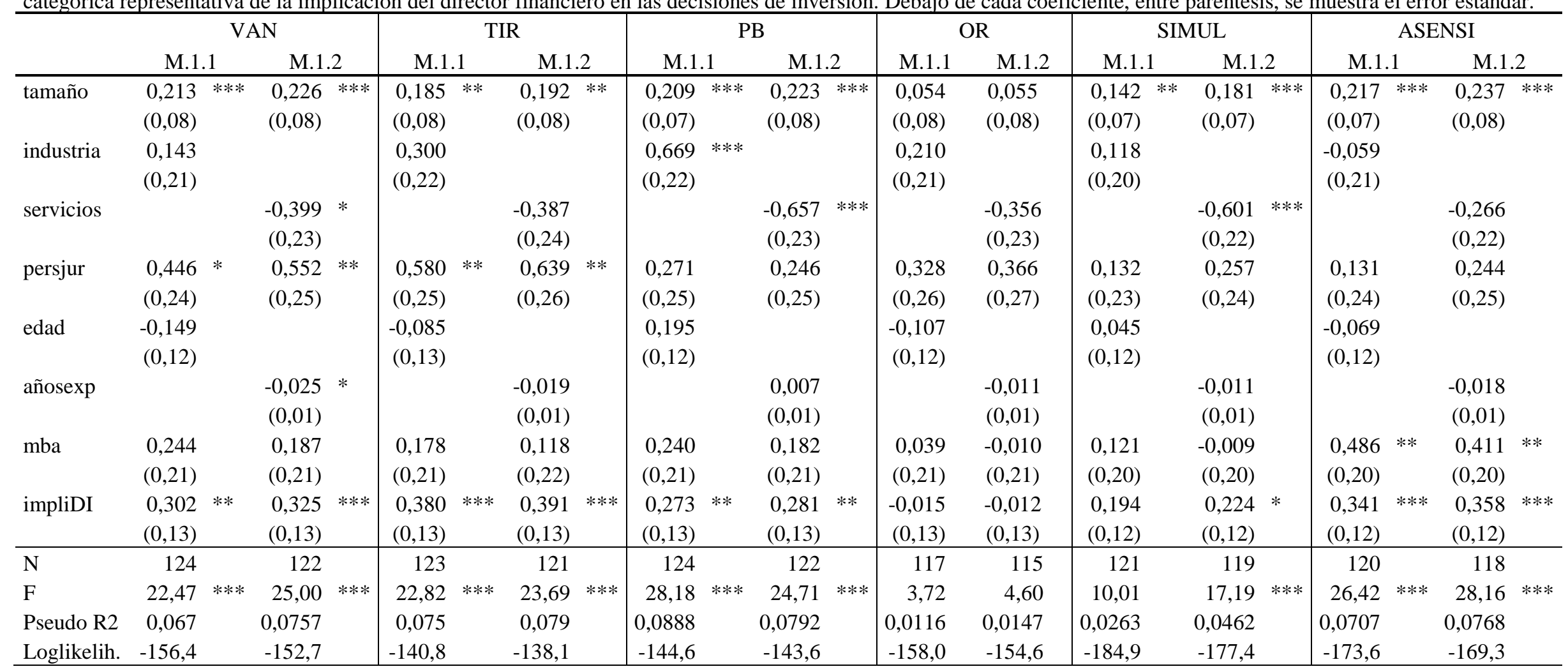

*** indica significativo al $1 \%, * *$ al $5 \% \mathrm{y} *$ al $10 \%$ 
Los resultados indican que el tamaño de la empresa es un factor altamente determinante (con una relación positiva y estadísticamente significativa) de la mayor utilización de las técnicas de selección de inversiones. Este resultado, sin embargo, no es aplicable al caso de las opciones reales, donde la utilización del método es independiente (estadísticamente) de la dimensión empresarial. Parte de este resultado se corrobora, por ejemplo, en Graham y Harvey (2001), donde las empresas más pequeñas utilizan menos frecuentemente el VAN.

Al igual que anteriores trabajos, una medida del riesgo al que se enfrenta la empresa es aproximada a partir del sector de actividad en el que opera. Los resultados indican que las empresas que pertenecen al sector industria usan en mayor medida el payback y las empresas del sector servicios lo utilizan menos (aunque también tienden a utilizar menos el VAN). El resultado es coherente con lo evidenciado en otros países y en cierto modo apoya el que se desprende de la hipótesis 1. Respecto de la formación del directivo financiero, los resultados indican cierta relación con la frecuencia de uso del análisis de sensibilidad. En el resto de técnicas, no se evidencia relación estadísticamente significativa.

Finalmente, cabe destacar que la implicación del directivo financiero en las decisiones de inversión de la empresa está relacionado significativamente con el mayor uso de cuatro de las técnicas propuestas. Este resultado está en línea con Rayo et al. (2007), quienes argumentan que la mayor implicación directiva lleva a un mayor conocimiento de las técnicas y, como consecuencia de ello, a una mayor utilización. Sin embargo, no encontramos que la mayor implicación directiva favorezca el mayor uso de las técnicas más sofisticadas (opciones reales y modelos de simulación), sino sólo reafirma la mayor utilización de las técnicas tradicionales y del análisis de sensibilidad.

Estos resultados son parcialmente favorables a lo esgrimido en la hipótesis 1, en lo que concierne a que las características empresariales y la implicación directiva influyen en la frecuencia de uso de las técnicas.

La tabla 5.5 presenta los resultados de la estimación del modelo (2), que sirve para contrastar la influencia de los mecanismos de disciplina sobre la frecuencia 
de uso de las técnicas (hipótesis 2). Han sido formulados dos alternativas de modelo. En el modelo M2.1, los mecanismos de disciplina son aproximados mediante la variable que mide el endeudamiento a largo plazo (deudalp) y la variable indicativa de la frecuencia con la que se estima el valor de la empresa (medivalor). En el modelo M2.2, esta última variable es reemplazada por la dummy que recoge si el director financiero participa en la propiedad de la empresa (propiedad). Además, se incluyen dos variables de control tamaño y mba indicativas de la dimensión de la empresa y de la formación del directivo. 


\section{Tabla 5.5: Técnica de selección de inversiones y mecanismos de disciplina}

La tabla presenta los coeficientes estimados mediante regresiones multivariantes tipo probit ordenado del modelo 2, con el que se relaciona la frecuencia de uso de cada una de las seis técnicas y distintas medidas de los mecanismos de disciplina, junto con las variables de mba y tamaño. Debajo de cada coeficiente, entre paréntesis, se muestra el error estándar. Los mecanismos de disciplina se aproximan de la siguiente forma. La variable deudalp es el cociente de deuda a largo plazo entre activo total. La variable medivalor es una medida categórica ordenada en cinco niveles que indica la frecuencia con la que se estima el valor de la empresa. La variable propiedad es una dummy que toma el valor uno cuando el director financiero participa en el accionariado y cero en caso contrario.

\begin{tabular}{|c|c|c|c|c|c|c|c|c|c|c|c|c|c|c|c|}
\hline \multirow[b]{3}{*}{ tamaño } & \multicolumn{2}{|c|}{ VAN } & \multicolumn{2}{|c|}{ TIR } & \multicolumn{3}{|c|}{ PB } & \multicolumn{2}{|r|}{ OR } & \multicolumn{2}{|c|}{ SIMUL } & \multicolumn{4}{|c|}{ ASENSI } \\
\hline & M2.1 & M2.2 & M2.1 & M2.2 & \multicolumn{2}{|l|}{ M2.1 } & M2.2 & \multirow{2}{*}{$\begin{array}{c}\text { M2.1 } \\
0,091\end{array}$} & \multirow{2}{*}{$\begin{array}{l}\text { M2.2 } \\
0,079\end{array}$} & \multirow{2}{*}{$\begin{array}{r}\text { M2.1 } \\
0,123\end{array}$} & \multirow{2}{*}{$\begin{array}{c}\text { M2.2 } \\
0,123\end{array}$} & \multicolumn{2}{|l|}{ M2.1 } & \multicolumn{2}{|c|}{ M2.2 } \\
\hline & $0,228 * * *$ & $0,220 * *$ & $0,194 * *$ & $0,185 * *$ & 0,203 & $* *$ & $0,195 * *$ & & & & & 0,202 & $* *$ & 0,203 & $* *$ \\
\hline & $(0,09)$ & $(0,09)$ & $(0,09)$ & $(0,09)$ & $(0,09)$ & & $(0,08)$ & $(0,09)$ & $(0,09)$ & $(0,08)$ & $(0,08)$ & $(0,08)$ & & $(0,08)$ & \\
\hline \multirow[t]{2}{*}{ mba } & 0,345 & 0,292 & 0,214 & 0,135 & 0,486 & $* *$ & 0,386 & 0,205 & 0,048 & 0,062 & 0,002 & 0,479 & $* *$ & 0,479 & $* *$ \\
\hline & $(0,25)$ & $(0,24)$ & $(0,25)$ & $(0,25)$ & $(0,247)$ & & $(0,24)$ & $(0,25)$ & $(0,24)$ & $(0,23)$ & $(0,23)$ & $(0,23)$ & & $(0,23)$ & \\
\hline \multirow[t]{2}{*}{ deudalp } & $-0,073$ & $-0,052$ & 0,164 & 0,195 & $-0,745$ & & $-0,686$ & 0,526 & 0,521 & $-0,120$ & $-0,102$ & 0,307 & & 0,292 & \\
\hline & $(0,52)$ & $(0,52)$ & $(0,52)$ & $(0,52)$ & $(0,53)$ & & $(0,52)$ & $(0,52)$ & $(0,52)$ & $(0,51)$ & $(0,51)$ & $(0,51)$ & & $(0,51)$ & \\
\hline \multirow[t]{2}{*}{ medivalor } & 0,039 & & 0,060 & & 0,154 & & & 0,299 & $* *$ & $0,209 *$ & & $-0,004$ & & & \\
\hline & $(0,11)$ & & $(0,12)$ & & $(0,12)$ & & & $(0,12)$ & & $(0,11)$ & & $(0,11)$ & & & \\
\hline \multirow[t]{2}{*}{ propiedad } & & 0,076 & & 0,241 & & & 0,025 & & 0,389 & & 0,242 & & & 0,363 & \\
\hline & & $(0,37)$ & & $(0,39)$ & & & $(0,36)$ & & $(0,34)$ & & $(0,34)$ & & & $(0,35)$ & \\
\hline $\mathrm{N}$ & 95 & 96 & 94 & 95 & 95 & & 96 & 89 & 90 & 93 & 94 & 93 & & 94 & \\
\hline LR chi2 & $8,88 *$ & $8,17 *$ & 5,74 & 5,45 & 12,32 & $* *$ & $9,80 * *$ & 8,45 & 5,44 & 6,19 & 3,60 & 10,51 & $* *$ & 12,66 & $* *$ \\
\hline Pseudo R2 & 0,035 & 0,032 & 0,025 & 0,023 & 0,05 & & 0,040 & 0,0335 & 0,021 & 0,0215 & 0,012 & 0,0369 & & 0,044 & \\
\hline Log likelihood & $-122,50$ & $-123,53$ & $-113,89$ & $-114,64$ & $-117,23$ & & $-119,19$ & $-121,856$ & $-124,26$ & $-140,84$ & $-144,33$ & $-137,16$ & & $-138,48$ & \\
\hline
\end{tabular}

*** indica significativo al 1\%, ** al 5\% y * al 10\%. 
Los resultados de la estimación indican que, de entre los mecanismos de disciplina examinados, únicamente la variable que mide si la empresa supervisa la evolución de su valor de mercado, medivalor, presenta cierta significación estadística. Concretamente, los resultados muestran que esta variable propicia el uso de las opciones reales y los modelos de simulación, que son precisamente las dos técnicas cuya frecuencia de empleo es independiente del tamaño de la empresa. En la literatura previa, Graham y Harvey (2001) encuentran que el endeudamiento favorece el uso de las técnicas VAN, TIR y análisis de sensibilidad, mientras que la propiedad del CFO propicia el empleo del payback y desincentiva la aplicación de VAN y TIR. Por el contrario, nuestros resultados indican que ni el endeudamiento a largo plazo ni la participación del director financiero en el accionariado influyen significativamente en la frecuencia de empleo de ninguno de las seis técnicas.

Por lo demás, los resultados de la tabla 5.5 corroboran los resultados previos sobre la utilización más frecuente de las técnicas del VAN, TIR, payback y análisis de sensibilidad por parte de las empresas de mayor tamaño. Adicionalmente, los coeficientes estimados de la variable mba sugieren que la formación superior especializada favorece la utilización del payback y el análisis de sensibilidad. La relación entre la formación y el uso del payback aunque sorprendente, viene a confirmar los resultados del contraste de medias obtenido por Brounen et al. (2004) para las empresas del Reino Unido; mientras que la influencia sobre el empleo del análisis de sensibilidad apoya los resultados obtenidos en ese mismo trabajo para las empresas alemanas.

La hipótesis 2 encuentra cierto respaldo en lo que atañe a uno de los mecanismos de disciplina considerados (el caso de aquellas empresas que con mayor frecuencia realizan el ejercicio de valorar la compañía) y su influencia sobre el mayor uso de las técnicas de opciones reales y modelos de simulación.

La tabla 5.6 permite evaluar el poder explicativo de la hipótesis 3, En esta tabla se presentan los coeficientes estimados del modelo 3 para distintas variables aproximativas de las fuentes de valor de la inversión de la empresa. Las variables 
son potencia, que mide la frecuencia con la que las inversiones de la empresa abren futuras oportunidades de inversión, e inputs, aplazar y modtam que aproximan respectivamente la importancia de la flexibilidad de los proyectos que procede de las opciones de intercambiar los factores de producción, aplazar su iniciación y modificar su tamaño.

La variable potencia se muestra estadísticamente significativa para explicar la aplicación de los modelos de opciones reales. Como era de esperar, cuanto mayor es la potencia de las inversiones de la empresa, mayor es la frecuencia de uso de las opciones reales, que teóricamente es el enfoque más apropiado para estimar esta fuente de valor. La potencia de las inversiones también parece propiciar el uso del payback y, en menor medida, de los modelos de simulación, en una de las dos especificaciones del modelo estimado. La relación entre payback y las opciones de crecimiento encaja en los argumentos esgrimidos por McDonald (2000) sobre la "razonable” utilización de los métodos de "la cuenta de la vieja” (“rules of thumb") para aproximar el valor de las opciones reales. Alkaraan y Northcott (2006) comparan la utilización del VAN, TIR y payback según la naturaleza estratégica de las inversiones y encuentran relación entre proyectos estratégicos y el mayor uso de la TIR.

Del resto de variables que aproximan las opciones de flexibilidad, las variables modtam y aplazar, que miden respectivamente la relevancia de las opciones de ampliación/reducción y de aplazamiento de la inversión, también inciden en el mayor uso de los modelos de opciones reales. La tabla 5.6 indica además que, junto con las opciones reales, los directores financieros recurren al modelo de simulación para capturar el valor de la opción de modificación del tamaño de la inversión. Menos fácil de justificar resulta la mayor frecuencia de uso del VAN, TIR y payback en aquellas empresas que mayor relevancia dan a la opción de intercambio de inputs y del VAN, TIR y análisis de sensibilidad en los casos de mayor relevancia de las opciones de aplazamiento. 


\section{Tabla 5.7: Técnica de selección de inversiones y fuentes de valor}

La tabla presenta los coeficientes estimados mediante regresiones multivariantes tipo probit ordenado del modelo 3, con el que se relaciona la frecuencia de uso de cada una de las técnicas con la potencia y flexibilidad de las inversiones, junto con las variables de tamaño y mba. Las medidas de las fuentes de valor son todas variables categóricas ordenadas en cinco niveles que se definen de la siguiente forma. La variable potencia aproxima la frecuencia con que las inversiones pasadas abren oportunidades futuras. Las variables inputs, aplazar y modtam aproximan la importancia de la flexibilidad procedente de la opción de intercambiar los factores, aplazar la inversión y adaptar su tamaño. Debajo de cada coeficiente, entre paréntesis, se muestra el error estándar.

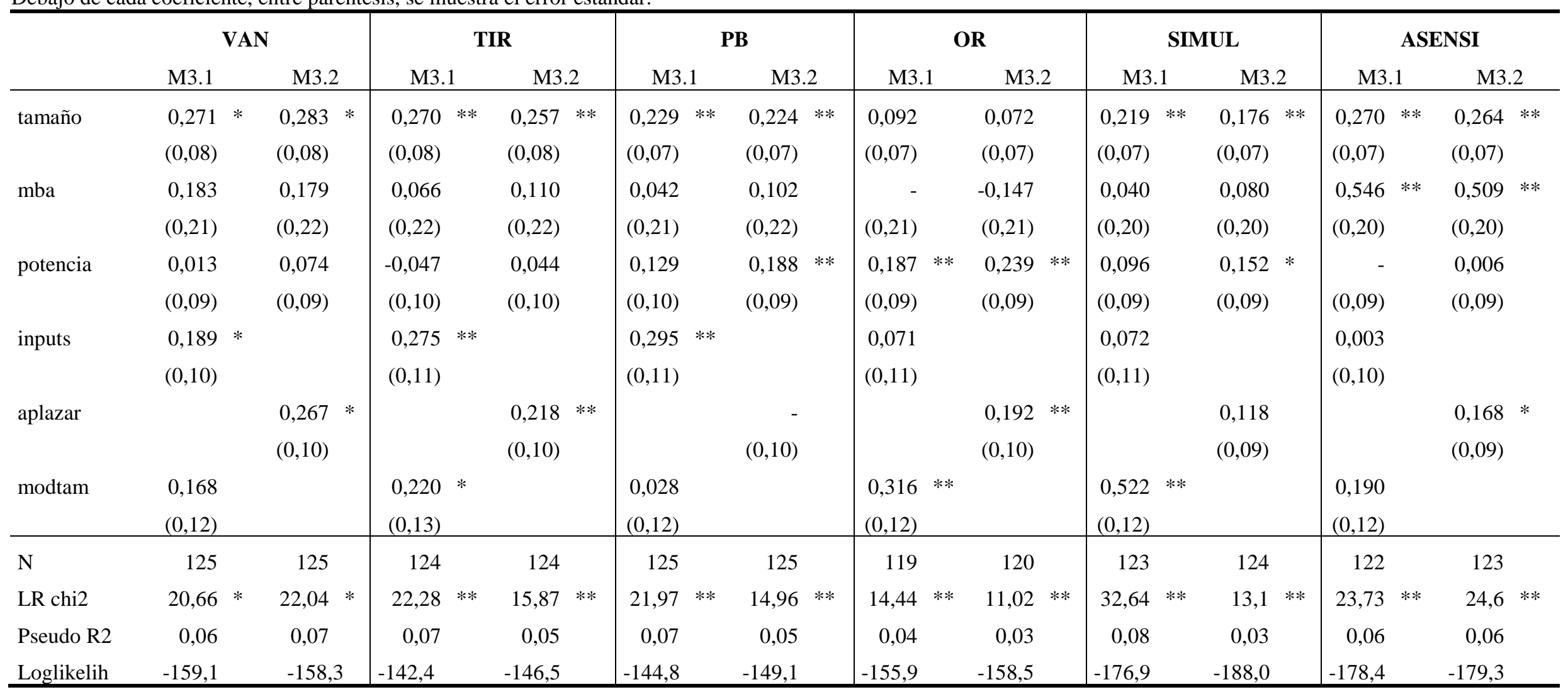

$* * *$ indica significativo al 1\%, ** al 5\% y * al 10\% 
La verificación de los postulados de la hipótesis 3 es parcial pues tan sólo algunas de las fuentes de valor hipotéticamente relacionadas con la frecuencia de uso de las opciones reales encuentran respaldo empírico. Concretamente, varias de las medidas de la flexibilidad asociada a los proyectos de inversión de la empresa no parecen relacionadas con la utilización de técnicas más acordes con lo propuesto por la teoría financiera.

El efecto conjunto de los mecanismos de disciplina y la relevancia de las oportunidades de crecimiento y flexibilidad sobre la frecuencia de uso de las técnicas puede examinarse a la luz de las estimaciones del modelo 4 recogidos en la tabla 5.7. Se aprecia la clara preeminencia de las variables relacionadas con las fuentes de valor sobre los mecanismos de disciplina, cuyos coeficientes pierden la significación estadística. Se confirma que la potencia de las inversiones favorece el uso de las opciones reales y el payback y que la relevancia de la flexibilidad del tamaño de la inversión propicia la utilización de las opciones reales y los modelos de simulación. La relevancia de la opción de intercambio de inputs vuelve a aparecer asociada a la aplicación del VAN, TIR y payback, y se confirma que la formación de MBA se traduce en un mayor empleo del análisis de sensibilidad. Por último, la consideración conjunta de mecanismos de disciplina y fuentes de valor permiten corroborar que la utilización del payback viene favorecida no sólo por el mayor tamaño de la empresa, sino también por la potencia de sus inversiones y la flexibilidad operativa asociada a las opciones de intercambio de inputs. 


\section{Tabla 5.7: Técnica, mecanismos de disciplina y fuentes de valor}

La tabla presenta los coeficientes estimados mediante regresiones multivariantes tipo probit ordenado del modelo 4, con el que se relaciona la frecuencia de uso de cada una de las técnicas con variables aproximativas de los mecanismos de disciplina y las fuentes de valor de la inversión, junto con las variables de tamaño y mba. Debajo de cada coeficiente, entre paréntesis, se muestra el error estándar.

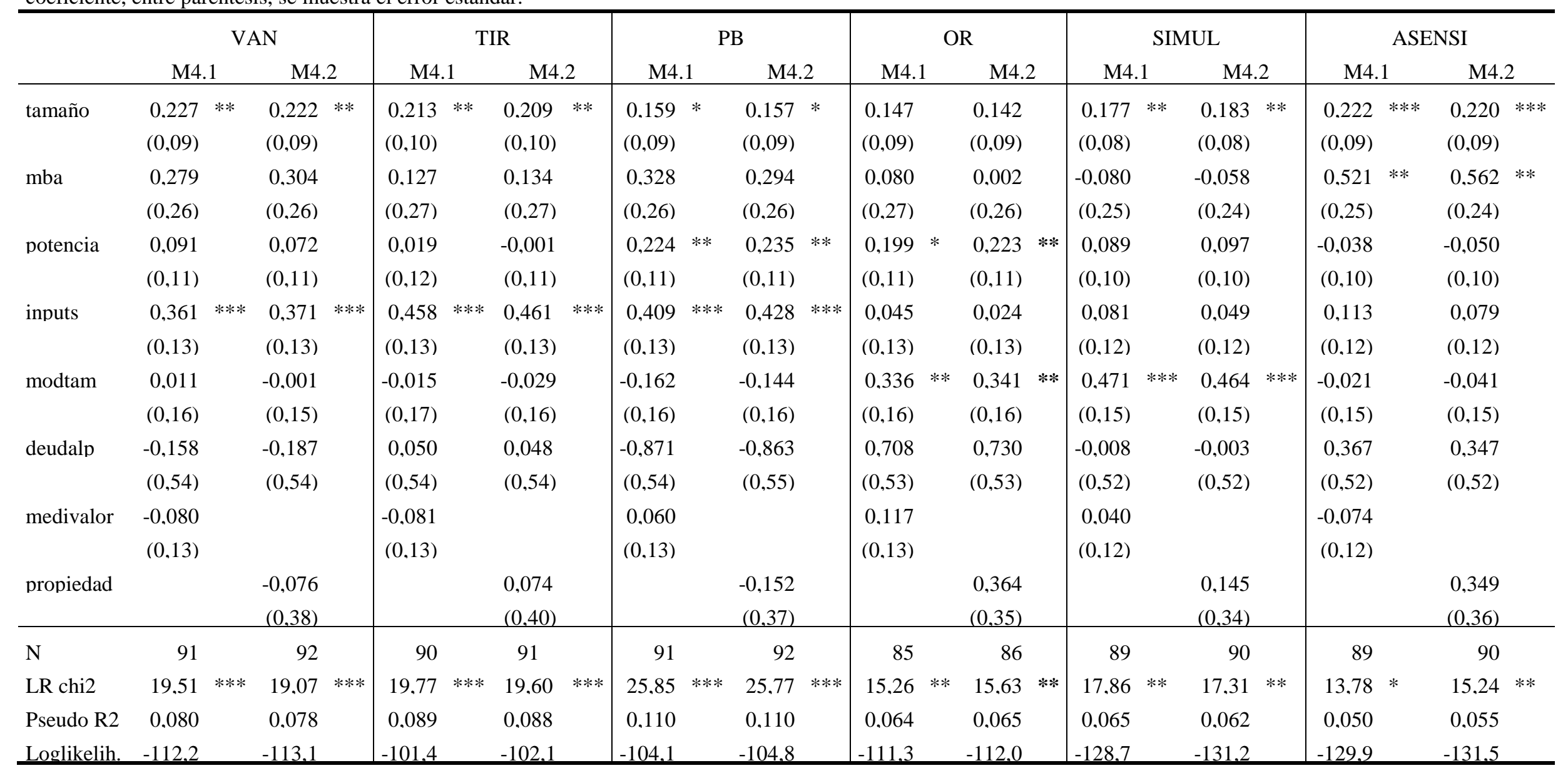

*** indica significativo al 1\%, ** al $5 \% \mathrm{y} *$ al $10 \%$ 
Con el fin de comprobar la robustez de nuestros resultados, reestimamos parte de los modelos anteriores con medidas alternativas de las variables independientes y de control. En términos generales, los resultados del contraste de hipótesis son robustos a diferentes configuraciones de las variables de control y a la aproximación de los mecanismos de disciplina, pero son sensibles a algunas medidas de la naturaleza de las fuentes de valor.

En la tabla 5.8 se comprueba el poder explicativo de la potencia y flexibilidad cuando las variables de control de tamaño y mba son reemplazadas por las variables indicativas de si la empresa invierte en el extranjero (invext), el grado de implicación del director financiero en las decisiones de inversión (impliDI) y sus años de experiencia en la empresa (experemp). La principal conclusión que se extrae es que el modelo pierde significación conjunta para explicar las cinco técnicas que eran más utilizadas por las empresas de mayor tamaño y gana significación estadística para el caso de las opciones reales, que era la única técnica cuyo uso se mostraba independiente del tamaño de la empresa. En consonancia con este resultado, la inversión en el exterior sólo incide en el mayor uso de las opciones reales. También corrobora los resultados univariantes relativos a que los directores financieros que más utilizan el análisis de sensibilidad son quienes acumulan menos años en la empresa y se sienten más implicados en las decisiones de inversión. La potencia de las inversiones y la flexibilidad de la inversión confirman su poder explicativo de la frecuencia de uso de las opciones reales, mientras que los modelos VAN, TIR y payback repiten su relación con la opción de intercambio de inputs y potencia.

En el modelo 4.4, la variable indicativa de si la empresa cotiza en bolsa sustituye a la variable de medición del valor. En términos generales, los resultados de la estimación se mantienen. El único cambio que merece ser destacado es la significación estadística de la propia variable de negociación en bolsa para el caso de las opciones reales, que viene a constatar el papel disciplinario que la supervisión institucional ejerce sobre las empresas cotizadas. Finalmente, estas dos especificaciones del modelo revelan cierta relación entre la deuda a largo 
plazo y el payback, que indica que el poder disciplinario de la deuda a largo plazo reduce la propensión del director financiero a utilizarlo. 


\section{Tabla 5.8: Robustez frente a las variables de control y la cotización en bolsa}

La tabla presenta los coeficientes estimados mediante regresiones multivariantes tipo probit ordenado del modelo 4, con el que se relaciona la frecuencia de uso de cada una de las técnicas con variables aproximativas de los mecanismos de disciplina y las fuentes de valor de la inversión. Las variables de control son invext que es una dummy indicativa de si la empresa invierte en el exterior, impliDI que mide el grado de implicación del director financiero en las decisiones de inversión y experemp que aproxima el número de años del director financiero en la empresa. El modelo 4.4 incluye las mismas variables de control, pero sustituye medivalor por bolsa, que es una dummy que toma el valor uno si la empresa cotiza en bolsa y cero en caso contrario. Debajo de cada coeficiente, entre paréntesis, se muestra el error estándar.

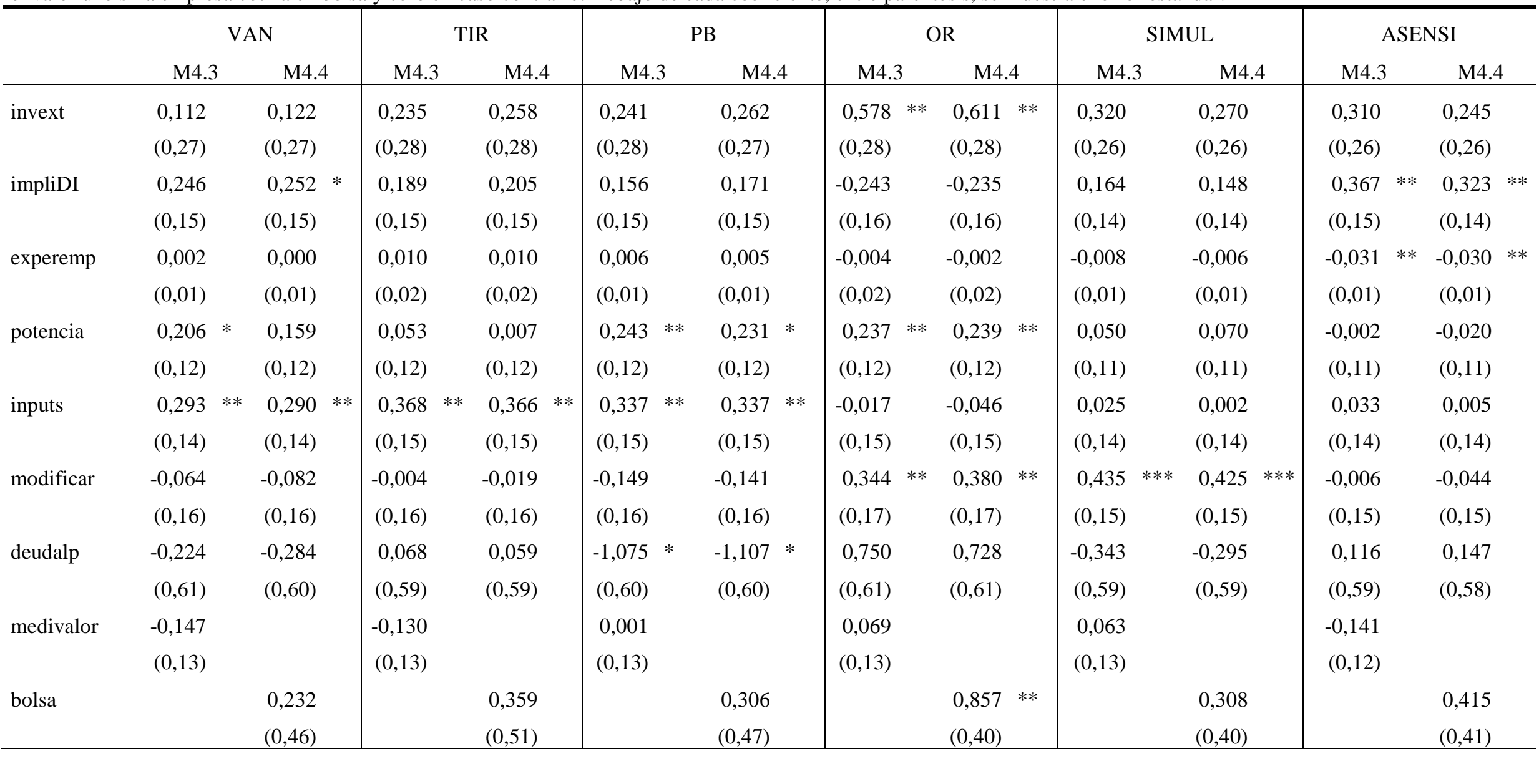




\section{CAPÍTULO 5}

\begin{tabular}{|c|c|c|c|c|c|c|c|c|c|c|c|c|}
\hline $\mathrm{N}$ & 85 & 86 & 85 & 86 & 85 & 86 & 80 & 81 & 83 & 84 & 83 & 84 \\
\hline LR chi2 & $14,51 *$ & $13,97 *$ & 14,01 & $* \quad 14,14 *$ & $20,44 * * *$ & $21,4 * * *$ & $19,54 * *$ & $23,61 * * *$ & $14,47 *$ & 12,95 & $16,81 * *$ & $13,95 *$ \\
\hline Pseudo R2 & 0,062 & 0,060 & 0,065 & 0,066 & 0,092 & 0,096 & 0,088 & 0,106 & 0,056 & 0,050 & 0,066 & 0,054 \\
\hline Loglikelih. & $-109,1$ & $-110,0$ & $-100,2$ & $-100,7$ & $-100,5$ & $-100,7$ & $-101,0$ & $-99,9$ & $-121,4$ & $-124,4$ & $-119,8$ & $-123,5$ \\
\hline
\end{tabular}

*** indica significativo al $1 \%$, ** al $5 \%$ y * al $10 \%$. 
La estabilidad de los resultados se comprueba cuando la variable de endeudamiento a largo plazo es remplazada por el cociente entre deuda total y total activo, que en términos generales tampoco aporta poder explicativo a la elección de la técnica utilizada por los directivos (tabla 5.9).

\section{Tabla 5.9: Robustez frente a las variables de control y de deuda}

La tabla presenta los coeficientes estimados mediante regresiones multivariantes tipo probit ordenado del modelo 4, con el que se relaciona la frecuencia de uso de cada una de las técnicas con variables aproximativas de los mecanismos de disciplina y las fuentes de valor de la inversión. Las variables de control son invext que es una dummy que toma el valor 1 si la empresa invierte en el exterior y cero en caso contrario, impliDI que mide el grado de implicación del director financiero en las decisiones de inversión según una escala de 1 a 4 y experemp que aproxima el número de años del director financiero en la empresa. El modelo 4.5 incluye las mismas variables de la tabla 5.7, pero sustituye deudalp por deuda, que indica el nivel de endeudamiento total de la empresa (cociente entre deuda total y activo). Debajo de cada coeficiente, entre paréntesis, se muestra el error estándar.

\begin{tabular}{|c|c|c|c|c|c|c|c|c|c|c|c|c|}
\hline & VAN & & TIR & & PB & & OR & & SIMUL & & ASENSI & \\
\hline & M4.5 & & M4.5 & & M4.5 & & M4.5 & & M4.5 & & M4.5 & \\
\hline \multirow[t]{2}{*}{ invext } & 0,162 & & 0,315 & & 0,188 & & 0,451 & $*$ & 0,236 & & 0,364 & \\
\hline & $(0,26)$ & & $(0,26)$ & & $(0,26)$ & & $(0,26)$ & & $(0,24)$ & & $(0,25)$ & \\
\hline \multirow[t]{2}{*}{ impliDI } & 0,283 & $* *$ & 0,250 & $*$ & 0,268 & $*$ & $-0,207$ & & 0,184 & & 0,325 & $* *$ \\
\hline & $(0,14)$ & & $(0,15)$ & & $(0,15)$ & & $(0,15)$ & & $(0,14)$ & & $(0,14)$ & \\
\hline \multirow[t]{2}{*}{ expempr } & 0,010 & & 0,017 & & 0,015 & & $-0,006$ & & 0,004 & & $-0,020$ & \\
\hline & $(0,01)$ & & $(0,01)$ & & $(0,01)$ & & $(0,02)$ & & $(0,01)$ & & $(0,01)$ & \\
\hline \multirow[t]{2}{*}{ potencia } & 0,161 & & 0,011 & & 0,175 & & 0,219 & $* *$ & 0,089 & & $-0,002$ & \\
\hline & $(0,11)$ & & $(0,11)$ & & $(0,11)$ & & $(0,11)$ & & $(0,11)$ & & $(0,11)$ & \\
\hline \multirow[t]{2}{*}{ inputs } & 0,226 & $*$ & 0,310 & $* *$ & 0,317 & $* *$ & $-0,014$ & & 0,010 & & $-0,073$ & \\
\hline & $(0,13)$ & & $(0,14)$ & & $(0,14)$ & & $(0,14)$ & & $(0,13)$ & & $(0,13)$ & \\
\hline \multirow[t]{2}{*}{ modificar } & 0,028 & & 0,091 & & $-0,034$ & & 0,288 & $*$ & 0,452 & $* * *$ & 0,027 & \\
\hline & $(0,15)$ & & $(0,15)$ & & $(0,15)$ & & $(0,15)$ & & $(0,15)$ & & $(0,14)$ & \\
\hline \multirow[t]{2}{*}{ deuda } & 0,398 & & 0,136 & & $-0,727$ & & 0,157 & & $-0,342$ & & 0,143 & \\
\hline & $(0,46)$ & & $(0,46)$ & & $(0,46)$ & & $(0,49)$ & & $(0,44)$ & & $(0,44)$ & \\
\hline \multirow[t]{2}{*}{ propiedad } & 0,097 & & 0,117 & & $-0,151$ & & 0,516 & & 0,196 & & 0,485 & \\
\hline & $(0,37)$ & & $(0,39)$ & & $(0,36)$ & & $(0,35)$ & & $(0,34)$ & & $(0,36)$ & \\
\hline $\mathrm{N}$ & 96 & & 96 & & 96 & & 91 & & 94 & & 94 & \\
\hline LR chi2 & 15,65 & $* *$ & 15,89 & $* *$ & 18,54 & $* *$ & 17,72 & $* *$ & 15,97 & $* *$ & 14,20 & $*$ \\
\hline Pseudo R2 & 0,060 & & 0,065 & & 0,075 & & 0,070 & & 0,054 & & 0,048 & \\
\hline Log likelih. & $-122,7$ & & $-114,3$ & & $-114,2$ & & $-117,2$ & & $-140,3$ & & $-139,8$ & \\
\hline
\end{tabular}

*** indica significativo al $1 \%, * *$ al $5 \% \mathrm{y} *$ al $10 \%$.

A pesar de estas señales de robustez, hemos encontrado cierta sensibilidad de los resultados a la medición de la potencia y flexibilidad de las inversiones. 
Concretamente, el conjunto de modelos se reestimaron mediante la sustitución de la variable potencia por ocenvalor que mide el peso de las oportunidades futuras de inversión en el valor actual de la empresa y las variables relativas a las opciones de flexibilidad (inputs, ritmo, aplazar y modtam) por una medida global de la relevancia de la flexibilidad en el proceso de creación de valor de la empresa (flexibilidad). Ninguna de estas dos variables mostró poder explicativo sobre la frecuencia de uso de las técnicas evaluadas en general y de los modelos de opciones reales en particular (tabla 5.10).

\section{Tabla 5.10: Robustez frente a las variables de fuentes de valor}

La tabla presenta los coeficientes estimados mediante regresiones multivariantes tipo probit ordenado del modelo 4, con el que se relaciona la frecuencia de uso de cada una de las técnicas con variables aproximativas de los mecanismos de disciplina y las fuentes de valor de la inversión. Las variables de control son tamaño, impliDI y experemp. El modelo 4.6 incluye las mismas variables de la tabla 5.7, pero sustituye potencia por ocenvalor, que indica el peso de las oportunidades de crecimiento en el valor de la empresa y flexibilidad que es una variable categórica que indica la importancia atribuida a la flexibilidad en el proceso de creación de valor de la empresa. Debajo de cada coeficiente, entre paréntesis, se muestra el error estándar.

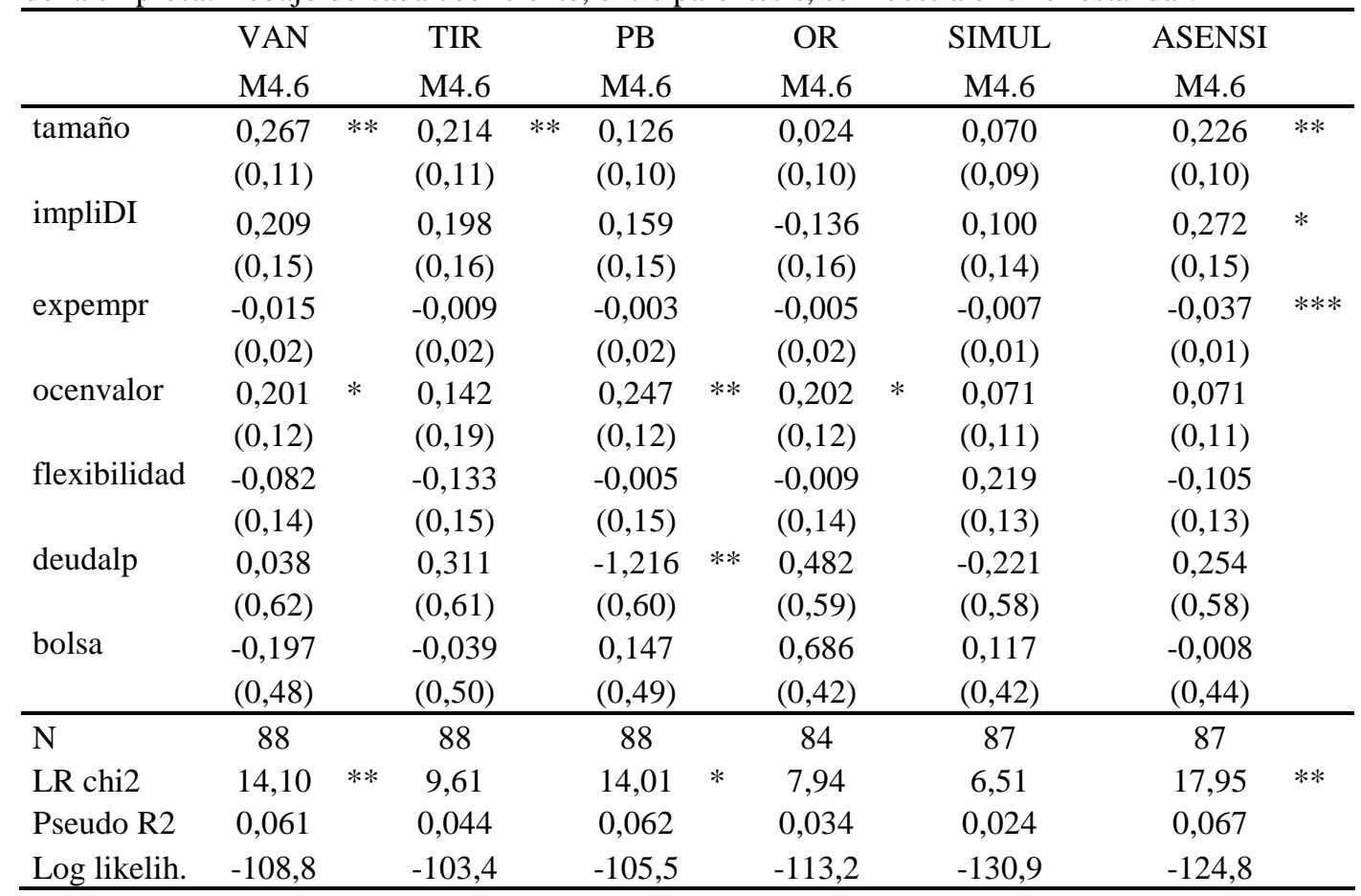

*** indica significativo al $1 \%$, ** al $5 \% \mathrm{y} *$ al $10 \%$ 
Otra de las cuestiones que merece un análisis adicional es la relativa a la medición de la variable dependiente. Siguiendo la práctica habitual, hemos determinado la frecuencia de utilización de las técnicas de selección de inversiones a partir de variables de escala ordenada en cinco niveles. Esta caracterización puede resultar adecuada para explicar el uso de las técnicas de tipo generalista, como el VAN, TIR, payback e incluso la simulación y el análisis de sensibilidad, puesto que son aplicables a todos los proyectos de inversión, cualquiera que sea su naturaleza. Sin embargo, el modelo de opciones reales es un modelo específico para la valoración de inversiones que proporcionan algún tipo de opciones, siendo teóricamente prescindible para el análisis del resto de proyectos.

Al margen de que, como afirma Myers (1996), sea difícil pensar en un proyecto que no proporcione opción de algún tipo, las empresas que utilizan las opciones reales quedarían mejor identificadas por descarte, a partir de las que dicen no aplicar este modelo en circunstancia alguna. Desde esta perspectiva, redefinimos la variable dependiente que mide la utilización de las opciones reales como una variable ficticia que toma el valor cero cuando el director financiero responde nunca aplicarlo y uno en caso contrario. La tabla 5.11 presenta los resultados de estimación de los modelos que incluyen esta variable dependiente y las anteriores combinaciones de independientes. 
Tabla 5.11: Robustez frente a definición de la variable dependiente “opciones reales"

La tabla presenta los coeficientes estimados mediante regresiones multivariantes tipo probit la relación entre el uso de cada una del modelo de opciones reales con variables aproximativas de los mecanismos de disciplina y las fuentes de valor de la inversión. La variable dependiente es una dummy que toma el valor cero si la empresa nunca utiliza el modelo de opciones reales y cero en caso contrario. Debajo de cada coeficiente, entre paréntesis, se muestra el error estándar.

\begin{tabular}{|c|c|c|c|c|c|c|c|c|}
\hline & M4.7 & & M4.7 & & M4.7 & & M4.7 & \\
\hline \multirow[t]{2}{*}{ _cons } & $-3,473$ & $* * *$ & $-3,478$ & $* * *$ & $-2,384$ & $* * *$ & $-2,441$ & $* * *$ \\
\hline & $(1,14)$ & & $(1,14)$ & & $(0,91)$ & & $(0,90)$ & \\
\hline \multirow[t]{2}{*}{ tamaño } & 0,221 & $*$ & 0,233 & $* *$ & 0,169 & & 0,172 & \\
\hline & $(0,12)$ & & $(0,12)$ & & $(0,11)$ & & $(0,11)$ & \\
\hline \multirow[t]{2}{*}{ mba } & $-0,447$ & & $-0,435$ & & $-0,441$ & & $-0,497$ & \\
\hline & $(0,33)$ & & $(0,31)$ & & $(0,32)$ & & $(0,32)$ & \\
\hline \multirow[t]{2}{*}{ potencia } & 0,234 & $*$ & 0,249 & $*$ & 0,309 & $* *$ & 0,336 & $* *$ \\
\hline & $(0,14)$ & & $(0,13)$ & & $(0,14)$ & & $(0,13)$ & \\
\hline \multirow[t]{2}{*}{ inputs } & 0,151 & & 0,124 & & & & & \\
\hline & $(0,16)$ & & $(0,15)$ & & & & & \\
\hline \multirow[t]{2}{*}{ aplazar } & & & & & 0,188 & & 0,207 & \\
\hline & & & & & $(0,14)$ & & $(0,14)$ & \\
\hline \multirow[t]{2}{*}{ modtam } & 0,335 & $*$ & 0,338 & * & & & & \\
\hline & $(0,19)$ & & $(0,19)$ & & & & & \\
\hline \multirow[t]{2}{*}{ deudalp } & 1,346 & $*$ & 1,351 & $*$ & 1,337 & $*$ & 1,366 & $*$ \\
\hline & $(0,75)$ & & $(0,74)$ & & $(0,74)$ & & $(0,74)$ & \\
\hline \multirow[t]{2}{*}{ medivalor } & 0,054 & & & & 0,102 & & & \\
\hline & $(0,17)$ & & & & $(0,16)$ & & & \\
\hline \multirow[t]{2}{*}{ propiedad } & & & 0,147 & & & & 0,249 & \\
\hline & & & $(0,45)$ & & & & $(0,44)$ & \\
\hline $\mathrm{N}$ & 85 & & 86 & & 86 & & 87 & \\
\hline LR chi2 & 17,15 & $* *$ & 16,66 & $* *$ & 14,14 & $* *$ & 14,35 & $* *$ \\
\hline Pseudo R2 & 0,150 & & 0,143 & & 0,122 & & 0,122 & \\
\hline Log likelihood & $-48,63$ & & $-49,78$ & & $-51,05$ & & $-51,83$ & \\
\hline
\end{tabular}

Los resultados de la estimación permiten confirmar que las compañías que utilizan alguna vez los modelos de opciones reales son aquellas de inversiones con mayor potencial en la generación de oportunidades futuras de inversión y mayor flexibilidad en la adaptación del tamaño de sus inversiones. La diferencia 
principal respecto a las anteriores estimaciones es la relevancia de la variable tamaño, en al menos dos de los cuatro modelos de la tabla 5.11. Puesto en relación con la evidencia de las tablas anteriores, este resultado revela que las opciones reales pudieran ser conocidas en mayor medida por las empresas de mayor tamaño, aunque la dimensión de la empresa no incida en la frecuencia de aplicación. Algo parecido cabría decir de la deuda a largo plazo. La significación estadística de su coeficiente, aunque moderada, manifiesta que la presión que ejercer la deuda a largo plazo sobre el comportamiento directivo es efectiva en la incorporación de las opciones reales entre las herramientas de análisis del director financiero, aunque no influya en la frecuencia de uso.

La relación entre la frecuencia de uso de las técnicas y el patrón de financiación enunciada en la hipótesis 4 se analiza a la luz de los resultados de estimación del modelo 5, que se resumen en la tabla 5.12. Los patrones de financiación utilizados son variables categóricas ordenadas de 1 a 5 donde los encuestados expresan el nivel de importancia atribuida a cada una de ellas en relación con cuestiones referidas a la financiación de la empresa (nivel de endeudamiento, política de endeudamiento y elección entre deuda de corto y largo plazo). Estos patrones, a su vez, reflejan comportamientos asociados a las teorías de estructura de capital revisadas en la presente investigación ${ }^{43}$.

Los patrones de financiación se aproximan por medio de una variable dicotómica y por variables categóricas ordenadas en cinco niveles según nivel de importancia atribuida por los directores financieros. La variable dicomótica es target que indica si la empresa establece (o no) un ratio de deuda objetivo. Las variables categóricas miden la importancia atribuida a: la búsqueda de una estructura de financiación objetivo (deudaobj), la utilización de deuda para reducir el coste medio ponderado del capital (redwacc); la flexibilidad financiera (flexifin); la utilización de deuda de corto plazo cuando los tipos de interés son bajos (CPinteresbajo); utilizar deuda de corto plazo para evitar invertir en

\footnotetext{
${ }^{43}$ Estas variables han sido elegidas considerando la aproximación al modelo conceptual detrás de cada teoría, pero también en virtud de los problemas de correlación que pudiesen existir entre ellas.
} 
proyectos arriesgados (sustitución) y contratar deuda de corto plazo para reducir el coste de financiación e incrementar la rentabilidad de los accionistas (CPcosterentab).

En primer término se verifica que cuanto más preocupación manifiesta el director financiero en la maximización de la diferencia entre beneficios y costes y, por tanto, por la búsqueda de una estructura de financiación objetivo, más relevantes y mayor utilización tienen las técnicas tradicionales de creación de valor (VAN y TIR). Destaca la variable redwacc (la búsqueda de la reducción del coste medio ponderado del capital) como la que de manera más significativa da cuenta de esta relación. En ambos modelos (modelo 5.1 y 5.2) y en ambas técnicas (VAN y TIR) esta variable es altamente significativa (al 99\% distinta de cero). Las otras dos variables, referidas al establecimiento y búsqueda de una financiación objetivo (target y deudaobj) también muestran significación estadística, aunque deudaobj sólo es significativa en el caso del uso de la TIR.

Este resultado indica que las empresas con un patrón de financiación acorde con la teoría del trade off utilizan en mayor medida las técnicas tradicionales VAN y TIR-, como se pronosticaba en la hipótesis 4.1.

En segundo lugar los resultados no permiten verificar la importancia relativa a la utilización de técnicas producto de comportamientos del tipo pecking order. A pesar de la alta importancia atribuida a la flexibilidad financiera por parte de los encuestados, ésta no explica el uso de casi ninguna de las técnicas de selección de inversiones, ni del popular periodo de recuperación (hipótesis 4.2). 


\section{Tabla 5.12: Técnica y patrón de financiación}

La tabla presenta los coeficientes estimados mediante regresiones multivariantes tipo probit ordenado del modelo 5, con el que se relaciona la frecuencia de uso de cada una de las técnicas con variables aproximativas de los patrones de financiación. Debajo de cada coeficiente, entre paréntesis, se muestra el error estándar. Los patrones de financiación se aproximan por medio de una variable dicotómica y por variables categóricas ordenadas en cinco niveles según nivel de importancia atribuida por los directores financieros. Variable dicomótica: Target: Si la empresa establece (o no) un ratio de deuda objetivo. Variables categóricas: Deudaobj: Búsqueda de una estructura de financiación objetivo. Redwacc: utilización de deuda para reducir el WACC. Flexifin: Flexibilidad financiera. CPinteresbajo: Se utiliza deuda de corto plazo cuando los tipos de interés son bajos. Sustitucion: Utilizar deuda de corto plazo para evitar invertir en proyectos arriesgados. CPcosterentab: Se contrata deuda de corto plazo para reducir el coste de financiación y subir la rentabilidad de los accionistas.

\begin{tabular}{|c|c|c|c|c|c|c|c|c|c|c|c|c|c|c|c|c|c|c|c|}
\hline & \multicolumn{4}{|c|}{ VAN } & \multicolumn{4}{|c|}{ TIR } & \multicolumn{2}{|c|}{ PB } & \multicolumn{3}{|c|}{ OR } & \multicolumn{2}{|c|}{ SIMUL } & \multicolumn{4}{|c|}{ ASENSI } \\
\hline & \multicolumn{2}{|c|}{ M5.1 } & \multicolumn{2}{|c|}{ M5.2 } & \multicolumn{2}{|c|}{ M5.1 } & \multicolumn{2}{|c|}{ M5.2 } & M5.1 & M5.2 & \multicolumn{2}{|c|}{ M5.1 } & M5.2 & \multicolumn{2}{|c|}{ M5.1 $\quad$ M5.2 } & \multicolumn{2}{|c|}{ M5.1 } & \multicolumn{2}{|l|}{ M5.2 } \\
\hline Target & $\begin{array}{l}0,425 \\
(0,23)\end{array}$ & $*$ & & & $\begin{array}{l}0,388 \\
(0,23)\end{array}$ & & & & $\begin{array}{l}0,463 \\
(0,23)\end{array}$ & & $\begin{array}{l}0,033 \\
(0,23)\end{array}$ & & & $\begin{array}{l}0,329 \\
(0,22)\end{array}$ & & $\begin{array}{l}0,339 \\
(0,22)\end{array}$ & & & \\
\hline Deudaobj & & & $\begin{array}{l}0,125 \\
(0,09)\end{array}$ & & & & $\begin{array}{l}0,237 \\
(0,10)\end{array}$ & $* *$ & & $\begin{array}{l}0,216 * * \\
(0,09)\end{array}$ & & & $\begin{array}{l}0,061 \\
(0,09)\end{array}$ & & $\begin{array}{l}0,249 * * * \\
(0,09)\end{array}$ & & & $\begin{array}{l}0,292 \\
(0,09)\end{array}$ & $* * *$ \\
\hline Redwacc & $\begin{array}{l}0,431 \\
(0,13)\end{array}$ & $* * *$ & $\begin{array}{l}0,361 \\
(0,13)\end{array}$ & $* * *$ & $\begin{array}{l}0,399 \\
(0,13)\end{array}$ & $* * *$ & $\begin{array}{l}0,301 \\
(0,13)\end{array}$ & $* *$ & $\begin{array}{l}0,035 \\
(0,11)\end{array}$ & $\begin{array}{l}-0,045 \\
(0,11)\end{array}$ & $\begin{array}{l}0,108 \\
(0,11)\end{array}$ & & $\begin{array}{l}0,146 \\
(0,10)\end{array}$ & $\begin{array}{r}0,039 \\
(0,10)\end{array}$ & $\begin{array}{l}0,010 \\
(0,10)\end{array}$ & $\begin{array}{l}0,500 \\
(0,12)\end{array}$ & $* * *$ & $\begin{array}{l}0,411 \\
(0,12)\end{array}$ & $* * *$ \\
\hline Flexifin & $\begin{array}{l}0,099 \\
(0,10)\end{array}$ & & $\begin{array}{l}0,016 \\
(0,10)\end{array}$ & & $\begin{array}{l}0,115 \\
(0,10)\end{array}$ & & $\begin{array}{l}-0,021 \\
(0,10)\end{array}$ & & $\begin{array}{l}0,124 \\
(0,10)\end{array}$ & $\begin{array}{l}0,020 \\
(0,10)\end{array}$ & $\begin{array}{l}0,115 \\
(0,10)\end{array}$ & & $\begin{array}{l}0,088 \\
(0,10)\end{array}$ & $\begin{array}{l}0,015 \\
(0,10)\end{array}$ & $\begin{array}{r}-0,080 \\
(0,09)\end{array}$ & $\begin{array}{l}-0,087 \\
(0,10)\end{array}$ & & $\begin{array}{l}-0,197 \\
(0,10)\end{array}$ & $* *$ \\
\hline CPinteresbajo & $\begin{array}{l}0,187 \\
(0,12)\end{array}$ & & $\begin{array}{l}0,185 \\
(0,12)\end{array}$ & & $\begin{array}{l}0,206 \\
(0,13)\end{array}$ & & $\begin{array}{l}0,208 \\
(0,12)\end{array}$ & $*$ & $\begin{array}{c}0,136 \\
(0,12)\end{array}$ & $\begin{array}{l}0,117 \\
(0,12)\end{array}$ & $\begin{array}{l}0,000 \\
(0,11)\end{array}$ & & $\begin{array}{l}0,012 \\
(0,11)\end{array}$ & $\begin{array}{l}0,073 \\
(0,11)\end{array}$ & $\begin{array}{l}0,056 \\
(0,10)\end{array}$ & $\begin{array}{l}0,109 \\
(0,11)\end{array}$ & & $\begin{array}{l}0,077 \\
(0,11)\end{array}$ & \\
\hline Sustitución & $\begin{array}{r}-0,069 \\
(0,16)\end{array}$ & & & & $\begin{array}{l}-0,099 \\
(0,17)\end{array}$ & & & & $\begin{array}{l}-0,101 \\
(0,15)\end{array}$ & & $\begin{array}{l}0,402 \\
(0,15)\end{array}$ & $* * *$ & & $\begin{array}{l}0,011 \\
(0,14)\end{array}$ & & $\begin{array}{r}-0,016 \\
(0,15)\end{array}$ & & & \\
\hline CPcosterentab & & & $\begin{array}{r}0,018 \\
(0,11) \\
\end{array}$ & & & & $\begin{array}{r}-0,018 \\
(0,12) \\
\end{array}$ & & & $\begin{array}{r}0,014 \\
(0,12) \\
\end{array}$ & & & $\begin{array}{l}0,209 * \\
(0,11)\end{array}$ & & $\begin{array}{r}-0,006 \\
(0,10) \\
\end{array}$ & & & $\begin{array}{l}0,030 \\
(0,11) \\
\end{array}$ & \\
\hline $\mathrm{N}$ & 114 & & 123 & & 113 & & 122 & & 114 & 123 & 109 & & 119 & 113 & 123 & 111 & & 121 & \\
\hline LR Chi2 & 23,77 & $* * *$ & 20,34 & $* * *$ & 20,53 & $* * *$ & 20,53 & $* * *$ & 8,60 & 8,88 & 15,39 & $* * *$ & $11,26 * *$ & 3,94 & 9,17 & 23,75 & $* * *$ & 33,40 & $* * *$ \\
\hline Pseudo R2 & 0,0766 & & 0,0622 & & 0,0733 & & 0,0733 & & 0,0296 & 0,0292 & 0,0504 & & 0,0339 & 0,0112 & 0,0238 & 0,0692 & & 0,0894 & \\
\hline Loglikelih. & $-143,2$ & & $-153,3$ & & $-129,8$ & & $-136,5$ & & $-140,8$ & $-147,5$ & $-145,0$ & & $-160,3$ & $-174,0$ & $-187,9$ & $-159,6$ & & $-170,0$ & \\
\hline
\end{tabular}

*** indica significativo al 1\%, ** al 5\% y * al 10\% 
Finalmente, la última hipótesis plantea la relación entre el interés de la dirección por los problemas de agencia (del tipo sustitución de activos y de subinversión) y la mayor utilización de los modelos de valoración a través de opciones reales (hipótesis 4.3). Por una parte, la variable aproximativa de los problemas de sustitución de activos (sustitución), que hace referencia a la importancia atribuida al uso de deuda de corto plazo para evitar invertir en proyectos de riesgo elevado, influye positivamente en la mayor utilización de los modelos de opciones reales. Por otra parte, la variable indicativa de los problemas de subinversión (CPinteresbajo), que hace referencia a la importancia de contratar deuda de corto plazo para reducir el coste de financiación e incrementar la rentabilidad de los accionistas, influye de manera positiva (y estadísticamente significativa) en la mayor utilización de las opciones reales (aunque sólo al 10\%).

En suma, los resultados de la tabla 5.12 dan apoyo parcial a lo esgrimido en la hipótesis cuarta, destacando el hecho de que los resultados no evidencian que el uso del periodo de recuperación se encuentre correlacionado (estadísticamente) con comportamientos del tipo pecking order, y de manera específica, con la flexibilidad financiera.

\subsection{La selección de las fuentes de financiación}

En una primera aproximación al análisis de los principales considerandos de la selección de fuentes de financiación, la tabla 5.13 presenta la importancia atribuida por los directores financieros a diferentes cuestiones en función de distintas características de la empresa y de su director financiero. Las distintas cuestiones están clasificadas según su vinculación con una de las cuatro teorías de estructura de capital consideradas. Los resultados del test de diferencias de medias proporcionan una primera evaluación de las hipótesis 5, 6 y 7 planteadas en la presente investigación. 


\subsubsection{Teoría del trade off}

Una pregunta recurrente en finanzas corporativas es si las empresas establecen ratios de deuda objetivo. La teoría del trade off establece que las empresas tienen un nivel de deuda óptimo, que se obtiene de la optimización de la diferencia entre los beneficios (deducibilidad de intereses) y costes de la deuda (riesgo de insolvencia financiera y quiebra) (Scott, 1976; Myers, 1984a; 2001). Al preguntar directamente si la empresa acomoda su política de financiación a un nivel de endeudamiento de referencia, un 66,7\% respondió afirmativamente. Sin embargo, no existen diferencias estadísticamente significativas acerca de variables que hacen más relevante este considerando.

Sólo un 14,6\% de los directores financieros creen que las ventajas fiscales de la deuda son un determinante de importancia del nivel de endeudamiento de la empresa. Sin embargo, existen diferencias marcadas (estadísticamente significativas) de que para las empresas con mayor nivel de tangibilidad de sus activos esta importancia es relativamente mayor. Este hallazgo indica que las empresas con menores dificultades financieras tienden a explotar en mayor medida la ventaja fiscal del endeudamiento. No obstante, difiere de lo que cabría esperar del efecto sustitutivo entre las ventajas fiscales de la deuda y otras provenientes de los activos tangibles, tales como las depreciaciones y/o amortizaciones. Varios artículos han propuesto y verificado un efecto sustitución entre ambas variables (DeAngelo y Masulis, 1980; Dammon y Senbet, 1988; Miguel y Pindado, 2001; López-Gracia y Sogor-Mira, 2008).

Poca importancia relativa tiene el ahorro de costes de transacción y negociación, con una media de 2,84, sin embargo ésta es mayor para empresas que dicen establecer un ratio de deuda objetivo. Para este mismo grupo de empresas, y de acuerdo con la teoría del trade off, también son importantes los potenciales riesgos de insolvencia financiera y quiebra, que es estadísticamente superior, con una media de 3,06, en comparación a empresas que no establecen un ratio de deuda objetivo. 
A su vez, los potenciales riesgos de insolvencia financiera y quiebra exhiben mayor importancia relativa en empresas donde su director financiero se involucra más activamente en la empresa: que participa de la propiedad de la misma y tiene mayor implicación tanto en las decisiones de inversión como de financiación (con medias de 3,43; 3,05 y 3,06, respectivamente).

Se observa una clara diferencia en la importancia atribuida a la búsqueda de una estructura de financiación objetivo ${ }^{44}$ (con una media de 3,37 y alta importancia para un 52,7\% de los encuestados) frente a la relevancia concedida al nivel de endeudamiento de la competencia (con una media de 1,69 e importante para el 5,5\% de los directores financieros). Sin embargo, estos factores aparecen como especialmente relevantes para las empresas que realizan inversiones en el extranjero, así como para empresas en las que su director financiero participa en la propiedad (media de 2,36 versus 1,59, para quienes no participan en la propiedad).

La utilización del endeudamiento para reducir el coste medio ponderado del capital (WACC) no parece una de las principales preocupaciones de los encuestados (con media de 1,75 e importante para un 77\% de los encuestados). Sin embargo, se observa que es más relevante para los directivos de las empresas grandes, así como en las empresas que no pertenecen al sector económico industria o que cotizan en bolsa. Este tipo de empresas implícitamente reconocen la existencia de un ratio de deuda que permite minimizar el WACC y lo persiguen.

La utilización del endeudamiento de largo plazo como medida para evitar potenciales riesgos de insolvencia financiera y quiebra es un factor de importancia media, la respuesta promedio es un 2,63 y tiene alta importancia para el 31,5\% de los encuestados. No obstante, este factor es más relevante para empresas en crecimiento que para las maduras ${ }^{45}$. Este resultado, en línea con los

\footnotetext{
${ }^{44}$ Que la búsqueda de una estructura de financiación objetivo sea estadísticamente mayor para empresas que dicen establecer un nivel de deuda de referencia es indicativo de la coherencia de las respuestas.

${ }^{45}$ La visión del director financiero sobre el peso de los resultados de la inversión futura y pasada nos han permitido clasificar a las empresas de acuerdo a su ciclo de vida, así las empresas que dan
} 
planteamientos de la teoría del trade off, indica que las empresas en crecimiento, que tienen mayores necesidades de flujo de efectivo, evitan la deuda de corto plazo que podría generar problemas de insolvencia financiera. Johnson (2003) verifica que disminuir el plazo medio del endeudamiento actúa como mitigador de los problemas asociados a la deuda (disminuye el problema de subinversión), sin embargo, también acrecienta el riesgo de liquidación o quiebra. Este mismo comportamiento, no obstante, no se evidencia en las demás proxies utilizadas para medir las oportunidades de crecimiento.

\subsubsection{Teoría del pecking order}

El análisis de la evidencia relativa a los factores determinantes de la financiación según la teoría del pecking order, se inicia con los resultados de la importancia que le atribuyen los directores financieros a la flexibilidad financiera ${ }^{46}$. Este factor, considerado muy importante por un 56,9\% para los directores financieros encuestados y con una media de 3,62, es el que más peso tiene en la definición del nivel de endeudamiento de la empresa. La importancia de la flexibilidad es mayor en las empresas de crecimiento, cuyas inversiones pasadas abren nuevas oportunidades futuras de inversión, con un valor medio de 3,82. Desde la perspectiva de la teoría del pecking order, este resultado se explica por el hecho de que las empresas con mayores oportunidades de inversión tienen mayores necesidades de fondos (Beck y Demirguc-Kunt, 2006; Hovakimian y Titman, 2006), por lo que prefieren la creación de holgura financiera ${ }^{47}$.

mayor relevancia a los resultados de la inversión futura son asociadas a empresas en crecimiento y las empresas con mayor énfasis en la inversión pasada, empresas maduras.

${ }^{46}$ Gamba y Triantis (2008) definen flexibilidad financiera como la "capacidad de una empresa para acceder y reestructurar su financiación a un bajo coste. En la literatura financiera, este concepto también ha sido asociado al de holgura financiera (Myers y Majluf, 1984; Opler y Titman, 1994; Hadlock y James, 2002; Beattie et al., 2006; Hovakimian y Titman, 2006).

${ }^{47}$ Marchica y Mura (2010) señalan que, a través de conservadoras políticas de endeudamiento, las empresas mantienen un nivel de flexibilidad financiera que les permiten tener mejor acceso a los mercados externos cuando se enfrentan a shocks positivos en el conjunto de oportunidades de inversión. 
En contra de lo que cabría esperar, la flexibilidad financiera es más importante también para empresas que establecen un nivel de endeudamiento de referencia. Este resultado se obtiene también en trabajos anteriores como el de Beattie et al. (2006), indicando que las dos variables clásicas de trade off y pecking order no son necesariamente patrones que compiten por explicar las prácticas de las empresas. Si estas dos teorías fueran consideradas como excluyentes por los encuestados, la relación verificada hubiese sido negativa. Sin embargo, estos resultados sugieren que los directores no realizan sus decisiones de estructura de capital de acuerdo con una de las teorías de manera exclusiva. Norton (1989) señala que "las empresas parecen utilizar indistintamente los enfoques cuando consideran las alternativas de financiación”. Beattie et al. (2006) apunta a que este comportamiento mixto puede deberse al hecho de que cuando un directivo se enfrenta a una decisión de financiación en un momento puntual, es influenciado en mayor o menor medida por los razonamientos que sustentan estas dos principales teorías, y habiendo sido afectado por las circunstancias.

La utilización de deuda cuando no se dispone de fondos internos (con una media de 3,39) es un factor importante para un 55,5\% de los directores financieros. Este factor que considera el orden de preferencia en la financiación sugerido por la teoría es, sin embargo, más relevante para las empresas pequeñas, no cotizadas, cuyas inversiones pasadas abren pocas nuevas oportunidades de inversión y que sus directores financieros se encuentran más implicados en las decisiones de inversión y financiación de la empresa. La literatura evidencia que son, precisamente, las empresas pequeñas (generalmente, no cotizadas) las que en mayor medida sufren de restricciones financieras (Danielson y Scott, 2006; Danielson y Scott, 2007; Campello et al., 2010), con lo que tienden a crear holguras financieras y a mantener excesos de liquidez para financiar futuras inversiones (Graham, 2000).

La importancia de la utilización de deuda debido a las buenas relaciones con entidades bancarias es especialmente baja (sólo importante para el 12,5\% y de poca importancia para un $60,2 \%$ de los directores financieros) y sólo reviste 
mayor relevancia para las empresas sociedades anónimas y aquellas que establecen un target de deuda. El trabajo de Lindblom et al. (2011) revela que aproximadamente un 60\% de sus encuestados están de acuerdo con la idea de que se financian por medio del "banco de la casa”, situación que es más importante para las empresas pequeñas ${ }^{48}$. Faulkender y Petersen (2006) verifican que empresas menos visibles en el mercado (opacas, según los autores, por su dificultad de obtener información ex ante) tienden a utilizar acreedores activos (bancos, por ejemplo) y que las empresas más visibles (con clasificación de riesgo) utilizan acreedores pasivos (mercado de deuda).

La preferencia del endeudamiento bancario sobre la emisión de bonos para evitar revelar información estratégica, no parece demasiado importante para los encuestados (sólo un 20,5\% opina que es importante frente a un 68\%, con una media de 2,05). Entre empresas de distinta personalidad jurídica, las sociedades anónimas son las que mayor importancia le atribuyen. En este caso, la predicción teórica es la contraria, pues las sociedades anónimas son las que menores problemas de asimetrías de información enfrentan (Pettit y Singer, 1985; Fazzari et al., 1988; Titman y Wessels, 1988; Michaelas et al., 1999). Este factor también se revela de mayor importancia para las empresas cuyos activos son menos tangibles, como cabía esperar. Finalmente, este factor es más relevante para las empresas cuyos directores financieros no tienen formación superior especializada (ni MBA, ni máster de especialidad en finanzas).

\subsubsection{Teoría de agencia}

Los directores financieros encuestados no ven en la contratación de deuda un mecanismo para mejorar la reputación de la empresa ${ }^{49}$. Sólo un 7,09\% le

\footnotetext{
48 En el supuesto que con el banco habitual ya se han resuelto, en parte, los problemas de información asimétrica.

${ }^{49}$ Con una media de 1,88 (en escala de 1 a 5) es similar a lo obtenido por Graham y Harvey (2001) (0,96 en escala de 0 a 4) y por Brounen et al. (2006) (0,91; 0,65; 0,75 y 1,06 para Reino Unido, Holanda, Alemania y Francia, respectivamente).
} 
atribuye alta importancia versus el $74 \%$ que piensa que tiene baja importancia. Además, es sólo más importante para aquellos directores financieros que no perciben que tengan una activa participación en las decisiones de financiación de la empresa.

El tipo de inversión a realizar o los activos a financiar son considerados por los directivos de manera notable (por su media de 3,53). La relevancia de la naturaleza de la inversión incrementa en el caso de las empresas pequeñas y de responsabilidad limitada. En relación con la presencia de oportunidades de crecimiento este factor es más relevante en empresas cuyas inversiones pasadas abren mayor cantidad de oportunidades de inversión futura (media de 4,02), con oportunidades de crecimiento que representan una mayor proporción del valor de la empresa (media de 4,00) y cuando el valor de mercado es muy superior al valor contable (media de 3,70).

Que las empresas tiendan a hacer coincidir la vida útil de sus activos con el plazo de la deuda es una idea aceptada y extendida entre los directores financieros. La gestión del riesgo provee una explicación a la existencia de estas prácticas en las empresas. Si los activos y los pasivos no se encuentran alineados, las variaciones de los tipos de interés y vencimientos pueden afectar la liquidez de la empresa, al tiempo que incrementan los problemas de riesgo moral relacionados con la transferencia de riqueza accionistas-acreedores. El trabajo de Graham y Harvey (2001) muestra que “emparejar los vencimientos” es el factor más importante en la elección entre endeudamiento de corto y de largo plazo. Stohs y Mauer (1996) confirman, además, que las empresas con predominio de activos de largo plazo (como proporción de los activos totales) contratan en mayor medida pasivos de largo plazo y Ozkan (2000) confirma que las empresas, con el objetivo de minimizar los costes de subinversión, debería elegir la madurez de su deuda en función de la vida útil restante de sus activos.

Nuestros resultados confirman que emparejar los vencimientos de activos y pasivos es el principal factor en la elección del plazo de la deuda (con una media de 3,37 y de alta importancia para el 53,5\% de los encuestados). Este resultado se 
vuelve particularmente relevante para empresas con altas oportunidades de crecimiento, empresas en que las inversiones pasadas abren mayor cantidad de oportunidades futuras y en que las oportunidades de crecimiento representan parte importante de su valor actual (con medias de 3,80 y 3,84, respectivamente).

La posibilidad de utilizar los activos de la empresa como garantía crediticia (collateral) es otro factor de relevancia en la política de financiación seguida por la empresa (con una media de 2,28, aunque de alta importancia sólo para un $17,3 \%$ ). Sin embargo, se vuelve más relevante para las empresas que cuentan con mayores oportunidades de crecimiento (mayor proporción de nuevas oportunidades de inversión y empresas en ciclo de crecimiento).

Esta misma evidencia se reafirma en la importancia atribuida, en la elección de deuda de corto y largo plazo, a "hacer coincidir plazos" (con media de 3,26 e importante para el 53,5\%). Sin embargo, la tabla 5.14 indica que esta importancia es aún mayor para empresas que se encuentran en un ciclo de crecimiento. Resalta en este caso también que este factor sea de mayor relevancia para empresas que establecen un ratio de deuda objetivo y cuyos directores financieros participan de la propiedad.

La composición del activo, es decir, la relación entre activos tangibles e intangibles, reviste poca importancia para los encuestados (con media de 1,75 y sólo importante para el 8,1\%). La literatura muestra que la composición del activo es un factor importante en la determinación del nivel de deuda. Por ejemplo, los activos fijos aumentan la capacidad de endeudamiento de la empresa (Benmelech y Bergman, 2009). La mayor proporción de activos intangibles implica mayores problemas de asimetrías de información para con los inversores externos, por una parte, y favorecen la aparición de problemas de agencia, por otra, con lo que a este tipo de activos se les asocia menores niveles de deuda.

Myers (1977) argumenta que con el objetivo de reducir los costes de subinversión las empresas debieran limitar su endeudamiento o usar deuda de corto plazo. Ante la pregunta de si la deuda de corto plazo actúa como mecanismo para desincentivar proyectos arriesgados, sólo un 2,4\% de los encuestados 
responde positivamente. Sin embargo, este problema se muestra más relevante para empresas que cuentan con oportunidades de inversión futura y se encuentran en ciclo de crecimiento, de manera consistente con las predicciones de la teoría. Este problema es, además, de mayor relevancia para empresas que establecen un ratio de deuda objetivo y cuyos directores financieros participan de la propiedad y se sienten más implicados en los procesos de la empresa (decisiones de inversión y financiación).

La preferencia por deuda de largo plazo a objeto de evitar problemas y costes de refinanciación tiene bastante relevancia (con una media de 3,16 e importante para el 50\% de los directores financieros) y, prácticamente, no existen diferencias (estadísticamente) significativas entre las variables con que se discrimina. La excepción la constituyen las variables relativas a la formación del director financiero y al grado de implicación en las decisiones de inversión de la empresa. A mayor formación e implicación más relevante es esta variable.

El tercer factor más importante en la elección entre deuda de corto y de largo plazo, con una media de 2,91, es la definición de una política específica e independiente para cada proyecto de la empresa. Con un nivel de importancia que alcanza un 37,5\%, encuentra aún más relevancia entre las empresas que no realizan inversiones en el extranjero, aquellas cuyas inversiones pasadas abren nuevas oportunidades de inversión y las que establecen un nivel de endeudamiento objetivo.

\subsubsection{Teoría del market timing}

La disponibilidad y acceso al endeudamiento es un factor con alto peso en la determinación del nivel de endeudamiento de las empresas (en segundo lugar, con una media de 3,56 y primero por orden de importancia, con un 64,6\%). Tiene, sin embargo, mayor importancia para aquellas empresas que establecen un target de deuda y cuyos directores financieros se encuentran más implicados en las decisiones de financiación. La mayor implicación podría indicar una mayor 
preocupación por verificar las condiciones de mercado que favorezcan en mayor medida a la empresa.

Una premisa de la teoría del market timing es que los directores de la empresa conocen (implícitamente) el valor de la empresa, con lo que pueden aprovechar las ventajas del mercado. En este sentido, el aprovechamiento de los bajos tipos de interés para contratar deuda es un comportamiento directivo acorde con esta teoría. Sin embargo, este factor es tercero en orden de trascendencia, con una media de 2,20, de baja importancia para un 62,2\% y de alta importancia sólo para el $11 \%$ de los encuestados. La baja importancia atribuida por los directores financieros encuestados a este factor, se encuentra en línea con los resultados obtenidos por Graham y Harvey (2001) y Beattie et al. (2006) ${ }^{50}$. En nuestro caso, este factor es más relevante para los directores financieros que participan de la propiedad de la empresa.

Sólo un $14 \%$ de las empresas de la muestra son cotizadas con lo que la importancia de las fluctuaciones del precio de las acciones en la política financiera era previsible que no tuviese demasiada importancia: se obtiene un valor medio de 1,34 e importante sólo para el 0,8\%. Esta relevancia atribuida, aunque menor, es significativa para las sociedades anónimas, como también era previsible.

El uso de deuda de corto plazo con el propósito de aprovechar las oportunidades del mercado (con una media de 1,81) es importante sólo para el 7,8\% de los directores financieros. Aunque más relevante para las sociedades anónimas, empresas cotizadas, que invierten en el extranjero y en los casos de menor tangibilidad del activo.

\footnotetext{
${ }^{50}$ El trabajo de Lindblom et al. (2011) indica que cerca del 50\% de los encuestados se encuentran en desacuerdo respecto de este planteamiento, aprovechar los bajos tipos de interés de mercado para contratar deuda.
} 
Tabla 5.13: Considerandos de la decisión de financiación según características de la empresa y del director financiero

Parte A

\begin{tabular}{|c|c|c|c|c|c|c|c|c|c|c|c|c|c|c|c|}
\hline \multirow[t]{2}{*}{ Teoría del Trade Off } & \multirow[t]{2}{*}{ Media } & \multicolumn{2}{|c|}{ Importancia } & \multicolumn{2}{|c|}{ Tamaño } & \multicolumn{2}{|c|}{ Industria } & \multicolumn{2}{|c|}{$\begin{array}{l}\text { Personalidad } \\
\text { jurídica }\end{array}$} & \multicolumn{2}{|c|}{ Empresa cotizada } & \multicolumn{2}{|c|}{$\begin{array}{l}\text { Inversión } \\
\text { extranjero }\end{array}$} & \multicolumn{2}{|c|}{ Tangibilidad } \\
\hline & & Baja & Alta & Pequeñas & Grandes & No & $\mathrm{Si}$ & SL & SA & No & $\mathrm{Si}$ & No & $\mathrm{Si}$ & Baja & Alta \\
\hline a) Ratio de endeudamiento objetivo & 0,67 & & & 0,66 & 0,70 & 0,65 & 0,71 & 0,61 & 0,69 & 0,65 & 0,81 & 0,64 & 0,69 & 0,60 & 0,78 \\
\hline b) Ahorro de impuestos & 2,36 & $59,2 \%$ & $14,6 \%$ & 2,39 & 2,36 & 2,42 & 2,30 & 2,23 & 2,41 & 2,35 & 2,50 & 2,29 & 2,41 & 2,13 & $2,66 * *$ \\
\hline $\begin{array}{l}\text { c) Ahorro de costes de transacción y } \\
\text { negociación }\end{array}$ & 2,84 & $39,5 \%$ & $31,0 \%$ & 2,97 & 2,73 & 2,82 & 2,92 & 2,87 & 2,86 & 2,88 & 2,78 & 2,84 & 2,84 & 2,67 & 2,90 \\
\hline $\begin{array}{l}\text { d) Búsqueda de una estructura de deuda } \\
\text { objetivo }\end{array}$ & 3,37 & $21,7 \%$ & $52,7 \%$ & 3,29 & 3,51 & 3,42 & 3,34 & 2,87 & 3,39 & 3,42 & 3,22 & 3,16 & $3,56^{*}$ & 3,22 & 3,44 \\
\hline $\begin{array}{l}\text { e) Nivel de endeudamiento de la } \\
\text { competencia }\end{array}$ & 1,69 & $82,0 \%$ & $5,5 \%$ & 1,62 & 1,77 & 1,65 & 1,76 & 1,62 & 1,71 & 1,67 & 1,89 & 1,51 & $1,85^{*}$ & 1,93 & $1,51^{* *}$ \\
\hline $\begin{array}{l}\text { f) Potenciales riesgos de insolvencia y } \\
\text { quiebra }\end{array}$ & 2,91 & $36,7 \%$ & $35,9 \%$ & 3,03 & 2,86 & 2,79 & 3,12 & 3,17 & 2,86 & 2,93 & 2,89 & 2,85 & 2,93 & 3,16 & 2,80 \\
\hline g) Se usa deuda para reducir el WACC & 1,75 & $77,0 \%$ & $5,6 \%$ & 1,55 & $1,95^{* *}$ & 1,90 & $1,53^{* *}$ & 1,48 & 1,82 & 1,66 & $2,27 * *$ & 1,66 & 1,82 & 1,78 & 1,73 \\
\hline $\begin{array}{l}\text { h) Deuda LP para evitar problemas de } \\
\text { insolvencia y quiebra }\end{array}$ & 2,63 & $47,3 \%$ & $31,5 \%$ & 2,63 & 2,70 & 2,57 & 2,79 & 2,59 & 2,66 & 2,57 & 2,94 & 2,54 & 2,66 & 2,81 & 2,68 \\
\hline
\end{tabular}

\begin{tabular}{|c|c|c|c|c|c|c|c|c|c|c|c|c|c|c|c|}
\hline \multirow[t]{2}{*}{ Teoría del Pecking Order } & \multirow[t]{2}{*}{ Media } & \multicolumn{2}{|c|}{ Importancia } & \multicolumn{2}{|c|}{ Tamaño } & \multicolumn{2}{|c|}{ Industria } & \multicolumn{2}{|c|}{$\begin{array}{l}\text { Personalidad } \\
\text { jurídica }\end{array}$} & \multicolumn{2}{|c|}{ Empresa cotizada } & \multicolumn{2}{|c|}{$\begin{array}{c}\text { Inversión } \\
\text { extranjero }\end{array}$} & \multicolumn{2}{|c|}{ Tangibilidad } \\
\hline & & Baja & Alta & Pequeñas & Grandes & No & $\mathrm{Si}$ & SL & SA & No & $\mathrm{Si}$ & No & Si & Baja & Alta \\
\hline a) La flexibilidad financiera & 3,62 & $16,2 \%$ & $56,9 \%$ & 3,69 & 3,61 & 3,63 & 3,64 & 3,67 & 3,61 & 3,60 & 3,89 & 3,48 & 3,75 & 3,61 & 3,76 \\
\hline $\begin{array}{l}\text { b) Utilización de deuda cuando no hay } \\
\text { fondos internos }\end{array}$ & 3,39 & $25,8 \%$ & $55,5 \%$ & 3,76 & $3,14^{* * *}$ & 3,32 & 3,59 & 3,45 & 3,40 & 3,51 & $2,94 *$ & 3,55 & 3,31 & 3,65 & 3,29 \\
\hline $\begin{array}{l}\text { c) Uso de deuda se debe a buenas } \\
\text { relaciones con bancos }\end{array}$ & 2,20 & $60,2 \%$ & $12,5 \%$ & 2,07 & 2,38 & 2,17 & 2,29 & 1,93 & $2,30^{*}$ & 2,17 & 2,44 & 2,14 & 2,30 & 2,37 & 2,12 \\
\hline $\begin{array}{l}\text { d) Deuda bancaria a bonos pues se revela } \\
\text { menos información }\end{array}$ & 2,05 & $68,0 \%$ & $20,5 \%$ & 1,98 & 2,16 & 2,08 & 2,02 & 1,54 & $2,20 * *$ & 2,04 & 2,00 & 1,91 & 2,19 & 2,51 & $1,74^{* * *}$ \\
\hline
\end{tabular}




\begin{tabular}{|c|c|c|c|c|c|c|c|c|c|c|c|c|c|c|c|}
\hline \multirow[t]{2}{*}{ Teoría de Agencia } & \multirow[t]{2}{*}{ Media } & \multicolumn{2}{|c|}{ Importancia } & \multicolumn{2}{|c|}{ Tamaño } & \multicolumn{2}{|c|}{ Industria } & \multicolumn{2}{|c|}{$\begin{array}{l}\text { Personalidad } \\
\text { jurídica }\end{array}$} & \multicolumn{2}{|c|}{ Empresa cotizada } & \multicolumn{2}{|c|}{$\begin{array}{l}\text { Inversión } \\
\text { extranjero }\end{array}$} & \multicolumn{2}{|c|}{ Tangibilidad } \\
\hline & & Baja & Alta & Pequeñas & Grandes & No & Si & SL & SA & No & Si & No & $\mathrm{Si}$ & Baja & Alta \\
\hline $\begin{array}{l}\text { a) El endeudamiento mejora la reputación } \\
\text { de la empresa }\end{array}$ & 1,88 & $74,02 \%$ & $7,09 \%$ & 1,78 & 2,00 & 1,96 & 1,78 & 1,57 & 1,98 & 1,84 & 2,00 & 1,84 & 1,86 & 1,91 & 1,88 \\
\hline $\begin{array}{l}\text { b) Tipo de inversión a realizar o los activos } \\
\text { a financiar }\end{array}$ & 3,53 & $19,2 \%$ & $56,9 \%$ & 3,77 & $3,36^{*}$ & 3,51 & 3,62 & 3,93 & $3,43^{*}$ & 3,55 & 3,5 & 3,41 & 3,69 & 3,46 & 3,60 \\
\hline $\begin{array}{l}\text { c) Vida económica de la inversión a } \\
\text { financiar }\end{array}$ & 3,37 & $23,3 \%$ & $53,5 \%$ & 3,48 & 3,33 & 3,43 & 3,33 & 3,63 & 3,32 & 3,34 & 3,61 & 3,13 & 3,64 & 3,35 & 3,22 \\
\hline $\begin{array}{l}\text { d) A mayor garantía ofrecida por los } \\
\text { activos mayor deuda }\end{array}$ & 2,28 & $66,2 \%$ & $17,3 \%$ & 2,19 & 2,33 & 2,21 & 2,42 & 2,24 & 2,30 & 2,23 & 2,56 & 2,20 & 2,41 & 2,30 & 2,45 \\
\hline e) Composición del activo es importante & 1,75 & $79,8 \%$ & $8,1 \%$ & 1,61 & 1,90 & 1,70 & 1,85 & 1,66 & 1,78 & 1,74 & 1,78 & 1,60 & 1,88 & 1,98 & 1,65 \\
\hline $\begin{array}{l}\text { f) Se hace coincidir plazo de deuda con } \\
\text { vida de los activos }\end{array}$ & 3,26 & $28,7 \%$ & $53,5 \%$ & 3,42 & 3,14 & 3,32 & 3,24 & 3,34 & 3,24 & 3,26 & 3,33 & 3,13 & 3,43 & 3,25 & 3,44 \\
\hline $\begin{array}{l}\text { g) Deuda CP para desincentivar proyectos } \\
\text { arriesgados }\end{array}$ & 1,53 & $85,8 \%$ & $2,4 \%$ & 1,56 & 1,50 & 1,47 & 1,64 & 1,34 & 1,58 & 1,47 & 1,78 & 1,51 & 1,55 & 1,58 & 1,52 \\
\hline $\begin{array}{l}\text { h) Deuda LP para evitar problemas de } \\
\text { refinanciación }\end{array}$ & 3,16 & $29,7 \%$ & $50,0 \%$ & 3,23 & 3,14 & 3,21 & 3,19 & 2,59 & 2,66 & 3,16 & 3,22 & 3,15 & 3,21 & 3,26 & 3,32 \\
\hline $\begin{array}{l}\text { i) Deuda CP para bajar coste financiación y } \\
\text { subir rentabilidad }\end{array}$ & 1,92 & $74,2 \%$ & $9,4 \%$ & 1,89 & 1,97 & 1,87 & 2,04 & 1,72 & 1,98 & 1,90 & 2,00 & 1,73 & $2,09^{*}$ & 2,06 & 1,88 \\
\hline $\begin{array}{l}\text { j) Cada proyecto tiene su propia política de } \\
\text { financiación }\end{array}$ & 2,91 & $41,4 \%$ & $37,5 \%$ & 3,00 & 2,83 & 2,88 & 3,02 & 3,03 & 2,87 & 2,90 & 3,06 & 3,69 & $3,12^{*}$ & 2,84 & 3,02 \\
\hline \multirow[t]{2}{*}{ Teoría del Market Timing } & \multirow[t]{2}{*}{ Media } & \multicolumn{2}{|c|}{ Importancia } & \multicolumn{2}{|c|}{ Tamaño } & \multicolumn{2}{|c|}{ Industria } & \multicolumn{2}{|c|}{$\begin{array}{l}\text { Personalidad } \\
\text { jurídica }\end{array}$} & \multicolumn{2}{|c|}{ Empresa cotizada } & \multicolumn{2}{|c|}{$\begin{array}{l}\text { Inversión } \\
\text { extranjero }\end{array}$} & \multicolumn{2}{|c|}{ Tangibilidad } \\
\hline & & Baja & Alta & Pequeñas & Grandes & No & $\mathrm{Si}$ & SL & SA & No & $\mathrm{Si}$ & No & $\mathrm{Si}$ & Baja & Alta \\
\hline $\begin{array}{l}\text { a) Disponibilidad y acceso al } \\
\text { endeudamiento }\end{array}$ & 3,56 & $16,9 \%$ & $64,6 \%$ & 3,55 & 3,66 & 3,51 & 3,62 & 3,50 & 3,56 & 3,54 & 3,67 & 3,52 & 3,57 & 3,52 & 3,76 \\
\hline $\begin{array}{l}\text { b) Se recurre a la deuda cuando los } \\
\text { intereses son bajos }\end{array}$ & 2,20 & $62,2 \%$ & $11,0 \%$ & 2,15 & 2,27 & 2,21 & 2,21 & 2,21 & 2,21 & 2,21 & 2,17 & 2,18 & 2,18 & 2,22 & 2,14 \\
\hline $\begin{array}{l}\text { c) Se usa deuda cuando precio acciones } \\
\text { disminuye }\end{array}$ & 1,34 & $92,0 \%$ & $0,8 \%$ & 1,30 & 1,38 & 1,35 & 1,35 & 1,14 & $1,41^{* *}$ & 1,30 & 1,50 & 1,25 & 1,43 & 1,41 & 1,31 \\
\hline $\begin{array}{l}\text { d) Deuda de corto plazo pues espera bajada } \\
\text { tipos de interés }\end{array}$ & 1,81 & $75,2 \%$ & $7,8 \%$ & 1,68 & 1,95 & 1,73 & 1,96 & 1,45 & $1,92 * *$ & 1,70 & $2,50 * * *$ & 1,53 & $1,97 * *$ & 2,07 & $1,66^{*}$ \\
\hline
\end{tabular}




\section{Tabla 5.13: continuación}

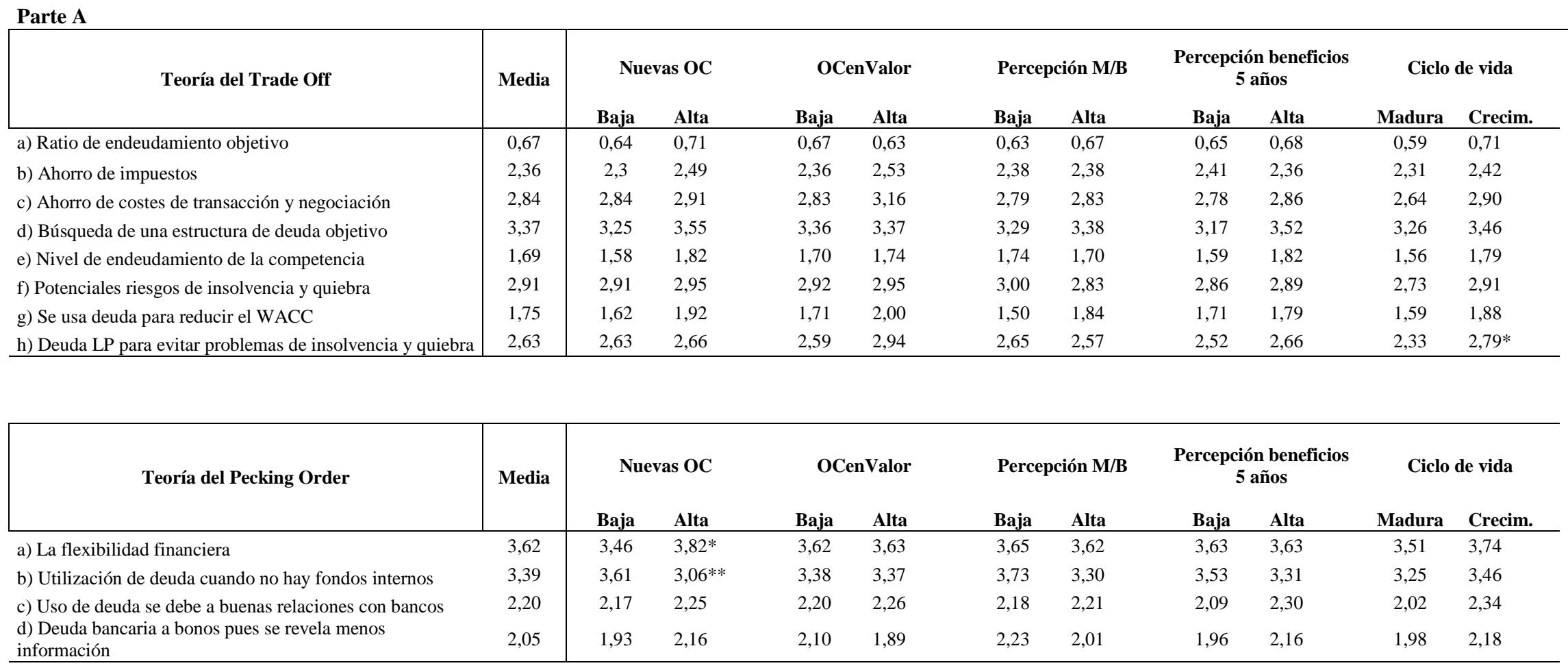


Parte B

\begin{tabular}{|c|c|c|c|c|c|c|c|c|c|c|c|}
\hline \multirow[t]{2}{*}{ Teoría de Agencia } & \multirow[t]{2}{*}{ Media } & \multicolumn{2}{|c|}{ Nuevas OC } & \multicolumn{2}{|c|}{ OCenValor } & \multicolumn{2}{|c|}{ Percepción M/B } & \multicolumn{2}{|c|}{$\begin{array}{l}\text { Percepción beneficios } \\
5 \text { años }\end{array}$} & \multicolumn{2}{|c|}{ Ciclo de vida } \\
\hline & & Baja & Alta & Baja & Alta & Baja & Alta & Baja & Alta & Madura & Crecim. \\
\hline a) El endeudamiento mejora la reputación de la empresa & 1,88 & 1,81 & 2,02 & 1,91 & 1,79 & 1,94 & 1,83 & 1,86 & 1,86 & 1,82 & 1,88 \\
\hline b) Tipo de inversión a realizar o los activos a financiar & 3,53 & 3,20 & $4,02 * * *$ & 3,44 & $4,00^{*}$ & 3,24 & $3,70^{*}$ & 3,47 & 3,66 & 3,47 & 3,62 \\
\hline c) Vida económica de la inversión a financiar & 3,37 & 3,13 & $3,80^{* * *}$ & 3,27 & $3,84^{*}$ & 3,18 & 3,49 & 3,22 & 3,58 & 3,16 & 3,54 \\
\hline d) A mayor garantía ofrecida por los activos mayor deuda & 2,28 & 2,04 & $2,55^{* *}$ & 2,23 & 2,63 & 2,36 & 2,30 & 2,21 & 2,40 & 2,08 & $2,48^{*}$ \\
\hline e) Composición del activo es importante & 1,75 & 1,60 & 1,88 & 1,68 & 2,00 & 1,64 & 1,79 & 1,69 & 1,80 & 1,76 & 1,77 \\
\hline f) Se hace coincidir plazo de deuda con vida de los activos & 3,26 & 3,13 & 3,44 & 3,15 & 3,67 & 3,06 & 3,41 & 3,27 & 3,35 & 3,00 & $3,53 * *$ \\
\hline g) Deuda CP para desincentivar proyectos arriesgados & 1,53 & 1,33 & $1,78^{* * *}$ & 1,54 & 1,56 & 1,59 & 1,53 & 1,61 & 1,48 & 1,41 & $1,66^{*}$ \\
\hline h) Deuda LP para evitar problemas de refinanciación & 3,16 & 3,00 & 3,30 & 3,13 & 3,39 & 3,15 & 3,17 & 3,15 & 3,17 & 2,98 & 3,31 \\
\hline $\begin{array}{l}\text { i) Deuda CP para bajar coste financiación y subir } \\
\text { rentabilidad }\end{array}$ & 1,92 & 1,81 & 2,04 & 1,92 & 1,94 & 1,94 & 1,92 & 1,92 & 1,94 & 1,71 & $2,10^{* *}$ \\
\hline j) Cada proyecto tiene su propia política de financiación & 2,91 & 2,61 & $3,31^{* * *}$ & 2,87 & 3,39 & 2,65 & 3,04 & 2,85 & 3,02 & 2,85 & 3,06 \\
\hline
\end{tabular}

\begin{tabular}{|c|c|c|c|c|c|c|c|c|c|c|c|}
\hline \multirow[t]{2}{*}{ Teoría del Market Timing } & \multirow[t]{2}{*}{ Media } & \multicolumn{2}{|c|}{ Nuevas OC } & \multicolumn{2}{|c|}{ OCenValor } & \multicolumn{2}{|c|}{ Percepción M/B } & \multicolumn{2}{|c|}{$\begin{array}{l}\text { Percepción beneficios } \\
5 \text { años }\end{array}$} & \multicolumn{2}{|c|}{ Ciclo de vida } \\
\hline & & Baja & Alta & Baja & Alta & Baja & Alta & Baja & Alta & Madura & Crecim. \\
\hline a) Disponibilidad y acceso al endeudamiento & 3,56 & 3,45 & 3,69 & 3,63 & 3,32 & 3,59 & 3,58 & 3,56 & 3,60 & 3,61 & 3,49 \\
\hline b) Se recurre a la deuda cuando los intereses son bajos & 2,20 & 2,15 & 2,23 & 2,16 & 2,32 & 2,24 & 2,13 & 2,11 & 2,21 & 2,18 & 2,21 \\
\hline c) Se usa deuda cuando precio acciones disminuye & 1,34 & 1,30 & 1,37 & 1,33 & 1,50 & 1,41 & 1,34 & 1,36 & 1,35 & 1,28 & 1,42 \\
\hline d) Deuda de corto plazo pues espera bajada tipos de interés & 1,81 & 1,79 & 1,84 & 1,84 & 1,72 & 1,82 & 1,80 & 1,69 & 1,91 & 1,87 & 1,78 \\
\hline
\end{tabular}




\section{Tabla 5.13. Continuación}

\begin{tabular}{|c|c|c|c|c|c|c|c|c|c|c|c|c|c|}
\hline \multirow{2}{*}{ Teoría del Trade Off } & \multirow{2}{*}{ Media } & \multicolumn{2}{|c|}{ Ratio objetivo } & \multicolumn{2}{|c|}{ Propiedad CFO } & \multicolumn{2}{|c|}{ MBA } & \multicolumn{2}{|c|}{ Implicación en las DF } & \multicolumn{2}{|c|}{ Implicación en las DI } & \multicolumn{2}{|c|}{ Implicación } \\
\hline & & No & $\mathrm{Si}$ & NO & SI & No & SI & Poca & Mucha & Poca & Mucha & Poca & Mucha \\
\hline a) Ratio de endeudamiento objetivo & 0,67 & & & 0,64 & 0,86 & 0,72 & 0,60 & 0,65 & 0,68 & 0,68 & 0,67 & 0,63 & 0,73 \\
\hline b) Ahorro de impuestos & 2,36 & 2,15 & 2,46 & 2,35 & 2,57 & 2,30 & 2,43 & 2,41 & 2,35 & 2,04 & 2,44 & 2,38 & 2,31 \\
\hline $\begin{array}{l}\text { c) Ahorro de costes de transacción y } \\
\text { negociación }\end{array}$ & 2,84 & 2,42 & $2,98^{* * *}$ & 2,87 & 2,79 & 2,86 & 2,82 & 2,71 & 2,89 & 2,65 & 2,92 & 2,87 & 2,85 \\
\hline $\begin{array}{l}\text { d) Búsqueda de una estructura de } \\
\text { deuda objetivo }\end{array}$ & 3,37 & 2,62 & $3,72^{* * *}$ & 3,37 & 3,43 & 3,40 & 3,40 & 3,29 & 3,41 & 3,27 & 3,42 & 3,28 & 3,56 \\
\hline $\begin{array}{l}\text { e) Nivel de endeudamiento de la } \\
\text { competencia }\end{array}$ & 1,69 & 1,68 & 1,77 & 1,59 & $2,36^{* * *}$ & 1,63 & 1,77 & 1,71 & 1,67 & 1,56 & 1,70 & 1,59 & 1,81 \\
\hline $\begin{array}{l}\text { f) Potenciales riesgos de insolvencia } \\
\text { y quiebra }\end{array}$ & 2,91 & 2,62 & $3,06^{*}$ & 2,85 & $3,43^{*}$ & 2,81 & 3,02 & 2,29 & $3,05 * *$ & 2,56 & $3,04 *$ & 2,87 & 3,06 \\
\hline $\begin{array}{l}\text { g) Se usa deuda para reducir el } \\
\text { WACC }\end{array}$ & 1,75 & 1,58 & 1,87 & 1,72 & 2,00 & 1,76 & 1,75 & 1,88 & 1,73 & 1,58 & 1,80 & 1,70 & 1,83 \\
\hline $\begin{array}{l}\text { h) Deuda LP para evitar problemas } \\
\text { de insolvencia y quiebra }\end{array}$ & 2,63 & 2,56 & 2,70 & 2,55 & $3,21^{*}$ & 2,63 & 2,69 & 2,88 & 2,62 & 2,52 & 2,69 & 2,68 & 2,63 \\
\hline
\end{tabular}

\begin{tabular}{|c|c|c|c|c|c|c|c|c|c|c|c|c|c|}
\hline \multirow{2}{*}{ Teoría del Pecking Order } & \multirow{2}{*}{ Media } & \multicolumn{2}{|c|}{ Ratio objetivo } & \multicolumn{2}{|c|}{ Propiedad CFO } & \multicolumn{2}{|c|}{ MBA } & \multicolumn{2}{|c|}{ Implicación en las DF } & \multicolumn{2}{|c|}{ Implicación en las DI } & \multicolumn{2}{|c|}{ Implicación } \\
\hline & & No & $\mathrm{Si}$ & NO & SI & No & SI & Poca & Mucha & Poca & Mucha & Poca & Mucha \\
\hline a) La flexibilidad financiera & 3,62 & 3,33 & $3,79 * *$ & 3,60 & 3,86 & 3,48 & 3,76 & 3,65 & 3,67 & 3,58 & 3,69 & 3,59 & 3,79 \\
\hline $\begin{array}{l}\text { b) Utilización de deuda cuando no } \\
\text { hay fondos internos }\end{array}$ & 3,39 & 3,64 & 3,34 & 3,38 & 3,46 & 3,49 & 3,29 & 2,76 & $3,54 * *$ & 3,04 & $3,54^{*}$ & 3,33 & 3,58 \\
\hline $\begin{array}{l}\text { c) Uso de deuda se debe a buenas } \\
\text { relaciones con bancos }\end{array}$ & 2,20 & 1,97 & $2,35^{*}$ & 2,18 & 2,46 & 2,28 & 2,15 & 2,24 & 2,23 & 2,12 & 2,26 & 2,19 & 2,29 \\
\hline $\begin{array}{l}\text { d) Deuda bancaria a bonos pues se } \\
\text { revela menos información }\end{array}$ & 2,05 & 1,95 & 2,17 & 2,08 & 2,08 & 2,33 & $1,81^{* *}$ & 1,93 & 2,08 & 1,96 & 2,09 & 1,94 & 2,24 \\
\hline
\end{tabular}


Parte B

\begin{tabular}{|c|c|c|c|c|c|c|c|c|c|c|c|c|c|}
\hline \multirow{2}{*}{ Teoría de Agencia } & \multirow{2}{*}{ Media } & \multicolumn{2}{|c|}{ Ratio objetivo } & \multicolumn{2}{|c|}{ Propiedad CFO } & \multicolumn{2}{|c|}{ MBA } & \multicolumn{2}{|c|}{ Implicación en las DF } & \multicolumn{2}{|c|}{ Implicación en las DI } & \multicolumn{2}{|c|}{ Implicación } \\
\hline & & No & $\mathrm{Si}$ & NO & SI & No & SI & Poca & Mucha & Poca & Mucha & Poca & Mucha \\
\hline $\begin{array}{l}\text { a) El endeudamiento mejora la } \\
\text { reputación de la empresa }\end{array}$ & 1,88 & 1,92 & 1,77 & 1,91 & 1,62 & 1,97 & 1,82 & 2,29 & $1,83^{*}$ & 1,84 & 1,91 & 1,89 & 1,90 \\
\hline $\begin{array}{l}\text { b) Tipo de inversión a realizar o los } \\
\text { activos a financiar }\end{array}$ & 3,53 & 3,46 & 3,72 & 3,54 & 3,43 & 3,44 & 3,65 & 3,41 & 3,55 & 3,31 & 3,59 & 3,38 & $3,77^{*}$ \\
\hline $\begin{array}{l}\text { c) Vida económica de la inversión a } \\
\text { financiar }\end{array}$ & 3,37 & 3,36 & 3,52 & 3,31 & 3,79 & 3,27 & 3,50 & 3,41 & 3,56 & 3,28 & 3,39 & 3,20 & $3,63^{*}$ \\
\hline $\begin{array}{l}\text { d) A mayor garantía ofrecida por los } \\
\text { activos mayor deuda }\end{array}$ & 2,28 & 2,36 & 2,33 & 2,17 & $3,23 * * *$ & 2,25 & 2,31 & 2,12 & 2,34 & 2,15 & 2,35 & 2,12 & $2,58 * *$ \\
\hline $\begin{array}{l}\text { e) Composición del activo es } \\
\text { importante }\end{array}$ & 1,75 & 1,53 & $1,94 * *$ & 1,74 & 1,83 & 1,79 & 1,71 & 1,82 & 1,73 & 1,62 & 1,78 & 1,71 & 1,80 \\
\hline $\begin{array}{l}\text { f) Se hace coincidir plazo de deuda } \\
\text { con vida de los activos }\end{array}$ & 3,26 & 2,98 & $3,63^{* *}$ & 3,17 & $3,86^{*}$ & 3,27 & 3,28 & 3,24 & 3,30 & 3,04 & 3,35 & 2,96 & $3,81 * * *$ \\
\hline $\begin{array}{l}\text { g) Deuda CP para desincentivar } \\
\text { proyectos arriesgados }\end{array}$ & 1,53 & 1,36 & $1,67^{* *}$ & 1,47 & $1,93 * *$ & 1,57 & 1,51 & 1,76 & 1,51 & 1,54 & 1,55 & 1,41 & $1,78^{* *}$ \\
\hline $\begin{array}{l}\text { h) Deuda LP para evitar problemas } \\
\text { de refinanciación }\end{array}$ & 3,16 & 3,08 & 3,33 & 3,14 & 3,50 & 2,97 & $3,43^{*}$ & 3,12 & 3,22 & 2,68 & $3,34 * *$ & 3,14 & 3,32 \\
\hline $\begin{array}{l}\text { i) Deuda CP para bajar coste } \\
\text { financiación y subir rentabilidad }\end{array}$ & 1,92 & 1,62 & $2,10^{* *}$ & 1,86 & 2,29 & 2,03 & 1,84 & 2,00 & 1,91 & 1,88 & 1,94 & 1,79 & $2,15^{*}$ \\
\hline $\begin{array}{l}\text { j) Cada proyecto tiene su propia } \\
\text { política de financiación }\end{array}$ & 2,91 & 2,65 & $3,19 * *$ & 2,86 & 3,36 & 2,77 & 3,10 & 3,35 & 2,89 & 2,80 & 3,00 & 2,81 & 3,19 \\
\hline
\end{tabular}

\begin{tabular}{|c|c|c|c|c|c|c|c|c|c|c|c|c|c|}
\hline \multirow{2}{*}{ Teoría del Market Timing } & \multirow{2}{*}{ Media } & \multicolumn{2}{|c|}{ Ratio objetivo } & \multicolumn{2}{|c|}{ Propiedad CFO } & \multicolumn{2}{|c|}{ MBA } & \multicolumn{2}{|c|}{ Implicación en las DF } & \multicolumn{2}{|c|}{ Implicación en las DI } & \multicolumn{2}{|c|}{ Implicación } \\
\hline & & No & $\mathrm{Si}$ & NO & SI & No & SI & Poca & Mucha & Poca & Mucha & Poca & Mucha \\
\hline $\begin{array}{l}\text { a) Disponibilidad y acceso al } \\
\text { endeudamiento }\end{array}$ & 3,56 & 3,31 & $3,74^{*}$ & 3,50 & 3,86 & 3,45 & 3,63 & 2,94 & $3,69 * *$ & 3,31 & 3,66 & 3,53 & 3,69 \\
\hline $\begin{array}{l}\text { b) Se recurre a la deuda cuando los } \\
\text { intereses son bajos }\end{array}$ & 2,20 & 2,15 & 2,22 & 2,15 & $2,69 *$ & 2,16 & 2,27 & 2,24 & 2,20 & 2,04 & 2,25 & 2,21 & 2,21 \\
\hline $\begin{array}{l}\text { c) Se usa deuda cuando precio } \\
\text { acciones disminuye }\end{array}$ & 1,34 & 1,32 & 1,38 & 1,34 & 1,38 & 1,43 & 1,27 & 1,65 & $1,31^{*}$ & 1,32 & 1,37 & 1,36 & 1,36 \\
\hline $\begin{array}{l}\text { d) Deuda de corto plazo pues espera } \\
\text { bajada tipos de interés }\end{array}$ & 1,81 & 1,60 & 1,91 & 1,77 & 2,14 & 1,94 & 1,72 & 2,18 & 1,75 & 1,81 & 1,81 & 1,73 & 1,94 \\
\hline
\end{tabular}


La relación entre el patrón de financiación seguido por la empresa y las características generales de las empresas consideradas en este estudio se muestra en la tabla 5.14. Destaca la influencia positiva (y significativa) de la dimensión empresarial en tres de los seis variables representativas del patrón de financiación de la empresa. Cuanto mayor es el tamaño de la empresa, mayor es la importancia que se le atribuye a la búsqueda de una estructura de financiación objetivo, así como a la utilización de deuda para reducir el coste medio ponderado del capital. Además, para este tipo de empresas la contratación de deuda de corto plazo a la espera de una bajada de los tipos de interés también es de alta importancia. Todas estas cuestiones, reivindican en cierto modo los postulados tradicionales acerca de la mayor posibilidad de las empresas más grandes de acceder de manera más fácil al mercado y de buscar aquellas alternativas que favorezcan a la empresa, aprovechándose de las ventanas de oportunidad que se generan (Pettit y Singer, 1985; Graham y Harvey, 2001).

Las sociedades anónimas y empresas no industriales son las que mayor relevancia otorgan a la utilización de deuda para reducir el WACC, mientras que las sociedades anónimas y las empresas de sectores distintos al de servicios son las que favorecen la utilización de deuda de corto plazo a la espera de una bajada de los tipos de interés. Finalmente, la realización de inversiones en el extranjero (invext), presumiblemente empresas de mayor dimensión ${ }^{51}$, favorece la búsqueda de una estructura de financiación objetivo (deudaobj), la utilización de deuda para reducir el WACC (redwacc) y la supervisión del mercado (CPintbajo).

${ }^{51}$ Existe correlación estadísticamente significativa (al 1\%) entre las variables tamaño e inversión en el extranjero, con una correlación no demasiado alta del 28\% (Tabla 5.2). 


\section{Tabla 5.14: Influencia de las características de la empresa sobre el patrón de financiación seguido por la empresa}

La tabla presenta los coeficientes estimados mediante regresiones univariantes tipo probit ordenado en las que se relaciona la frecuencia de uso de cada una de las técnicas con distintas variables representativas de las características de la empresa. Debajo de cada coeficiente, en cursiva, se muestra el pseudo R2, Las variables independientes se definen de la siguiente forma. La variable tamaño es el logaritmo neperiano de las ventas (en millones). Las variables de sector son dummies que indican la pertenencia a uno de los seis sectores considerados: energía, industria, consumo, servicios, inmobiliario y telecomunicación. La variable persjur es una dummy que adopta el valor uno si la empresa es Sociedad Anónima y cero en caso de Sociedad de Responsabilidad Limitada. La variable invext es una dummy que toma valor uno si la empresa invierte en el exterior y cero en caso contrario.

\begin{tabular}{|c|c|c|c|c|c|c|}
\hline & Deudaobj & Redwacc & Flexifin & CPcosterent & Sustitución & CPintbajo \\
\hline \multirow[t]{2}{*}{ tamaño } & $0,135^{* *}$ & $0,220 * * *$ & $-0,015$ & 0,058 & $-0,051$ & $0,114^{*}$ \\
\hline & 0,0130 & 0,0368 & 0,0002 & 0,0026 & 0,0021 & 0,0095 \\
\hline \multirow[t]{2}{*}{ energía } & 0,185 & $-0,050$ & $-0,200$ & $-0,316$ & $-0,712$ & 0,299 \\
\hline & 0,0008 & 0,0001 & 0,0010 & 0,0025 & 0,0113 & 0,0025 \\
\hline \multirow[t]{2}{*}{ industria } & $-0,064$ & $-0,443 * *$ & 0,009 & 0,155 & 0,263 & 0,196 \\
\hline & 0,0003 & 0,0143 & 0,0000 & 0,0019 & 0,0060 & 0,0029 \\
\hline \multirow[t]{2}{*}{ consumo } & $-0,299$ & 0,363 & $-0,173$ & 0,127 & 0,115 & 0,310 \\
\hline & 0,0035 & 0,0061 & 0,0012 & 0,0007 & 0,0007 & 0,0043 \\
\hline \multirow[t]{2}{*}{ servicios } & 0,136 & 0,095 & 0,139 & $-0,150$ & $-0,123$ & $-0,449 *$ \\
\hline & 0,0012 & 0,0006 & 0,0012 & 0,0015 & 0,0011 & 0,0124 \\
\hline \multirow[t]{2}{*}{ inmobiliario } & 0,208 & 0,462 & 0,321 & $-0,176$ & 0,100 & $-0,495$ \\
\hline & 0,0007 & 0,0043 & 0,0017 & 0,0006 & 0,0002 & 0,0039 \\
\hline \multirow[t]{2}{*}{ telecomunicación } & $-0,013$ & 0,243 & $-0,593$ & 0,617 & $-4,645$ & $-0,244$ \\
\hline & 0,0000 & 0,0003 & 0,0018 & 0,0022 & 0,0077 & 0,0003 \\
\hline \multirow[t]{2}{*}{ persjur } & $-0,084$ & $0,450^{*}$ & $-0,057$ & 0,345 & 0,417 & $0,637^{* *}$ \\
\hline & 0,0004 & 0,0110 & 0,0002 & 0,0065 & 0,0100 & 0,0195 \\
\hline \multirow[t]{2}{*}{ invext } & $0,375^{*}$ & 0,200 & 0,247 & $0,412 * *$ & 0,072 & $0,544^{* *}$ \\
\hline & 0,0103 & 0,0032 & 0,0046 & 0,0132 & 0,0005 & 0,0226 \\
\hline
\end{tabular}

*** indica significativo al 1\%, ** al 5\% y * al 10\% 
A diferencia de las características empresariales, las relativas al director financiero no parecen tener demasiada relevancia en la determinación del patrón de financiación de la empresa (tabla 5.15). No obstante, la mayor experiencia profesional del director financiero implica mayor utilización de deuda para reducir el WACC y para reducir los problemas de agencia de subinversión (utilizar deuda de corto plazo para reducir el coste de financiación y así aumentar la rentabilidad de los accionistas). Además, la pertenencia al consejo de administración está asociada a una mayor importancia atribuida a la flexibilidad financiera. 


\section{Tabla 5.15: Influencia de las características del director financiero sobre el patrón de financiación seguido por la empresa}

La tabla presenta los coeficientes estimados mediante regresiones univariantes tipo probit ordenado en las que se relaciona la frecuencia de uso de cada una de las técnicas con distintas variables representativas del director financiero. Debajo de cada coeficiente, en cursiva, se muestra el pseudo R2. Las variables independientes se definen de la siguiente forma. La variable edad es una variable categórica ordenada en cinco niveles. Las variables añosexp, experemp y expercfo indican, respectivamente, el número de años de experiencia laboral, en la empresa y en el cargo de director financiero. La variable $m b a$ es una dummy que toma valor igual a uno si el director financiero tiene un MBA o máster especializado en finanzas y cero en caso contrario. La variable consejo es una dummy que toma valor uno si el director financiero es miembro del Consejo de Administración y cero en caso contrario. Finalmente, la variable impliDF es una variable categórica ordenada en cuatro niveles que mide el grado de implicación del director financiero en las decisiones de financiación de la empresa.

\begin{tabular}{lcccccc}
\hline & Deudaobj & Redwacc & Flexifin & CPcosterent & Sustitución & CPintbajo \\
\hline edad & 0,064 & 0,109 & $-0,115$ & 0,094 & 0,087 & 0,060 \\
& 0,0009 & 0,0028 & 0,0028 & 0,0020 & 0,0019 & 0,0008 \\
\hline añosexp & $-0,003$ & $0,023^{*}$ & $-0,016$ & $0,022^{*}$ & 0,015 & 0,012 \\
& 0,0001 & 0,0104 & 0,0049 & 0,0096 & 0,0052 & 0,0025 \\
\hline experemp & 0,002 & 0,004 & $-0,006$ & 0,004 & 0,005 & 0,014 \\
& 0,0001 & 0,0005 & 0,0007 & 0,0004 & 0,0008 & 0,0050 \\
\hline \multirow{2}{*}{ expercfo } & $-0,015$ & 0,010 & $-0,002$ & 0,019 & 0,017 & 0,011 \\
& 0,0027 & 0,0012 & 0,0001 & 0,0046 & 0,0043 & 0,0014 \\
\hline consejo & 0,029 & $-0,075$ & 0,272 & $-0,205$ & $-0,107$ & $-0,216$ \\
& 0,0001 & 0,0005 & 0,0057 & 0,0034 & 0,0010 & 0,0037 \\
\hline impliDF & $-0,020$ & $-0,223$ & $0,449 * *$ & 0,063 & 0,361 & $-0,123$ \\
& 0,0000 & 0,0032 & 0,0123 & 0,0003 & 0,0100 & 0,0010 \\
\hline
\end{tabular}

*** indica significativo al 1\%, ** al 5\% y * al 10\% 
La tabla 5.16 presenta los resultados de la estimación del modelo 6, con el que se contrasta la hipótesis de influencia simultánea de las características de la empresa y del director financiero sobre el patrón de financiación seguido por la empresa (hipótesis 5). Se estiman dos especificaciones diferentes del modelo. En el modelo 6.1, las características de la empresa han sido aproximadas mediante el tamaño (medido a través del logaritmo neperiano de las ventas), industria (que es una dummy que indica si la empresa pertenece al sector industria), y persjur (variable dicotómica que indica si la empresa es sociedad anónima o de responsabilidad limitada). Las características del director financiero se aproximan a través de las variables edad (variable categórica de cinco niveles que refleja la edad del director financiero), mba (variable dummy que toma valor 1 si el director tiene un MBA o máster de especialidad en finanzas), e impliDF (variable categórica de cuatro niveles que refleja el nivel de implicación perciba por el director financiero en las decisiones financieros de su empresa). En el modelo 6.2 se reemplaza la variable industria por servicios (dummy que indica si la empresa pertenece al sector servicios), y edad por añosexp (indicativa de la experiencia en la profesión). 
ANÁLISIS DE RESULTADOS

Tabla 5.16: Patrón de financiación y características de la empresa y del director financiero

\begin{tabular}{|c|c|c|c|c|c|c|c|c|c|c|c|c|c|c|c|c|c|}
\hline & \multicolumn{4}{|c|}{ deudaobj } & \multicolumn{4}{|c|}{ redwacc } & \multicolumn{2}{|c|}{ flexifin } & \multicolumn{2}{|c|}{ subinver } & \multicolumn{2}{|c|}{ sustitución } & \multicolumn{3}{|c|}{ bajaint } \\
\hline & M6.1 & & M6.2 & & M6.1 & & M6.2 & & M6.1 & M6.2 & M6.1 & M6.2 & M6.1 & M6.2 & M6.1 & M6.2 & \\
\hline \multirow[t]{2}{*}{ tamaño } & 0,136 & $* *$ & 0,134 & $* *$ & 0,193 & $* * *$ & 0,197 & $* * *$ & $-0,006$ & $-0,013$ & 0,038 & 0,029 & $-0,079$ & $-0,087$ & 0,100 & 0,110 & \\
\hline & $(0,06)$ & & $(0,07)$ & & $(0,07)$ & & $(0,07)$ & & $(0,06)$ & $(0,07)$ & $(0,07)$ & $(0,07)$ & $(0,08)$ & $(0,08)$ & $(0,07)$ & $(0,07)$ & \\
\hline \multirow[t]{2}{*}{ industria } & $-0,005$ & & & & $-0,364$ & & & & 0,012 & & 0,149 & & 0,251 & & 0,177 & & \\
\hline & $(0,20)$ & & & & $(0,23)$ & & & & $(0,20)$ & & $(0,21)$ & & $(0,23)$ & & $(0,22)$ & & \\
\hline \multirow[t]{2}{*}{ servicios } & & & 0,126 & & & & 0,103 & & & 0,227 & & $-0,109$ & & $-0,095$ & & $-0,515$ & ** \\
\hline & & & $(0,22)$ & & & & $(0,25)$ & & & $(0,22)$ & & $(0,23)$ & & $(0,26)$ & & $(0,25)$ & \\
\hline \multirow[t]{2}{*}{ persjur } & $-0,102$ & & $-0,069$ & & 0,336 & & 0,265 & & 0,002 & 0,035 & 0,352 & 0,297 & $0,500 *$ & 0,444 & 0,540 & 0,606 & ** \\
\hline & $(0,24)$ & & $(0,24)$ & & $(0,28)$ & & $(0,29)$ & & $(0,24)$ & $(0,24)$ & $(0,26)$ & $(0,27)$ & $(0,29)$ & $(0,30)$ & $(0,28)$ & $(0,29)$ & \\
\hline \multirow[t]{2}{*}{ mba } & $-0,027$ & & $-0,033$ & & $-0,136$ & & $-0,070$ & & 0,242 & 0,237 & $-0,090$ & $-0,072$ & 0,049 & 0,063 & $-0,075$ & $-0,138$ & \\
\hline & $(0,20)$ & & $(0,20)$ & & $(0,22)$ & & $(0,23)$ & & $(0,20)$ & $(0,20)$ & $(0,21)$ & $(0,21)$ & $(0,23)$ & $(0,23)$ & $(0,22)$ & $(0,22)$ & \\
\hline \multirow[t]{2}{*}{ edad } & 0,029 & & & & 0,060 & & & & $-0,123$ & & 0,045 & & 0,074 & & 0,001 & & \\
\hline & $(0,12)$ & & & & $(0,13)$ & & & & $(0,12)$ & & $(0,13)$ & & $(0,14)$ & & $(0,13)$ & & \\
\hline \multirow[t]{2}{*}{ añosexp } & & & $-0,006$ & & & & 0,014 & & & $-0,013$ & & 0,013 & & 0,011 & & $-0,007$ & \\
\hline & & & $(0,01)$ & & & & $(0,02)$ & & & $(0,01)$ & & $(0,01)$ & & $(0,02)$ & & $(0,01)$ & \\
\hline \multirow[t]{2}{*}{ impliDF } & 0,181 & & 0,179 & & $-0,090$ & & $-0,096$ & & 0,126 & 0,110 & 0,040 & 0,048 & $-0,111$ & $-0,094$ & $-0,113$ & $-0,090$ & \\
\hline & $(0,12)$ & & $(0,12)$ & & $(0,13)$ & & $(0,13)$ & & $(0,12)$ & $(0,12)$ & $(0,13)$ & $(0,13)$ & $(0,13)$ & $(0,13)$ & $(0,12)$ & $(0,12)$ & \\
\hline $\mathrm{N}$ & 119 & & 117 & & 116 & & 114 & & 120 & 118 & 117 & 115 & 116 & 115 & 118 & 116 & \\
\hline $\mathrm{F}$ & 7,39 & & 7,75 & & 15,63 & $* *$ & 13,31 & $* *$ & 4,10 & 5,18 & 3,49 & 4,06 & 5,64 & 4,77 & 8,76 & 12,14 & $*$ \\
\hline Pseudo R2 & 0,021 & & 0,022 & & 0,059 & & 0,051 & & 0,012 & 0,015 & 0,012 & 0,014 & 0,025 & 0,021 & 0,031 & 0,043 & \\
\hline Loglikelih. & $-172,5$ & & $-170,0$ & & $-125,0$ & & $-122,8$ & & $-169,7$ & $-166,5$ & $-146,2$ & $-143,5$ & $-110,4$ & $-109,4$ & $-138,9$ & $-134,8$ & \\
\hline
\end{tabular}

$* * *, * *, *$ indica significativa al 1\%, 5\% y 10\%, respectivamente. 
Los resultados indican que la variable tamaño es la más relevante en términos de poder explicativo del patrón de financiación. La mayor importancia atribuida a la búsqueda de una estructura de financiación objetivo (acorde con la existencia de un nivel óptimo de endeudamiento) y a la utilización de deuda para reducir el coste medio ponderado de la empresa viene determinada, positivamente, por el tamaño de la empresa. A mayor tamaño de la empresa, mayor es la importancia atribuida a los elementos del patrón de financiación asociado a la teoría del trade off (tanto en el modelo 6.1 como en el modelo 6.2). La personalidad jurídica es la que determina en mayor medida la importancia atribuida al problema de sustitución de activos (emisión de deuda de corto plazo para evitar acometer proyectos de riesgo elevado) y al de monitoreo del mercado (contratación de deuda de corto plazo a la espera de una bajada en los tipos de interés). De manera particular, esta importancia es mayor en las empresas que revisten la forma de sociedades anónimas y pertenecen a sectores distintos al de servicios.

En conjunto estos resultados se muestran parcialmente en línea con lo expuesto en la hipótesis 5 . No encontramos que las características del director financiero sean determinantes en la definición del patrón de financiación seguido y sólo algunas variables que definen el perfil de la empresa son relevantes, destacando el papel de la dimensión empresarial en el sentido descrito por la hipótesis 5.1.

El contraste de la hipótesis 6 se realiza por medio de los resultados presentados en la tabla 5.17. Esta hipótesis, que relaciona la influencia de las fuentes de valor a disposición de la empresa sobre su patrón de financiación, se estudia por medio de las versiones del modelo 7. Las variables aproximativas de las fuentes de valor son potencia, que mide la frecuencia con que las inversiones pasadas abren nuevas oportunidades de inversión, y las variables que aproximan la relevancia de la flexibilidad asociada a los proyectos de inversión: posibilidad de intercambiar los inputs de producción (inputs), de modificar el tamaño (modtam) y de aplazar su iniciación (aplazar). 
ANÁlisis DE RESULTADOS

Tabla 5.17: Patrón de financiación y fuentes de valor

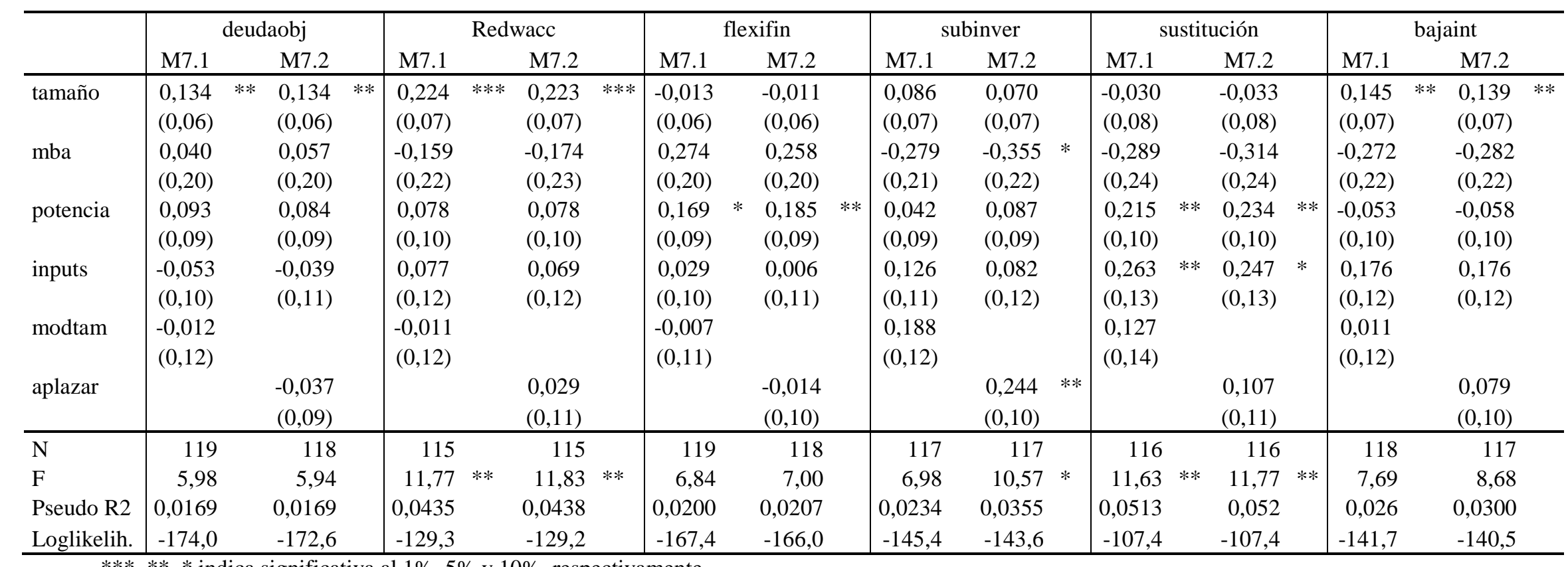

***, **, * indica significativa al 1\%, 5\% y $10 \%$, respectivamente. 
Los resultados confirman una alta (y significativa) influencia positiva de la variable potencia sobre la flexibilidad financiera, indicando que aquellas empresas con mayores oportunidades de crecimiento son las que mayor relevancia atribuyen a la flexibilidad financiera. La teoría del pecking order establece que las empresas con mayores oportunidades futuras de crecimiento tienden a crear mayor holgura financiera y dar alta importancia a la flexibilidad financiera. Estos resultados sirven de respaldo a la hipótesis 6.1: en aquellas empresas donde los resultados intangibles y estratégicos predominen sobre los resultados monetarios, los problemas de información asimétrica cobran mayor importancia (que se acentúa en empresas con altas oportunidades de crecimiento).

Las empresas con elevadas oportunidades de crecimiento son también las que mayor importancia atribuyen a la utilización de deuda de corto plazo para la resolución de los problemas de sustitución de activos y subinversión, en línea con lo planteado por la teoría de la agencia y lo propuesto en la hipótesis 6.1. En cuanto a las variables de flexibilidad operativa asociada a los proyectos, sólo el intercambio de inputs productivos tiene significación estadística (en ambos modelos) con el patrón de agencia, específicamente con el efecto sustitución. La mayor discrecionalidad directiva asociada a la flexibilidad de la inversión incrementa la relevancia de los problemas de selección adversa y riesgo moral de la empresa, por lo que encontramos evidencia favorable a la importancia atribuida a la contratación de deuda de corto plazo en la solución de los problemas de agencia, particularmente, como desincentivo para acometer proyectos de riesgo elevado.

Finalmente, los resultados del modelo 7.2 indican que las empresas que mayor importancia atribuyen a la facilidad con que los proyectos permiten aplazar su iniciación (flexibilidad de la inversión) son también las que mayor importancia otorgan a la utilización de deuda de corto plazo para reducir el coste de financiación y aumentar la rentabilidad y, por tanto, también resolver problemas de agencia del tipo subinversión. 
Aparte de corroborar la relevancia del tamaño en el patrón de financiación seguido por la empresa, estos resultados sólo respaldan la hipótesis 6.1, de manera particular, en la influencia positiva (y significativa) de la mayor tenencia de oportunidades de crecimiento en el patrón de financiación acorde con la teoría del peking order y de agencia (para el caso del problema de sustitución de activos).

Con el objetivo de verificar los anteriores resultados hemos realizado un análisis de robustez sobre el modelo 7. La tabla 5.18 comprueba el poder explicativo de las oportunidades de inversión y flexibilidad cuando las variables de control de tamaño y mba son reemplazadas por las variables indicativas de si la empresa invierte en el extranjero (invext), el grado de implicación del director financiero en las decisiones de financiación (impliDF) y sus años de experiencia en la empresa (experemp).

Comparado con la tabla 5.17, cabe destacar que los modelos pierden significación conjunta para explicar el patrón de financiación. La variable invext es menos determinante en el patrón seguido por la empresa que el tamaño de la empresa, así como la relevancia de las empresas con mayores oportunidades de crecimiento en la resolución de los problemas de agencia. La mayor experiencia profesional del director financiero favorece el mayor monitoreo del mercado para “aprovechar” sus oportunidades. 
Tabla 5.18: Variables de control y de fuentes de valor

La tabla presenta los coeficientes estimados mediante regresiones multivariantes tipo probit ordenado del modelo 7, con el que se relaciona la importancia atribuida a cada uno de los patrones de financiación seguido por la empresa y variables aproximativas de las fuentes de valor de la inversión. Las variables de control son invext que es una dummy que toma el valor 1 si la empresa invierte en el exterior y cero en caso contrario, impliDF que mide el grado de implicación del director financiero en las decisiones de financiación según una escala de 1 a 4 y experemp que aproxima el número de años del director financiero en la empresa. Además, se sustituye potencia por OCenvalor, que es una variable categórica ordenada en cinco niveles según peso de las oportunidades futuras de inversión en el valor actual de la empresa. Debajo de cada coeficiente, entre paréntesis, se muestra el error estándar.

\begin{tabular}{|c|c|c|c|c|c|c|c|c|}
\hline & deudaobj & \multicolumn{2}{|c|}{ redwacc } & flexifin & \multirow{2}{*}{$\begin{array}{r}\text { CPcosterent } \\
\text { M7.3 }\end{array}$} & \multirow{2}{*}{$\begin{array}{r}\text { Sustitución } \\
\text { M7.3 }\end{array}$} & \multirow{2}{*}{\multicolumn{2}{|c|}{$\begin{array}{r}\text { CPintbajo } \\
\text { M7.3 }\end{array}$}} \\
\hline & M7.3 & & M7.3 & M7.3 & & & & \\
\hline \multirow[t]{2}{*}{ invext } & 0,391 & $*$ & 0,074 & 0,273 & 0,382 & $-0,030$ & 0,482 & $* *$ \\
\hline & $(0,22)$ & & $(0,24)$ & $(0,22)$ & $(0,23)$ & $(0,24)$ & $(0,24)$ & \\
\hline \multirow[t]{2}{*}{ impliDF } & 0,171 & & $-0,008$ & 0,154 & $-0,019$ & $-0,078$ & $-0,067$ & \\
\hline & $(0,13)$ & & $(0,15)$ & $(0,13)$ & $(0,14)$ & $(0,15)$ & $(0,14)$ & \\
\hline \multirow[t]{2}{*}{ experemp } & $-0,002$ & & 0,000 & $-0,004$ & 0,012 & 0,006 & 0,022 & $*$ \\
\hline & $(0,01)$ & & $(0,01)$ & $(0,01)$ & $(0,01)$ & $(0,01)$ & $(0,01)$ & \\
\hline \multirow[t]{2}{*}{ OCenvalor } & 0,215 & $* *$ & 0,269 & ** $\quad-0,003$ & 0,016 & 0,113 & 0,079 & \\
\hline & $(0,10)$ & & $(0,11)$ & $(0,10)$ & $(0,11)$ & $(0,11)$ & $(0,11)$ & \\
\hline \multirow[t]{2}{*}{ inputs } & $-0,059$ & & 0,035 & 0,037 & 0,067 & 0,194 & 0,076 & \\
\hline & $(0,11)$ & & $(0,13)$ & $(0,11)$ & $(0,12)$ & $(0,14)$ & $(0,13)$ & \\
\hline \multirow[t]{2}{*}{ modtam } & $-0,084$ & & $-0,130$ & 0,095 & 0,175 & 0,182 & $-0,011$ & \\
\hline & $(0,13)$ & & $(0,14)$ & $(0,13)$ & $(0,14)$ & $(0,15)$ & $(0,14)$ & \\
\hline $\mathrm{N}$ & 112 & & 109 & 112 & 109 & 109 & 110 & \\
\hline F & 12,25 & $*$ & 7,65 & 5,50 & 6,30 & 6,27 & 8,53 & \\
\hline Pseudo R2 & 0,0361 & & 0,0308 & 0,0171 & 0,0228 & 0,0291 & 0,0328 & \\
\hline
\end{tabular}

La tabla 5.19 verifica la sensibilidad de los resultados frente al cambio en una de las variables dependientes, deudaobj por target, que indica si la empresa establece un ratio de endeudamiento de referencia. Los resultados de la estimación confirman que las compañías de mayor tamaño son las que mayor importancia atribuyen al establecimiento del target, similar al resultado de la tabla 5.18. Sin embargo, comparado con aquella misma tabla también asume relevancia (aunque sólo en uno de los cuatro modelos) la mayor especialización del director financiero (directores financieros con MBA o máster de especialidad). Esta mayor formación se muestra asociada a una tendencia a no seguir la teoría del trade off, específicamente, en el establecimiento de un target de deuda. Las demás variables 
siguen un comportamiento similar al de la tabla 5.17 en su relación con este patrón de financiación.

\title{
Tabla 5.19: Robustez sobre la variable dependiente target
}

\begin{abstract}
La tabla presenta los coeficientes estimados, mediante regresiones multivariantes tipo probit, que relacionan el establecimiento de un ratio de deuda objetivo (target) con variables aproximativas de las fuentes de valor de la inversión. La variable dependiente es una dummy que toma el valor uno si la empresa establece un target y cero en caso contrario. Debajo de cada coeficiente, entre paréntesis, se muestra el error
\end{abstract} estándar.

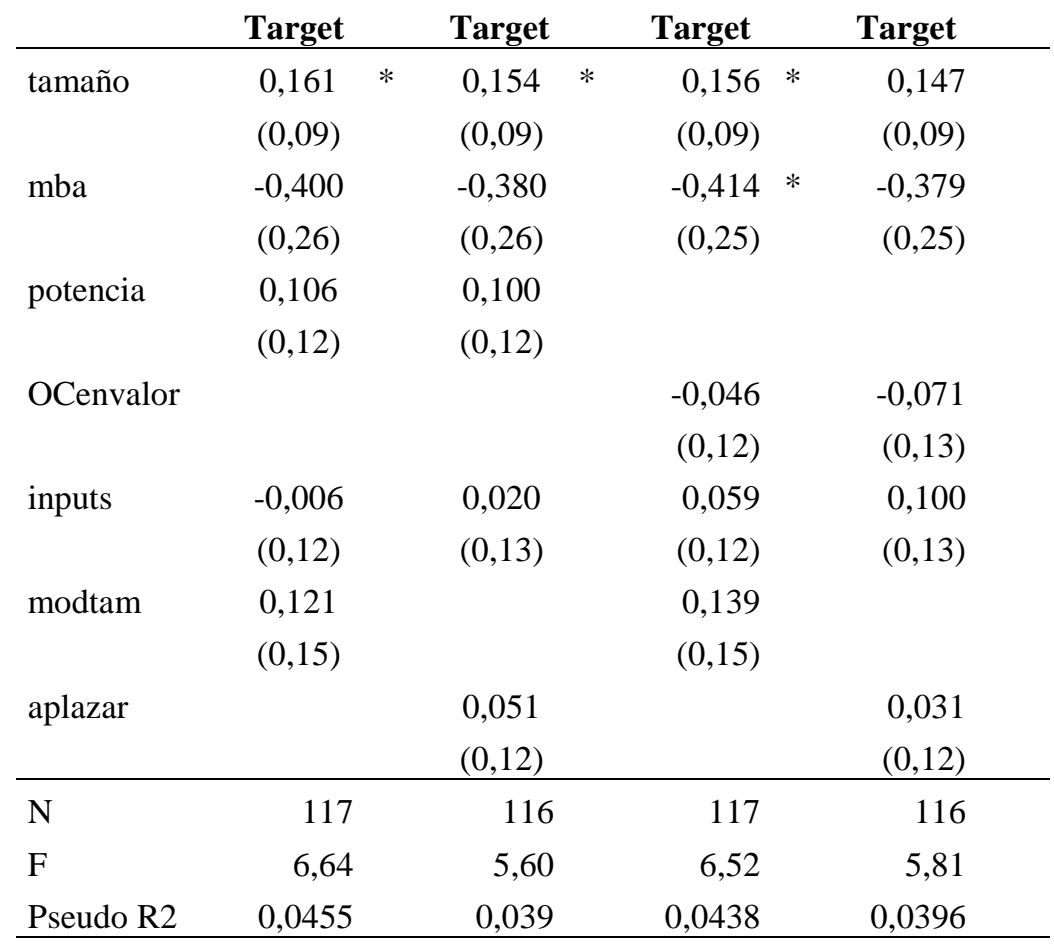

*** indica significativo al $1 \%$, ** al $5 \% \mathrm{y} *$ al $10 \%$

La tabla 5.20 muestra los resultados del contraste de la hipótesis 7, que relaciona los determinantes estándar de la estructura de capital y el nivel observado de endeudamiento de las empresas. Esta relación es evaluada para cada uno de los cuatro patrones de financiación, mediante su estimación en cada una de las dos submuestras (a y b) que resultan de segmentar de acuerdo con la importancia del patrón. Esta última se aproxima a partir de la importancia conferida a una de las variables representativas de las teorías. En cada contraste se 
revisan dos modelos diferentes en la especificación de las proxies de los determinantes estándar del endeudamiento.

Los determinantes estándar utilizados en las regresiones son tamaño, a través del logaritmo neperiano de los ingresos, tangibilidad, que corresponde al porcentaje que representa el valor contable neto del inmovilizado intangible en el activo total, rentab1, que considera el grado de acuerdo/desacuerdo en cuanto a que la empresa aumentará mucho sus beneficios dentro de cinco años, rentab2, importancia atribuida a la rentabilidad de la inversión pasada, $M B$, que indica la percepción directiva acerca de la superioridad del valor de la empresa respecto de su valor contable, y potencia, que es una variable categórica que indica la frecuencia con que las inversiones pasadas abren nuevas oportunidades de inversión. 


\section{Tabla 5.20: Determinantes estándar del endeudamiento y el patrón de financiación de la empresa}

La tabla presenta la regresión de hechos estilizados, del tipo lineales múltiples, en las dos primeras columnas (M.81 y M8.2). En las siguientes columnas se presenta esta misma regresión en submuestras, a partir de la mediana, de baja (modelo 8.1a y 8.2a) y alta (modelo 8.1b y 8.2b) de la importancia atribuida a cada una de las seis variables representativas del patrón de financiación seguido por la empresa. La variable dependiente es deuda que indica el porcentaje de deuda total a total activos. Las variables independientes del modelo 8.1 son tamaño (logaritmo neperiano de las ventas); tangibilidad (porcentaje del valor contable neto del inmovilizado intangible sobre el activo total); rentab1 (variable categórica que indica el grado de desacuerdo/acuerdo con que la empresa aumentará mucho sus beneficios dentro de cinco años), rentab2 (variable categórica que indica la importancia atribuida a la rentabilidad de la inversión pasada); $M B$ (variable categórica que indica la percepción de la superioridad del valor de la empresa respecto de su valor contable) y potencia (variable categórica que indica la frecuencia con que las inversiones pasadas abren nuevas oportunidades de inversión). Debajo de cada coeficiente, entre paréntesis, se muestra el error estándar.

\begin{tabular}{|c|c|c|c|c|c|c|c|c|c|c|c|c|c|c|c|c|}
\hline \multirow[b]{3}{*}{ constante } & \multicolumn{2}{|c|}{ Hechos estilizados } & \multicolumn{7}{|c|}{$\begin{array}{c}\text { Tradeoff1 } \\
\text { Variable de segmentación: } \\
\text { "Búsqueda de endeudamiento objetivo" }\end{array}$} & \multicolumn{7}{|c|}{$\begin{array}{c}\text { Tradeoff2 } \\
\text { Variable de segmentación: } \\
\text { "Utilización de endeudamiento para reducir el coste medio } \\
\text { ponderado del capital” }\end{array}$} \\
\hline & \multirow{2}{*}{$\begin{array}{c}\text { M8.1 } \\
0,985^{* * *} \\
(0,267)\end{array}$} & \multirow{2}{*}{$\begin{array}{c}\text { M8.2 } \\
0,810^{* * *} \\
(0,267)\end{array}$} & \multirow{2}{*}{$\begin{array}{c}\text { M8.1a } \\
0,561 \\
(0,377)\end{array}$} & \multicolumn{2}{|c|}{ M8.2a } & \multirow{2}{*}{$\begin{array}{c}\text { M8.1b } \\
1,094 \\
(0,404)\end{array}$} & \multicolumn{3}{|c|}{ M8.2b } & \multirow{2}{*}{$\begin{array}{c}\text { M8.1a } \\
0,770 \\
(0,323)\end{array}$} & \multicolumn{2}{|c|}{ M8.2a } & \multicolumn{2}{|c|}{ M8.1b } & \multicolumn{2}{|c|}{ M8.2b } \\
\hline & & & & $\begin{array}{c}0,879 \\
(0,384)\end{array}$ & $* *$ & & $* * *$ & $\begin{array}{c}1,208 \\
(0,388)\end{array}$ & $* * *$ & & $* *$ & $\begin{array}{c}0,953 \\
(0,326)\end{array}$ & $* * *$ & $\begin{array}{c}0,840 \\
(0,572)\end{array}$ & $\begin{array}{c}1,197 \\
(0,581)\end{array}$ & $* *$ \\
\hline tamaño & $\begin{array}{l}-0,011 \\
(0,019)\end{array}$ & $\begin{array}{l}-0,012 \\
(0,019)\end{array}$ & $\begin{array}{l}-0,029 \\
(0,027)\end{array}$ & $\begin{array}{l}-0,030 \\
(0,028)\end{array}$ & & $\begin{array}{c}0,012 \\
(0,029)\end{array}$ & & $\begin{array}{c}0,012 \\
(0,028)\end{array}$ & & $\begin{array}{l}-0,008 \\
(0,028)\end{array}$ & & $\begin{array}{l}-0,023 \\
(0,027)\end{array}$ & & $\begin{array}{l}-0,016 \\
(0,034)\end{array}$ & $\begin{array}{l}-0,022 \\
(0,036)\end{array}$ & \\
\hline tangibilidad & $\begin{array}{l}-0,003 \\
(0,002)\end{array}$ & $\begin{array}{l}-0,001 \\
(0,002)\end{array}$ & $\begin{array}{c}0,001 \\
(0,003)\end{array}$ & $\begin{array}{l}-0,001 \\
(0,003)\end{array}$ & & $\begin{array}{l}-0,005 \\
(0,004)\end{array}$ & & $\begin{array}{l}-0,007 \\
(0,003)\end{array}$ & $* *$ & $\begin{array}{c}0,000 \\
(0,003)\end{array}$ & & $\begin{array}{l}-0,002 \\
(0,003)\end{array}$ & & $\begin{array}{l}-0,002 \\
(0,004)\end{array}$ & $\begin{array}{l}-0,007 \\
(0,005)\end{array}$ & \\
\hline rentab1 & & $\begin{array}{l}-0,033 \\
(0,031)\end{array}$ & & $\begin{array}{c}0,010 \\
(0,046)\end{array}$ & & & & $\begin{array}{l}-0,060 \\
(0,043)\end{array}$ & & & & $\begin{array}{l}-0,043 \\
(0,042)\end{array}$ & & & $\begin{array}{c}0,026 \\
(0,055)\end{array}$ & \\
\hline rentab2 & $\begin{array}{c}0,030 \\
(0,031)\end{array}$ & & $\begin{array}{c}0,032 \\
(0,042)\end{array}$ & & & $\begin{array}{c}0,009 \\
(0,048)\end{array}$ & & & & $\begin{array}{c}0,045 \\
(0,044)\end{array}$ & & & & $\begin{array}{c}0,026 \\
(0,058)\end{array}$ & & \\
\hline MB & $\begin{array}{c}-0,063 * * \\
(0,031)\end{array}$ & & $\begin{array}{l}-0,041 \\
(0,050)\end{array}$ & & & $\begin{array}{l}-0,065 \\
(0,041)\end{array}$ & & & & $\begin{array}{l}-0,094 \\
(0,044)\end{array}$ & $* *$ & & & $\begin{array}{l}-0,036 \\
(0,067)\end{array}$ & & \\
\hline potencia & & $\begin{array}{c}0,013 \\
(0,026) \\
\end{array}$ & & $\begin{array}{l}-0,060 \\
(0,039)\end{array}$ & & & & $\begin{array}{c}0,032 \\
(0,035)\end{array}$ & & & & $\begin{array}{l}-0,017 \\
(0,038)\end{array}$ & & & $\begin{array}{l}-0,018 \\
(0,041)\end{array}$ & \\
\hline $\mathrm{N}$ & 83 & 80 & 37 & 38 & & 42 & & 44 & & 45 & & 48 & & 33 & 33 & \\
\hline $\mathrm{F}$ & 1,08 & 1,69 & 0,75 & 1,33 & & 1,66 & & 1,58 & & 1,48 & & 1,08 & & 0,28 & 0,59 & \\
\hline R2 & 0,0040 & 0,0337 & $-0,029$ & 0,0343 & & 0,0608 & & 0,0513 & & 0,042 & & 0,0067 & & $-0,0986$ & $-0,0539$ & \\
\hline
\end{tabular}




\section{Tabla 5.20: Continuación}

\begin{tabular}{|c|c|c|c|c|c|c|c|c|c|c|c|c|c|c|}
\hline \multirow[b]{3}{*}{ constante } & \multicolumn{7}{|c|}{$\begin{array}{l}\text { Pecking Order } \\
\text { Variable de segmentación: } \\
\text { "Flexibilidad financiera" }\end{array}$} & \multicolumn{7}{|c|}{$\begin{array}{c}\text { Teoría de agencia - Subinversión } \\
\text { Variable de segmentación: } \\
\text { "Utilización de endeudamiento para reducir el coste de } \\
\text { financiación y aumentar la rentabilidad de los accionistas” }\end{array}$} \\
\hline & \multicolumn{2}{|l|}{ M8.1a } & \multicolumn{2}{|c|}{ M8.2a } & \multirow{2}{*}{$\begin{array}{c}\text { M8.1b } \\
0,956 \\
(0,512)\end{array}$} & \multicolumn{2}{|r|}{ M8.2b } & \multicolumn{2}{|c|}{ M8.1a } & \multicolumn{2}{|c|}{ M8.2a } & $\begin{array}{c}\text { M8.1b } \\
0,777\end{array}$ & \multicolumn{2}{|c|}{ M8.2b } \\
\hline & $\begin{array}{c}0,846 \\
(0,351)\end{array}$ & $* *$ & $\begin{array}{c}1,027 \\
(0,339)\end{array}$ & $* * *$ & & * & $\begin{array}{c}0,961 \\
(0,491)\end{array}$ & $\begin{array}{c}1,029 \\
(0,348)\end{array}$ & $* * *$ & $\begin{array}{c}1,304 \\
(0,385)\end{array}$ & $* * *$ & $\begin{array}{c}0,777 \\
(0,415)\end{array}$ & $*$ & $\begin{array}{c}0,636 \\
(0,414)\end{array}$ \\
\hline tamaño & $\begin{array}{c}-0,006 \\
(0,036)\end{array}$ & & $\begin{array}{c}0,024 \\
(0,033)\end{array}$ & & $\begin{array}{l}-0,024 \\
(0,025)\end{array}$ & & $\begin{array}{c}-0,026 \\
(0,026)\end{array}$ & $\begin{array}{c}-0,017 \\
(0,022)\end{array}$ & & $\begin{array}{c}-0,011 \\
(0,024)\end{array}$ & & $\begin{array}{c}-0,014 \\
(0,034)\end{array}$ & & $\begin{array}{l}-0,003 \\
(0,032)\end{array}$ \\
\hline tangibilidad & $\begin{array}{c}0,001 \\
(0,003)\end{array}$ & & $\begin{array}{c}-0,004 \\
(0,003)\end{array}$ & & $\begin{array}{l}-0,003 \\
(0,004)\end{array}$ & & $\begin{array}{c}-0,003 \\
(0,004)\end{array}$ & $\begin{array}{c}-0,004 \\
(0,003)\end{array}$ & & $\begin{array}{l}-0,005 \\
(0,004)\end{array}$ & & $\begin{array}{c}0,000 \\
(0,003)\end{array}$ & & $\begin{array}{c}-0,002 \\
(0,003)\end{array}$ \\
\hline rentab1 & & & $\begin{array}{c}-0,057 \\
(0,047)\end{array}$ & & & & $\begin{array}{c}-0,018 \\
(0,044)\end{array}$ & & & $\begin{array}{c}-0,082 \\
(0,041)\end{array}$ & $*$ & & & $\begin{array}{c}0,024 \\
(0,050)\end{array}$ \\
\hline rentab2 & $\begin{array}{c}0,003 \\
(0,056)\end{array}$ & & & & $\begin{array}{c}0,035 \\
(0,040)\end{array}$ & & & $\begin{array}{c}0,072 \\
(0,037)\end{array}$ & $*$ & & & $\begin{array}{c}-0,024 \\
(0,048)\end{array}$ & & \\
\hline MB & $\begin{array}{l}-0,109 \\
(0,064)\end{array}$ & & & & $\begin{array}{c}-0,041 \\
(0,038)\end{array}$ & & & $\begin{array}{l}-0,105 \\
(0,037)\end{array}$ & $* * *$ & & & $\begin{array}{l}-0,030 \\
(0,049)\end{array}$ & & \\
\hline potencia & & & $\begin{array}{c}-0,046 \\
(0,041) \\
\end{array}$ & & & & $\begin{array}{l}-0,005 \\
(0,038) \\
\end{array}$ & & & $\begin{array}{c}-0,035 \\
(0,038) \\
\end{array}$ & & & & $\begin{array}{l}-0,009 \\
(0,036) \\
\end{array}$ \\
\hline $\mathrm{N}$ & 31 & & 34 & & 48 & & 48 & 34 & & 36 & & 44 & & 44 \\
\hline $\mathrm{F}$ & 0,91 & & 0,86 & & 1,12 & & 0,48 & 3,33 & $* *$ & 2,57 & $*$ & 0,22 & & 0,20 \\
\hline $\mathrm{R} 2$ & $-0,0126$ & & $-0,0176$ & & 0,0098 & & $-0,0465$ & 0,22 & & 0,1519 & & $-0,0782$ & & $-0,0807$ \\
\hline
\end{tabular}

$* * *, * *, *$ indica significativa al $1 \%, 5 \%$ y $10 \%$, respectivamente. 


\section{Tabla 5.20: Continuación}

\begin{tabular}{|c|c|c|c|c|c|c|c|c|c|c|c|c|c|}
\hline \multirow[b]{3}{*}{ constante } & \multicolumn{6}{|c|}{$\begin{array}{c}\text { Teoría de agencia - Sustitución de activos } \\
\text { Variable de segmentación: } \\
\text { 2Utilización de deuda de corto plazo para reducir el incentivo a } \\
\text { invertir en proyectos de riesgo elevado" }\end{array}$} & \multicolumn{7}{|c|}{$\begin{array}{c}\text { Market Timing } \\
\text { Variable de segmentación: } \\
\text { 2Utilización de deuda de corto plazo a la espera tipos de interés } \\
\text { más bajos” }\end{array}$} \\
\hline & \multicolumn{2}{|c|}{ M8.1a } & \multicolumn{2}{|c|}{ M8.2a } & \multirow{2}{*}{$\begin{array}{c}\text { M8.1b } \\
0,860 \\
(0,809)\end{array}$} & \multirow{2}{*}{$\begin{array}{c}\text { M8.2b } \\
0,660 \\
(0,723)\end{array}$} & \multicolumn{2}{|c|}{ M8.1a } & \multicolumn{2}{|c|}{ M8.2a } & \multirow{2}{*}{$\begin{array}{l}\text { M8.1b } \\
0,774 \\
(0,582)\end{array}$} & \multicolumn{2}{|c|}{ M8.2b } \\
\hline & $\begin{array}{c}0,838 \\
(0,263)\end{array}$ & $* * *$ & $\begin{array}{c}1,108 \\
(0,296)\end{array}$ & $* * *$ & & & $\begin{array}{c}0,823 \\
(0,298)\end{array}$ & $* * *$ & $\begin{array}{c}1,023 \\
(0,330)\end{array}$ & $* * *$ & & $\begin{array}{c}0,652 \\
(0,519)\end{array}$ & \\
\hline tamaño & $\begin{array}{c}-0,013 \\
(0,021)\end{array}$ & & $\begin{array}{c}-0,013 \\
(0,022)\end{array}$ & & $\begin{array}{c}-0,014 \\
(0,049)\end{array}$ & $\begin{array}{c}0,006 \\
(0,050)\end{array}$ & $\begin{array}{l}-0,033 \\
(0,024)\end{array}$ & & $\begin{array}{c}-0,038 \\
(0,024)\end{array}$ & & $\begin{array}{c}0,018 \\
(0,037)\end{array}$ & $\begin{array}{c}0,040 \\
(0,037)\end{array}$ & \\
\hline tangibilidad & $\begin{array}{c}-0,001 \\
(0,002)\end{array}$ & & $\begin{array}{c}-0,004 \\
(0,003)\end{array}$ & & $\begin{array}{l}-0,002 \\
(0,006)\end{array}$ & $\begin{array}{l}-0,001 \\
(0,005)\end{array}$ & $\begin{array}{c}0,000 \\
(0,003)\end{array}$ & & $\begin{array}{l}-0,003 \\
(0,003)\end{array}$ & & $\begin{array}{c}-0,002 \\
(0,004)\end{array}$ & $\begin{array}{c}-0,002 \\
(0,004)\end{array}$ & \\
\hline rentab1 & & & $\begin{array}{c}-0,056 \\
(0,037)\end{array}$ & & & $\begin{array}{c}0,017 \\
(0,059)\end{array}$ & & & $\begin{array}{c}-0,053 \\
(0,038)\end{array}$ & & & $\begin{array}{c}0,005 \\
(0,053)\end{array}$ & \\
\hline rentab2 & $\begin{array}{c}0,043 \\
(0,034)\end{array}$ & & & & $\begin{array}{c}-0,030 \\
(0,064)\end{array}$ & & $\begin{array}{c}0,038 \\
(0,039)\end{array}$ & & & & $\begin{array}{c}-0,019 \\
(0,050)\end{array}$ & & \\
\hline MB & $\begin{array}{c}-0,092 \\
(0,035)\end{array}$ & $* *$ & & & $\begin{array}{c}-0,003 \\
(0,056)\end{array}$ & & $\begin{array}{c}-0,086 \\
(0,043)\end{array}$ & & & & $\begin{array}{c}-0,024 \\
(0,045)\end{array}$ & & \\
\hline potencia & & & $\begin{array}{c}-0,017 \\
(0,033)\end{array}$ & & & $\begin{array}{c}-0,055 \\
(0,046)\end{array}$ & & & $\begin{array}{c}0,015 \\
(0,036)\end{array}$ & & & $\begin{array}{c}-0,074 \\
(0,036)\end{array}$ & \\
\hline $\mathrm{N}$ & 46 & & 48 & & 32 & 31 & 39 & & 41 & & 39 & 39 & \\
\hline $\mathrm{F}$ & 2,58 & $*$ & 1,74 & & 0,07 & 0,37 & 2,17 & $*$ & 1,77 & & 0,30 & 1,36 & \\
\hline $\mathrm{R} 2$ & 0,1228 & & 0,0595 & & $-0,1368$ & $-0,0914$ & 0,1097 & & 0,0715 & & $-0,0795$ & 0,0364 & \\
\hline
\end{tabular}

***, **, * indica significativa al 1\%, 5\% y 10\%, respectivamente. 
De los resultados de la estimación, destaca la alta y significativa importancia del término constante, lo que no hace más que confirmar la importancia del endeudamiento como fuente de financiación de las empresas españolas. Se confirma además la relación negativa (y estadísticamente significativa) de la variable $M B$, valor de la empresa a valor contable, con el nivel de endeudamiento en las submuestras de empresas que atribuyen menor importancia a los patrones de trade-off, agencia y market timing. En las submuestras de empresas que confieren mayor importancia a las variables relacionas con estas teorías, la relación entre deuda y $M B$ es negativa, pero no significativa. En el caso de la variable aproximativa del patrón pecking order, la variable $M B$ presenta un coeficiente negativo, pero no significativo, en ambas submuestras de empresas.

La hipótesis 7 se divide en tres sub hipótesis que matizan el comportamiento de la regresión de hechos estilizados en cada uno de los patrones de financiación. La hipótesis 7.1 plantea que en las empresas de comportamiento más acorde con el trade-off las variables de tamaño, tangibilidad y rentabilidad debiera ser positiva y significativa. Los resultados muestran que sólo la tangibilidad presenta influencia estadísticamente significativa, pero del signo contrario al esperado. Este resultado es contrario al rol de “amplificador del crédito” atribuido por Campello y Hackbarth (2012) y a lo planteado en la hipótesis 7.1.

Tampoco encontramos respaldo a la relación negativa esperada entre endeudamiento y rentabilidad, especialmente significativa en el caso de empresas que sigan un patrón de comportamiento acorde a la teoría del pecking order. Ninguna de las dos variables aproximativas de la rentabilidad de la empresa, rentab1 y rentab2, se muestran significativas en el patrón asociado a la teoría del trade off. Por tanto, no encontramos evidencia a favor de la sub hipótesis 7.2.

La hipótesis 7.3 presupone una relación negativa entre endeudamiento y el peso relativo de las oportunidades de crecimiento, especialmente significativa en el caso de las empresas que sigan un patrón acorde a la teoría de agencia. Los resultados del contraste no avalan el sentido de la hipótesis. La relación negativa y estadísticamente significativa, entre endeudamiento y el cociente valor de la 
empresa a su valor contable, se produce precisamente en aquellas empresas que menor importancia atribuyen a los problemas de subinversión y sustitución de activos.

En conjunto, los resultados de la tabla 5.20 sugieren el rechazo de la hipótesis 7 y por tanto de la existencia de diferencias en la influencia de los determinantes estándar sobre el endeudamiento según la teoría de estructura de capital seguida por la empresa. Conviene matizar que estos resultados se encuentran condicionados por los grados de libertad de las estimaciones y las aproximaciones utilizadas en la identificación del patrón financiero.

Estos resultados son corroborados en la estimación del modelo que reemplaza la división de la muestra con la inclusión de dummies de segmentación. En este caso, el modelo a estimar es el siguiente

$$
\text { Deuda }_{i}=\gamma \cdot \text { Determinante }_{i}+\omega \cdot \text { Determinant }_{i} \cdot \text { DumPatrón }_{i}+e_{i}
$$

siendo DumPatrón una variable ficticia que divide la muestra en función de la mayor (menor) adhesión al patrón de financiación y toma el valor 1 para las empresas situadas por encima de la mediana y valor cero en el resto de casos.

La contrastación de la hipótesis 7 se realiza mediante el análisis de la significación estadística de los parámetros $\gamma$ y $\omega$, siendo $\gamma$ el coeficiente para la regresión de hechos estilizados y $\omega$ el coeficiente que captura la influencia de la mayor adhesión al patrón (dumpatrón=1). 


\section{Tabla 5.21: Interacción de los determinantes estándar y el patrón de financiación de la empresa}

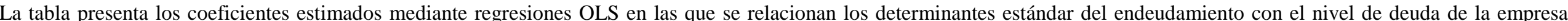

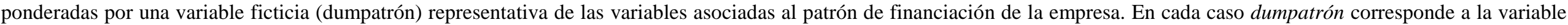

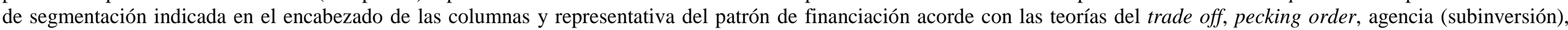

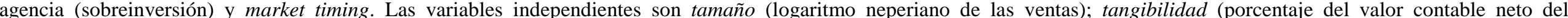

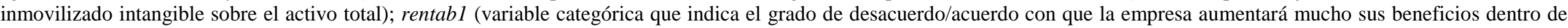

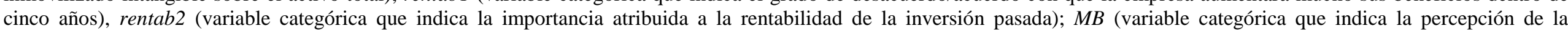

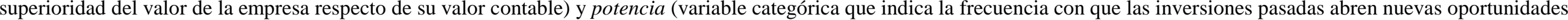
de inversión). Debajo de cada coeficiente, entre paréntesis, se muestra el error estándar.

\begin{tabular}{|c|c|c|c|c|c|c|c|c|c|c|c|c|}
\hline & \multicolumn{2}{|c|}{$\begin{array}{c}\text { Tradeoff1 } \\
\text { Variable de segmentación: } \\
\text { "Búsqueda de } \\
\text { endeudamiento objetivo" }\end{array}$} & \multicolumn{2}{|c|}{$\begin{array}{l}\text { Tradeoff2 } \\
\text { Variable de segmentación: } \\
\text { "Utilización de } \\
\text { endeudamiento para reducir } \\
\text { el coste medio ponderado del } \\
\text { capital” }\end{array}$} & \multicolumn{2}{|c|}{$\begin{array}{l}\text { Pecking Order } \\
\text { Variable de segmentación: } \\
\text { "Flexibilidad financiera" }\end{array}$} & \multicolumn{2}{|c|}{$\begin{array}{l}\text { Teoría de agencia - } \\
\text { Subinversión } \\
\text { Variable de } \\
\text { segmentación: } \\
\text { "Utilización de } \\
\text { endeudamiento para } \\
\text { reducir el coste de } \\
\text { financiación y aumentar la } \\
\text { rentabilidad de los } \\
\text { accionistas” }\end{array}$} & \multicolumn{2}{|c|}{$\begin{array}{c}\text { Teoría de agencia - } \\
\text { Sustitución de activos } \\
\text { Variable de } \\
\text { segmentación: } \\
\text { “Utilización de deuda de } \\
\text { corto plazo para reducir el } \\
\text { incentivo a invertir en } \\
\text { proyectos de riesgo } \\
\text { elevado” }\end{array}$} & \multicolumn{2}{|c|}{$\begin{array}{c}\text { Market Timing } \\
\text { Variable de } \\
\text { segmentación: } \\
\text { “Utilización de deuda de } \\
\text { corto plazo a la espera } \\
\text { tipos de interés más bajos” }\end{array}$} \\
\hline & Modelo 1 & Modelo2 & Modelo 1 & Modelo2 & Modelo 1 & Modelo2 & Modelo 1 & Modelo2 & Modelo 1 & Modelo2 & Modelo 1 & Modelo2 \\
\hline _cons & $\begin{array}{cc}0,982 & * * * \\
(0,267) & \end{array}$ & $\begin{array}{cc}0,888 & * * * \\
(0,270) & \end{array}$ & $\begin{array}{cc}1,005 & * * * \\
(0,280) & \end{array}$ & $\begin{array}{cc}0,786 & * * * \\
(0,278) & \end{array}$ & $\begin{array}{cc}1,028 & * * * \\
(0,270) & \end{array}$ & $\begin{array}{cc}0,864 & * * * \\
(0,271) & \end{array}$ & $\begin{array}{cc}0,916 \quad * * * \\
(0,290) & \end{array}$ & $\begin{array}{cc}0,862 & * * * \\
(0,283) & \end{array}$ & $\begin{array}{cc}1,032 & * * * \\
(0,280) & \end{array}$ & $\begin{array}{cc}0,841 & * * * \\
(0,265) & \end{array}$ & $\begin{array}{cc}0,932 & * * * \\
(0,271) & \end{array}$ & $\begin{array}{cc}0,813 & * * * \\
(0,263) & \end{array}$ \\
\hline tamaño & $\begin{array}{l}-0,019 \\
(0,022)\end{array}$ & $\begin{array}{l}-0,018 \\
(0,022)\end{array}$ & $\begin{array}{c}-0,024 \\
(0,026)\end{array}$ & $\begin{array}{l}-0,008 \\
(0,027)\end{array}$ & $\begin{array}{c}0,006 \\
(0,024)\end{array}$ & $\begin{array}{l}-0,005 \\
(0,025)\end{array}$ & $\begin{array}{l}-0,008 \\
(0,021)\end{array}$ & $\begin{array}{l}-0,022 \\
(0,022)\end{array}$ & $\begin{array}{l}-0,012 \\
(0,023)\end{array}$ & $\begin{array}{l}-0,013 \\
(0,022)\end{array}$ & $\begin{array}{l}-0,037 \quad * \\
(0,022)\end{array}$ & $\begin{array}{l}-0,033 \\
(0,023)\end{array}$ \\
\hline $\begin{array}{l}\text { tamaño x } \\
\text { dumpatrón }\end{array}$ & $\begin{array}{c}0,030 \\
(0,044)\end{array}$ & $\begin{array}{c}0,020 \\
(0,048)\end{array}$ & $\begin{array}{c}0,009 \\
(0,041)\end{array}$ & $\begin{array}{l}-0,007 \\
(0,040)\end{array}$ & $\begin{array}{l}-0,057 \\
(0,041)\end{array}$ & $\begin{array}{l}-0,036 \\
(0,039)\end{array}$ & $\begin{array}{l}-0,047 \\
(0,047)\end{array}$ & $\begin{array}{c}0,018 \\
(0,043)\end{array}$ & $\begin{array}{c}0,000 \\
(0,003)\end{array}$ & $\begin{array}{l}-0,001 \\
(0,038)\end{array}$ & $\begin{array}{c}0,065 \\
(0,040)\end{array}$ & $\begin{array}{c}0,049 \\
(0,037)\end{array}$ \\
\hline tangibilidad & $\begin{array}{l}-0,003 \\
(0,002)\end{array}$ & $\begin{array}{l}-0,001 \\
(0,002)\end{array}$ & $\begin{array}{l}-0,002 \\
(0,003)\end{array}$ & $\begin{array}{c}0,000 \\
(0,003)\end{array}$ & $\begin{array}{l}-0,003 \\
(0,002)\end{array}$ & $\begin{array}{l}-0,001 \\
(0,003)\end{array}$ & $\begin{array}{l}-0,002 \\
(0,003)\end{array}$ & $\begin{array}{l}-0,001 \\
(0,003)\end{array}$ & $\begin{array}{l}-0,003 \\
(0,003)\end{array}$ & $\begin{array}{l}-0,001 \\
(0,003)\end{array}$ & $\begin{array}{l}-0,002 \\
(0,003)\end{array}$ & $\begin{array}{l}0,000 \\
(0,003)\end{array}$ \\
\hline $\begin{array}{l}\text { tangibilidad } \\
\text { x dumpatrón }\end{array}$ & $\begin{array}{l}-0,001 \\
(0,005)\end{array}$ & $\begin{array}{l}-0,009 \\
(0,007)\end{array}$ & $\begin{array}{l}-0,003 \\
(0,003)\end{array}$ & $\begin{array}{l}-0,002 \\
(0,003)\end{array}$ & $\begin{array}{l}-0,001 \\
(0,002)\end{array}$ & $\begin{array}{l}-0,003 \\
(0,003)\end{array}$ & $\begin{array}{l}-0,003 \\
(0,003)\end{array}$ & $\begin{array}{c}0,000 \\
(0,004)\end{array}$ & $\begin{array}{c}0,000 \\
(0,003)\end{array}$ & $\begin{array}{l}-0, .000 \\
(0,003)\end{array}$ & $\begin{array}{l}-0,002 \\
(0,002)\end{array}$ & $\begin{array}{l}-0,003 \\
(0,003)\end{array}$ \\
\hline rentab1 & $\begin{array}{l}-0,011 \\
(0,034)\end{array}$ & & $\begin{array}{l}-0,045 \\
(0,040)\end{array}$ & & $\begin{array}{l}-0,047 \\
(0,034)\end{array}$ & & $\begin{array}{l}-0,038 \\
(0,035)\end{array}$ & & $\begin{array}{l}-0,052 \\
(0,038)\end{array}$ & & $\begin{array}{l}-0,049 \\
(0,036)\end{array}$ & \\
\hline rentab1 x & $-0,089$ & & 0,074 & & 0,077 & & 0,087 & & 0,061 & & 0,051 & \\
\hline
\end{tabular}


ANÁLISIS DE RESUltAdOS

\begin{tabular}{|c|c|c|c|c|c|c|c|c|c|c|c|c|c|c|c|c|c|c|c|}
\hline dumpatrón & $(0,099)$ & & & & $(0,068)$ & & & $(0,089)$ & & & $(0,068)$ & & & $(0,065)$ & & & $(0,066)$ & & \\
\hline rentab2 & & & $\begin{array}{c}0,005 \\
(0,032)\end{array}$ & & & $\begin{array}{c}0,044 \\
(0,043)\end{array}$ & & & $\begin{array}{c}0,005 \\
(0,038)\end{array}$ & & & $\begin{array}{c}0,035 \\
(0,035)\end{array}$ & & & $\begin{array}{c}0,043 \\
(0,037)\end{array}$ & & & $\begin{array}{c}0,038 \\
(0,039)\end{array}$ & \\
\hline $\begin{array}{l}\text { rentab2 x } \\
\text { dumpatrón }\end{array}$ & & & $\begin{array}{c}0,113 \\
(0,107)\end{array}$ & & & $\begin{array}{l}-0,016 \\
(0,067)\end{array}$ & & & $\begin{array}{c}0,038 \\
(0,061)\end{array}$ & & & $\begin{array}{l}-0,072 \\
(0,067)\end{array}$ & & & $\begin{array}{l}-0,072 \\
(0,059)\end{array}$ & & & $\begin{array}{l}-0,059 \\
(0,058)\end{array}$ & \\
\hline potencia & $\begin{array}{l}-0,040 \\
(0,029)\end{array}$ & & & & $\begin{array}{l}-0,018 \\
(0,037)\end{array}$ & & & $\begin{array}{c}-0,037 \\
(0,030)\end{array}$ & & & $\begin{array}{l}-0,047 \\
(0,032)\end{array}$ & & & $\begin{array}{l}-0,015 \\
(0,034)\end{array}$ & & & $\begin{array}{c}0,018 \\
(0,034)\end{array}$ & & \\
\hline $\begin{array}{l}\text { potencia } \mathrm{x} \\
\text { dumpatrón }\end{array}$ & $\begin{array}{c}0,106 \\
(0,062)\end{array}$ & $*$ & & & $\begin{array}{c}0,006 \\
(0,054)\end{array}$ & & & $\begin{array}{c}0,036 \\
(0,064)\end{array}$ & & & $\begin{array}{c}0,097 \\
(0,058)\end{array}$ & & & $\begin{array}{l}-0,043 \\
(0,054)\end{array}$ & & & $\begin{array}{l}-0,095 \\
(0,050)\end{array}$ & $*$ & \\
\hline $\mathrm{MB}$ & & & $\begin{array}{l}-0,068 \\
(0,033)\end{array}$ & $* *$ & & $\begin{array}{c}-0,094 \\
(0,043)\end{array}$ & $* *$ & & $\begin{array}{l}-0,084 \\
(0,038)\end{array}$ & $* *$ & & $\begin{array}{c}-0,069 \\
(0,034)\end{array}$ & $* *$ & & $\begin{array}{l}-0,092 \\
(0,038)\end{array}$ & $* *$ & & $\begin{array}{l}-0,085 \\
(0,043)\end{array}$ & * \\
\hline $\begin{array}{l}\text { MB x } \\
\text { dumpatrón }\end{array}$ & & & $\begin{array}{c}0,080 \\
(0,139)\end{array}$ & & & $\begin{array}{c}0,061 \\
(0,075)\end{array}$ & & & $\begin{array}{c}0,075 \\
(0,070) \\
\end{array}$ & & & $\begin{array}{c}0,041 \\
(0,079)\end{array}$ & & & $\begin{array}{c}0,089 \\
(0,062)\end{array}$ & & & $\begin{array}{c}0,061 \\
(0,062) \\
\end{array}$ & \\
\hline $\mathrm{N}$ & 82 & & 79 & & 81 & 78 & & 82 & 79 & & 80 & 78 & & 79 & 78 & & 80 & 78 & \\
\hline $\mathrm{F}$ & 1,08 & & $1, .25$ & & 0,85 & 0,91 & & 0,85 & 1,04 & & 1,38 & 1,03 & & 1,15 & 1,46 & & 1,64 & 1,40 & \\
\hline R2 & 0,008 & & 0,0247 & & $-0,0151$ & $-0,0099$ & & $-0,0154$ & 0,0037 & & 0,0368 & 0,003 & & 0,0151 & 0,0453 & & 0,0613 & 0,0401 & \\
\hline
\end{tabular}

$* * *, * *, *$ indica significativa al $1 \%, 5 \%$ y $10 \%$, respectivamente. 
La tabla 5.21 muestra los resultados obtenidos, que indican que el tamaño de la empresa tiene una influencia negativa sobre el nivel de deuda de la empresa en el caso de las empresas que sigan un comportamiento acorde con la teoría del market timing. Esta influencia no se verifica, sin embargo, en el efecto interacción, además, la prueba de restricción lineal de ambos coeficientes $(\gamma+\omega)$ es no significativa ( $p=0,421)$. Los resultados evidencian además, y en línea con la literatura previa, una relación negativa entre la variable MB (variable categórica de la percepción directiva de la relación entre valor de la empresa y su valor contable) y la deuda de la empresa. La hipótesis 7.3 plantea que esta relación sería especialmente relevante en empresas que sigan un patrón de financiación acorde con la teoría de agencia. No obstante, no se confirman los resultados a favor de este comportamiento, pues el efecto interacción no es estadísticamente significativo (prueba de restricción de lineal de la suma de ambos coeficientes) en ninguno de los dos casos $(\mathrm{p}>0,1)$. 


\section{CAPÍTULO 6: CONCLUSIONES}

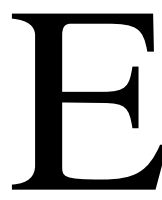

l objetivo principal de la presente investigación ha sido identificar las distintas técnicas y modelos de valoración de inversiones y de financiación que utilizan los directores financieros en la práctica y estudiar su adecuación a las recomendaciones extraídas de la teoría financiera.

Para abordar este objetivo se envió un cuestionario a las 2.000 mayores empresas españolas en febrero de 2011 que en 140 casos fueron debidamente cumplimentados y reenviados. Esta tasa del 7\%, pareciendo escasa, es similar a la de otros estudios en este campo y los resultados parecen exentos de potenciales problemas de representatividad o de sesgo de respuesta.

El desarrollo de este trabajo se inicia con el planteamiento y descripción de las principales teorías financieras en relación con los temas de presupuesto de capital y estructura de capital de la empresa. Se han discutido las principales contribuciones de la literatura precedente en el problema objeto de estudio y en especial en aquellos trabajos que aportan evidencia empírica recogida por medio de encuestas. Esta revisión proporciona respaldo a la utilidad de la investigación realizada por medio de encuestas. Adicionalmente, sirve de apoyo para articular la discusión teórica a partir de la que se formulan las hipótesis a contrastar.

Estas hipótesis nos han servido de hoja de ruta para diseñar la investigación empírica en general y el cuestionario en particular, pero sobre todo para abordar de manera sistemática y exhaustiva la abundante información recogida. De esta forma ha sido posible no sólo describir el modo en que los directivos adoptan sus decisiones de inversión y financiación y las cuestiones a las que prestan mayor atención, sino además abordar el análisis del grado en que determinadas 
características de la empresa y sus directivos financieros pueden ayudar a interpretar aquella evidencia.

Con relación a las decisiones de inversión, nuestra investigación confirma que los directores financieros españoles, en línea con sus homólogos extranjeros, utilizan múltiples técnicas y no siempre las más recomendadas. Los resultados de este trabajo evidencian que el método utilizado con mayor frecuencia en las empresas de la muestra es el payback, seguido a distancia de la TIR y el VAN. La popularidad del payback entre los directivos españoles es notablemente superior a la registrada en otros países, tanto europeos como americanos. Se ha discutido mucho sobre las posibles razones de la popularidad del payback. Las razones esgrimidas van desde su simplicidad y sintonía con el cortoplacismo de los directivos a su utilidad para reemplazar a técnicas más sofisticadas y complejas en la medición de los diversos ingredientes del valor de las inversiones. Nuestro análisis revela que el payback es aplicado en mayor medida por las empresas más grandes, al igual que el VAN y TIR, pero además su uso es más frecuente cuando las inversiones son más potentes en la generación de oportunidades de crecimiento futuro.

De otro lado, la técnica aparentemente menos popular es el modelo de opciones reales, que teóricamente es la perspectiva más adecuada para capturar el valor de los resultados estratégicos de la inversión. En contra de lo que cabría esperar, nuestro análisis indica que la frecuencia de uso del modelo de opciones no depende ni del tamaño de la empresa ni de la formación del director financiero. Este resultado contrasta con la creencia generalizada y algunos resultados de investigaciones previas que indicaban que la aplicación de las técnicas más avanzadas se hallaba reservada a las empresas de mayor tamaño. Sin embargo, nuestro análisis revela que el uso de los modelos de opciones reales está relacionado con la presión de los mecanismos de disciplina y, sobre todo, con la naturaleza de las fuentes de valor.

A pesar del menor uso de las opciones reales, se observa claramente que su aplicación incrementa en aquellas compañías cuyas inversiones generan mayores 
oportunidades de crecimiento y presentan mayor flexibilidad. La práctica de medición del valor de mercado y la participación en mercados negociados también parece propiciar la frecuencia de aplicación de estos modelos. Nuestros resultados revelan, con patente lógica, que la presión que puede ejercer la deuda como mecanismo de disciplina favorece la incorporación de las opciones reales a la batería de técnicas de análisis del director financiero, pero no incide en el número de veces que se utiliza. La frecuencia de uso de esta técnica depende especialmente de la potencia y flexibilidad de sus inversiones.

Aparte de la disparidad entre teoría y práctica, los estudios empíricos previos revelaban que los directivos suelen utilizar más de una técnica y las combinaciones suelen estar formadas por modelos poco relacionadas entre sí (Pike, 1996; Abdel-Kader y Dugdale, 1998; Carr et al., 2010). El argumento de la progresiva acumulación de técnicas ofrece una explicación válida tanto para el mantenimiento de las “antiguas” como para la utilización de múltiples técnicas. El temor de los directivos a proponer una decisión incorrecta ante un futuro, que es por definición incierto, disuade el abandono de las antiguas prácticas y favorece el refuerzo de sus propuestas con la acumulación de cálculos y estimaciones dispares (Verbeeten, 2006). La consecuencia directa de este tipo de hábitos es que las técnicas más antiguas y teóricamente “superadas” no sean abandonadas, impidiendo el reemplazo esperado por los académicos. La acumulación de cálculos puede ser percibida como una forma de enriquecer el proceso de análisis especialmente cuando el directivo desconfíe de las técnicas teóricamente mejores. Esta circunstancia probablemente altere la evidencia analizada e influya en los resultados alcanzados por estudios como el nuestro, impidiendo identificar patrones de relación aún más nítidos entre el uso de las técnicas más avanzadas y las fuentes de valor y, también, entre la frecuencia de aplicación de los modelos teóricamente menos apropiados y la presión de los mecanismos de disciplina.

En el ámbito de las decisiones de estructura de capital, la investigación por medio de encuestas ofrece una visión complementaria a la habitual. Las respuestas de los directores financieros sobre las cuestiones consideradas en sus decisiones 
de financiación ayudan a interpretar la evidencia relativa a los niveles de deuda observados y las variables explicativas propuestas por las principales teorías de la estructura de capital. Nuestro trabajo se centra en cuatro de ellas: teoría estática del trade off, teoría del pecking order, teoría de la agencia y teoría del market timing y analiza el papel que desempeñan en la explicación del modo en que los directivos determinan su estructura de financiación.

El análisis de los resultados permite concluir que los directivos otorgan gran relevancia al establecimiento y seguimiento de un ratio de endeudamiento objetivo acorde con la teoría del trade off, pero muestran menos indicios de interés por la maximización de la diferencia entre beneficios y costes del endeudamiento. Igualmente importante se revela el interés por el mantenimiento de capacidad de endeudamiento adicional, que tradicionalmente se asocia con los postulados del pecking order. De hecho, la flexibilidad financiera se revela como principal factor en la determinación del nivel de endeudamiento para la mayoría de los encuestados, resultados que se encuentran en consonancia con la literatura previa (Pinegar y Wilbricht, 1989; Graham y Harvey, 2001; Beattie et al., 2006; Brounen et al., 2006; Lindblom et al., 2011). Además, las empresas de la muestra prefieren la financiación interna a la externa, y la financiación externa más importante es la deuda bancaria. Este comportamiento viene reforzado por el hecho de que el principal factor determinante de la política financiera de la empresa viene dado por la utilización de deuda cuando los fondos internos no permiten financiar las actividades. En términos generales, cabe concluir que las empresas señalan tener un orden de preferencia bastante acorde con la teoría del pecking order.

Considerada de manera conjunta, la evidencia recogida parece indicar que estas dos teorías (trade off y pecking order) no son visiones alternativas a un mismo problema, sino que representan imágenes complementarias de la forma en que las empresas definen sus estructuras de capital, tal cual ha sido sugerido por la literatura previa (Myers, 2001; Graham y Harvey, 2002; Beattie et al., 2006; Lindblom et al., 2011). 
Los resultados no permiten confirmar que los considerandos del market timing tengan efecto notable en la mayoría de los encuestados. Destaca tan sólo que la disponibilidad y acceso al endeudamiento sea un factor relevante en el nivel de endeudamiento de la empresa. Aunque conscientes de las ineficiencias del mercado, no parece que esto tenga influencia en la emisión de deuda o nuevo capital propio. La evidencia obtenida sobre cuestiones relacionadas con la visión de la teoría de agencia no parece concluyente. Los encuestados no se muestran a favor del uso de la deuda como un mecanismo disciplinario. Nuestros resultados están en línea con trabajos similares (Graham y Harvey, 2001; Bancel y Mittoo, 2004; Beattie et al., 2006; Brounen et al., 2006). Beattie et al. (2006), los que sugieren que la formulación de este tipo de preguntas debe hacerse con cautela para no provocar una actitud defensiva que podría condicionar la respuesta. Sin embargo, cuando ponemos en relación fuentes de valor y estructura de financiación, las cuestiones de agencia se tornan relevantes, en especial, en el caso de las empresas de mayor tamaño.

A pesar del desarrollo y refinamiento conseguido por las teorías de estructura de capital, ninguna de ellas parece ofrecer una explicación satisfactoria a la pregunta de cómo los directores financieros adoptan las decisiones de financiación. Los beneficios y los costes asociados a las distintas fuentes de financiación difieren entre las empresas, al igual que la importancia relativa atribuida a cada una de ellas. Este proceso de decisión es complejo, multidimensional y, al parecer, determinado por la situación. Baker et al. (2010) concluyen que el resultado más consistente a través de décadas de investigación por medio de encuestas, es que la mayoría de las empresas utilizan reglas heurísticas (rules of thumb). En esta línea Merton Miller (1977) plantea en su discurso presidencial de la American Finance Association que "la configuración del mundo real es compleja, por lo que los procesos de toma de decisión (de estructura de capital) son inevitablemente heurísticos, a juicio del que toma la decisión, de imitación y de tanteo”. Los usos y costumbres en la aplicación de reglas heurísticas, consolidados por resultados de éxito en el tiempo, podrían ser 
la clave para entender las limitaciones explicativas de las teorías de la estructura de capital.

Este trabajo ha contribuido a actualizar los datos disponibles sobre la práctica de las decisiones de inversión y financiación y a ampliar el ámbito geográfico de la evidencia disponible. El análisis de los resultados permite concluir que las decisiones adoptadas en la arena de la empresa son un reflejo desfigurado de la teoría que se predica desde la tribuna de lo teórico. Los directivos manejan múltiples técnicas y considerandos, de rigor variopinto, que combinan y complementan para fraguar sus decisiones de inversión y financiación. En la elección de estos instrumentos influyen algunas características básicas de la empresa, como su tamaño, pero también la naturaleza de las fuentes de valor y la interdependencia de la inversión y la financiación.

Estos resultados pueden servir de estímulo al investigador para seguir profundizando en la comprensión del gap entre teoría y práctica y en la propuesta y adaptación de modelos decisionales que incorporen de manera explícita la relación entre inversión y financiación. La comprensión del distanciamiento pasa necesariamente por la adopción de instrumentos de investigación empírica complementarios a las encuestas, tales como el estudio de casos y los experimentos, que ayudarían a comprender mejor cuándo y por qué las empresas se desvían de las principales teorías. A este respecto, la teoría del Behavioural Finance se erige como elemento clave para la fundamentación de las futuras hipótesis explicativas y la interpretación de la evidencia.

Tal como ha sido sugerido por anteriores investigaciones, este trabajo redunda en la necesidad de una teoría integrada de la estructura de capital, que contemple tanto el objetivo de adoptar un nivel de endeudamiento óptimo como el establecimiento de un orden de preferencias de financiación. El desarrollo de los nuevos modelos decisionales en los que sin duda seguirá trabajando la comunidad científica no pueden obviar la evidencia sobre la predilección por lo sencillo y la complementariedad que los directivos otorgan a las técnicas y teorías. La necesidad de la simplificación es obvia, al tiempo que la ampliación de las 
dimensiones abordadas y, en especial, de la relación entre la inversión y la financiación a partir de la bisagra de las fuentes de valor. 
CAPÍTULO 6 


\section{REFERENCIAS BIBLIOGRÁFICAS}

Abdel-Kader, M. G. y D. Dugdale (1998). "Investment in advanced manufacturing technology: a study of practice in large U.K. companies". Management Accounting Research, Vol. 9, 3, pág. 261 - 284.

Adler, R. W. (2000). "Strategic Investment Decision Appraisal Techniques: The Old and the New". Business Horizons, Vol. 43, 6, pág. 15 - 22.

Adner, R. y D. A. Levinthal (2004). "What is Not a Real Option: Considering Boundaries for the Application of Real Options to Business Strategy". Academy of Management Review, Vol. 29, 1, pág. 74 - 85.

Aggarwal, R. (1993). "Theory and Practice in Finance Education: Or Why we Shouldn’t just Ask them". Financial Practice and Education, Vol. 3, 3, pág. $15-18$.

Akerlof, G. A. (1970). "The Market for "Lemons": Quality Uncertainty and the Market Mechanism". Quarterly Journal of Economics, Vol. 84, pág. 488 500 .

Al-Mutairi, M., G. Tian, H. Hasan y A. Tan (2012). "Corporate Governance and Corporate Finance Practices in a Kuwait Stock Exchange Market Listed Firm: A Survey to Confront Theory with Practice". Corporate Governance, Vol. 12, 5, pág. 595 - 615.

Alkaraan, F. y D. Northcott (2006). "Strategic capital investment decision-making: A role for emergent analysis tools?: A study of practice in large UK manufacturing companies". The British Accounting Review, Vol. 38, 2, pág. 149 - 173.

Allen, D. E. (1991). "The Determinants of the Capital Structure of Listed Australian Companies: The Financial Manager's Perspective". Australian Journal of Management, Vol. 16, 2, pág. 103 - 128.

Allen, D. E. (2000). "Spare debt capacity: Company practices in Australia, Britain and Japan". Australian Journal of Management, Vol. 25, 3, pág. 299 - 326.

Almeida, H. y M. Campello (2007). "Financial Constraints, Asset Tangibility, and Corporate Investment". The Review of Financial Studies, Vol. 20, 5, pág. 1429 - 1460. 
Anand, M. (2002). "Corporate Finance Practices in India: A Survey". Vikalpa. The Journal of Decision Makers, Vol. 27, 4, pág. 29 - 56.

Andrés, P. y V. Azofra (1992). "Enfoques Alternativos en la Valoración de Estrategias" en Le Management des Entreprises dans l'Espace Economique Europeen, pág. 1 - 23. Ed. G. Hirigoyen. Bordeaux, Francia.

Andrés, P., V. Azofra y G. Fuente (2005). "Real options as a component of the market value of stocks: evidence from the Spanish Stock Market". Applied Economics, Vol. 37, 14, pág. 1673 - 1691.

Ang, J. S. y M. Jung (1993). "An alternate test of Myers' pecking order theory of capital structure: the case of South Korean firms". Pacific-Basin Finance Journal, Vol. 1, 1, pág. 31 - 46.

Ann, W. K., E. J. Farragher y R. K. C. Leung (1987). "Capital investment practices: A survey of large corporations in Malaysia, Singapore and Hong Kong". Asia Pacific Journal of Management, Vol. 4, 2, pág. 112 - 123.

Apap, A. y D. J. Masson (2004 - 2005). "A Survey of Capital Budgeting in Publicly Traded Utility Companies". Southwest Business and Economics Journal, Vol. 13, pág. 45 - 52.

Armstrong, J. S. y T. S. Overton (1977). "Estimating Nonrespone Bias in Mail Surveys". Journal of Marketing Research, Vol. 14, 3, pág. 396 - 402.

Arnold, G. C. y P. D. Hatzopoulos (2000). "The Theory-Practice Gap in Capital Budgeting: Evidence from the United Kingdom". Journal of Business Finance \& Accounting, Vol. 27, 5-6, pág. 603 - 626.

Ayala, J. C. y J. E. Rodríguez (2000). "Gestión Financiera en Empresas Industriales: Análisis Empírico de la Realidad Riojana". Boletín de Estudios Económicos, Vol. 55, 171, pág. 543 - 570.

Azofra, V. y A. I. Fernández (1992). "Evolución reciente de la Moderna Teoría Financiera". Anales de Estudios Económicos y Empresariales, Vol. 7, pág. $111-126$.

Azofra, V. y G. Fuente (2008). "La Huella Indeleble de Modigliani y Miller". Boletín de Estudios Económicos, Vol. 63, 194, pág. 373 - 401.

Azofra, V. y A. d. Miguel (1990). "La Interrelación de las Decisiones Financieras en la Gran Empresa Industrial Española". Investigaciones Económicas (Segunda época), Vol. 14, suplemento, pág. 159 - 166.

Azofra, V. y J. A. Rodríguez (2012). "El Endeudamiento de la Empresa Española: Teorías y Realidades". Papeles de Economía Española, Vol. 132, pág. $37-61$.

Baddeley, M. (2006). "Behind the black box: a survey of real-world investment appraisal approaches". Empirica, Vol. 33, 5, pág. 329 - 350. 
Baker, H. K., S. Dutta y S. Saadi (2011a). "Corporate Finance Practices in Canada: Where Do We Stand?". Multinational Finance Journal, Vol. 15, 3-4, pág. 157 - 192.

Baker, H. K., S. Dutta y S. Saadi (2011b). "Management Views on Real Options in Capital Budgeting". Journal of Applied Finance, Vol. 21, 1, pág. 18 29.

Baker, H. K. y T. K. Mukherjee (2007). "Survey research in finance: views from journal editors". International Journal of Managerial Finance, Vol. 3, 1, pág. $11-25$.

Baker, H. K., J. C. Singleton y E. T. Veit (2010). "Survey Research in Corporate Finance: Bridging the Gap between Theory and Practice", Oxford University Press. New York, Estados Unidos.

Baker, M. y J. Wurgler (2002). "Market Timing and Capital Structure". The Journal of Finance, Vol. 57, 1, pág. 1 - 32.

Baldwin, C. Y. y K. B. Clark (1992). "Capabilities and Capital Investment: New Perspectives on Capital Budgeting". Journal of Applied Corporate Finance, Vol. 5, 2, pág. 67 - 82.

Bancel, F. y U. R. Mittoo (2004). "Cross-Country Determinants of Capital Structure Choice: A Survey of European Firms". Financial Management, Vol. 33, 4, pág. 103 - 132.

Bancel, F. y U. R. Mittoo (2011). "Financial flexibility and the impact of the global financial crisis". International Journal of Managerial Finance, Vol. 7, 2, pág. 179-216.

Barclay, M. J., C. W. Smith y E. Morellec (2006). "On the Debt Capacity of Growth Options". Journal of Business, Vol. 79, 1, pág. 37 - 59.

Bayless, M. y S. Chaplinsky (1996). "Is There a Window of Opportunity for Seasoned Equity Issuance?". The Journal of Finance, Vol. 51, 1, pág. 253 278.

Beattie, V., A. Goodacre y S. J. Thomson (2006). "Corporate Financing Decisions: UK Survey Evidence". Journal of Business Finance \& Accounting, Vol. 33, 9-10, pág. 1402 - 1434.

Beck, T. y A. Demirguc-Kunt (2006). "Small and medium-size enterprises: Access to finance as a growth constraint". Journal of Banking \& Finance, Vol. 30, 11, pág. 2931 - 2943.

Becker, C., W. Ferson, D. H. Myers y M. J. Schill (1999). "Conditional market timing with benchmark investors". Journal of Financial Economics, Vol. 52, 1, pág. 119 - 148.

Benetti, C., R. Frota D. y P. R. Soares T. (2007). "The Practice of Corporate Finance in an Emerging Market: Preliminary Evidence from the Brazilian Survey". Working Paper, Universidade Federal do Rio Grande do Sul. 
Benmelech, E. y N. K. Bergman (2009). "Collateral Princing". Journal of Financial Economics, Vol. 91, pág. 339 - 360.

Bennouna, K., G. G. Meredith y T. Marchant (2010). "Improved capital budgeting decision making: evidence from Canada". Management Decision, Vol. 28, 2, pág. 225 - 247.

Berger, P. (2003). "Discussion of "Differential Market Reactions to Revenue and Expense Surprises”". Review of Accounting Studies, Vol. 8, 2-3, pág. $213-220$.

Berger, P. G. y E. Ofek (1995). "Diversification's effect on firm value". Journal of Financial Economics, Vol. 37, 1, pág. 39 - 65.

Berkovitch, E. y R. Israel (2004). "Why the NPV Criterion does not Maximize NPV". The Review of Financial Studies, Vol. 17, 1, pág. 239 - 255.

Bernstein, P. L. (2006). "The Real Efficient Market". Journal of Portfolio Management, Vol. 32, 4, pág. 1-1.

Bettis, R. A. y M. A. Hitt (1995). "The new competitive landscape". Strategic Management Journal, Vol. 16, S1, pág. 7 - 19.

Bhattacharya, S. (1979). "Imperfect Information, Dividend Policy, and "The Bird in the Hand" Fallacy". The Bell Journal of Economics, Vol. 10, 1, pág. $259-270$.

Bierman, H. J. (1993). "Capital Budgeting in 1992: A Survey". Financial Management, Vol. 22, 3, pág. 24.

Billet, M. T., T. D. King y D. C. Mauer (2007). "Growth Opportunities and the Choice of Leverage, Debt Maturity, and Covenants". The Journal of Finance, Vol. 66, 2, pág. 697 - 730.

Black, F. y M. Scholes (1973). "The Pricing of Options and Corporate Liabilities". Journal of Political Economy, Vol. 81, pág. 637 - 654.

Block, S. (1997). "Capital Budgeting Techniques Used by Small Business Firms in the 1990s". The Engineering Economist, Vol. 42, 4, pág. 289 - 302.

Block, S. (2005). "Are There Differences in Capital Budgeting Procedures between Industries? An Empirical Study". The Engineering Economist, Vol. 50, 1, pág. 55 - 67.

Block, S. (2007). "Are "Real Options" actually used in the real World?". The Engineering Economist, Vol. 52, 3, pág. 255 - 267.

Bloom, N. y J. Van Reenen (2010). "Why Do Management Practices Differ across Firms and Countries?". Journal of Economic Perspectives, Vol. 24, 1, pág. 203 - 224.

Booth, L., V. Aivazian, A. Demirguc-Kunt y V. Maksimovic (2001). "Capital Structures in Developing Countries". The Journal of Finance, Vol. 56, 1, pág. 87 - 130. 
Boyle, G. y G. Guthrie (2006). "Payback without apology". Accounting \& Finance, Vol. 46, 1, pág. 1 - 10.

Bradley, M., G. A. Jarrell y E. H. Kim (1984). "On the Existence of an Optimal Capital Structure: Theory and Evidence". The Journal of Finance, Vol. 39, 3, pág. 857 - 878.

Brealey, R. A., S. C. Myers y F. Allen (2010). "Principios de Finanzas Corporativas", 9a edición. McGraw-Hill. México DF, México.

Brennan, M. J. (1973). "An Approach to the Valuation of Uncertain Income Streams". The Journal of Finance, Vol. 28, 3, pág. 661 - 674.

Brennan, M. J. (1995). "Corporate Finance over the Past 25 Years". Financial Management, Vol. 24, 2, pág. 9 - 22.

Brounen, D., A. de Jong y K. Koedijk (2004). "Corporate Finance in Europe: Confronting Theory with Practice". Financial Management, Vol. 33, 4, pág. 71 - 101.

Brounen, D., A. de Jong y K. Koedijk (2006). "Capital Structure in Europe: Survey evidence". Journal of Banking \& Finance, Vol. 30, pág. 1409 1442.

Bruner, R. F. (2002). "Does M\&A Pay? A Survey of Evidence for the Decision-Maker". Journal of Applied Finance, Vol. 12, 1, pág. 48 - 68.

Bruner, R. F., K. M. Eades, R. S. Harris y R. C. Higgins (1998). "Best Practices in Estimating the Cost of Capital: Survey and Synthesis". Financial Practice and Education, Vol. 8, 1, pág. 13 - 28.

Brunzell, T., E. Liljeblom y M. Vaihekoski (2013). "Determinants of Capital Budgetings Methods and Hurdle Rates in Nordic firms". Accounting and Finance, Forthcoming.

Burns, R. y J. Walker (1997). "Capital Budgeting Techniques among the Fortune 500: A Rationale Approach". Managerial Finance, Vol. 23, 9, pág. 3 15.

Burns, R. y J. Walker (2009). "Capital Budgeting Surveys: The Future is Now". Journal of Applied Finance, Vol. 19, 1/2, pág. 78 - 90.

Busby, J. S. y C. G. C. Pitts (1997). "Real Options in Practice: An Exploratory Survey of How Finance Officers deal with Flexibility in Capital Appraisal". Management Accounting Research, Vol. 8, 2, pág. 169 - 186.

Campello, M., J. R. Graham y C. R. Harvey (2010). "The Real Effects of Financial Constraints: Evidence from a Financial Crisis". Journal of Financial Economics, Vol. 97, 3, pág. 470 - 487.

Campello, M. y D. Hackbarth (2012). "The firm-level credit multiplier". Journal of Financial Intermediation, Vol. 21, 3, pág. 446 - 472. 
Cantillo, M. y J. Wright (2000). "How do firms choose their lenders? An empirical investigation". The Review of Financial Studies, Vol. 13, 1, pág. 155 189.

Carr, C., K. Kolehmainen y F. Mitchella (2010). "Strategic investment decision making practices: A contextual approach". Management Accounting Research, Vol. 21, pág. 167 - 184.

Cescon, F. (2010). "Investment in New Manufacturing Systems: An Italian-based empirical analysis". Economia Aziendale Online, Vol. 1, pág. 13 26.

Chan, H., K. Haddad y W. Sterk (2008). "Capital Budgeting Practices of Chinese Firms". Journal of Global Business Management, Vol. 4, 2, pág. 0-0.

Chance, D. M. y P. P. Peterson (2002). "Real Options and Investment Valuation", $1^{\mathrm{a}}$ edition. The Research Foundation of the AIMR. Charlottesville, VA.

Chazi, A., T. Paulo Renato Soares y Z. Fernando Caputo (2010). "Theory versus practice: perspectives of Middle Eastern financial managers". European Business Review, Vol. 22, 2, pág. 195 - 221.

Chen, A. H. y E. H. Kim (1979). "Theories of Corporate Debt Policy: A Synthesis". The Journal of Finance, Vol. 34, 2, pág. 371 - 384.

Chen, S. (1995). "An empirical examination of capital budgeting techniques: Impact of investment types and firm characteristics". The Engineering Economist, Vol. 40, 2, pág. 145 - 170.

Chen, S. (2008). "DCF Techniques and Nonfinancial Measures in Capital Budgeting: A Contingency Approach Analysis". Behavioral Research in Accounting, Vol. 20, 1, pág. 13 - 29.

Childs, P. D., D. C. Mauer y S. H. Ott (2005). "Interactions of Corporate Financing and Investment Decisions: The effects of Agency Conflicts". Journal of Financial Economics, Vol. 76, pág. 667 - 690.

Chirinko, R. S. y A. R. Singha (2000). "Testing static tradeoff against pecking order models of capital structure: a critical comment". Journal of Financial Economics, Vol. 58, 3, pág. 417 - 425.

Cohen, G. y J. Yagil (2007). "A Multinational Survey of Corporate Financial Policies". Journal of Applied Finance, Vol. 17, 1, pág. 57 - 69.

Coleman, S. y A. Robb (2012). "Capital structure theory and new technology firms: is there a match?". Management Research Review, Vol. 35, 2, pág. $106-120$.

Colombage, S. R. N. (2007). "Consistency and Controversy in Corporate Financing Practices: Evidence from an Emerging Market". Studies in Economics and Finance, Vol. 24, 1, pág. 51 - 71. 
Comment, R. y G. A. Jarrell (1995). "Corporate focus and stock returns". Journal of Financial Economics, Vol. 37, 1, pág. 67 - 87.

Copeland, T. E. (2000). "New Developments in Valuation" en Strategic finance in the 21st century: 15 expert opinions, pág. Ed. W. Verhoog, L. Keuleneer and D. Swagerman. Royal NIVRA, Continuing Professional Education (VERA),

Copeland, T. E. (2002). "What do Practitioners Want?". Journal of Applied Finance, Vol. 12, 1, pág. 7 - 14.

Cox, J. C., S. A. Ross y M. Rubinstein (1979). "Option Pricing: A simplified aproach". Journal of Financial Economics, Vol. 7, 3, pág. 229 - 263.

Da, Z., R.-J. Guo y R. Jagannathan (2012). "CAPM for estimating the Cost of Equity Capital: Interpreting the Empirical Evidence". Journal of Financial Economics, Vol. 103, 1, pág. 204 - 220.

Dammon, R. M. y L. W. Senbet (1988). "The Effect of Taxes and Depreciation on Corporate Investment and Financial Leverage". The Journal of Finance, Vol. 43, 2, pág. 357 - 373.

Danielson, M. G. y J. A. Scott (2006). "The Capital Budgeting Decisions of Small Businesses". Journal of Applied Finance, Vol. 16, 2, pág. 45 - 56.

Danielson, M. G. y J. A. Scott (2007). "A Note on Agency Conflicts and the Small Firm Investment Decision". Journal of Small Business Management, Vol. 45, 1, pág. 157 - 175.

de Jong, A., M. Verbeek y P. Verwijmeren (2011). "Firms' debt-equity decisions when the static tradeoff theory and the pecking order theory disagree". Journal of Banking \& Finance, Vol. 35, 5, pág. 1303 - 1314.

de Jong, A. y P. Verwijmeren (2010). "To have a target debt ratio or not: what difference does it make?". Applied Financial Economics, Vol. 20, 3, pág. 219 - 226.

DeAngelo, H. y R. W. Masulis (1980). "Optimal capital structure under corporate and personal taxation". Journal of Financial Economics, Vol. 8, 1, pág. $3-29$.

Dedi, L. y S. Orsag (2007). "Capital Budgeting Practices: A Survey of Croatian Firms". SEE Journal of Economics and Business, Vol. 2, 1, pág. 59 - 67.

Diamond, D. W. (1989). "Reputation Adquisitions in Debt Markets". Journal of Political Economy, Vol. 97, 4, pág. 828 - 862.

Dillman, D. A., G. Phelps, R. Tortora, K. Swift, J. Kohrell, J. Berck y B. L. Messer (2009). "Response rate and measurement differences in mixedmode surveys using mail, telephone, interactive voice response (IVR) and the Internet". Social Science Research, Vol. 38, 1, pág. 1 - 18. 
Donaldson, G. (1961). "Corporate debt capacity: A study of corporate debt policy and the determination of corporate debt capacity", Harvard Graduate School of Business Administration. Boston, Estados Unidos.

Downs, T. W. (1993). "Corporate leverage and nondebt tax shields: Evidence on crowding-out". The Financial Review, Vol. 28, 4, pág. 549 - 583.

Drury, C. y M. Tayles (1996). "UK capital budgeting practices: some additional survey evidence". The European Journal of Finance, Vol. 2, 4, pág. 371 - 388.

Drury, C. y M. Tayles (1997). "The misapplication of capital investment appraisal techniques". Management Decision, Vol. 35, 2, pág. 86 - 93.

Dutordoir, M. y L. Van de Gucht (2007). "Are there windows of opportunity for convertible debt issuance? Evidence for Western Europe". Journal of Banking \& Finance, Vol. 31, 9, pág. 2828 - 2846.

El-Sady, H. M., H. I. Hamdy y V. Sultanova (2011). "Capital Investment Practices: A Survey of Large Corporations in a Developing Market". Global Review of Accounting and Finance, Vol. 2, 2, pág. 39 - 60.

Ertimur, Y., J. Livnat y M. Martikainen (2003). "Differential Market Reactions to Revenue and Expense Surprises". Review of Accounting Studies, Vol. 8, 2-3, pág. 185 - 211.

Evans, D. A. y S. M. Forbes (1993). "Decision making and display methods: The case of prescription and practice in capital budgeting". The Engineering Economist, Vol. 39, 1, pág. 87 - 92.

Fama, E. F. (1977). "Interest Rates and Inflation: The Message in the Entrails". American Economic Review, Vol. 67, 3, pág. 487 - 496.

Fama, E. F. (1978). "The Effects of a Firm's Investment and Financing Decisions on the Welfare of Its Security Holders". American Economic Review, Vol. 68, 3, pág. 272 - 284.

Fama, E. F. y K. R. French (2002). "Testing Trade-Off and Pecking Order Theory about Dividends and Debt". The Review Of Financial Studies, Vol. 15, 1, pág. 1 - 33.

Fan, D. K. K. y R. W. So (2004). "What managers think of capital structure: the evidence from Hong Kong". Journal of Asian Economics, Vol. 15, 4, pág. 817 - 830.

Faulkender, M. y M. A. Petersen (2006). "Does the Source of Capital Affect Capital Structure?". The Review of Financial Studies, Vol. 19, 1, pág. 45 79 .

Fazzari, S. M., R. G. Hubbard y B. C. Petersen (1988). "Financing Constraints and Corporate Investment; Comments and Discussion". Brookings Papers on Economic Activity, Vol. 1988, 1, pág. 141 - 206. 
Flannery, M. J. y K. P. Rangan (2006). "Partial adjustment toward target capital structures". Journal of Financial Economics, Vol. 79, 3, pág. 469 - 506.

Frank, M. Z. y V. K. Goyal (2003). "Testing the Pecking Order Theory of Capital Structure". Journal of Financial Economics, Vol. 67, 2, pág. 217 - 248.

Frank, M. Z. y V. K. Goyal (2004). "The effect of market conditions on capital structure adjustment". Finance Research Letters, Vol. 1, 1, pág. 47 - 55.

Frank, M. Z. y V. K. Goyal (2007). "Trade-Off and Pecking Order Theories of Debt" en Handbook of Empirical Corporate Finance, pág. 135 - 202. Ed. B. E. Eckbo. Elsevier, San Diego.

Frank, M. Z. y V. K. Goyal (2009). "Capital Structure Decisions: Which factors are reliably important?". Financial Management, Vol. 38, 1, pág. 1 - 37.

Fuente, G. (2004). "La Valoración de Opciones Reales: El caso de una inversión en el Sector de Componentes del Automóvil", Secretariado de Publicaciones e Intercambio Editorial. Universidad de Valladolid. Valladolid, España.

Gamba, A., G. Sick y C. Aranda (2008). "Investment under Uncertainty, Debt and Taxes". Economics Notes, Vol. 37, 1, pág. 31 - 58.

Gamba, A. y A. J. Triantis (2008). "The Value of Financial Flexibility". The Journal of Finance, Vol. 63, 5, pág. 2263 - 2296.

Ghahremani, M., A. Aghaie y M. Abedzadeh (2012). "Capital Budgeting Technique Selection through Four Decades: With a Great Focus on Real Options". International Journal of Business and Management, Vol. 7, 17, pág. 98 - 119.

Ghosh, S. (2007). "Bank Debt Use and Firm Size: Indian Evidence". Small Business Economics, Vol. 29, 1-2, pág. 15 - 23.

Gilbert, E. y A. Reichert (1995). "The practice of financial management among large United States corporations". Financial Practice \& Education, Vol. 5, 1, pág. 16 - 23.

Gitman, L. y J. Forrester (1977). "A Survey of Capital Budgeting Techniques used by Major U.S. Firms". Financial Management, Vol. 6, 3, pág. 66 $-71$.

Gómez-Bezares, F. (2005). "Una Nota Crítica acerca de la Actual Investigación en Finanzas". Cuadernos de Economía y Dirección de la Empresa, Vol. 24, pág. 105 - 120.

Gonenc, H. (2009). "How do business group firms utilize internal capital markets?". International Journal of Managerial Finance, Vol. 5, 4, pág. 360 375.

González, V. M. y F. González (2008). "Influence of bank concentration and institutions on capital structure: New international evidence". Journal of Corporate Finance, Vol. 14, 4, pág. 363 - 375. 
González, V. M. y F. González (2012). "Firm size and capital structure: evidence using dynamic panel data". Applied Economics, Vol. 44, 36, pág. 4745 4754.

Graham, J. R. (2000). "How Big Are the Tax Benefits of Debt?". The Journal of Finance, Vol. 55, 5, pág. 1901 - 1941.

Graham, J. R. (2004). "Roundtable on Corporate Disclosure". Journal of Applied Corporate Finance, Vol. 16, 4, pág. 36 - 62.

Graham, J. R. y C. R. Harvey (2001). "The Theory and Practice of Corporate Finance: Evidence from the field". Journal of Financial Economics, Vol. 60, 2 - 3, pág. 187 - 243.

Graham, J. R. y C. R. Harvey (2002). "How do CFOs make capital budgeting and capital structure decisions?". Journal of Applied Corporate Finance, Vol. 15, 1, pág. 8 - 23.

Graham, J. R., C. R. Harvey y S. Rajgopal (2006). "Value Destruction and Financial Reporting Decisions". Financial Analyst Journal, Vol. 62, 6, pág. $27-39$.

Graham, J. R. y M. T. Leary (2011). "A Review of Empirical Capital Structure Research and Directions for the Future". Annual Review of Financial Economics, Vol. 3, 1, pág. 309 - 345.

Greene, W. H. (2012). "Econometric Analysis", 7ª edición. Pearson Higher Education. Essex, England.

Grossman, S. J. y O. D. Hart (1982). "Corporate Financial Structure and Managerial Incentives" en The Economics of Information and Uncertainty, pág. 107 - 137. Ed. J. McCall. University of Chicago Press, Chicago.

Groves, R. M., F. J. Fowler, M. P. Couper, J. M. Lepkowski, E. Singer y R. Tourangeau (2009). "Survey Methodology", 2da edición. WileyInterscience. Hoboken, New Jersey, Estados Unidos.

Hackbarth, D. (2009). "Determinants of Corporate Borrowing: A behavioral Perspective". Journal of Corporate Finance, Vol. 15, pág. 389 - 411.

Haddad, K., W. Sterk y A. Wu (2010). "Capital Budgeting Practices of Taiwanese Firms". Journal of International Management Studies, Vol. 5, 1, pág. $178-182$.

Hadlock, C. J. y C. M. James (2002). "Do Banks Provide Financial Slack?". The Journal of Finance, Vol. 57, 3, pág. 1383 - 1419.

Hahn, J. y H. Lee (2009). "Financial Constraints, Debt Capacity, and the Cross-section of Stock Returns". The Journal of Finance, Vol. 64, 2, pág. 891 921.

Haka, S. F., L. A. Gordon y G. E. Pinches (1985). "Sophisticated Capital Budgeting Selection Techniques and Firm Performance". Accounting Review, Vol. 60, 4, pág. 651 - 669. 
Hall, J. y S. Millard (2010). "Capital budgeting practices used by selected listed South African firms". South African Journal of Economic and Management Sciences, Vol. 13, 1, pág. 85 - 97.

Harris, M. y A. Raviv (1990). "Capital Structure and the information role of Debt". The Journal of Finance, Vol. 45, 2, pág. 321 - 349.

Harris, M. y A. Raviv (1991). "The Theory of Capital Structure". The Journal of Finance, Vol. 46, 1, pág. 297 - 355.

Hayes, R. H. y D. A. Garvin (1982). "Managing as if Tomorrow Mattered". Harvard Business Review, Vol. May-June, pág. 70 - 79.

Herbert, W. E. y R. S. O. Wallace (1996). "A Corporate View of Research Needs in Corporate Finance". Accounting and Business Research, Vol. 26, 2, pág. 107 - 124.

Hermes, N., P. Smid y L. Yao (2007). "Capital budgeting practices: A comparative study of the Netherlands and China". International Business Review, Vol. 16, 5, pág. 630 - 654.

Holmen, M. y B. Pramborg (2009). "Capital Budgeting and Political Risk: Empirical Evidence". Journal of International Financial Management \& Accounting, Vol. 20, 2, pág. 105 - 134.

Hovakimian, A. (2004). "The Role of Target Leverage in Security Issues and Repurchases". Journal of Business, Vol. 77, 4, pág. 1041 - 1071.

Hovakimian, A. (2006). "Are Observed Capital Structures Determined by Equity Market Timing?". Journal of Financial and Quantitative Analysis, Vol. 41, 1, pág. 221 - 243.

Hovakimian, A., G. Hovakimian y H. Tehranian (2004). "Determinants of target capital structure: The case of dual debt and equity issues". Journal of Financial Economics, Vol. 71, 3, pág. 517 - 540.

Hovakimian, A., T. Opler y S. Titman (2001). "The debt-equity choice". Journal of Financial and Quantitative Analysis, Vol. 36, 1, pág. 1 - 24.

Hovakimian, G. y S. Titman (2006). "Corporate Investment with Financial Constraints: Sensitivity of Investments to Funds from Voluntary Asset Sales". Journal of Money, Credit, and Banking, Vol. 38, 2, pág. 357 - 374.

Hwang, N.-C. R. y C. J. Chang (1999). "Financial managers' perceptions on research needs for the Asian-Pacific region". Journal of Multinational Financial Management, Vol. 9, 1, pág. 45 - 63.

Istvan, D. F. (1961). "The Economic Evaluation of Capital Expenditures". Journal of Business, Vol. 36, 1, pág. 3 - 53.

Iturralde, T. y A. Maseda (2004). "Tamaño de la Empresa y Gestión Financiera". Revista Europea de Dirección y Economía de la Empresa, Vol. 13, 3, pág. 183 - 198. 
Jagannathan, R. y I. Meier (2002). "Do we need CAPM for capital budgeting?". Financial Management, Vol. 31, 4, pág. 55 - 77.

Jagannathan, R., I. Meier y V. Tarhan (2011). "The Cross Section of Hurdle Rates for Capital Budgeting: An Empirical Analysis of Survey Data". Working Paper, Northwestern University.

Jensen, M. C. (1986). "Agency Costs of Free Cash Flow, Corporate Finance, and Takeovers". American Economic Review, Vol. 76, 2, pág. 323 - 329.

Jensen, M. C., E. F. Fama, J. B. Long Jr, R. S. Ruback, G. W. Schwert, C. W. Smith Jr y J. Warner (1989). "Clinical papers and their role in the development of financial economics". Journal of Financial Economics, Vol. 24, 1, pág. 3 - 6.

Jensen, M. C. $y$ W. H. Meckling (1976). "Theory of the Firm: Managerial Behavior, Agency Costs and Ownership Structure". Journal of Financial Economics, Vol. 3, pág. 305 - 360.

Jog, V. M. y A. K. Srivastava (1994). "Corporate Financial DecisionMaking in Canada". Revue Canadienne Des Sciences De L AdministrationCanadian Journal of Administrative Sciences, Vol. 11, 2, pág. 156 - 176.

Jog, V. M. y A. K. Srivastava (1995). "Capital Budgeting Practices in Corporate Canada". Financial Practice \& Education, Vol. 5, 2, pág. 37 - 43.

Johnson, S. A. (2003). "Debt Maturity and the Effects of Growth Opportunities and Liquidity Risk on Leverage". The Review Of Financial Studies, Vol. 16, 1, pág. 209 - 236.

Kamath, R. R. (1997). "Long-Term Financing Decisions: Views and Practices of Financial Managers of NYSE Firms". The Financial Review, Vol. 32, 2, pág. 331 - 356.

Kaplowitz, M. D., T. D. Hadlock y R. Levine (2004). "A Comparison of Web and Mail Survey Response Rates". Public Opinion Quarterly, Vol. 68, 1, pág. 94 - 101.

Karadeniz, E., S. Y. Kandır, Ö. Iskenderoğlu y Y. B. Onal (2011). "Firm Size and Capital Structure Decisions: Evidence From Turkish Lodging Companies". International Journal of Economics and Financial Issues, Vol. 1, 1, pág. 1 - 11.

Kester, G., R. P. Chang, E. S. Echanis, S. Haikal, M. Isa, M. T. Skully, K. Tsui y C. J. Wang (1999). "Capital Budgeting Practices in the Asia Pacific Region: Australia, Hong Kong, Indonesia, Malaysia, Phillipines and Singapore". Financial Practice and Education, Vol. 9, 1, pág. 25 - 33.

Kester, G. W., R. P. Chang y T. Kai-Chong (1994). "Corporate Financial Policy in the Pacific Basin: Hong Kong and Singapore". Financial Practice \& Education, Vol. 4, 1, pág. 117 - 127. 
Khanna, T. y K. Palepu (2000a). "The Future of Business Groups in Emerging Markets: Long-run evidence from Chile". Academy of Management Journal, Vol. 43, 3, pág. 268 - 285.

Khanna, T. y K. Palepu (2000b). "Is Group Affiliation Profitable in Emerging Markets? An Analysis of Diversified Indian Business Groups". The Journal of Finance, Vol. 55, 2, pág. 867 - 891.

Khanna, T. y J. W. Rivkin (2001). "Estimating the performance effects of business groups in emerging markets". Strategic Management Journal, Vol. 22, 1, pág. 45 - 74.

Kim, S. H., T. Crick y S. H. Kim (1986). "Do Executives Practice what Academics Preach?". Management Accounting, Vol. 68, 5, pág. 49 - 52.

Kim, S. H. y E. J. Farragher (1981). "Current Capital Budgeting Practices". Management Accounting, Vol. 62, 12, pág. 26 - 30.

Kim, S. H. y G. Ulferts (1996). "A Summary of Multinational Capital Budgeting Studies". Managerial Finance, Vol. 22, 1, pág. 75 - 85.

Kjellman, A. y S. Hansén (1995). "Determinants of capital structure: Theory vs. practice". Scandinavian Journal of Management, Vol. 11, 2, pág. 91 102.

Klamer, T. (1972). "Empirical Evidence of the Adoption of Sophisticated Capital Budgeting Techniques". The Journal of Business, Vol. 45, 3, pág. 387 397.

Klamer, T., N. Wilner y J. Smolarski (2002). "A comparative Survey of Capital Investment Decision Practices in the United States and the United Kingdom ". International Busines \& Economics Research Journal, Vol. 1, 11, pág. 103 - 114.

Klammer, T. y M. C. Walker (1984). "The Continuing Increase in the Use of Sophisticated Capital Budgeting Techniques". California Management Review, Vol. 27, 1, pág. 137 - 148.

Klammer, T., N. Wilner y J. Smolarski (2002). "A comparative Survey of Capital Investment Decision Practices in the United States and the United Kingdom ". International Busines \& Economics Research Journal, Vol. 1, 11, pág. 103 - 114.

Korajczyk, R. A. y A. Levy (2003). "Capital structure choice: macroeconomic conditions and financial constraints". Journal of Financial Economics, Vol. 68, 1, pág. 75 - 109.

Krychowski, C. y B. V. Quélin (2010). "Real Options and Strategic Investment Decisions: Can They Be of Use to Scholars?". Academy of Management Perspectives, Vol. 24, 2, pág. 65 - 78. 
Kulatilaka, N. y A. J. Marcus (1992). "Project Valuation under Uncertainty: When does DCF fail?". Journal of Applied Corporate Finance, Vol. 5, 3, pág. 92 - 100.

Kumar, K. B., R. G. Rajan y L. Zingales (2002). "What Determines Firm Size?". CRSP Working Paper No. 496, University of Chicago.

La Porta, R., F. Lopez-De-Silanes, A. Shleifer y R. W. Vishny (1997). "Legal Determinants of External Finance". The Journal of Finance, Vol. 52, 3, pág. 1131 - 1150.

Lander, D. M. y G. E. Pinches (1998). "Challenges to the practical implementation of modeling and valuing real options". The Quarterly Review of Economics and Finance, Vol. 38, 3, Part 2, pág. 537 - 567.

Lang, L., E. Ofek y R. Stulz (1996). "Leverage, Investment, and Firm Growth". Journal of Financial Economics, Vol. 40, 1, pág. 3 - 29.

Lazaridis, I. (2004). "Capital Budgeting Practices: A Surveyin the Firms in Cyprus". Journal of Small Business Management, Vol. 42, 4, pág. 427 - 433.

Leary, M. T. y M. R. Roberts (2010). "The pecking order, debt capacity, and information asymmetry". Journal of Financial Economics, Vol. 95, 3, pág. $332-355$.

Lefley, F. (1996). "The payback method of investment appraisal: A review and synthesis". International Journal of Production Economics, Vol. 44, 3, pág. $207-224$.

Lemmon, M. L. y J. F. Zender (2010). "Debt Capacity and Tests of Capital Structure Theories". Journal of Financial and Quantitative Analysis, Vol. 45, 5, pág. 1161 - 1187.

Leon, F., M. Isa y G. Kester (2008). "Capital Budgeting Practices of Listed Indonesian Companies". Asian Journal of Business and Accounting, Vol. 1, 2, pág. 175 - 192.

Liljeblom, E. y M. Vaihekoski (2004). "Investment Evaluation Methods and Required Rate of Return in Finnish Publicly Listed Companies". The Finnish Journal of Business Economics, Vol. 2004, 1, pág. 9 - 24.

Liljeblom, E. y M. Vaihekoski (2009). "Corporate ownership and managerial short-termism: Results from a Finnish study of management perceptions". International Journal of Production Economics, Vol. 117, 2, pág. $427-438$.

Lindblom, T., G. Sandahl y S. Sjogren (2011). "Capital Structure Choices". International Journal of Banking, Accounting and Finance, Vol. 3, 1, pág. 4 - 30.

López-Gracia, J. y F. Sogor-Mira (2008). "Testing trade-off and pecking order theories financing SMEs". Small Business Economics, Vol. 31, 2, pág. 117 136. 
Magni, C. A. (2008). "CAPM-based capital budgeting and nonadditivity". Journal of Property Investment \& Finance, Vol. 26, 5, pág. 388 - 398.

Mao, J. C. T. (1970). "Survey of Capital Budgeting: Theory and Practice". The Journal of Finance, Vol. 25, 2, pág. 349 - 360.

Maquieira, C. P., L. A. Preve y V. Sarria-Allende (2012). "Theory and practice of corporate finance: Evidence and distinctive features in Latin America". Emerging Markets Review, Vol. 13, 2, pág. 118 - 148.

Marchica, M.-T. y R. Mura (2010). "Financial Flexibility, Investment Ability, and Firm Value: Evidence from Firms with Spare Debt Capacity". Financial Management, Vol. 39, 4, pág. 1339 - 1365.

Maroyi, V. y H. M. van der Poll (2012). "A survey of Capital Budgeting Techniques used by Listed Mining Companies in South Africa". African Journal of Business Management, Vol. 6, 32, pág. 9279 - 9292.

Mathews, S., V. Datar y B. Johnson (2007). "A Practical Method for Valuing Real Options: The Boeing Approach". Journal of Applied Corporate Finance, Vol. 19, 2, pág. 95 - 104.

Mauer, D. C. y S. H. Ott (2000). "Agency Costs, Underinvestment, and Optimal Capital Structure. The effect of Growth Options to Expand" en Project Flexibility, Agency, and Competition, pág. 151 - 179. Ed. M. J. Brennan and L. Trigeorgis. Oxford University Press, New York.

Mauer, D. C. y S. Sarkar (2005). "Real Options, Agency Conflicts, and Optimal Capital Structure". Journal of Banking \& Finance, Vol. 29, pág. 1405 1428.

Mauer, D. C. y A. J. Triantis (1994). "Interactions of Corporate Financing and Investment Decisions: A Dynamic Framework". The Journal of Finance, Vol. 49, 4, pág. 1253 - 1277.

McDonald, R. L. (2000). "Real options and rules of thumb in capital budgeting" en Project Flexibility, Agency, and Competition, pág. 13 - 33. Ed. M. J. Brennan and L. Trigeorgis. Oxford University Press, New York.

McDonald, R. L. (2006). "The Role of Real Options in Capital Budgeting: Theory and Practice". Journal of Applied Corporate Finance, Vol. 18, 2, pág. 28 39.

Meier, I. y V. Tarhan (2007). "Corporate Investment Decision Practices and the Hurdle Rate Premium Puzzle". Social Science Research Network, SSRN.

Meier, I. y V. Tarhan (2009). "Cash Flow Practices in Capital Budgeting Decisions". Working paper, HEC Montreal y Kellog School of Management.

Michaelas, N., F. Chittenden y P. Poutziouris (1999). "Financial Policy and Capital Structure Choice in U.K. SMEs: Empirical Evidence from Company Panel Data". Small Business Economics, Vol. 12, 2, pág. 113 - 130. 
Miguel, A. d. y J. Pindado (2001). "Determinants of capital structure: new evidence from Spanish panel data". Journal of Corporate Finance, Vol. 7, 1, pág. 77 - 99.

Miller, J. H. (1960). "A Glimpse at Practice in Calculating and Using Return on Investment". National Association of Accountants. NAA Bulletin (pre1986), Vol. 41, 10, pág. 65 - 76.

Miller, M. H. (1977). "Debt and taxes". The Journal of Finance, Vol. 32, 2, pág. 261 - 275.

Modigliani, F. y M. H. Miller (1958). "The Cost of Capital, Corporate Finance and the Theory of Investment". American Economic Review, Vol. 48, 3, pág. 261 - 297.

Mongrut M., S. y D. Wong C. (2005). "Un Examen Empírico de las Pprácticas de Presupuesto de Capital en el Perú". Estudios Gerenciales, Vol. 95, pág. 95 - 111.

Moore, J. S. y A. K. Reichert (1983). "An Analisys of the Financial Management Techniques currently employed by Large U.S. Corporations". Journal of Business Finance \& Accounting, Vol. 10, 4, pág. 623 - 645.

Morellec, E. y A. Zhdanov (2008). "Financing and Takeovers". Journal of Financial Economics, Vol. 87, pág. 556 - 581.

Moutino, N. F. L. y H. I. Q. C. Mouta (2006). "Projectos de Investimento: Abordagem Tradicional nas Empresas Portuguesas". Working paper, Instituto Poltécnico de Bragança.

Mukherjee, T. K., H. Kiymaz y H. K. Baker (2004). "Merger Motives and Target Valuation: A Survey of Evidence from CFOs". Journal of Applied Finance, Vol. 14, 2, pág. 7 - 24.

Myers, S. C. (1974). "Interactions of Corporate Financing and Investment Decisions-Implications for Capital Budgeting". The Journal of Finance, Vol. 29, 1, pág. 1 - 25.

Myers, S. C. (1977). "Determinants of Corporate Borrowing". Journal of Financial Economics, Vol. 5, pág. 147 - 175.

Myers, S. C. (1984a). "The Capital Structure Puzzle". The Journal of Finance, Vol. 39, 3, pág. 575 - 592.

Myers, S. C. (1984b). "Finance Theory and Financial Strategy". Interfaces, Vol. 14, 1, pág. 126 - 137.

Myers, S. C. (1996). "Fischer Black's contributions to Corporate Finance". Financial Management, Vol. 25, 4, pág. 95 - 103.

Myers, S. C. (2001). "Capital Structure". Journal of Economics Perspectives, Vol. 15, 2, pág. 81 - 102. 
Myers, S. C. y N. S. Majluf (1984). "Corporate Financing and Investment Decisions when Firms have Information that Investors do not have". Journal of Financial Economics, Vol. 13, pág. 187 - 221.

Myers, S. C. y S. M. Turnbull (1977). "Capital Budgeting and the Capital Asset Pricing Model: Good News and Bad News". The Journal of Finance, Vol. 32, 2, pág. 321 - 333.

Newton, D. P. y A. W. Pearson (1994). "Application of option pricing theory to R\&D". R\&D Management, Vol. 24, 1, pág. 83 - 89.

Nor, F. M., K. Ibrahim, R. Haron, I. Ibrahum y M. A. Alias (2012). "Practices of Capital Structure Decisions: Malaysia Survey Evidence". International Review of Business Research Papers, Vol. 8, 1, pág. 33 - 63.

Norton, E. (1989). "Determinants of Capital Structure: A Survey". Advances in Financial Planning and Forecasting, Vol. 3, pág. 323 - 350.

Norton, E. (1990). "Similarities and differences in small and large corporation beliefs about capital structure policy". Small Business Economics, Vol. 2, 3, pág. 229 - 245.

Norton, E. (1991a). "Capital structure and small public firms". Journal of Business Venturing, Vol. 6, 4, pág. 287 - 303.

Norton, E. (1991b). "Factors Affecting Capital Structure Decisions". The Financial Review, Vol. 26, 3, pág. 431 - 446.

Oblak, D. J. y R. J. Helm, Jr. (1980). "Survey and Analysis of Capital Budgeting Methods Used by Multinationals". Financial Management, Vol. 9, 4, pág. $37-41$.

Opler, T. C. y S. Titman (1994). "Financial Distress and Corporate Performance". The Journal of Finance, Vol. 49, 3, pág. 1015 - 1040.

Osborne, M. J. (2010). "A resolution to the NPV-IRR debate?". Quarterly Review of Economics \& Finance, Vol. 50, 2, pág. 234 - 239.

Ozkan, A. (2000). "An empirical analysis of corporate debt maturity structure". European Financial Management, Vol. 6, 2, pág. 197 - 212.

Parsons, C. y S. Titman (2008). "Empirical Capital Structure: A Review". Foundations and Trends in Finance, Vol. 3, 1, pág. 1 - 93.

Payne, J., W. C. Heath y L. R. Gale (1999). "Comparative Financial Practice in the US and Canada: Capital Budgeting and Risk Assessment Techniques". Financial Practice and Education, Vol. 9, 1, pág. 16 - 24.

Pereiro, L. E. (2006). "The practice of investment valuation in emerging markets: Evidence from Argentina". Journal of Multinational Financial Management, Vol. 16, 2, pág. 160 - 183.

Petry, G. H. (1975). "Effective Use of Capital Budgeting Tools". Business Horizons, Vol. 18, 5, pág. 57 - 65. 
Petry, G. H. y J. Sprow (1993). "The theory and practice of finance in the 1990s". The Quarterly Review of Economics and Finance, Vol. 33, 4, pág. 359 381.

Pettit, R. R. y R. F. Singer (1985). "Small Business Finance: A Research Agenda". Financial Management (pre-1986), Vol. 14, 3, pág. 47 - 60.

Pike, R. (1996). "A Longitudinal Survey on Capital Budgeting Practices". Journal of Business Finance \& Accounting, Vol. 23, 1, pág. 79 - 92.

Pike, R. y T. S. Ooi (1988). "The Impact of Corporate Investment Objetives and Constraints on Capital Budgeting Practices". British Accounting Review, Vol. 20, pág. 159 - 173.

Pike, R. H. (1985). "Owner-Manager Conflict and the Role of the Payback Method". Accounting and Business Research, Vol. 16, 61, pág. 47 - 51.

Pindado, J. (2004). "Práctico: Conexión entre el VAN y el Valor de Mercado de las Acciones". Estrategia Financiera, Vol. 214, Febrero, pág. 12 - 18.

Pinegar, J. M. y L. Wilbricht (1989). "What Managers Think of Capital Structure Theory: A Survey". Financial Management, Vol. 18, 4, pág. 82 - 91.

Pinsonneault, A. y K. L. Kraemer (1993). "Survey Research Methodology in Management Information Systems: An Assessment". Journal of Management Information Systems, Vol. 10, 2, pág. 75 - 105.

Poterba, J. M. y L. H. Summers (1995). "A CEO Survey of U.S. Companies' Time Horizons and Hurdle Rates". Sloan Management Review, Vol. 37, 1, pág. 43 - 53.

Proctor, M. D. y J. R. Canada (1992). "Past and present methods of manufacturing investment evaluation: A review of the empirical and theoretical literature". The Engineering Economist, Vol. 38, 1, pág. 45 - 58.

Pruitt, S. W. y L. J. Gitman (1991). "The Interactions Between the Investment, Financing, and Dividend Decisions of Major U.S. Firms". The Financial Review, Vol. 26, 3, pág. 409 - 430.

Rajagopalan, N. y D. K. Datta (1996). "CEO Characteristics: Does Industry Matter?". Academy of Management Journal, Vol. 39, 1, pág. 197 - 215.

Rajan, R. G. y L. Zingales (1995). "What do we Know about Capital Structure?. Some evidence from International Data". The Journal of Finance, Vol. 50, 5, pág. 1421 - 1460.

Ramirez, G. G., D. A. Waldman y D. J. Lasser (1991). "Research Needs in Corporate Finance: Perspectives from Financial Managers". Financial Management, Vol. 20, 2, pág. 17 - 29.

Rappaport, A. (1979). "A Critique of Capital Budgeting Questionnaires". Interfaces, Vol. 9, 3, pág. 100 - 102. 
Rayo, S., A. M. Cortés y J. L. Sáez (2007). "Valoración empírica de las Opciones de Crecimiento. El caso de la Gran Empresa Española". Revista Europea de Dirección y Economía de la Empresa, Vol. 16, 2, pág. 147 - 166.

Ross, S. A. (1977). "The Determination of Financial Structure: The Incentive-Signalling Approach". The Bell Journal of Economics, Vol. 8, 1, pág. $23-40$.

Ryan, B., R. W. Scapens y M. Theobald (2004). "Metodología de la Investigación en Finanzas y Contabilidad", $1^{\text {a }}$ edición. Ediciones Deusto. Barcelona, España.

Ryan, P. y G. Ryan (2002). "Capital Budgeting Practices of the Fortune 1000: How Have Things Changed?". Journal of Business and Management, Vol. 8, 4, pág. 355 - 364.

Sandahl, G. y S. Sjögren (2003). "Capital budgeting methods among Sweden's largest groups of companies. The state of the art and a comparison with earlier studies". International Journal of Production Economics, Vol. 84, 1, pág. $51-69$.

Schall, L. D. y G. L. Sundem (1980). "Capital Budgeting Methods and Risk: A Further Analysis". Financial Management, Vol. 9, 1, pág. 7 - 13.

Schall, L. D., G. L. Sundem y W. J. Geijsbeek (1978). "Survey and Analysis of Capital Budgeting Methods". The Journal of Finance, Vol. 33, 1, pág. $281-287$.

Scholleova, H., J. Fotr y L. Svecova (2010). "Investment Decision Making Criterions in Practice". Economics and Management, Vol. 15, pág. 1018 1023.

Scott, D. F., Jr. y D. J. Johnson (1982). "Financing Policies and Practices in Large Corporations". Financial Management, Vol. 11, 2, pág. 51 - 59.

Scott, J. H. (1976). "A Theory of Optimal Capital Structure". Bell Journal of Economics, Vol. 7, 1, pág. 33 - 54.

Segelod, E. (1998). "A note on the Survey of Poject Evaluation Techniques in Major Corporations". International Journal of Production Economics, Vol. 54, pág. 207 - 213.

Shao, L. P. y A. T. Shao (1996). "Risk analysis and capital budgeting techniques of U.S. multinational enterprises". Managerial Finance, Vol. 22, 1, pág. 41 - 57.

Sharp, D. J. (1991). "Uncovering the hidden value in high-risk investments". Sloan Management Review, Vol. 32, pág. 69 - 74.

Shinoda, T. (2010). "Capital Budgeting Management Practices in Japan: A Focus on the Use of Capital Budgeting Methods". Economic Journal of Hokkaido University, Vol. 39, pág. 39 - 50. 
Shumway, T. (2001). "Forecasting Bankruptcy More Accurately: A Simple Hazard Model". Journal of Business, Vol. 74, 1, pág. 101 - 124.

Shyam-Sunder, L. y S. C. Myers (1999). "Testing static tradeoff against pecking order models of capital structure". Journal of Financial Economics, Vol. 51, 2, pág. 219 - 244.

Singh, S., P. K. Jain y S. S. Yadav (2012). "Capital budgeting decisions: evidence from India". Journal of Advances in Management Research, Vol. 9, 1, pág. 96 - 112.

Smith, C. W. y R. L. Watts (1992). "The Investment Opportunity Set and Corporate Financing, Dividend, and Compensation Policies". Journal of Financial Economics, Vol. 32, pág. 263 - 292.

Sridharan, U. V. y U. Schuele (2008). "Budget Size and Risk Perception in Capital Budgeting Decisions of German Managers". International Review of Business Research Papers, Vol. 4, 3, pág. 213 - 221.

Stanley, M. T. y S. Block (1984). "A Survey of Multinational Capital Budgeting". Financial Review, Vol. 19, 1, pág. 36 - 54.

Statman, M. (1982). "The Persistence of the Payback Method: A Principal-Agent Perspective". The Engineering Economist, Vol. 27, 2, pág. 95 100.

Stohs, M. H. y D. C. Mauer (1996). "The Determinants of Corporate Debt Maturity Structure". Journal of Business, Vol. 69, 3, pág. 279 - 312.

Stonehill, A., T. Beekhuisen, R. Wright, L. Remmers, N. Toy, A. Pares, A. C. Shapiro, D. Egan y T. Bates (1975). "Financial Goals and Debt Ratio Determinants: A Survey of Practice in five Countries". Financial Management, Vol. 4, 3, pág. 27 - 41.

Thakor, A. (1990). "Investment "myopia" and the internal organization of capital allocation decisions". Journal of Law, Economics \& Organizations, Vol. 6, 1, pág. 129 - 154.

Titman, S. y R. Wessels (1988). "The Determinants of Capital Structure Choice". The Journal of Finance, Vol. 43, 1, pág. 1 - 19.

Trahan, E. A. y L. J. Gitman (1995). "Bridging the Theory-Practice Gap in Corporate Finance: A Survey of Chief Financial Officers". The Quarterly Review of Economics and Finance, Vol. 35, 1, pág. 73 - 84.

Triantis, A. (2005). "Realizing the Potential of Real Options: Does Theory Meet Practice?". Journal of Applied Corporate Finance, Vol. 17, 2, pág. 8 $-16$.

Triantis, A. J. y A. Borison (2001). "Real Options: State of the Practice". Journal of Applied Corporate Finance, Vol. 14, 2, pág. 8 - 24.

Trigeorgis, L. (1993). "Real Options and Interactions with Financial Flexibility". Financial Management, Vol. 22, 3, pág. 202 - 224. 
Truong, G., G. Partington y M. Peat (2008). "Cost-of-Capital Estimation and Capital-Budgeting Practice in Australia". Australian Journal of Management, Vol. 33, 1, pág. 95 - 122.

Tse, A. C. B. (1998). "Comparing the response rate, response speed and response quality of two methods of sending questionnaires: E-mail vs. mail". Journal of the Market Research Society, Vol. 40, 4, pág. 353 - 361.

Tserlukevich, Y. (2008). "Can Real Options explain Financing Behavior?". Journal of Financial Economics, Vol. 89, pág. 232 - 252.

Tufano, P. (2001). "HBS-JFE conference volume: complementary research methods". Journal of Financial Economics, Vol. 60, 2-3, pág. 179 - 185.

Van Selm, M. y N. W. Jankowski (2006). "Conducting Online Surveys". Quality and Quantity, Vol. 40, 3, pág. 435 - 456.

Vasiliou, D. y N. Daskalakis (2009a). "Behavioral Capital Structure: Is the Neoclassical Paradigm Threatened? Evidence from the Field". Journal of Behavioral Finance, Vol. 10, 1, pág. 19 - 32.

Vasiliou, D. y N. Daskalakis (2009b). "Institutional Characteristics and Capital Structure: A cross-national comparision". Global Finance Journal, Vol. 19, pág. 286 - 306.

Velez, I. y G. Nieto (1986). "Investment Decision-Making Practices in Colombia: A Survey". Interfaces, Vol. 16, 4, pág. 60 - 65.

Verbeeten, F. H. M. (2006). "Do organizations adopt sophisticated capital budgeting practices to deal with uncertainty in the investment decision?: A research note". Management Accounting Research, Vol. 17, 1, pág. 106 - 120.

Verma, S., S. Gupta y R. Batra (2009). "A Survey of Capital Budgeting Practices in Corporate India". Vision, Vol. 13, 3, pág. 1 - 17.

Wald, J. K. (1999). "How Firm Characteristics affect Capital Structure: An International Comparision". Journal of Financial Research, Vol. 22, 2, pág. 161 - 187.

Wallace, R. S. O. y T. E. Cooke (1990). "Nonresponse bias in mail accounting surveys: A pedagogical extension". The British Accounting Review, Vol. 22, 3, pág. 283 - 288.

Wallace, R. S. O. y C. J. Mellor (1988). "Nonresponse Bias in Mail Accounting Surveys: A Pedagogical Note". The British Accounting Review, Vol. 20, 2, pág. 131 - 139.

Welch, I. (2011). "Two Common Problems in Capital Structure Research: The Financial-Debt-To-Asset Ratio and Issuing Activity versus Leverage Changes". International Review of Finance, Vol. 11, 1, pág. 1 - 17.

Welch, I. (2012). "A Critique of Recent Quantitative and Deep-Structure Modeling in Capital Structure Research and Beyond". University of California, Los Angeles (UCLA) y National Bureau of Economic Research (NBER). 
Williamson, O. E. (1988). "Corporate Finance and Corporate Governance". The Journal of Finance, Vol. 43, 3, pág. 567 - 591.

Wu, J., J. Song y C. Zeng (2008). "An empirical evidence of small business financing in China". Management Research News, Vol. 31, 12, pág. 959 - 975.

Zingales, L. (2000). "In Search of New Foundations". The Journal of Finance, Vol. 55, 4, pág. 1623 - 1653. 


\section{ANEXOS}

\section{Anexo 2.1. Trabajos de Referencia Relevantes en la Presente Investigación}

La columna autor / año indica el nombre del (los) autor (es) principales y año de publicación. La columna muestra (\% de respuesta) indica el número de observaciones de la muestra y, entre paréntesis, el porcentaje que representa la muestra de la población original. Las columnas Contexto hacen referencia al área geográfica del (los) país (es) analizados en la investigación. Las columnas tópicos indican las temáticas analizadas, las que se corresponden con $\mathrm{A}=$ Presupuesto de capital; B=Coste de capital; $\mathrm{C}=$ Estructura de capital.

\begin{tabular}{|c|c|c|c|c|c|c|c|c|c|}
\hline \multirow[b]{2}{*}{ Autor/Año } & \multirow[b]{2}{*}{$\begin{array}{c}\text { Muestra (\% } \\
\text { respuesta) }\end{array}$} & \multicolumn{5}{|c|}{ Contexto } & \multicolumn{3}{|c|}{ Tópicos } \\
\hline & & $\begin{array}{l}\text { Anglo } \\
\text { América }\end{array}$ & Europa & $\begin{array}{c}\text { Asia - } \\
\text { Oceanía }\end{array}$ & $\begin{array}{c}\text { América } \\
\text { Latina }\end{array}$ & África & A & $\mathbf{B}$ & C \\
\hline Miller (1960) & 127 (63,5\%) & $\mathrm{x}$ & & & & & $\mathrm{x}$ & & \\
\hline Istvan (1961) & 48 entrevistas & $\mathrm{x}$ & & & & & $\mathrm{x}$ & & \\
\hline Donaldson (1961) & 25 entrevistas & $\mathrm{x}$ & & & & & & & $\mathrm{x}$ \\
\hline Мао (1970) & 8 entrevistas & $\mathrm{x}$ & & & & & $\mathrm{x}$ & & \\
\hline Klamer (1972) & 184 (49,9\%) & $\mathrm{x}$ & & & & & $\mathrm{x}$ & & \\
\hline $\begin{array}{l}\text { Stonehill et al. } \\
\text { (1975) }\end{array}$ & 87 & $\mathrm{x}$ & $\mathrm{x}$ & $\mathrm{x}$ & & & & & $\mathrm{x}$ \\
\hline $\begin{array}{l}\text { Gitman y Forrester } \\
\text { (1977) }\end{array}$ & $110(38,4 \%)$ & $\mathrm{x}$ & & & & & $\mathrm{x}$ & & \\
\hline Schall et al. (1978) & $189(46,4 \%)$ & $\mathrm{x}$ & & & & & $\mathrm{x}$ & & \\
\hline $\begin{array}{l}\text { Schall y Sundem } \\
\text { (1980) }\end{array}$ & $189(46,4 \%)$ & $\mathrm{x}$ & & & & & $\mathrm{x}$ & & \\
\hline $\begin{array}{l}\text { Oblak y Helm } \\
\text { (1980) }\end{array}$ & $58(26 \%)$ & $\mathrm{x}$ & & & & & $\mathrm{x}$ & & \\
\hline $\begin{array}{l}\text { Moore y Reichert } \\
\text { (1983) }\end{array}$ & 298 (60\%) & $\mathrm{x}$ & & & & & $\mathrm{x}$ & & \\
\hline $\begin{array}{l}\text { Stanley y Block } \\
\text { (1984) }\end{array}$ & $121(35,7 \%)$ & $\mathrm{x}$ & & & & & $\mathrm{x}$ & & \\
\hline $\begin{array}{l}\text { Vélez y Nieto } \\
\text { (1986) }\end{array}$ & $70(40 \%)$ & & & & $\mathrm{x}$ & & & & \\
\hline Kim et al. (1986) & 367 (36,7\%) & $\mathrm{x}$ & & & & & $\mathrm{x}$ & & \\
\hline Ann et al. (1987) & $\begin{array}{c}105 \text { (Mal,40\%; Sing, } \\
26 \% \text { y HK,24\%) }\end{array}$ & & & $\mathrm{x}$ & & & $\mathrm{x}$ & & \\
\hline
\end{tabular}




\begin{tabular}{|c|c|c|c|c|c|c|c|c|}
\hline Pike y Ooi (1988) & $100(71,4 \%)$ & & $\mathrm{x}$ & & & $\mathrm{x}$ & & \\
\hline Pike (1988) & $250(71,8 \%)$ & & $\mathrm{x}$ & & & $\mathrm{x}$ & & \\
\hline $\begin{array}{l}\text { Pinegar y Wilbricht } \\
\text { (1989) }\end{array}$ & $176(35,2 \%)$ & $\mathrm{x}$ & & & & & & $\mathrm{x}$ \\
\hline Norton (1989) & 98 (21\%) & $\mathrm{x}$ & & & & & & $\mathrm{x}$ \\
\hline Norton (1990) & $110(27,2 \%)$ & $\mathrm{x}$ & & & & & & $\mathrm{x}$ \\
\hline Norton (1991a) & 98 (21\%) & $\mathrm{x}$ & & & & & & $\mathrm{x}$ \\
\hline Norton (1991b) & $110(27,2 \%)$ & $\mathrm{x}$ & & & & & & $\mathrm{x}$ \\
\hline Allen (1991) & 48 entrevistas & & & $\mathrm{x}$ & & & & $\mathrm{x}$ \\
\hline $\begin{array}{l}\text { Pruitt y Gitman } \\
\text { (1991) }\end{array}$ & $114(11,4 \%)$ & $\mathrm{x}$ & & & & $\mathrm{x}$ & & $\mathrm{x}$ \\
\hline $\begin{array}{l}\text { Cooper et al. } \\
\text { (1992) }\end{array}$ & 102 (22\%) & $\mathrm{x}$ & & & & $\mathrm{x}$ & & \\
\hline $\begin{array}{l}\text { Petry y Sprow } \\
\text { (1993) }\end{array}$ & $151(33,6 \%)$ & $\mathrm{x}$ & & & & $\mathrm{x}$ & $\mathrm{x}$ & \\
\hline Bierman (1993) & 74 (74\%) & $\mathrm{x}$ & & & & $\mathrm{x}$ & & \\
\hline Chen (1995) & 115 (20\%) & $\mathrm{x}$ & & & & $\mathrm{x}$ & & \\
\hline Kester et al. (1994) & 150 (57\%) & & & $\mathrm{x}$ & & & & $\mathrm{x}$ \\
\hline $\begin{array}{l}\text { Trahan y Gitman } \\
\text { (1995) }\end{array}$ & $84(12 \%)$ & $\mathrm{x}$ & & & & $\mathrm{x}$ & & \\
\hline $\begin{array}{l}\text { Jog y Srivastava } \\
\text { (1995) }\end{array}$ & 133 (22,9\%) & $\mathrm{x}$ & & & & $\mathrm{x}$ & & \\
\hline Pike (1996) & 99 (78,9\%) & & $\mathrm{x}$ & & & $\mathrm{x}$ & & \\
\hline Block (1997) & 232 (27,29\%) & $\mathrm{x}$ & & & & $\mathrm{x}$ & & \\
\hline $\begin{array}{l}\text { Burns y Walker } \\
\text { (1997) }\end{array}$ & $180(36 \%)$ & $\mathrm{x}$ & & & & $\mathrm{x}$ & & \\
\hline $\begin{array}{l}\text { Busby y Pitts } \\
\text { (1997) }\end{array}$ & 44 (44\%) & & $\mathrm{x}$ & & & $\mathrm{x}$ & & \\
\hline Kamath (1997) & $142(20,6 \%)$ & $\mathrm{x}$ & & & & & & $\mathrm{x}$ \\
\hline $\begin{array}{l}\text { Drury y Tayles } \\
\text { (1997) }\end{array}$ & 303 (35\%) & & $\mathrm{x}$ & & & $\mathrm{x}$ & & \\
\hline $\begin{array}{l}\text { Adbel-kader y } \\
\text { Dudgale (1998) }\end{array}$ & $102(23,7 \%)$ & & $\mathrm{x}$ & & & $\mathrm{x}$ & & \\
\hline Bruner et al. (1998) & 27 & $\mathrm{x}$ & & & & & $\mathrm{x}$ & \\
\hline Kester et al. (1999) & $\begin{array}{c}226 \text { (Australia, 20,3\%; } \\
\text { Hong Kong, 7,2\%; } \\
\text { Indonesia, 21,3\%; } \\
\text { Malasia, 6,2\%; } \\
\text { Filipinas,17,2\% y } \\
\text { Singapur, 25,6\%) } \\
\end{array}$ & & & $\mathrm{x}$ & & $\mathrm{x}$ & & \\
\hline Payne et al. (1999) & $155(10,8 \%)$ & $\mathrm{x}$ & & & & $\mathrm{x}$ & & \\
\hline $\begin{array}{l}\text { Arnold y } \\
\text { Hatzopoulos (2000) }\end{array}$ & $96(32,4 \%)$ & & $\mathrm{x}$ & & & $\mathrm{x}$ & & \\
\hline Hall (2000) & $70(23,3 \%)$ & & & & $\mathrm{x}$ & $\mathrm{x}$ & & \\
\hline Allen (2000) & $\begin{array}{c}252 \text { (Australia, 24,1\%; } \\
\text { Gran Bretaña, 13,4\% y } \\
\text { Japón, 9,6\%) }\end{array}$ & & $\mathrm{x}$ & $\mathrm{x}$ & & & & $\mathrm{x}$ \\
\hline $\begin{array}{l}\text { Ayala y Rodriguez } \\
(2000)\end{array}$ & $116(12 \%)$ & $\mathrm{x}$ & & & & $\mathrm{x}$ & & $\mathrm{x}$ \\
\hline $\begin{array}{l}\text { Graham y Harvey } \\
\text { (2001) }\end{array}$ & 392 (9\%) & $\mathrm{x}$ & & & & $\mathrm{x}$ & $\mathrm{x}$ & $\mathrm{x}$ \\
\hline
\end{tabular}




\begin{tabular}{|c|c|c|c|c|c|c|c|c|}
\hline $\begin{array}{l}\text { Triantis y Borison } \\
\text { (2001) }\end{array}$ & 39 entrevistas & $\mathrm{x}$ & & & & $\mathrm{x}$ & & \\
\hline $\begin{array}{l}\text { Ryan y Ryan } \\
(2002)\end{array}$ & 205 (20,5\%) & $\mathrm{x}$ & & & & $\mathrm{x}$ & & \\
\hline $\begin{array}{l}\text { McParland et al. } \\
(2002)\end{array}$ & $110(\% \mathrm{~N} / \mathrm{S})$ & $\mathrm{x}$ & & & & $\mathrm{x}$ & & \\
\hline $\begin{array}{l}\text { Klamer et al. } \\
(2002)\end{array}$ & $186(30,2 \%)$ & $\mathrm{x}$ & $\mathrm{x}$ & & & $\mathrm{x}$ & $\mathrm{x}$ & \\
\hline Anand (2002) & $81(15,4 \%)$ & & & $\mathrm{x}$ & & $\mathrm{x}$ & $\mathrm{x}$ & $\mathrm{x}$ \\
\hline $\begin{array}{l}\text { Sandahl y Sjogren } \\
(2003)\end{array}$ & $129(24,4 \%)$ & & $\mathrm{x}$ & & & $\mathrm{x}$ & & \\
\hline $\begin{array}{l}\text { Brounen et al. } \\
\text { (2004) }\end{array}$ & 313 (5\%) & & $\mathrm{x}$ & & & $\mathrm{x}$ & $\mathrm{x}$ & $\mathrm{x}$ \\
\hline $\begin{array}{l}\text { Bancel y Mittoo } \\
\text { (2004) }\end{array}$ & $87(12 \%)$ & & $\mathrm{x}$ & & & & & $\mathrm{x}$ \\
\hline Fan y So (2004) & $260(46,4 \%)$ & & & $\mathrm{x}$ & & & & $\mathrm{x}$ \\
\hline $\begin{array}{l}\text { Liljeblom y } \\
\text { Vaihekoski (2004) }\end{array}$ & $46(32 \%)$ & & $\mathrm{x}$ & & & $\mathrm{x}$ & $\mathrm{x}$ & \\
\hline Lazaridis (2004) & 56 (56\%) & & $\mathrm{x}$ & & & $\mathrm{x}$ & & \\
\hline $\begin{array}{l}\text { Iturralde y Maseda } \\
\text { (2004) }\end{array}$ & 217 (14,5\%) & & $\mathrm{x}$ & & & $\mathrm{x}$ & & $\mathrm{x}$ \\
\hline Block (2005) & $302(30,2 \%)$ & $\mathrm{x}$ & & & & $\mathrm{x}$ & & \\
\hline $\begin{array}{l}\text { Mongrut y Wong } \\
\text { (2005) }\end{array}$ & $74(2,2 \%)$ & & & & $\mathrm{x}$ & $\mathrm{x}$ & & \\
\hline $\begin{array}{l}\text { Alkaraan y } \\
\text { Northcott (2006) }\end{array}$ & 83 (30,63\%) & & $\mathrm{x}$ & & & $\mathrm{x}$ & & \\
\hline Verbeeten (2006) & 189 (26,9\%) & & $\mathrm{x}$ & & & $\mathrm{x}$ & & \\
\hline Beattie et al. (2006) & 198 (23\%) & & $\mathrm{x}$ & & & & & $\mathrm{x}$ \\
\hline $\begin{array}{l}\text { Brounen et al. } \\
\text { (2006) }\end{array}$ & 313 (5\%) & & $\mathrm{x}$ & & & & & $\mathrm{x}$ \\
\hline $\begin{array}{l}\text { Danielson y Scott } \\
(2006)\end{array}$ & 792 (\% N/S) & $\mathrm{x}$ & & & & $\mathrm{x}$ & & \\
\hline Baddeley (2006) & 99 (22\%) & & $\mathrm{x}$ & & & $\mathrm{x}$ & & \\
\hline $\begin{array}{l}\text { Muotinho y Mouta } \\
\text { (2006) }\end{array}$ & $96(9,6 \%)$ & & $\mathrm{x}$ & & & $\mathrm{x}$ & & \\
\hline Pereiro (2006) & $55(\% \mathrm{~N} / \mathrm{S})$ & & & & $\mathrm{x}$ & $\mathrm{x}$ & $\mathrm{x}$ & \\
\hline Benetti et al. (2007) & $160(9,4 \%)$ & & & & $\mathrm{x}$ & $\mathrm{x}$ & $\mathrm{x}$ & $\mathrm{x}$ \\
\hline Block (2007) & 279 (27,9\%) & $\mathrm{x}$ & & & & $\mathrm{x}$ & & \\
\hline $\begin{array}{l}\text { Hermes et al. } \\
(2007)\end{array}$ & $\begin{array}{c}87 \text { (Holanda, 17\% y } \\
\text { China, 15\%) }\end{array}$ & & $\mathrm{x}$ & $\mathrm{x}$ & & $\mathrm{x}$ & & \\
\hline Rayo et al. (2007) & $152(15,2 \%)$ & & $\mathrm{x}$ & & & $\mathrm{x}$ & & \\
\hline Colombage (2007) & $52(29,7 \%)$ & & & $\mathrm{x}$ & & & & $\mathrm{x}$ \\
\hline $\begin{array}{l}\text { Dedi y Orsag } \\
(2007)\end{array}$ & $59(25,2 \%)$ & & $\mathrm{x}$ & & & $\mathrm{x}$ & & \\
\hline Leon et al. (2008) & $108(47,2 \%)$ & & & $\mathrm{x}$ & & $\mathrm{x}$ & & \\
\hline $\begin{array}{l}\text { Sridharan y } \\
\text { Schuele (2008) }\end{array}$ & 65 (13\%) & & $\mathrm{x}$ & & & $\mathrm{x}$ & $\mathrm{x}$ & \\
\hline $\begin{array}{l}\text { Truong et al. } \\
\text { (2008) }\end{array}$ & $87(24,4 \%)$ & & & $\mathrm{x}$ & & $\mathrm{x}$ & $\mathrm{x}$ & \\
\hline Wu et al. (2008) & $60(60 \%)$ & & & $\mathrm{x}$ & & & & $\mathrm{x}$ \\
\hline Chen (2008) & $115(19,1 \%)$ & $\mathrm{x}$ & & & & $\mathrm{x}$ & & \\
\hline Chan et al (2008) & 54 & & & $\mathrm{x}$ & & $\mathrm{x}$ & & \\
\hline
\end{tabular}




\begin{tabular}{|c|c|c|c|c|c|c|c|c|c|}
\hline $\begin{array}{l}\text { Meier y Tarhan } \\
(2009)\end{array}$ & $114(2,8 \%)$ & $\mathrm{x}$ & & & & & & & $\mathrm{x}$ \\
\hline $\begin{array}{l}\text { Holmén y } \\
\text { Pramborg (2009) }\end{array}$ & $145(29,1 \%)$ & & $\mathrm{x}$ & & & & $\mathrm{x}$ & & \\
\hline Verma et al. (2009) & 30 (30\%) & & & $\mathrm{x}$ & & & $\mathrm{x}$ & $\mathrm{x}$ & \\
\hline $\begin{array}{l}\text { Vasiliou y } \\
\text { Daskalakis (2009a) }\end{array}$ & $89(29,3 \%)$ & & $\mathrm{x}$ & & & & & & $\mathrm{x}$ \\
\hline $\begin{array}{l}\text { Vasiliou y } \\
\text { Daskalakis (2009b) }\end{array}$ & $89(29,3 \%)$ & & $\mathrm{x}$ & & & & & & $\mathrm{x}$ \\
\hline Chazi et al. (2010) & $38(87,9 \%)$ & & & $\mathrm{x}$ & & & $\mathrm{x}$ & $\mathrm{x}$ & $\mathrm{x}$ \\
\hline $\begin{array}{l}\text { Khames et al. } \\
\text { (2010) }\end{array}$ & $53(65,4 \%)$ & & & $\mathrm{x}$ & & & $\mathrm{x}$ & $\mathrm{x}$ & \\
\hline Shinoda (2010) & 225 (10,1\%) & & & $\mathrm{x}$ & & & $\mathrm{x}$ & & \\
\hline $\begin{array}{l}\text { de Jong y } \\
\text { Verwijmeren } \\
\text { (2010) }\end{array}$ & 235 (\% N/S) & $\mathrm{x}$ & $\mathrm{x}$ & & & & & & $\mathrm{x}$ \\
\hline Cescon (2010) & 74 (24\%) & & $\mathrm{x}$ & & & & $\mathrm{x}$ & $\mathrm{x}$ & \\
\hline $\begin{array}{l}\text { Hall y Millard } \\
\text { (2010) }\end{array}$ & $41(61,2 \%)$ & & & & & $\mathrm{x}$ & $\mathrm{x}$ & & \\
\hline $\begin{array}{l}\text { Scholleova et al. } \\
(2010)\end{array}$ & 252 & & $\mathrm{x}$ & & & & $\mathrm{x}$ & & \\
\hline $\begin{array}{l}\text { Bennouna et al. } \\
(2010)\end{array}$ & $88(18,4 \%)$ & $\mathrm{x}$ & & & & & $\mathrm{x}$ & & \\
\hline Carr et al. 2010) & 14 casos & $\mathrm{x}$ & $\mathrm{x}$ & $\mathrm{x}$ & & & $\mathrm{x}$ & & \\
\hline Haddad et al (2010) & 25 & & & $\mathrm{x}$ & & & $\mathrm{x}$ & & \\
\hline Baker et al. (2011) & $\begin{array}{c}214(28,1 \%) .36 \\
\text { usuarios de RO }\end{array}$ & $\mathrm{x}$ & & & & & $\mathrm{x}$ & & \\
\hline Baker et al. (2011) & $214(28,1 \%)$ & $\mathrm{x}$ & & & & & $\mathrm{x}$ & & \\
\hline $\begin{array}{l}\text { Bancel y Mittoo } \\
\text { (2011) }\end{array}$ & $34(0,4 \%)$ & & $\mathrm{x}$ & & & & & & $\mathrm{x}$ \\
\hline $\begin{array}{l}\text { Karadeniz et al. } \\
\text { (2011) }\end{array}$ & $163(26,3 \%)$ & & & $\mathrm{x}$ & & & & & $\mathrm{x}$ \\
\hline $\begin{array}{l}\text { Lindblom et al. } \\
\text { (2011) }\end{array}$ & $139(35,4 \%)$ & & $\mathrm{x}$ & & & & & & $\mathrm{x}$ \\
\hline $\begin{array}{l}\text { Jagannathan et al. } \\
\text { (2011) }\end{array}$ & $127(2,8 \%)$ & $\mathrm{x}$ & & & & & & $\mathrm{x}$ & \\
\hline $\begin{array}{l}\text { El-Sady et al. } \\
\text { (2011) }\end{array}$ & $382(74,8 \%)$ & & & $\mathrm{x}$ & & & $\mathrm{x}$ & & \\
\hline $\begin{array}{l}\text { Maroyi et al. } \\
\text { (2012) }\end{array}$ & $13(37,1 \%)$ & & & & & $\mathrm{x}$ & $\mathrm{x}$ & & \\
\hline $\begin{array}{l}\text { Al-mutairi et al. } \\
\text { (2012) }\end{array}$ & 80 (53\%) & & & $\mathrm{x}$ & & & $\mathrm{x}$ & $\mathrm{x}$ & $\mathrm{x}$ \\
\hline $\begin{array}{l}\text { Maquieira et al. } \\
\text { (2012) }\end{array}$ & $290(\% \mathrm{~N} / \mathrm{S})$ & & & & $\mathrm{x}$ & & $\mathrm{x}$ & $\mathrm{x}$ & $\mathrm{x}$ \\
\hline Nor et al. (2012) & 203 (25\%) & & & $\mathrm{x}$ & & & & & $\mathrm{x}$ \\
\hline $\begin{array}{l}\text { Brunzell et al. } \\
\text { (2013) }\end{array}$ & 157 (22,1\%) & & $\mathrm{x}$ & & & & $\mathrm{x}$ & $\mathrm{x}$ & \\
\hline
\end{tabular}




\section{Anexo 3.1. Cuestionario}

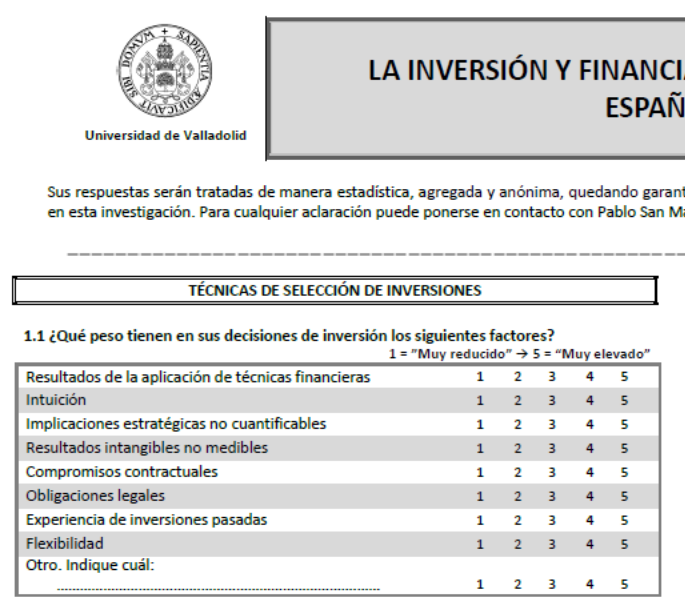

1.2 ¿Con qué frecuencia se aplican las siguientes técnicas financieras en su empresa?

\begin{tabular}{llllll|} 
& \multicolumn{1}{c}{$1=$ "Nunca" $\rightarrow 5=$ "Siempre" } \\
\hline VAN (Valor Actual Neto) & 1 & 2 & 3 & 4 & 5 \\
TIR (Tasa Interna de Retorno) & 1 & 2 & 3 & 4 & 5 \\
PayBack (Plazo de recuperación) & 1 & 2 & 3 & 4 & 5 \\
IR (índice de rentabilidad) & 1 & 2 & 3 & 4 & 5 \\
Modelos de valoración de opciones reales & 1 & 2 & 3 & 4 & 5 \\
Análisis de sensibilidad & 1 & 2 & 3 & 4 & 5 \\
Modelos de simulación & 1 & 2 & 3 & 4 & 5 \\
Otro. Indique cuál: & 1 & 2 & 3 & 4 & 5 \\
\hline
\end{tabular}

1.3 ¿Qué grado de confianza le merecen los resultados de estas técnicas? VAN (Valor Actual Neto) TIR (Tasa Interna de Retorno) PayBack (Plazo de recuperación IR (índice de rentabilidad) Modelos de valoración de opciones reales Análisis de sensibilidad Modelos de simulación Otro. Indique cuál:

do" $\rightarrow 5=$ "Muy confiado"; N/S="No conoce"
\begin{tabular}{llllll}
$\mathrm{N} / \mathrm{S}$ & 1 & 2 & 3 & 4 & 5 \\
$\mathrm{~N} / \mathrm{S}$ & 1 & 2 & 3 & 4 & 5 \\
$\mathrm{~N} / \mathrm{S}$ & 1 & 2 & 3 & 4 & 5 \\
$\mathrm{~N} / \mathrm{S}$ & 1 & 2 & 3 & 4 & 5 \\
$\mathrm{~N} / \mathrm{S}$ & 1 & 2 & 3 & 4 & 5 \\
$\mathrm{~N} / \mathrm{S}$ & 1 & 2 & 3 & 4 & 5 \\
$\mathrm{~N} / \mathrm{S}$ & 1 & 2 & 3 & 4 & 5 \\
& 1 & 2 & 3 & 4 & 5 \\
\hline
\end{tabular}

FLEXIBILIDAD DE LAS INVERSIONES EMPRENDIDAS

2.1 ¿Qué importancia atribuye a que un proyecto de inversión permita ...?

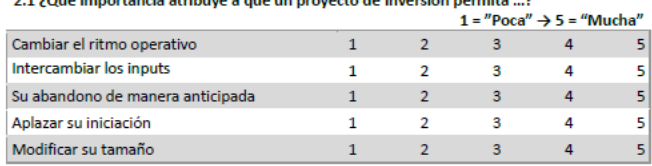

2.2 ¿Con qué frecuencia se adoptan estas decisiones?

\begin{tabular}{|c|c|c|c|c|}
\hline Cambiar el ritmo operativo & $0-20 \%$ & $20-40 \% \quad 40-60 \%$ & $60-80 \%$ & $80-100 \%$ \\
\hline Intercambiar los inputs & $0-20 \%$ & $20-40 \% 40-60 \%$ & $60-80 \%$ & $80-100 \%$ \\
\hline Su abandono de manera anticipada & $0-20 \%$ & $20-40 \% \quad 40-60 \%$ & $60-80 \%$ & $80-100 \%$ \\
\hline Aplazar su iniciación & $0.20 \%$ & $20-40 \% \quad 40-60 \%$ & $60-80 \%$ & $80-100 \%$ \\
\hline Modificar su tamaño & $0-20 \%$ & $20-40 \% \quad 40-60 \%$ & $60-80 \%$ & $80-100 \%$ \\
\hline
\end{tabular}

OPORTUNIDADES DE CRECIMIENTO

3.1 ¿Con qué frecuencia sus inversiones pasadas abren nuevas oportunidades futuras de inversión?

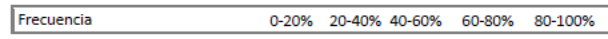

\begin{tabular}{|c|c|c|c|c|c|}
\hline $\begin{array}{l}3.2 \text { ¿Qué relevancia tienen los siguientes } \\
\text { oportunidades de inversión? }\end{array}$ & $\begin{array}{l}\text { items en la } 8 \\
1=" \text { Nada relevant }\end{array}$ & & & & $\begin{array}{l}\text { nueva } \\
\text { levante }\end{array}$ \\
\hline Relación con los clientes y proveedores & 1 & 2 & 3 & 4 & 5 \\
\hline Imagen de la empresa en el mercado & 1 & 2 & 3 & 4 & 5 \\
\hline Registro de marcas & 1 & 2 & 3 & 4 & 5 \\
\hline Conocimiento tecnológico & 1 & 2 & ${ }^{3}>>>>>$ & 4 & 5 \\
\hline Capacidad instalada & 1 & 2 & 3 & 4 & 5 \\
\hline Conocimiento especifico del producto & 1 & 2 & 3 & 4 & 5 \\
\hline Conocimiento específico del mercado & 1 & 2 & 3 & 4 & 5 \\
\hline Fase del ciclo del negocio & 1 & 2 & 3 & 4 & 5 \\
\hline Otros. Indique cuál: & & & & & \\
\hline
\end{tabular}

3.3 ¿A cuál de los siguientes ámbitos destina más recursos su empresa?

\begin{tabular}{|l|ccccc|}
$\qquad 1=$ "Muy por debajo de la media" $\rightarrow 5=$ "Muy por encima de la media" \\
\hline Relación con los clientes y proveedores & 1 & 2 & 3 & 4 & 5 \\
IImagen de le lempresa en el mercado & 1 & 2 & 3 & 4 & 5 \\
\hline Conocimiento tecnológico & 1 & 2 & 3 & 4 & 5 \\
Conocimiento especifico del producto & 1 & 2 & 3 & 4 & 5 \\
\hline Conocimiento especifico del mercado & 1 & 2 & 3 & 4 & 5 \\
\hline Flexibilidad & 1 & 2 & 3 & 4 & 5 \\
\hline Otros. Indique cuál: & 1 & 2 & 3 & 4 & 5 \\
\hline
\end{tabular}
3.4 ¿Con que frecuencia utiliza las siguientes técnicas para identificar las oportunidades
futuras de inversión?

\begin{tabular}{|lllllll|}
\multicolumn{1}{c}{} & \multicolumn{5}{c}{$1="$ "Muy baja" - $5="$ "Muy alta" } \\
\hline Matrices Boston Consulting Group o similares & 1 & 2 & 3 & 4 & 5 \\
\hline Modelos de descuento de flujos & 1 & 2 & 3 & 4 & 5 \\
\hline Técnicas de valoración de opciones reales & 1 & 2 & 3 & 4 & 5 \\
\hline Diamante de Porter o similares & 1 & 2 & 3 & 4 & 5 \\
\hline Árboles de decisión & 1 & 2 & 3 & 4 & 5 \\
\hline Otros. Indicar cuáles: & 1 & 2 & 3 & 4 & 5 \\
\hline
\end{tabular}

3.5 icuál es el peso de las oportunidades futuras de inversión en el valor actual de su empresa?

\begin{tabular}{|llllll}
\hline$\%$ sobre el valor total de la empresa & $0-20 \%$ & $20-40 \%$ & $40-60 \%$ & $60-80 \%$ & $80-100 \%$ \\
\hline
\end{tabular} COSTE DEL CAPITAL

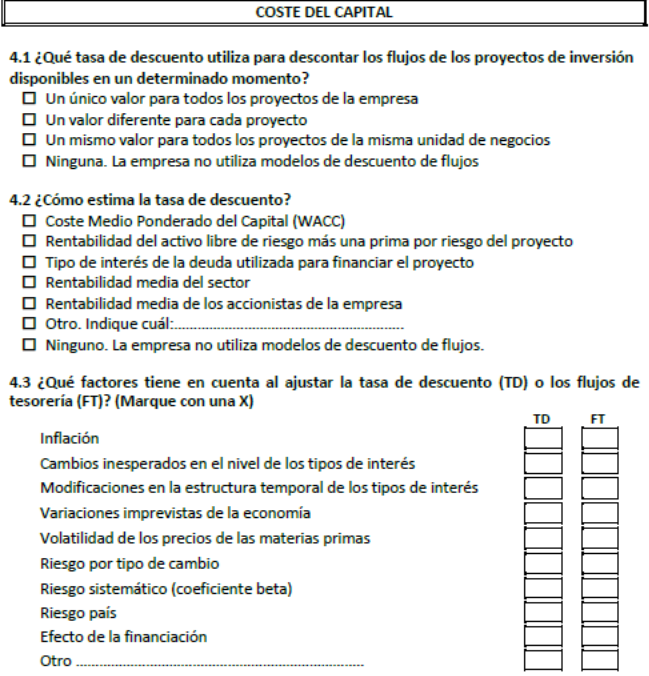




\begin{tabular}{|c|c|c|c|c|c|c|}
\hline \multicolumn{7}{|c|}{ POĹTICA DE FINANCIACIÓN } \\
\hline \multicolumn{7}{|c|}{$\begin{array}{l}5.1 \text { ¿Cuál es el peso de los siguientes medios de financiación en su empresa? } \\
\qquad \begin{array}{l}1=\text { "Nada importante" } \rightarrow 5=" \text { Muy importante" }\end{array}\end{array}$} \\
\hline \multicolumn{2}{|c|}{ Beneficios retenidos } & 12 & 3 & 4 & 5 & \\
\hline \multicolumn{2}{|c|}{ Préstamos/Créditos Bancarios } & 1 & 3 & 4 & 5 & \\
\hline \multicolumn{2}{|c|}{ Deuda negociada en mercados organizados } & 1 & 3 & 4 & 5 & \\
\hline \multicolumn{2}{|c|}{ Recursos procedentes de empresas del grupo } & 2 & 3 & 4 & 5 & \\
\hline \multicolumn{2}{|c|}{ Aportaciones de los accionistas / socios } & 1 & 3 & 4 & 5 & \\
\hline \multicolumn{2}{|c|}{ Proveedores } & 1 & 3 & 4 & 5 & \\
\hline \multicolumn{7}{|l|}{ Otras. Indique cuál: } \\
\hline \multicolumn{7}{|c|}{$\begin{array}{l}5.2 \text { Señale la situación financiera de la empresa con relación a: } \\
\text { Nivel de endeudamiento (deuda total entre total de activos) }\end{array}$} \\
\hline \multicolumn{7}{|c|}{ Sobre deuda total: } \\
\hline \multicolumn{4}{|c|}{ a) Porcentaje de la deuda con vencimiento superior al año } & & & $\%$ \\
\hline \multicolumn{4}{|c|}{ b) Porcentaje de la deuda concedido por entidades bancarias } & & & $\%$ \\
\hline \multicolumn{4}{|c|}{ c) Porcentaje de la deuda bancaria con vencimiento superior al año } & & & \\
\hline \multicolumn{4}{|c|}{ d) Porcentaje de la deuda concedida por el grupo } & & & \\
\hline \multirow{2}{*}{\multicolumn{7}{|c|}{$\begin{array}{l}5.3 \text { ¿Acomoda la empresa su politica de financiación a un nivel de endeudamiento de } \\
\text { referencia? }\end{array}$}} \\
\hline & & & & & & \\
\hline \multicolumn{7}{|c|}{\begin{tabular}{l|lllll}
\multirow{2}{*}{$\begin{array}{l}\text { ¿Con qué frecuencia alcanza } \\
\text { el nivel deseado? }\end{array}$} & $0-20 \%$ & $20-40 \%$ & $40-60 \%$ & $60-80 \%$ & $80-100 \%$ \\
\end{tabular}} \\
\hline \multicolumn{7}{|c|}{$\begin{array}{l}5.4 \text { ¿Cuál es el peso de los siguientes factores en el nivel de endeudamiento? } \\
\qquad \begin{array}{l}1=\text { "Nada importante" } \rightarrow 5=\text { "Muy importante" }\end{array}\end{array}$} \\
\hline \multicolumn{3}{|c|}{$\begin{array}{l}\text { La flexibilidad financiera (capacidad para modificar el nivel de } \\
\text { endeudamiento) }\end{array}$} & 12 & 23 & 45 & \\
\hline \multicolumn{3}{|c|}{ El ahorro de impuestos (deducibilidad de intereses) } & & 23 & 45 & \\
\hline \multicolumn{3}{|c|}{ El ahorro de costes de negociación y contratación } & & 23 & 45 & \\
\hline \multicolumn{3}{|c|}{ La búsqueda de una estructura de financiación objetivo } & & 23 & & \\
\hline \multicolumn{3}{|c|}{ El nivel de endeudamiento de los competidores } & & 23 & 45 & \\
\hline \multicolumn{3}{|c|}{ La disponibilidad y acceso al endeudamiento } & & 23 & 45 & \\
\hline \multicolumn{3}{|c|}{ Los potenciales riesgos de insolvencia financiera y quiebra } & & 23 & & \\
\hline \multicolumn{3}{|c|}{ El tipo de inversión a realizar o los activos a financiar } & & 23 & 45 & \\
\hline \multicolumn{3}{|c|}{ La vida económica de la inversión a financiar } & & 23 & & 5 \\
\hline 5.5 ¿Qué otros factores afectan & $\begin{array}{r}\text { la politica de endeuda } \\
1=" \text { Nada }\end{array}$ & $\begin{array}{l}\text { amiento de la emp } \\
\text { importante" } \rightarrow 5=\end{array}$ & $\begin{array}{l}\text { npresa? } \\
\text { n="Muy }\end{array}$ & ? & ortante & \\
\hline $\begin{array}{l}\text { Se utiliza deuda cuando la dispor } \\
\text { financiar nuestras actividades }\end{array}$ & nibilidad de fondos no & permite & 12 & 23 & 35 & \\
\hline & utación de la empresa & & 12 & 23 & 355 & \\
\hline Se recurre el endeudamiento cuz & ando los tipos de inter & rés son bajos & 12 & 23 & & \\
\hline $\begin{array}{l}\text { Se incrementa el endeudamientc } \\
\text { de la garantia ofrecida por los ac }\end{array}$ & $\begin{array}{l}\text { o de manera simultáne } \\
\text { tivos }\end{array}$ & ea al incremento & 12 & 23 & & \\
\hline $\begin{array}{l}\text { Usamos deuda debido a las buer } \\
\text { entidades bancarias }\end{array}$ & nas relaciones que mar & ntenemos con & 12 & 23 & 45 & \\
\hline Se utiliza deuda cuando el precio & o de nuestras acciones & disminuye & 12 & 23 & 45 & \\
\hline Se emite deuda para reducir el c & :oste medio ponderad & o del capital & 12 & 23 & 45 & \\
\hline $\begin{array}{l}\text { La composición de nuestro activ } \\
\text { importante a la hora de recurrir }\end{array}$ & o (tangible vs. Intangit & ble) es un factor & 12 & 23 & 45 & \\
\hline $\begin{array}{l}\text { Preferimos deuda bancaria a } \\
\text { información estratégica }\end{array}$ & emisión de bonos pa & & & & & \\
\hline
\end{tabular}

5.6 ¿Qué consideraciones afectan la elección entre endeudamiento de corto y largo plazo?

$1="$ Nada importante" $\rightarrow 5=$ "Muy importante"

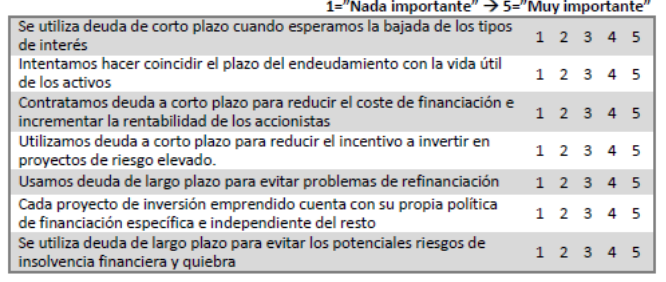

CONSIDERACIONES FINALES

6.1 ¿Con qué frecuencia determina el valor de su empresa?
$\square$ Nunca
$\square$ Anualmente
$\square$ semestralmente
$\square$ Trimestralmente
$\square$ Diariamente

6.2. Con relación al proceso de creación de valor, qué importancia tienen en su empresa los siguientes elementos:

\begin{tabular}{|c|c|c|c|c|c|}
\hline & & & & & \\
\hline Rentabilidad de la inversión pasada & 1 & 2 & 3 & 4 & 5 \\
\hline Rentabilidad de la inversión futura & 1 & 2 & 3 & 4 & 5 \\
\hline Tecnología & 1 & 2 & 3 & 4 & 5 \\
\hline Habilidades directivas & 1 & 2 & 3 & 4 & 5 \\
\hline Diferenciación del producto/servicio & 1 & 2 & 3 & 4 & 5 \\
\hline Ventajas en costes & 1 & 2 & 3 & 4 & 5 \\
\hline Flexibilidad & 1 & 2 & 3 & 4 & 5 \\
\hline Capacidad de anticipación & 1 & 2 & 3 & 4 & 5 \\
\hline \multicolumn{6}{|l|}{ Otros. Indique cuáles: } \\
\hline & 1 & 2 & 3 & 4 & 5 \\
\hline
\end{tabular}

6.3 ¿Cuál es su grado de acuerdo /desacuerdo con las siguientes afirmaciones?

\begin{tabular}{|lllllll}
$1=$ El valor de mi empresa es muy superior a su valor contable & 1 & 2 & 3 & 4 & 5
\end{tabular} $\begin{array}{llllll}\text { El valor de mi empresa es muy superior a su valor contable } & 1 & 2 & 3 & 4 & 5 \\ \text { Dentro de cinco años la empresa habrá aumentado mucho } & 1 & 2 & 3 & 4 & 5\end{array}$ Dentro de cinco años la empresa habra aumentado mucho
sus beneficios $\begin{array}{lllllll}\text { En los últimos cinco años la empresa ha aprovechado todas } & 1 & 2 & 3 & 4 & 5\end{array}$ En los últimos años, la politica de financiación ha hecho que $\begin{array}{lllllll}1 & 2 & 3 & 4 & 5\end{array}$ $\begin{array}{lllllll}\text { se desperdicien oportunidades de inversión rentable } & \\ \text { La politica de financiación seguida por la empresa ha } & 1 & 2 & 3 & 4 & 5\end{array}$ influido muy negativamente sobre el valor de la empr

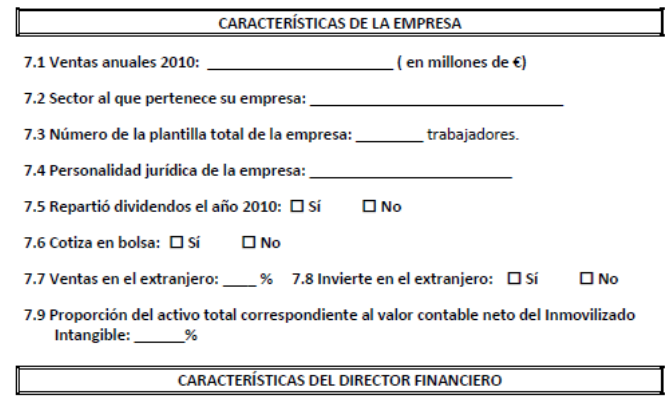

8.1 Años de experiencia profesional: 8.2 Años en la empresa:

8.3 Años como Director Financiero:
8.4 Edad:
$\square<30$
$\square 0-39$
$\square$ 40-49
$\square 50-59$
$\square \geq 60$

8.5 Formación:

$\square$ sin formación universitaria

$\square$ Diplomado. Indique cuál:

$\square$ Licenciatura. Indique cuát:

$\square$ MBA

$\square$ Otro tipo de máster. Indique cuá:

$\square$ Doctorado. Indique cuál:

8.6 Participa en la propiedad de la $\quad 8.7$ Forma parte del consejo de

$$
\square \text { si } \quad \square \text { No }
$$$$
\square \text { si } \quad \square \text { No }
$$

8.8 Grado de participación en las decisiones de inversión de su empresa:

$\square$ Poco implicado

$\square$ Medianamente implicado

$\square$ Bastante implicado

$\square$ Muy implicado

8.9 Grado de participación en las decisiones 8.9 Grado de participación en las
de financiación de su empresa:

$\square$ Poco implicado
$\square$ Medianamente implicado

$\square$ Bastante implicado

$\square$ Muy implicado

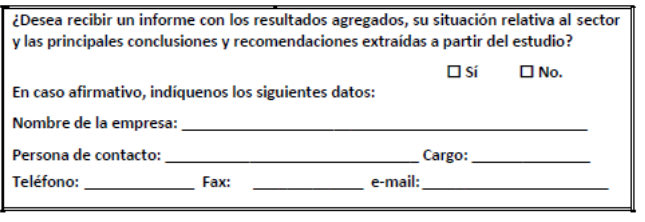
Reiteramos nuestro agradecimiento por colaborar 


\section{Anexo 3.2. Carta de Presentación y Objetivos}

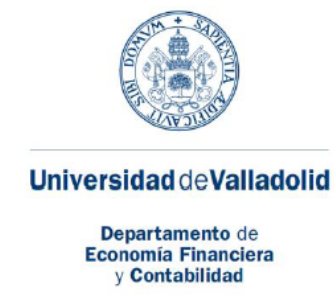

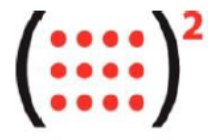

DiFíCyL

DIRECCIÓN FINANCIERA
DE CASTILLA Y LEÓN

Grupo 144

Valladolid, 07 de febrero de 2011

Nos dirigimos a usted para solicitar su colaboración en una investigación que venimos desarrollando en la Universidad de Valladolid el Grupo de Investigación de Excelencia en Economía Financiera y Contabilidad de la Junta de Castilla y León (GR144).

Nuestra investigación se centra en el estudio de las técnicas de selección de inversiones empleadas por las empresas españolas. El trabajo tiene como objetivo identificar las prácticas más habituales y ofrecer una explicación razonada y contrastada a partir del análisis de las características distintivas de la empresa, su política de financiación y los negocios en los que participa.

Estaríamos muy agradecidos si contestase el cuestionario que le adjuntamos. Como puede imaginar, el éxito de nuestra investigación depende de manera crítica de su participación. La aproximación de la "práctica" y la "teoría" en este tipo de problemas resulta imposible sin la colaboración de la empresa.

Al responder el cuestionario, tenga en cuenta que no hay respuestas ni buenas ni malas. Se trata de obtener una aproximación empírica lo más fidedigna posible de un cuestión habitualmente abordada desde una perspectiva teórica. Toda la información que nos proporcione será tratada de manera confidencial y sólo se publicarán los resultados del tratamiento estadístico de forma globalizada.

Adicionalmente y con el fin de compensar su esfuerzo, le ofrecemos la posibilidad de que nos solicite sin coste alguno para usted:

- Los resultados finales del trabajo y principales implicaciones para la gestión empresarial.

- Un análisis individualizado sobre la situación de su empresa respecto a la media de su sector.

- La inclusión del nombre de su empresa como colaboradora del proyecto de investigación en las publicaciones que se deriven del estudio.

Agradeciendo de antemano su generosa y valiosa colaboración, aprovechamos la ocasión para enviarle un cordial saludo.

Fdo.: Pablo de Andrés Alonso

Fdo.: Gabriel de la Fuente Herrero

Por favor, envíe su respuesta por cualquiera de los tres medios siguientes:

- Por fax al 983186484.

- Por correo postal: se adjunta sobre prefranqueado.

- Escaneada por correo electrónico: pablosm@eco.uva.es 
Anexo 5.1: Matriz de correlaciones de variables independientes y de control

\begin{tabular}{|c|c|c|c|c|c|c|c|c|c|c|c|c|c|c|c|c|c|c|c|c|c|c|c|c|c|c|c|c|c|c|c|c|c|c|c|}
\hline & & 1 & & 2 & & 3 & & 4 & & 5 & & 6 & & 7 & & 8 & & 9 & & 10 & & 11 & & 12 & & 13 & & 14 & & 15 & & 16 & & 17 & \\
\hline 1 & tamaño & 1,0000 & & & & & & & & & & & & & & & & & & & & & & & & & & & & & & & & & \\
\hline 2 & deuda & $-0,0729$ & & 1,0000 & & & & & & & & & & & & & & & & & & & & & & & & & & & & & & & \\
\hline 3 & deudalp & $-0,1190$ & & 0,6227 & $* * *$ & 1,0000 & & & & & & & & & & & & & & & & & & & & & & & & & & & & & \\
\hline 4 & añosexp & 0,1500 & * & 0,0774 & & 0,0566 & & 1,0000 & & & & & & & & & & & & & & & & & & & & & & & & & & & \\
\hline 5 & expempr & 0,1114 & & $-0,0059$ & & $-0,1574$ & & 0,6499 & $* * *$ & 1,0000 & & & & & & & & & & & & & & & & & & & & & & & & & \\
\hline 6 & expercfo & 0,0129 & & 0,1915 & $* *$ & 0,0374 & & 0,5776 & $* * *$ & 0,4195 & $* * *$ & 1,0000 & & & & & & & & & & & & & & & & & & & & & & & \\
\hline 7 & invext & 0,2755 & $* * *$ & 0,0756 & & 0,0205 & & $-0,0492$ & & $-0,0431$ & & $-0,0151$ & & 1,0000 & & & & & & & & & & & & & & & & & & & & & \\
\hline 8 & persjur & 0,1977 & $* *$ & $-0,0472$ & & $-0,0307$ & & 0,2409 & $* * *$ & 0,0405 & & $-0,0096$ & & 0,0124 & & 1,0000 & & & & & & & & & & & & & & & & & & & \\
\hline 9 & industria & $-0,0972$ & & 0,0540 & & 0,0157 & & 0,0608 & & 0,0389 & & 0,1284 & & 0,2425 & $* * *$ & $-0,0919$ & & 1,0000 & & & & & & & & & & & & & & & & & \\
\hline 10 & servicios & 0,0914 & & $-0,0923$ & & $-0,1609$ & & $-0,1522$ & * & $-0,1536$ & * & $-0,1217$ & & $-0,1604$ & $*$ & 0,1166 & & $-0,5273$ & $* * *$ & 1,0000 & & & & & & & & & & & & & & & \\
\hline 11 & bolsa & 0,2934 & $* * *$ & $-0,0581$ & & 0,0656 & & 0,0609 & & 0,0828 & & $-0,0634$ & & $-0,0502$ & & 0,1178 & & $-0,0899$ & & $-0,0024$ & & 1,0000 & & & & & & & & & & & & & \\
\hline 12 & target & 0,1669 & $*$ & $-0,0365$ & & $-0,0881$ & & $-0,0842$ & & 0,0594 & & $-0,0755$ & & 0,0529 & & 0,0752 & & 0,0611 & & 0,1140 & & 0,1180 & & 1,0000 & & & & & & & & & & & \\
\hline 13 & propiedad & 0,0106 & & $-0,0736$ & & 0,0272 & & $-0,0050$ & & $-0,0156$ & & 0,0698 & & 0,0309 & & $-0,0413$ & & 0,1351 & & $-0,0147$ & & 0,2490 & $* * *$ & 0,1476 & & 1,0000 & & & & & & & & & \\
\hline 14 & consejo & $-0,0731$ & & $-0,1283$ & & $-0,0271$ & & 0,0574 & & 0,0385 & & 0,0542 & & $-0,0865$ & & $-0,0675$ & & 0,0797 & & $-0,0112$ & & 0,0778 & & 0,1644 & * & 0,2634 & $* * *$ & 1,0000 & & & & & & & \\
\hline 15 & mba & 0,0558 & & 0,0157 & & 0,2343 & $* *$ & $-0,1462$ & * & $-0,2700$ & $* * *$ & $-0,0486$ & & 0,1055 & & $-0,0789$ & & $-0,0494$ & & $-0,0895$ & & $-0,0562$ & & $-0,1302$ & & 0,0649 & & 0,0571 & & 1,0000 & & & & & \\
\hline 16 & medivalor & 0,1033 & & 0,0041 & & $-0,0408$ & & $-0,0142$ & & 0,0284 & & $-0,0035$ & & 0,0708 & & $-0,1115$ & & 0,0358 & & $-0,0926$ & & 0,3644 & $* * *$ & 0,1700 & * & 0,2554 & $* * *$ & $-0,0063$ & & $-0,1031$ & & 1,0000 & & & \\
\hline 17 & impliDI & 0,1160 & & 0,1737 & * & 0,1835 & * & $-0,0327$ & & $-0,1280$ & & 0,0685 & & 0,0393 & & $-0,0159$ & & $-0,1165$ & & 0,0884 & & $-0,0051$ & & 0,0789 & & 0,1318 & & 0,2341 & ${ }^{* *}$ & 0,0869 & & 0,1384 & & 1,0000 & \\
\hline 18 & impliDF & 0,0276 & & 0,0400 & & 0,0506 & & 0,0017 & & $-0,0348$ & & 0,1152 & & 0,1052 & & $-0,0371$ & & 0,0333 & & 0,0750 & & $-0,1438$ & & 0,0880 & & 0,1559 & * & 0,0117 & & 0,1056 & & 0,0953 & & 0,4141 & ${ }^{* *}$ \\
\hline 19 & edad & 0,1136 & & 0,0452 & & $-0,0193$ & & 0,8270 & $* * *$ & 0,5830 & $* * *$ & 0,5473 & ${ }^{* * *}$ & $-0,0118$ & & 0,1060 & & 0,0477 & & $-0,2060$ & $* *$ & 0,0237 & & $-0,0268$ & & 0,0303 & & 0,0884 & & $-0,1039$ & & 0,0089 & & $-0,0423$ & \\
\hline 20 & potencia & 0,0493 & & $-0,0546$ & & $-0,0744$ & & $-0,0663$ & & $-0,0655$ & & $-0,0445$ & & 0,2514 & $* * *$ & $-0,1703$ & * & 0,1188 & & $-0,1421$ & & 0,1198 & & 0,0927 & & 0,0491 & & 0,0783 & & 0,2141 & ** & 0,1786 & ${ }^{* *}$ & 0,1605 & * \\
\hline 21 & ocenvalor & 0,1098 & & $-0,0018$ & & $-0,0369$ & & 0,0285 & & $-0,0112$ & & 0,0405 & & 0,1593 & $*$ & $-0,0264$ & & 0,0963 & & $-0,1250$ & & 0,0830 & & $-0,0597$ & & $-0,0024$ & & $-0,1703$ & * & 0,2003 & ** & 0,3207 & ${ }^{* *}$ & 0,1162 & \\
\hline 22 & ritmo & $-0,0261$ & & $-0,0343$ & & 0,0197 & & $-0,0517$ & & $-0,0620$ & & 0,1122 & & 0,1175 & & $-0,0191$ & & 0,0271 & & $-0,1732$ & $* *$ & $-0,0030$ & & $-0,0364$ & & 0,0642 & & 0,0093 & & 0,0865 & & 0,2606 & ** & 0,1087 & \\
\hline 23 & inputs & 0,0273 & & 0,0807 & & 0,0973 & & $-0,0759$ & & $-0,1816$ & $* *$ & 0,0882 & & 0,2691 & $* * *$ & 0,1651 & $*$ & 0,0867 & & $-0,0141$ & & 0,0561 & & 0,0165 & & 0,1056 & & $-0,0272$ & & 0,1886 & ** & 0,0633 & & 0,0841 & \\
\hline 24 & abandono & $-0,0045$ & & 0,1284 & & 0,1602 & & $-0,0641$ & & $-0,1505$ & $*$ & 0,0596 & & $-0,1164$ & & 0,0417 & & $-0,1453$ & $*$ & 0,1374 & & 0,0821 & & 0,0084 & & 0,0198 & & $-0,0393$ & & 0,1695 & $*$ & 0,0674 & & 0,1888 & $* *$ \\
\hline 25 & aplazar & 0,0328 & & 0,1274 & & 0,1709 & * & $-0,0171$ & & $-0,0205$ & & 0,0643 & & $-0,0730$ & & $-0,0067$ & & 0,0098 & & $-0,0377$ & & 0,0827 & & $-0,0060$ & & 0,0423 & & $-0,1703$ & * & 0,1681 & * & 0,1204 & & 0,0565 & \\
\hline 26 & modtam & $-0,0891$ & & $-0,0659$ & & 0,0372 & & $-0,0892$ & & $-0,1057$ & & 0,0306 & & $-0,0689$ & & 0,0211 & & 0,0530 & & $-0,0900$ & & $-0,0140$ & & 0,0040 & & 0,1047 & & $-0,0974$ & & 0,1087 & & 0,1832 & ** & 0,0139 & \\
\hline 27 & flexibilidad & 0,1260 & & $-0,1534$ & & $-0,0052$ & & $-0,1658$ & * & $-0,1257$ & & $-0,1056$ & & $-0,0329$ & & $-0,1042$ & & $-0,0362$ & & $-0,0439$ & & 0,0237 & & 0,1071 & & 0,2138 & $* *$ & 0,1188 & & 0,1711 & * & 0,1592 & $*$ & 0,2643 & $\stackrel{* *}{*}$ \\
\hline 28 & deudaobj & 0,1983 & $* *$ & 0,0299 & & 0,0398 & & $-0,0161$ & & 0,0146 & & $-0,0888$ & & 0,1638 & $*$ & $-0,0149$ & & $-0,0341$ & & 0,0599 & & $-0,0558$ & & 0,4191 & $* * *$ & 0,0166 & & 0,0105 & & 0,0000 & & 0,0996 & & 0,1125 & \\
\hline 29 & redwacc & 0,2844 & $* * *$ & 0,0676 & & 0,0951 & & 0,1250 & & 0,0330 & & 0,0374 & & 0,0759 & & 0,1445 & & $-0,1758$ & ** & 0,0327 & & 0,2164 & $* *$ & 0,1338 & & 0,0859 & & $-0,0936$ & & $-0,0059$ & & 0,1635 & * & 0,1278 & \\
\hline 30 & flexifin & $-0,0100$ & & $-0,0214$ & & 0,0144 & & $-0,1157$ & & $-0,0472$ & & $-0,0169$ & & 0,1200 & & $-0,0210$ & & 0,0031 & & 0,0595 & & 0,0911 & & 0,1970 & $* *$ & 0,0723 & & 0,1810 & $* *$ & 0,1261 & & 0,0560 & & 0,0405 & \\
\hline 31 & CPIntbajo & 0,1223 & & $-0,0216$ & & $-0,0840$ & & 0,0629 & & 0,1167 & & 0,0563 & & 0,2147 & $* *$ & 0,1870 & ** & 0,1056 & & $-0,1695$ & * & 0,2653 & $* * *$ & 0,1381 & & 0,1120 & & $-0,0378$ & & $-0,1027$ & & 0,1882 & $* *$ & 0,0622 & \\
\hline 32 & sustitución & $-0,0532$ & & 0,0771 & & $-0,0186$ & & 0,1028 & & 0,0446 & & 0,0991 & & 0,0225 & & 0,1265 & & 0,0998 & & $-0,0404$ & & 0,1424 & & 0,1817 & $* *$ & 0,1832 & ** & 0,1489 & * & $-0,0413$ & & 0,0038 & & 0,0948 & \\
\hline 33 & CPcosteren & 0,0685 & & 0,0416 & & $-0,0197$ & & 0,1390 & & 0,0282 & & 0,0997 & & 0,1758 & $*$ & 0,1069 & & 0,0820 & & $-0,0632$ & & 0,0359 & & 0,2223 & $* *$ & 0,1332 & & 0,0274 & & $-0,0946$ & & 0,0709 & & 0,0947 & \\
\hline
\end{tabular}


AneXos

\section{Anexo 5.1. Continuación}

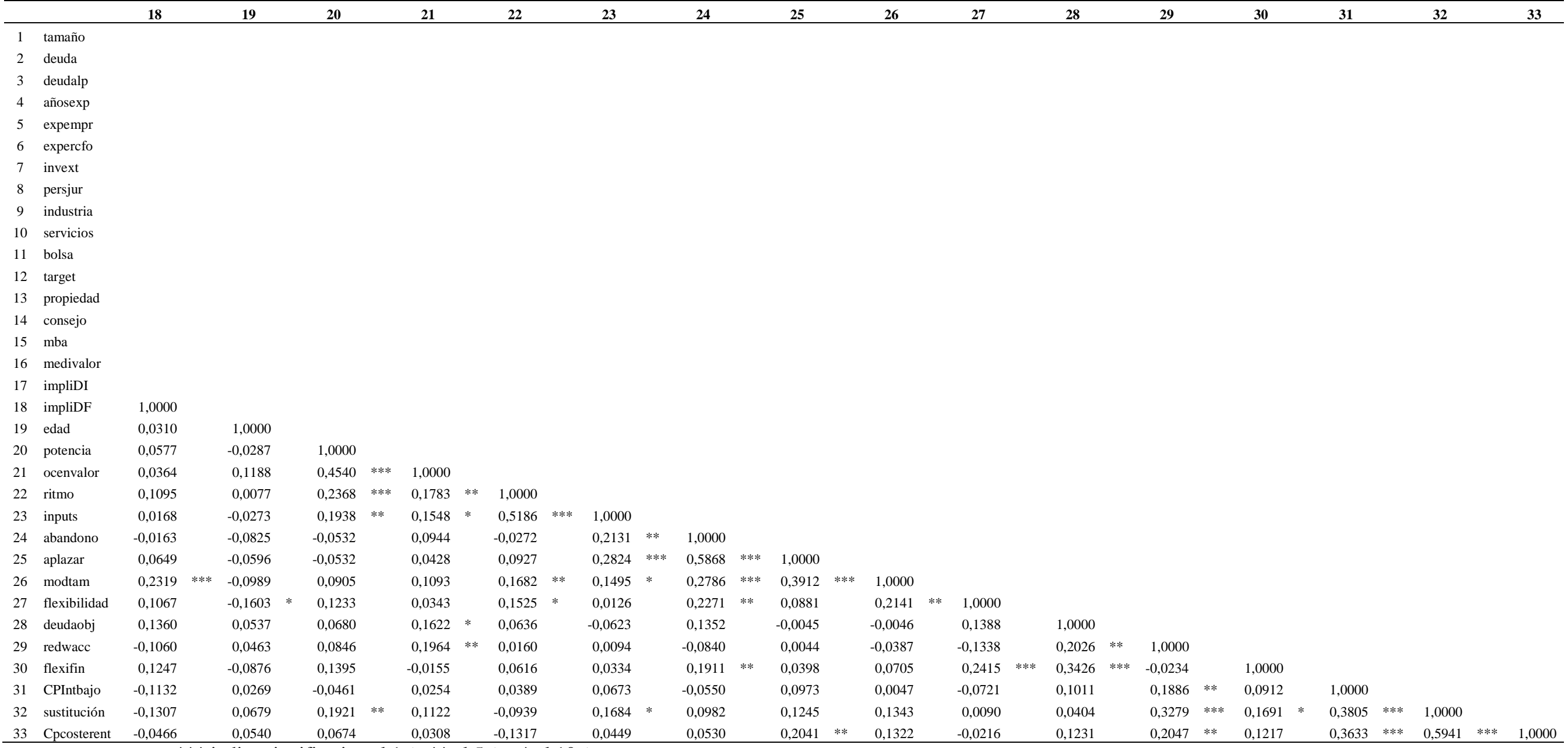

*** indica significativo al 1\%, ** al 5\% y * al 10\% 

